NBSIR 74-389

\title{
ELECTROMAGNETIC NOISE IN MCELROY MINE
}

M. Kanda

J. W. Adams

W. D. Bensema

Electromagnetics Division Institute for Basic Standards National Bureau of Standards Boulder, Colorado 80302

June 1974

Prepared for

U. S. Bureau of Mines

United States Department of the Interior

Pittsburgh, Pennsylvania 15222

Working Fund Agreement HO 133005 
$$
s
$$ 


\section{NBSIR $74-389$}

\section{ELECTROMAGNETIC NOISE IN McELROY MINE}

M. Kanda

J. W. Adams

W. D. Bensema

Electromagnetics Division

Institute for Basic Standards

National Bureau of Standards

Boulder, Colorado 80302

The views and conclusions contained in this document should not be interpreted as necessarily representing the official policies or recommendations of the Interior Department's Bureau of Mines of the U. S. Government.

June 1974

Prepared for

U. S. Bureau of Mines

United States Department of the Interior

Pittsburgh, Pennsylvania 15222

Working Fund Agreement HO 133005

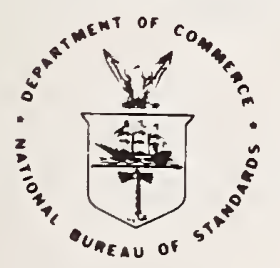

U.S. DEPARTMENT OF COMMERCE. Frederick B. Dent. Secretary 
This report was prepared by the National Bureau of Standards, Boulder, Colorado, under USBM Contract No. HO 133005. The contract was initiated under the Coal Mine Health and Safety Research Program. It was administered under the technical direction of the Pittsburgh Mining and Safety Research Center with Mr. Howard Parkinson and Mr. Harry Dobroski acting as the technical project officers.

This report is a summary of the work completed as part of this contract during the period January 1973 to June 1974. This report was submitted by the authors in October 1974 . 


\section{CONTENTS}

$\underline{\text { Page }}$

1. INT RODUCT I ON $\ldots \ldots \ldots \ldots$

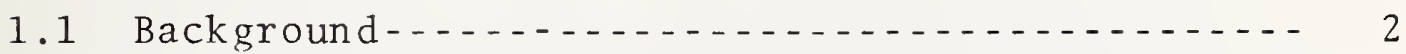

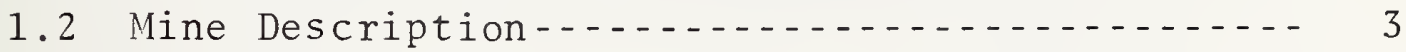

2. MEASUREMENT INSTRUMENTATION $\ldots \ldots \ldots \ldots$

3. SPECT RUM MEASUREMENT RESULTS - . . . . . . . . . . . . . . . 10

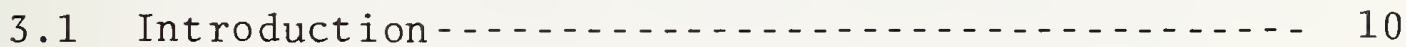

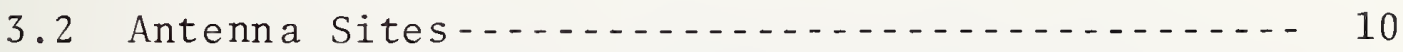

3.3 Electromagnetic Noise Spectrum Results-...... 10

3.3.1 Interpretation - . . . . . . . . 10

3.3.2 Uncertainties ....................... 11

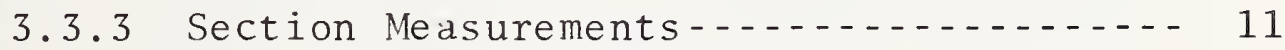

3.3.4 Haulageway Measurements-_.......... 14

3.3.5 Arc We1der Measurement_........... 15

3.3.6 Surface Measurements-.................. 16

3.4 Misce11aneous Measurements............... 17

3.4.1 Measurement of Voltage Between Roof Bolts - ......................... 17

3.4.2 Shuttle-Car Current Spectrum-....... 17

3.5 Intercomparison of Magnetic-Field Noise in

Different Mines.............................. 18

3.5.1 Summary of $1 \mathrm{kHz}$ to $3 \mathrm{kHz}$ Data-....... 18

3.5.2 Summary of $3 \mathrm{kHz}$ to $180 \mathrm{kHz}$ Data-..... 19 
4. AMPLITUDE PROBABILITY DISTRIBUTION MEASUREMENTS-..- 67 4.1 Introduction and Uncertainties-.......... 67 4.2 Results $\ldots \ldots \ldots$

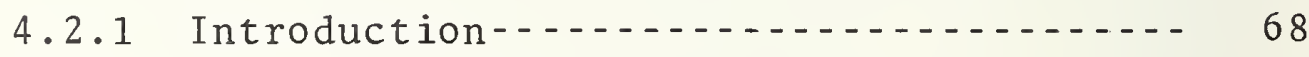

4.2.2 Measurement Results-_................. 69

4.2.3 RMS and Average Values-............... 70

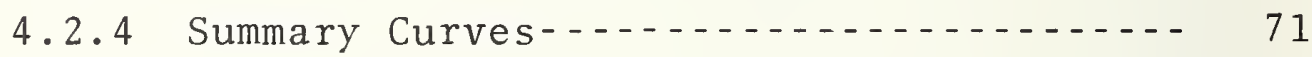

5. CONCLUSIONS - $\ldots \ldots \ldots \ldots$

6. RECOMMENDATIONS - . . . . . . . . 153

7. ACKNOWLEDGMENTS - . . . . . . . . 153

8. REFERENCES - . . . . . . 154

9. APPENDIX $\ldots \ldots \ldots \ldots$ 


\section{LIST OF FIGURES}

$\underline{\text { Page }}$

Figure 2-1. Block diagram of portable instrumentation-- 7

Figure 2-2. System for field recording data to obtain amplitude probability distributions-...... 8

Figure 2-3. Block diagram of laboratory recording system modified for field use............. 9

Figure 3-1. Map of portion of McElroy Coal Mine where first day measurements were made (April 10,

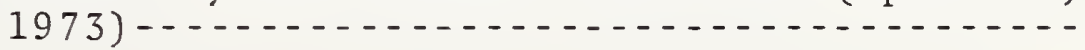

Figure 3-2. Map of portion of McElroy Coal Mine where second day measurements were made (April 12, 1973 ) - . . . . . . . . . . . . . . . . .

Figure 3-3. Spectrum at location $C$ in power entry. Spectral resolution is $78.1 \mathrm{~Hz} \ldots \ldots . . . . .$.

Figure 3-4. Expanded spectrum at location $C$ in power entry. Spectral resolution is $3.91 \mathrm{~Hz} \ldots .$.

Figure $3-5$. Spectrum at location $D$ near operating miner. Spectral resolution is $78.1 \mathrm{~Hz} \ldots .$.

Figure 3-6.

Spectrum at location $E$ in crosscut.

Spectral resolution is $78.1 \mathrm{~Hz} \ldots \ldots \ldots 25$

Figure 3-7. Expanded spectrum at location $\mathrm{E}$ in crosscut. Spectral resolution is $3.91 \mathrm{~Hz} \ldots \ldots 26$

Figure 3-8. Spectrum at location $F$ in middle of angle cut. Spectral resolution is $78.1 \mathrm{~Hz} \ldots \ldots 27$

Figure 3-9. Spectrum at location B with no equipment operating. Spectral resolution is $78.1 \mathrm{~Hz}-28$

Figure 3-10. Expanded spectrum at location B with no equipment operating. Spectral resolution is $3.91 \mathrm{~Hz} \ldots \ldots$

Figure 3-11. Spectrum at location B near operating miner and loader. Spectral resolution is $78.1 \mathrm{~Hz}$ 
Figure 3-12. Expanded spectrum at 1ocation B near operating miner and loader. Spectral resolution is $3.91 \mathrm{~Hz} \ldots \ldots \ldots$

Figure 3-13. Spectrum at location $F$ in return entry.

Spectral resolution is $78.1 \mathrm{~Hz} \ldots \ldots-\ldots . .-32$

Figure 3-14. Expanded spectrum at location $\mathrm{G}$ in return entry. Spectral resolution is $3.91 \mathrm{~Hz}-\ldots 33$

Figure 3-15. Spectrum at 1ocation A near operating machinery. Spectral resolution is $156 \mathrm{~Hz}-34$

Figure 3-16. Spectrum at location A near operating machinery. Spectral resolution is $19.5 \mathrm{~Hz}-35$

Figure 3-17. Spectrum at location A near operating machinery. Spectral resolution is $156 \mathrm{~Hz}--36$

Figure 3-18. Spectrum at location A near operating machinery. Spectral resolution is $156 \mathrm{~Hz}--37$

Figure 3-19. Spectrum at location A near operating machinery. Spectral resolution is $19.5 \mathrm{~Hz}-38$

Figure 3-20. Spectrum at 1ocation A near operating machinery. Spectral resolution is $156 \mathrm{~Hz}--39$

Figure 3-21. Spectrum at location A near operating machinery. Spectral resolution is $156 \mathrm{~Hz}--40$

Figure 3-22. Spectrum at location A near operating machinery. Spectral resolution is $19.5 \mathrm{~Hz}-41$

Figure 3-23. Spectrum at location A of an impulse. Spectral resolution is $156 \mathrm{~Hz} \ldots \ldots \ldots-\ldots 42$

Figure 3-24. Spectrum in haulageway near bottom of elevator shaft. Spectral resolution is $78.1 \mathrm{~Hz} \ldots \ldots \ldots \ldots$

Figure 3-25. Expanded spectrum in haulageway near bottom of elevator shaft. Spectral resolution is $3.91 \mathrm{~Hz} \ldots \ldots \ldots \ldots$ 
Figure 3-26. Spectrum at 1ocation B near train passing by. Spectral resolution is $78.1 \mathrm{~Hz}-\ldots-\ldots$

Figure 3-27. Expanded spectrum at 1ocation B near train passing by. Spectral resolution is $3.91 \mathrm{~Hz} 46$

Figure 3-28. Expanded spectrum at location B near empty train going by. Spectral resolution is

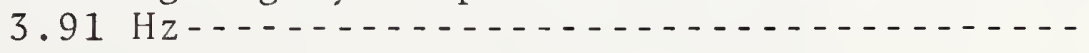

Figure 3-29. Spectrum at location C at head piece with conveyor and car-pull operating. Spectral resolution is $78.1 \mathrm{~Hz} \ldots \ldots$

Figure 3-30. Expanded spectrum at location $C$ at head piece with conveyor and car-pull operating. Spectral resolution is $3.91 \mathrm{~Hz} \ldots \ldots$

Figure 3-31. Spectrum at location A of haulageway. Spectral resolution is $156 \mathrm{~Hz} \ldots \ldots \ldots$

Figure 3-32. Expanded spectrum at location A of haulageway. Spectral resulution is $19.5 \mathrm{~Hz}$

Figure 3-33. Spectrum at location A which was the highest measured on April 12, 1973. Spectral resolution is $78.1 \mathrm{~Hz} \ldots \ldots$

Figure 3-34. Spectrum of operating arc welder 15 meters away. Spectral resolution is $78.1 \mathrm{~Hz} \ldots \ldots$

Figure 3-35. Spectrum of noise near powerline on surface above McElroy Mine. Spectral resolution is $78.1 \mathrm{~Hz} \ldots \ldots \ldots \ldots$

Figure 3-36. Expanded spectrum of noise near powerline on surface above McElroy Mine. Spectral resolution is $3.91 \mathrm{~Hz} \ldots \ldots$

Figure 3-37. Spectrum of noise at surface above McElroy Mine. Spectral resolution is $156 \mathrm{~Hz} \ldots \ldots 56$

Figure 3-38. Spectrum of noise at surface above McElroy Mine. Spectral resolution is $156 \mathrm{~Hz}-\ldots-\ldots$ 
Figure 3-39. Expanded spectrum of noise at surface above McElroy Mine. Spectral resolution is 19.5 $\mathrm{Hz} \ldots \ldots \ldots \ldots \ldots$

Figure 3-40. Voltage spectrum from roof bolts separated 21.7 meters. Spectral resolution is 78.1

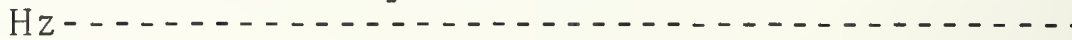

Figure 3-41. Expanded voltage spectrum from roof bolts separated 21.7 meters. Spectral resolution is $3.91 \mathrm{~Hz} \ldots \ldots$

Figure 3-42. Expanded voltage spectrum from roof bolts separated 11.2 meters. Spectral resolution is $3.91 \mathrm{~Hz} \ldots \ldots \ldots$

Figure 3-43. Expanded spectrum of noise from currentcarrying conductor. Spectral resolution is $3.91 \mathrm{~Hz} \ldots \ldots \ldots$

Figure 3-44. Logarithmic average magnetic field strength in McElroy Coal Mine in the frequency $r$ ange $1080 \mathrm{~Hz}$ to $2880 \mathrm{~Hz}$, produced usually by power line harmonics 3 through 8 of $360 \mathrm{~Hz}$. Antenna sensitive axis orientation is vertical (up-down) -

Figure 3-45. Comparison of magnetic field strengths of Grace and Robena Mines as a function of distance from noise source.............

Figure 3-46. Comparison of E-M noise levels near operating machinery from four mines. Vertical magnetic-field components are shown. Broken sections of the curves represent system noise-.....................

Figure 3-47. Comparison of E-M noise levels along haulageways in four mines. Vertical magnetic-field components are shown. Broken sections of the curves represent measurement-system noise levels.........

Figure 4-1. APD, $10 \mathrm{kHz}$, vertical component, location $B$

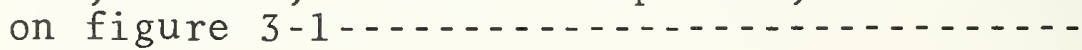


Figure 4-2. APD, $30 \mathrm{kHz}$, vertical component, location B

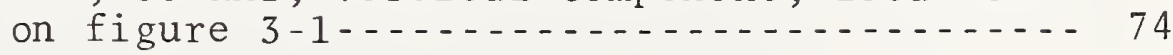

Figure 4-3. APD, $70 \mathrm{kHz}$, vertical component, location $B$ on figure 3-1......................... 75

Figure 4-4. APD, $130 \mathrm{kHz}$, vertical component, location $\mathrm{B}$

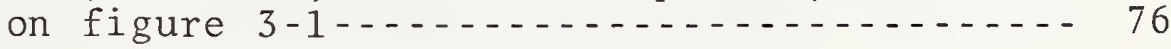

Figure 4-5. APD, $160 \mathrm{kHz}$, vertical component, location $B$

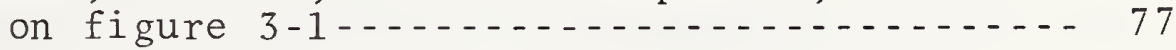

Figure 4-6. APD, $250 \mathrm{kHz}$, vertical component, location $B$

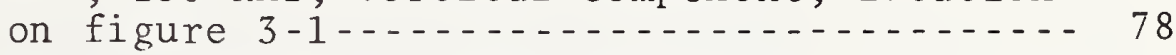

Figure 4-7. APD, $500 \mathrm{kHz}$, vertical component, location B

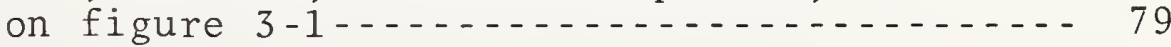

Figure 4-8. APD, $1 \mathrm{MHz}$, vertical component, location B

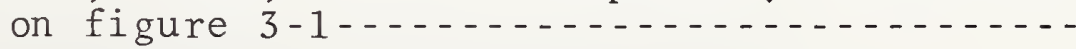

Figure 4-9. APD, $2 \mathrm{MHz}$, vertical component, location $\mathrm{B}$

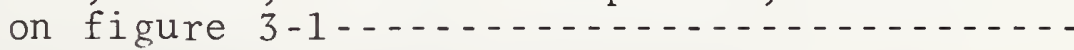

Figure 4-10. APD, $6 \mathrm{MHz}$, vertical component, location B

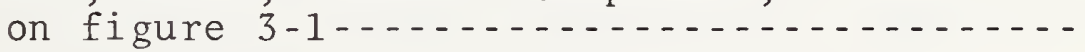

Figure 4-11. APD, 14 MHz, vertical component, location B

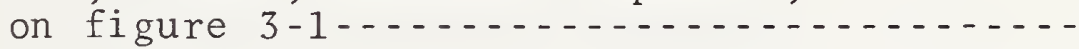

Figure 4-12. APD, $10 \mathrm{kHz}$, horizontal component, (NE-SW),

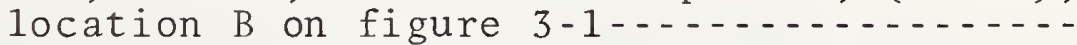

Figure 4-13. APD, $30 \mathrm{kHz}$, horizontal component, (NE-SW),

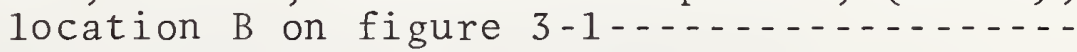

Figure 4-14. APD, $70 \mathrm{kHz}$, horizontal component, (NE-SW), location $\mathrm{B}$ on figure 3-1............

Figure 4-15. APD, $130 \mathrm{kHz}$, horizontal component, (NE-SW), location $\mathrm{B}$ on figure 3-1.............

Figure 4-16. APD $160 \mathrm{kHz}$, horizontal component, (NE-SW),

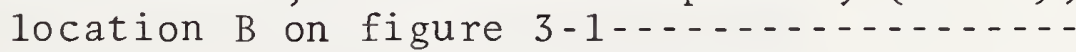

Figure 4-17. APD, $250 \mathrm{kHz}$, horizontal component, (NE-SW),

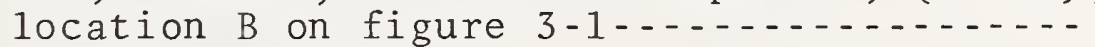




\section{LIST OF FIGURES (continued)}

$\underline{\text { Page }}$

Figure 4-18. APD, $500 \mathrm{kHz}$, horizontal component (NE-SW), location $B$ on figure 3-1............ 90

Figure 4-19. APD, $1 \mathrm{MHz}$, horizontal component, (NE-SW), location $B$ on figure 3-1............ 91

Figure 4-20. APD, 2 MHz, horizontal component, (NE-SW),

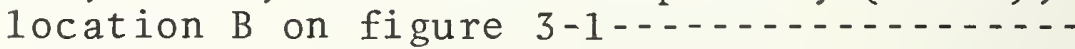

Figure 4-21. APD, $6 \mathrm{MHz}$, horizontal component, (NE-SW), location $B$ on figure 3-1..... 93

Figure 4-22. APD, $14 \mathrm{MHz}$, horizontal component, (NE-SW), location $B$ on figure 3-1....... 94

Figure 4-23. APD, $32 \mathrm{MHz}$, horizontal component, (NE-SW), location $B$ on figure 3-1............ 95

Figure 4-24. APD, $10 \mathrm{kHz}$, vertical component, quiet time, location B on figure 3-1-......-9 96

Figure 4-25. APD, $30 \mathrm{kHz}$, vertical component, quiet time, location $B$ on figure 3-1........ 97

Figure 4-26. APD, $70 \mathrm{kHz}$, vertical component, quiet time, location $B$ on figure 3-1-....... 98

Figure 4-27. APD, $130 \mathrm{kHz}$, vertical component, quiet time, location B on figure 3-1........ 99

Figure 4-28. APD, $10 \mathrm{kHz}$, vertical component, location $\mathrm{A}$ on figure 3-1.......................... 100

Figure 4-29. APD, $30 \mathrm{kHz}$, vertical component, location A

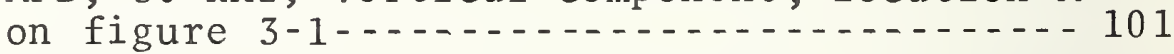

Figure 4-30. APD, $70 \mathrm{kHz}$, vertical component, location $A$

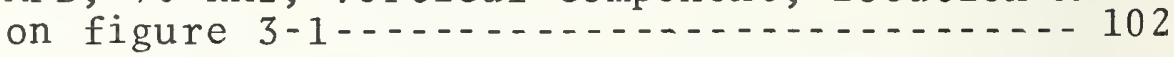

Figure 4-31. APD, $130 \mathrm{kHz}$, vertical component, location

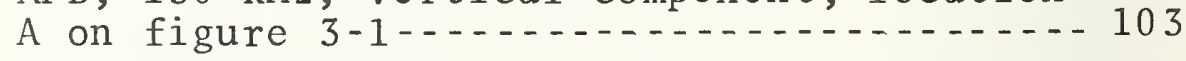

Figure 4-32. APD, $160 \mathrm{kHz}$, vertical component, location A on figure 3-1....................... 104 
Figure 4-33. APD, $250 \mathrm{kHz}$, vertical component, location A on figure 3-1........................... 105

Figure 4-34. APD, $500 \mathrm{kHz}$, vertical component, location A on figure 3-1...................... 106

Figure 4-35. APD, $1 \mathrm{MHz}$, vertical component, location A

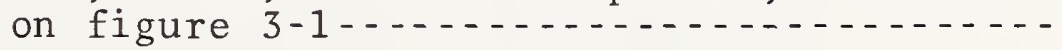

Figure 4-36. APD, $2 \mathrm{MHz}$, vertical component, location $\mathrm{A}$ on figure 3-1........................... 108

Figure 4-37. APD, $10 \mathrm{kHz}$, horizontal component (N-S), location A on figure 3-1............. 109

Figure 4-38. APD, $30 \mathrm{kHz}$, horizontal component (N-S), 1ocation $A$ on figure 3-1............. 110

Figure 4-39. APD, $70 \mathrm{kHz}$, horizontal component (N-S), location $A$ on figure 3.1............. 111

Figure 4-40. APD, $130 \mathrm{kHz}$, horizontal component (N-S), location A on figure 3-1............ 112

Figure 4-41. APD, $160 \mathrm{kHz}$, horizontal component (N-S), location A on figure 3-1............. 113

Figure 4-42. APD, $500 \mathrm{kHz}$, horizontal component (N-S), location $A$ on figure 3-1........... 114

Figure 4-43. APD, $1 \mathrm{MHz}$, horizontal component (N-S), location $A$ on figure 3.1...... 115

Figure 4-44. APD, $10 \mathrm{kHz}$, vertical component, quiet time, location A on figure 3-1....... 116

Figure 4-45. APD, $30 \mathrm{kHz}$, vertical component, quiet time, location A on figure 3-1....... 117

Figure 4-46. APD, $70 \mathrm{kHz}$, vertical component, quiet time, location A on figure 3-1........ 118

Figure 4-47. APD, $130 \mathrm{kHz}$, vertical component, quiet time, location A on figure 3-1....... 119 
Figure 4-48. APD, $1 \mathrm{MHz}$, vertical component, quiet time, location A on figure 3-1-....... 120

Figure 4-49. APD, $10 \mathrm{kHz}$, vertical component, location B

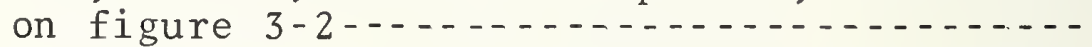

Figure 4-50. APD, $30 \mathrm{kHz}$, vertical component, 1 ocation $B$

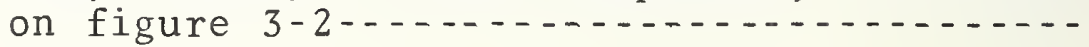

Figure 4-51. APD, $70 \mathrm{kHz}$, vertical component, location B

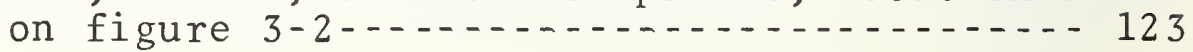

Figure 4-52. APD, $130 \mathrm{kHz}$, vertical component, location

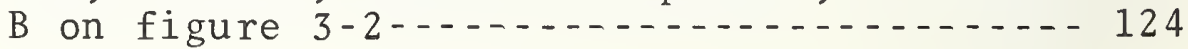

Figure 4-53. APD, $160 \mathrm{kHz}$, vertical component, location

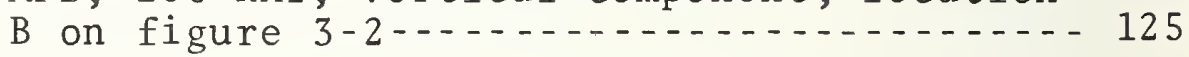

Figure 4-54. APD, $500 \mathrm{kHz}$, vertical component, location

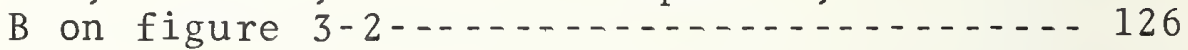

Figure 4-55. APD, $1 \mathrm{MHz}$, vertical component, location $B$

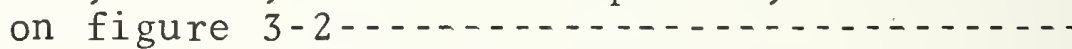

Figure 4-56. APD, 2 MHz, vertical component, location $B$

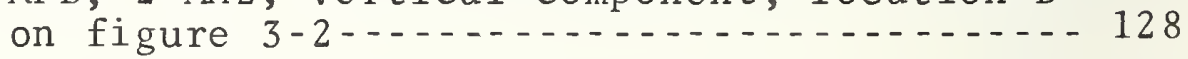

Figure 4-57. APD, $6 \mathrm{MHz}$, vertical component, location $\mathrm{B}$

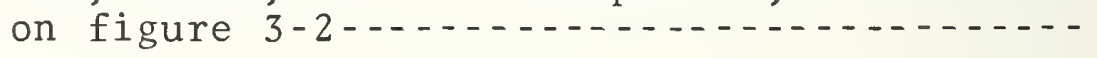

Figure 4-58. APD, $14 \mathrm{MHz}$, vertical component, location B

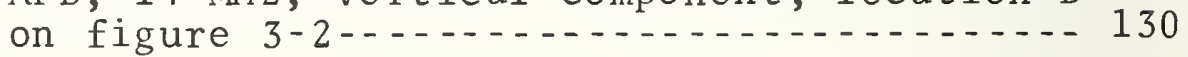

Figure 4-59. APD, $10 \mathrm{kHz}$, vertical component, location A

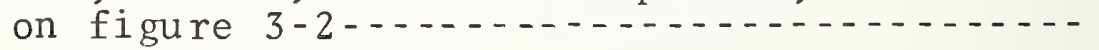

Figure 4-60. APD, $30 \mathrm{kHz}$, vertical component, location A

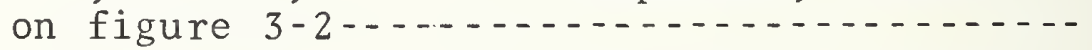

Figure 4-61. APD, $70 \mathrm{kHz}$, vertical component, location A

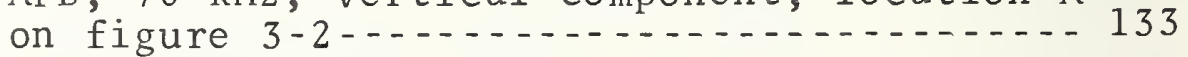

Figure 4-62. APD, $130 \mathrm{kHz}$, vertical component, location

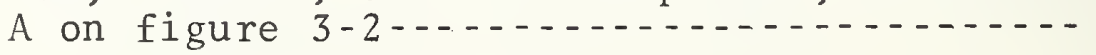




\section{LIST OF FIGURES (continued)}

$\underline{\text { Page }}$

Figure 4-63. APD, $160 \mathrm{kHz}$, vertical component, location

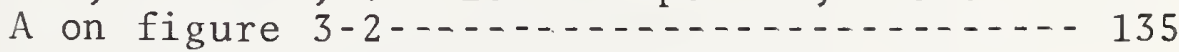

Figure 4-64. APD, $250 \mathrm{kHz}$, vertical component, location A on figure 3-2....................... 136

Figure 4-65. APD, $500 \mathrm{kHz}$, vertical component, location

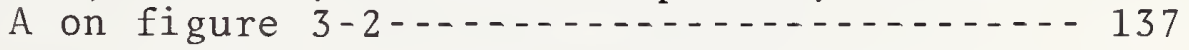

Figure 4-66. APD, $1 \mathrm{MHz}$, vertical component, location $A$

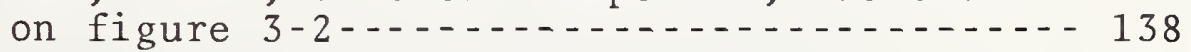

Figure 4-67. APD, $2 \mathrm{MHz}$, vertical component, location $\mathrm{A}$

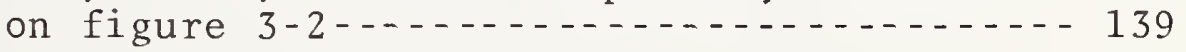

Figure 4-68. APD, $6 \mathrm{MHz}$, vertical component, 1ocation $\mathrm{A}$ on figure 3-2......................... 140

Figure 4-69. APD, $10 \mathrm{kHz}$, roof bolt measurements-.-.-- 141

Figure 4-70. APD, $150 \mathrm{kHz}$, roof bolt measurements-..-.- 142

Figure 4-71. Field strength excursions between 0.001 and $99 \%$ of the time as a function of frequency, vertical component, location $B$ on figure 3-1 ...............................

Figure 4-72. Field strength excursions between 0.001 and $99 \%$ of the time as a function of frequency, horizontal component, (NE-SW), location B on figure 3-1.......................... 144

Figure 4-73. Field strength excursions between 0.001 and $99 \%$ of the time as a function of frequency, vertical component, quiet time, location B

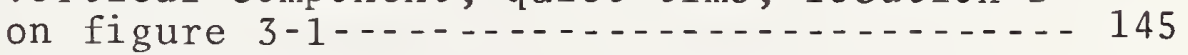

Figure 4-74. Field strength excursions between 0.001 and $99 \%$ of the time as a function of frequency, vertical component, location A on figure

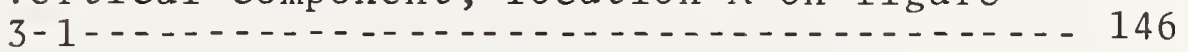




\section{LIST OF FIGURES (continued)}

Figure 4-75. Field strength excursions between 0.001 and $99 \%$ of the time as a function of frequency, horizontal component, location A on figure

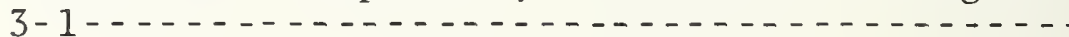

Figure 4-76. Field strength excursions between 0.001 and $99 \%$ of the time as a function of frequency, vertical component, quiet time, location A

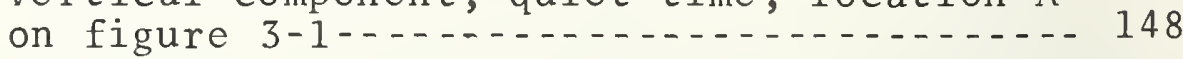

Figure 4-77. Field strength excursions between 0.001 and $99 \%$ of the time as a function of frequency, vertical component, location $B$ on figure

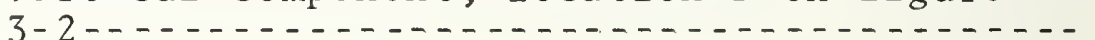

Figure 4-78. Field strength excursions between 0.001 and $99 \%$ of the time as a function of frequency, vertical component, location A on figure 
Two different techniques were used to make measurements of the absolute value of electromagnetic noise in and above an operating coal mine, McElroy Mine, located near Moundsville, West Virginia. The electromagnetic environment created by 300 volt dc and 480 volt ac machinery was measured. In one technique noise was measured over the entire electromagnetic spectrum of interest for brief time periods. The noise was recorded using broadband analog magnetic tape. The noise data was later transformed to give spectral plots. In the other technique, noise amplitudes were recorded at several discrete frequencies for a sufficient length of time to provide amplitude probability distributions.

The specific, measured results are given in a number of spectral plots and amplitude probability distribution plots.

Key words: Amplitude probability distribution; coal mine noise; digital data; electromagnetic communications; electromagnetic interference; electromagnetic noise; Fast Fourier Transform; Gaussian distribution; impulsive noise; magnetic field strength; measurement instrumentation; spectral density; time-dependent spectral density.

\section{INTRODUCTION}

This report gives data concerning electromagnetic noise in a coal mine that used dc shuttle-car and rail-haulage power; the remainder of the section machinery and belt haulage used ac power. In this section, background information and a brief mine description are covered. In Section 2, measurement instrumentation is discussed. In Section 3, spectral plots of data are presented. In Section 4, amplitude probability distributions (APD) of magnetic-field noise are given. The last two sections cover conclusions and recommendations. 
Only representative samples of the total data measured are given in this report, and only a limited set of datapresentation formats have been used. Additional data, or data presentation in other formats may be obtained from the authors with the specific permission of the Bureau of Mines. A more complete description of the measurement systems used is given in previous publications $[1,4]$.

\subsection{Background}

The need for reliable communication systems in mines is a long-standing problem. For emergency use, when all power in a mine is off, the residual electromagnetic noise is no problem. However, if a communication system were designed only for emergency use, it would have two serious drawbacks. First, it would not be ready for immediate use in an emergency; second, it would not be of any value during normal operations. Therefore, the Bureau of Mines decided to design a communication system that could be used for both emergency and normal operational conditions.

During operation, the electrical machinery used in mines creates a wide range of many types of intense electromagnetic interference (EMI). This EMI is a major limiting factor in the design of a communication system.

The work reported here gives the results of comprehensive measurements of this EMI in critical communication locations where miners extract coal, as well as along haulageways.

There are several EMI parameters that can be measured: magnetic field strength, $\mathrm{H}$; electric field strength, E; conducted current, I; and voltage, V, between two conductors. One parameter was emphasized, magnetic field strength. There are several reasons. First, electric field sensors are very 
insensitive at lower frequencies, and hence probably will not be useful in any practical mine communication system. Second, at any air-earth interface, only the magnetic field is essentially undisturbed, while the electric field is severely reduced. Third, any currents will induce magnetic fields, and hence measurement of the magnetic field will directly sense currents. Fourth, power line voltages are propagated as transmission 1 ine phenomena, are directly related to transmission line currents, and hence to magnetic fields induced. Thus, measuring magnetic field strength gives a representative composite picture of noise from currents and voltages from most sources, as we11 as measuring the magnetic fields induced by arcing equipment.

Although magnetic field strength measurements are emphasized, this parameter is difficult to measure meaningfully. The IEEE definition [2] of magnetic field strength, H (magnitude of the magnetic field vector), is used in this report. Since there are a multitude of different sources that generate all known types of noise, the resultant magnetic field strength noise vector is a function of frequency, time, orientation, and location. Small variations in these parameters can cause several orders of magnitude difference in measured field strength.

\subsection{Mine Description}

The results and data presented in this report are based on measurements made on April 10 and 12, 1973, in the McElroy Coal Mine, near Moundsville, West Virginia. The mine belongs to the Consolidation Coal Company. Room-and-pillar mining techniques are used. The measurements were made primarily in section 1-left, 1-north. The overburden in this area is 200 to 275 meters. 
Mining is accomplished using a continuous miner, headloader, shuttle-cars (buggies), conveyor belt, and electrictrolley haulage. The electric trolley and the shuttle-cars were powered by 300 volts dc. All other equipments, including fans and rock dusting machines, were ac powered. The continuous miner had a telescoping feature to allow roof bolting simultaneous with mining. No one had to work under roofing that had not been bolted. 


\section{MEASUREMENT INSTRUMENTATION}

Two measurement techniques were used. In the first technique used, a large portion of the spectrum is covered as a "snapshot" at one relatively short period of time. In threedimensional form, several such "snapshots" can show how drastically a signal varies, not on $1 y$ with frequency, but also with time. In the second technique, variations over a 20 minute time interval are measured at a single frequency. Usually, a set of twelve different frequencies was used. Both techniques were used to measure two orthogonal components of magnetic field strength. This was done either by using two systems simultaneously or by varying the orientation of one system; both techniques were used in as many different locations as possible.

With the exception of the roof bolt APD plots, all measured noise is reported in absolute quantities (instead of relative) to allow others to make effective use of the data. For the magnetic field strength measurements, the NBS field calibration site was used with each complete measurement system to assure correct calibration [3].

A complication to making these measurements is the mine environment, which is generally humid, dusty, poorly lighted, and potentially explosive. Battery-operated, dust-protected, permissible gear was used for most of our portable measuring equipment.

There are two types of noise recorded in the spectral plots, and hence two different magnetic-field-strength parameters are required, $H$ and $H_{d}$. Results are given as the rms value of one component of magnetic field strength, $H$, versus frequency for discrete frequencies, or as one component of magnetic-fieldstrength spectrum density level [2], $\mathrm{H}_{\mathrm{d}}$, versus frequency for broadband noise in the spectral plots. In the amplitude probability distributions, results are given as the rms value 
of one component of the instantaneous magnetic field strength versus percent of time this value is exceeded. The APD gives the distribution of the actual instantaneous value only as far as the measurement-system detector bandwidth will allow the detector to follow the time variations of the actual magnetic field. (In this context, noise envelope is sometimes used.) Thus, the results are applicable for a communication receiver whose bandwidth is similar to the measurement-system detector bandwidth.

Three measurement systems were used to make measurements underground. The three systems are described in the block diagrams shown in figures 2-1, 2-2, and 2-3. Figures are located at the end of each section in this report. For a detailed description of these systems, see previous publications [1,4]. The systems used in McElroy are the same as those used in Grace.

In the first system, data is measured for spectral plots and is fully mine permissible and portable. In the second system, data is measured for statistical descriptions of time variations, most commonly amplitude probability distribution; it is also permissible. The third system is not permissible but is portable (with considerable effort); it records data for both spectral plots and statistical presentations. 


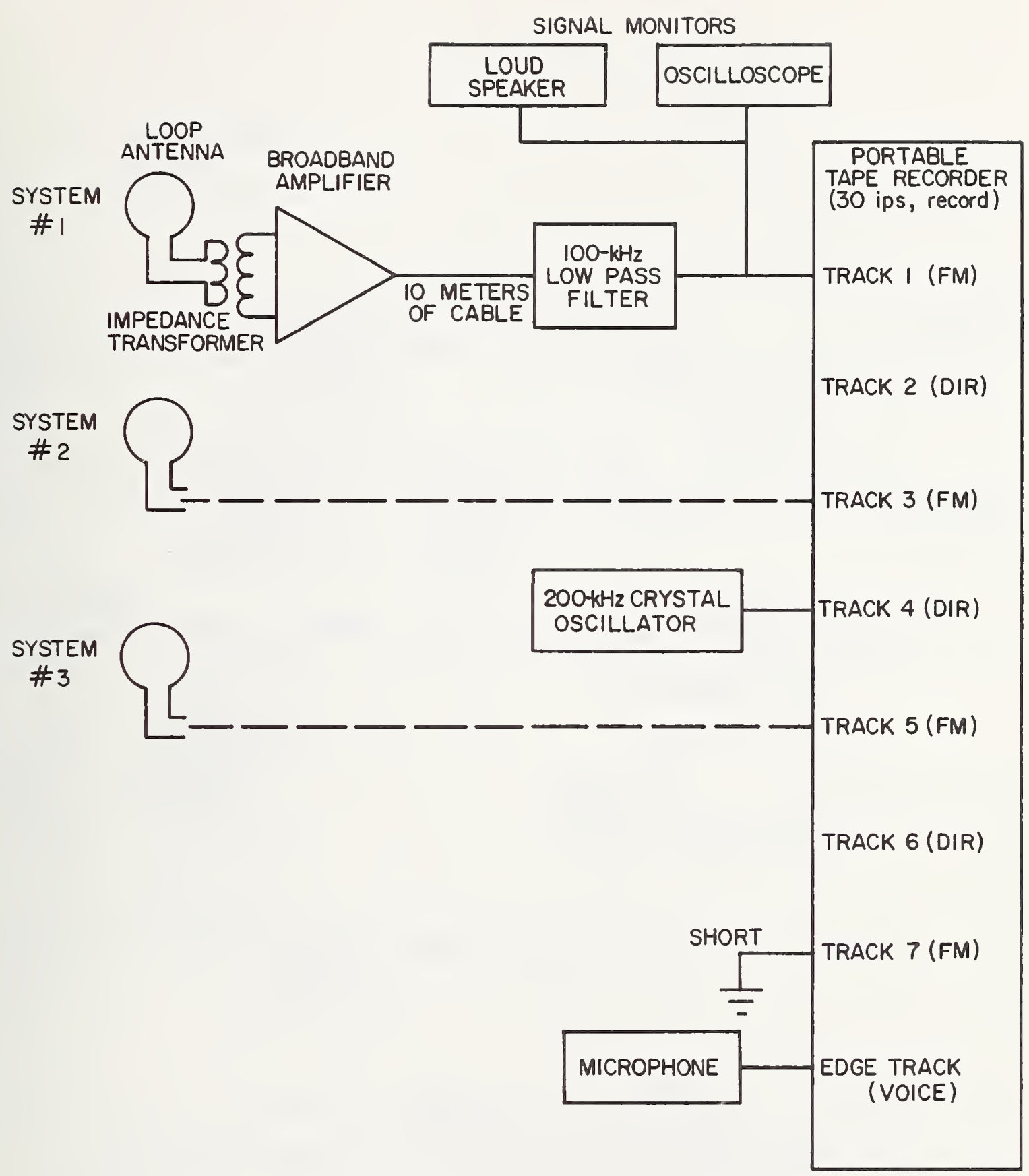

Figure 2-1 Block diagram of portable instrumentation. FM tracks are used to record from $100 \mathrm{~Hz}$ to $100 \mathrm{kHz}$; direct tracks are used from $3 \mathrm{kHz}$ to $320 \mathrm{kHz}$. Systems 2 and 3 are identical to system 1 . When the direct tracks are used, the $100-\mathrm{kHz}$ low pass filters are eliminated, and the amplifier bandwidth is increased from $100 \mathrm{kHz}$ to $300 \mathrm{kHz}$. The microphone is used for occasional vocal comments by the operator. 


\section{COLLAPSIBLE}

ANTENNA

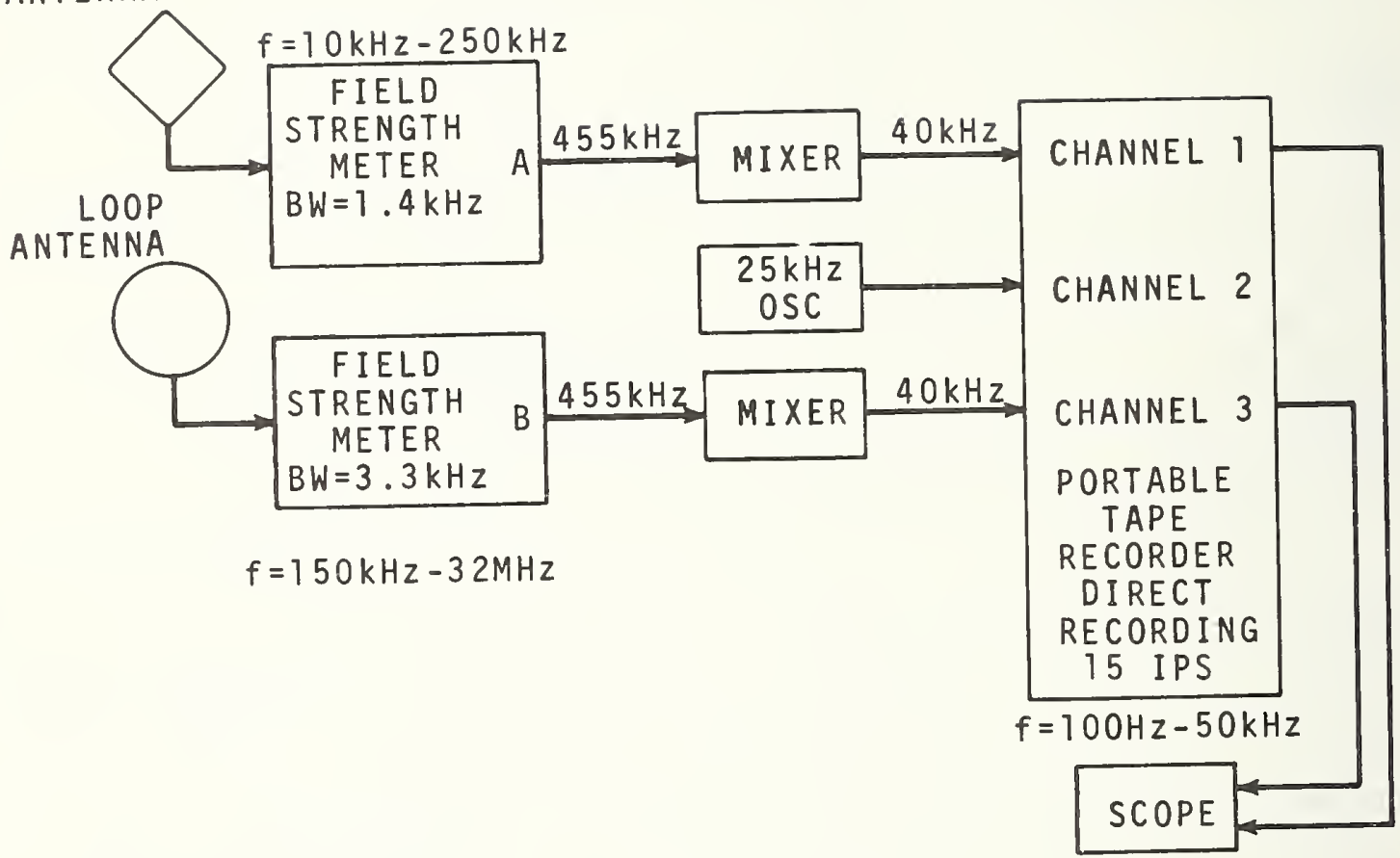

Figure 2-2 System for field recording data to obtain amplitude probability distributions. 

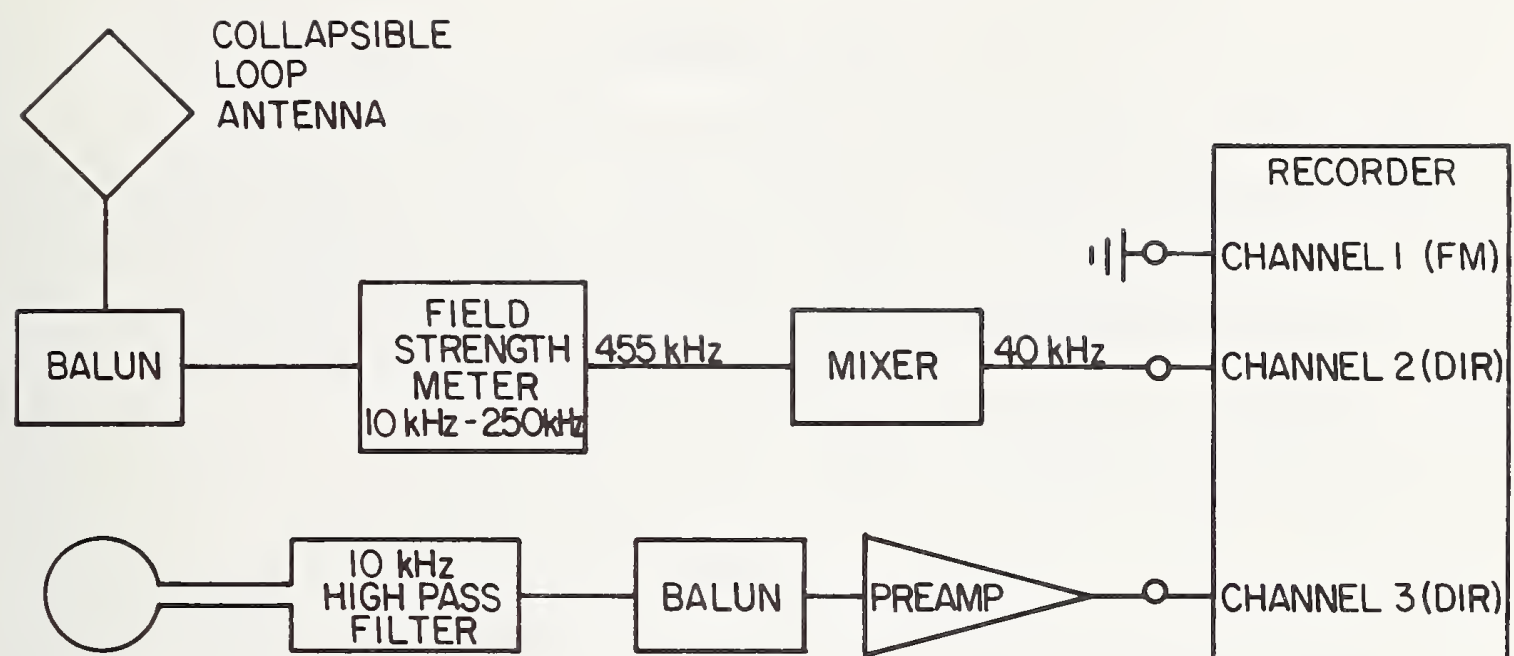

BALUN

LOOP

ANTENNA

(SENSITIVE AXIS VERTICAL)

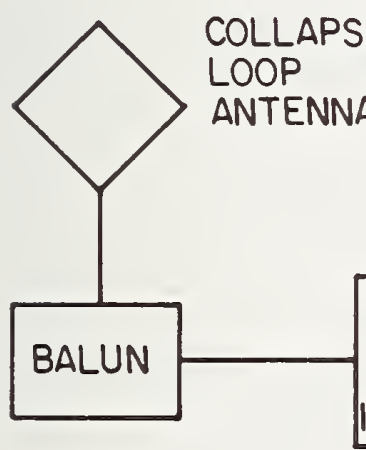

\section{BLE}

NNA

EQUIPMENT

SIMILAR TO 3, O- CHANNEL 5 (DIR) BUT WITH HORIZONTAL ANTENNA ORIENTATION

CHANNEL 3(DIR) \begin{tabular}{c|c|c|c|}
$25 \mathrm{kHz}$ & & \\
OSCILLATOR & &
\end{tabular}

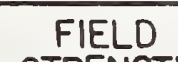
STRENGTH METER $150 \mathrm{kHz}-32 \mathrm{MHz}$
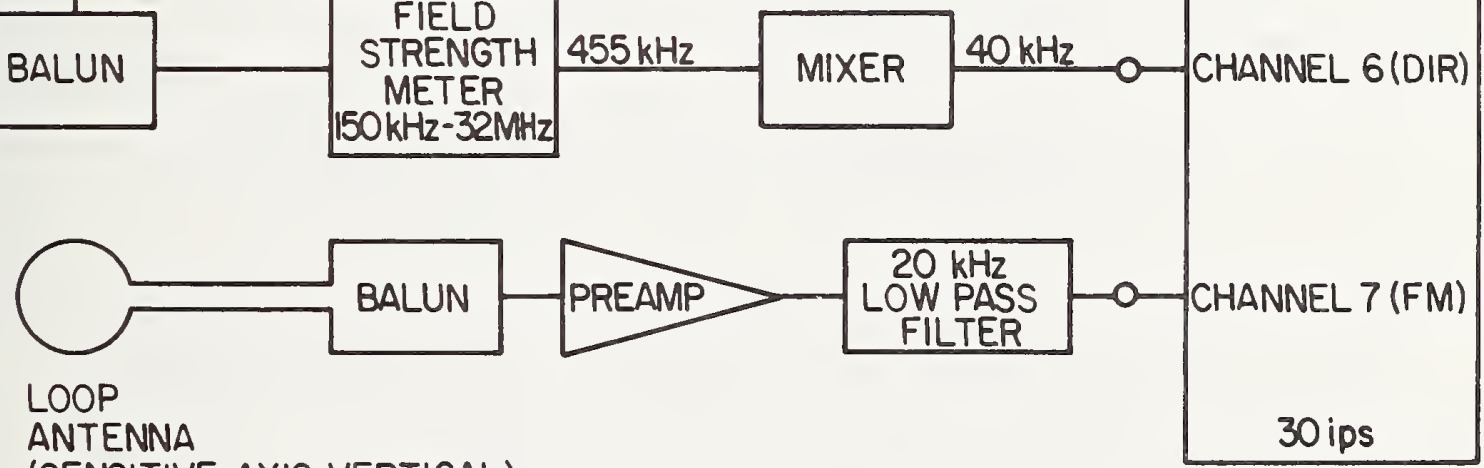

(SENSITIVE AXIS VERTICAL)

Figure 2-3 Block diagram of laboratory recording system modified for field use. 


\subsection{Introduction}

In this section of the report, spectrum plots are presented and discussed. Most of these plots present magnetic field strength up to $100 \mathrm{kHz}$. Measurements were made at many different locations and results can be used to characterize electromagnetic noise levels generated by most fixed and mobile equipment used in this mine.

\subsection{Antenna Sites}

Figure 3-1 is a map of section 1-left 1 -north as it was on April 10, 1973 when the first day of measurements were made. In the mining operation, four entries are driven forward and are identified on figure 3-1, from right to left: power entry, rail entry (trolley tracks), belt entry, and return air entry. Noise spectrum measurements were taken in 7 locations the first day and are designated by letters A through G on figure 3-1. Results are reported from measurements taken at five locations on the second day, four of which are designated by letters A through D on figure 3-2.

\subsection{Electromagnetic Noise Spectrum Results}

\subsubsection{Interpretation}

When reading values from the spectra in this report, the following points should be kept in mind:

1. Field strength values above the upper roll-off

frequency and below the lower roll-off frequency are not calibrated and are therefore not shown on most spectra.

2. The correct units for the spectral peaks are microamperes per meter $(\mu \mathrm{A} / \mathrm{m})$, as these are $\mathrm{cw}$ signals. 
3. The broadband noise between spectral peaks is as seen by a receiver having the same bandwidth as the Fast Fourier Transform (FFT) spectral resolution bandwidth used to compute the spectrum. The correct units for the background noise between peaks are microamperes per meter per square root $x$ hertz $[(\mu \mathrm{A} / \mathrm{m}) / \sqrt{\mathrm{xHz}}]$, where $x$ is the spectral resolution of the FFT ( $x$ equals $78.1 \mathrm{~Hz}$ for the 1 -to-100-kHz graphs).

An easy way to obtain the spectral density per (one) root hertz for broadband noise is to subtract the required number of $\mathrm{dB}$, remembering that the units have now changed to $(\mu \mathrm{A} / \mathrm{m}) / \sqrt{\mathrm{Hz}}$. For spectra with a resolution bandwidth of 78.1 $\mathrm{Hz}$, subtract $10 \log _{10}(78.1)$ or $18.93 \mathrm{~dB}$.

The Appendix gives the code key used in determining the meaning of the numbers in the header block at the top of each spectrum. The resolution bandwidth is also given on the ordinate of the plots.

\section{3 .2 Uncertainties}

The spectra to $100 \mathrm{kHz}$, to $3 \mathrm{kHz}$, and to $20 \mathrm{kHz}$ have uncertainties of $\pm 1 \mathrm{~dB}$ over the following portions of the spectra. The $100 \mathrm{kHz}$ spectra are valid either from 1 to 100 $\mathrm{kHz}$ or $10 \mathrm{kHz}$ to $100 \mathrm{kHz}$ as stated or shown. The $3 \mathrm{kHz}$ spectra have a $\pm 1 \mathrm{~dB}$ uncertainty from $100 \mathrm{~Hz}$ to $3 \mathrm{kHz}$. The $20 \mathrm{kHz}$ spectra have an uncertainty of $\pm 1 \mathrm{~dB}$ from $750 \mathrm{~Hz}$ to $20 \mathrm{kHz}$.

The spectra shown to $180 \mathrm{kHz}$ have an uncertainty of $\pm 2 \mathrm{~dB}$ from $3 \mathrm{kHz}$ to $180 \mathrm{kHz}$.

\subsubsection{Section Measurements}

Figure 3-3, upper curve, shows the magnetic field noise spectrum from $1 \mathrm{kHz}$ to $100 \mathrm{kHz}$ received at the antenna location identified as $\mathrm{C}$ (in figure 3-1). Location $\mathrm{C}$ is the section 
power center and contains the step-down transformer and rectifier. $C$ is one of the noisier locations in the mine (a small band of frequencies around $10 \mathrm{kHz}$ measured at location $\mathrm{B}$ on the second day was $8 \mathrm{~dB}$ higher). This steady background noise is made up primarily of harmonics of $360 \mathrm{~Hz}$, produced when three-phase, $60 \mathrm{~Hz}$ power is full-wave rectified. Figure 3-4 shows the expanded spectrum measured at 1ocation C. This spectrum is one of the strongest measured in the mine. Oddly, while multiples of $360 \mathrm{~Hz}$ ( $6 \mathrm{th}$ harmonic of $60 \mathrm{~Hz}$ ) predominate elsewhere in the mine, in this case, harmonics $60 \mathrm{~Hz}$ on either side of multiples of $360 \mathrm{~Hz}$ predominate.

Figure 3-5 shows the noise spectrum measured two meters from the continuous miner (location D on figure 3-1). This location was also a relatively noisy location in the mine in the frequency range from $20 \mathrm{kHz}$ to $60 \mathrm{kHz}$. With the headloader operating, and the miner not operating, the noise spectrum is similar to figure 3-5. With both the miner and head-loader not operating, the noise above $10 \mathrm{kHz}$ drops 6 to $10 \mathrm{~dB}$.

Figures 3-6 and 3-7 show noise spectra measured at 1ocation $E$. A measurement made 30 minutes later showed a $10 \mathrm{~dB}$ increase from 8 to $12 \mathrm{kHz}$ and a 3 to $5 \mathrm{~dB}$ decrease from 25 to $60 \mathrm{kHz}$. Figure 3-8 shows the noise spectrum measured at location $F$. This spectrum was taken when most equipment in the mine was not working. The noise spectrum has about the same shape as shown in the previous location, but at location $\mathrm{F}$, the noise is 5 to $14 \mathrm{~dB}$ less from 5 to $60 \mathrm{kHz}$. This figure also shows the signal from the $100 \mathrm{kHz}$ mine phone.

Figures 3-9 and 3-10 show the noise measured at location $B$ on the first day, with no equipment running. Figures 3-11 and 3-12 show the noise measured at the same location later when all the mining equipment was working and about 15 meters distant. The latter two figures show a noise increase of 8 to $30 \mathrm{~dB}$, depending on frequency, when the face machinery 15 meters distant was working. 
The quietest location measured in McElroy mine was in the return air entry, during shift change. This area is designated by letter $G$ on figure 3-1, and is located 55 meters from the power center. Figures 3-13 and 3-14 show one of the strongest of the three orthogonal components measured at location G. The antenna sensitive axis was horizontal and parallel with the return-air-entry. The spectrum taken with the antenna sensitive axis horizontal and perpendicular to the return-air-entry shows the harmonics to be within 6 to $10 \mathrm{~dB}$ of those shown in figure 3-14. The spectrum of the vertical noise shows about $13 \mathrm{~dB}$ higher noise levels at the low end and about $22 \mathrm{~dB}$ lower at the high end of the spectrum than the horizontal, parallel spectrum shown in figure 3-14. The crossover occurs near $500 \mathrm{~Hz}$. Measurements made in the same location 2 days later (1etter D, figure 3-2) during shift change, and also after the mine had closed for a strike, show that the noise was within a few $d B$ of that shown on figure 3-13. This return-air-entry location is unusual in that the noise received with the antenna axis horizontal was stronger than for the antenna axis vertical.

The noise measured at the section power center with the mine running (noisy location), with the antenna axis vertical, is 40 to $60 \mathrm{~dB}$ stronger over the 1 to $100 \mathrm{kHz}$ frequency range than the noise measured in the return-air-entry (quiet location), between shifts, with the antenna axis vertical.

Measurements were taken with the third measurement system in a crosscut shown as location A on figure 3-2 in the immediate (one to three meters) vicinity of a continuous miner and supporting shuttle buggies. Figures 3-15 through 3-22 show spectra of noise generated by this machinery. Figure 3-23 shows field levels generated by an impulse in this same location. 


\subsubsection{Haulageway Measurements}

On April 12, 1973, the second day in the mine, measurements were made at three locations along the mine haulageway.

Figures 3-24 and 3-25 show the vertical-antenna-axis noise spectrum measured at the point in the haulageway where men board man-trips for transportation to the working sections. No trains were in the vicinity when the measurement was made. This point is near the bottom of an elevator shaft and is several kilometers from the locations measured in section 1-left, 1 -north. Between 5 and $60 \mathrm{kHz}$ the noise received with the antenna sensitive axis vertical was stronger by 10 to $20 \mathrm{~dB}$ than the noise received for horizontal antenna axis orientation. Here, as in most other locations, the noise is primarily powerline-related multiples of $360 \mathrm{~Hz}$. The spectrum shape was slightly different. For example, the relative minimum was at $25 \mathrm{kHz}$ instead of $22 \mathrm{kHz}$. Below $2 \mathrm{kHz}$, the noise received on the antenna with the sensitive axis horizontal was 8 to $15 \mathrm{~dB}$ stronger than the noise shown on figure 3-25. At this location, the $100 \mathrm{kHz}$ unmodulated carrier signal strength from a mine phone on a portal-bus 210 meters away was measured as $47 \mathrm{~dB} \mu \mathrm{A} / \mathrm{m}$.

A second haulageway location where noise was measured was on the main-line haulage near section 1-1eft, 1 -north. This location is lettered B on figure 3-2. Figures 3-26 and 3-27 show the noise recorded during the passing of a rapidly moving train that was drawing power. The noise at this location was found to vary more than in other locations. Other spectra taken here showed 10 to $20 \mathrm{~dB}$ lower noise than figure 3-26 for trains moving slowly, or for the absence of trains. As an illustration, figure 3-28 shows the spectrum from $100 \mathrm{~Hz}$ to $3 \mathrm{kHz}$ for a train of empty cars 
moving slowly. From this it can be seen that a transient has briefly raised the background level of the previous spectrum, figure 3-27. While at location B, second day, a $100 \mathrm{kHz}$ trolley phone signal from a remote location was measured as $27 \mathrm{~dB}$ relative to $1 \mu \mathrm{A} / \mathrm{m}$.

The third location along a haulageway where noise was measured is lettered $\mathrm{C}$ on figure 3-2. This location is on the opposite side of the recirculating "run-around" from location B. The left side of the run-around is kept supplied with empty coal cars. An automatic car-pull located at C moves the empty cars forward as the coal coming off the conveyor belt "headpiece" fills the cars. Full cars are then periodically removed from the right hand side of the runaround. Figures 3-29 and 3-30 show the noise measured at location C. At this time, the conveyor belt and the car pull were running.

Data from measurements taken at the end of a rail haulage, location $A$ in figure 3-1, are shown in figures 3-31 and 3-32. These data were taken with the third measurement system.

\subsubsection{Arc Welder Measurement}

On the second day in the mine, the face had advanced as shown in figure 3-2. Figure 3-33 shows the noise measured in location $A$ in figure $3-2$ (the arc welder was not operating). Later, a helium-gas-shielded arc welder began operation. The welder used ac input voltage, and delivered 250 amperes at 30 volts to the welding rod. Figure 3-34 shows the spectrum measured with the welder drawing full current. The antenna was about 15 meters away. The spectrum with the welder operating is lower than with the welder off by as much as $16 \mathrm{~dB}$ at some frequencies. A quiet crackling, sounding like grease frying, was heard on the audio monitor. This indicates 
that this particular welder produced no strong spectral components. It did produce some impulses, but they were generally of a smaller amplitude than those associated with switching transients from section mining equipment.

\subsubsection{Surface Measurements}

Noise measurements were made on the surface of the ground, above the mine, at 5:25 p.m. on April 11, 1973. The location was a rural hilltop over 1 left, 1 north. The antenna site was 12 meters from a rural, single-phase distribution power line. The site was about one kilometer from a large, high tension 1 ine. Figures 3-35 and 3-36 show the spectrum measured on the surface with the antenna sensitive axis pointing $\mathrm{N}-\mathrm{S}$ and parallel to the local power 1 ine. This figure shows many man-made transmitted signals, as well as what appears to be some atmospheric noise in the region below $30 \mathrm{kHz}$. The energy shown around $100 \mathrm{kHz}$ is broadcast by a Loran-C navigation system. Note the signal from the National Bureau of Standards WWVB, frequency-and-time radio station transmission at $60 \mathrm{kHz}$. This transmitter is located near Fort Collins, Colorado. Surface noise measurements were made in al1 3 orthogonal directions; however, only one direction (N-S) is shown. The other orthogonal directions showed lower signal strengths from man-made carriers and more momentary broadband sferics.

Other spectral plots taken with the third measurement system are shown in figures 3-37, 3-38, and 3-39. 


\subsection{Miscellaneous Measurements}

\subsubsection{Measurement of Voltage Between Roof Bolts}

Two roof-support bolt measurements were performed at location $F$ on the first day. The voltage was measured using non-shielded copper wire clipped to the bolts. For the first measurement, the separation between bo1ts was 21.7 meters. Figures 3-40 and 3-41 show the spectrum measured. For the second measurement, the separation between bolts was reduced to 11.2 meters. Figure $3-42$ shows the spectrum measured. No receiver system noise curve is available for these spectra. With the exception of the sixth harmonic of $60 \mathrm{~Hz}$, the shorter distance between roof bolts shows higher power line noise than the longer separation. The second spectrum (shorter separation) shows an impulse that has been picked up. It is not possible to say that the voltage measured between bolts was induced by any single mechanism. It may be any combination of electric and magnetic fields acting on the copper wires connected to the bolts, as well as by any potential produced by current flow between the bolts.

\subsubsection{Shutt1e-Car Current Spectrum}

While no calibrated current measurements were made in McElroy mine, one measurement was made with the 100 p antenna placed directly adjacent to the shuttle-car power cable. This adjacent placement caused the loop to strongly couple to the current in the cable. Figure 3-43 shows the resulting spectrum. Note the strong $360 \mathrm{~Hz}$ fundamental and harmonics of this dc-driven machine. This spectrum gives the characteristic signature of dc-powered machinery supplied by three-phase, full-wave rectifiers. This figure shows the highest field strength values measured; this is due to the loop being unusually and artificially close to the current carrying cable. 


\subsection{Intercomparison of Magnetic-Field Noise in Different Mines}

\section{5 .1 Summary of $1 \mathrm{kHz}$ to $3 \mathrm{kHz}$ Data}

Figure 3-44 is a summary of magnetic field strength at power-1ine harmonic frequencies observed within McE1roy. Plotted are the logarithmic averages (arithmetic average $d B$ value) of the six highest powerline harmonics. The logarithmic average masks the highest single value. Average fields at nine locations in the mine and one on the surface are plotted as a function of distance from the nearest current-carrying cable or wire. The six frequencies chosen are between $1020 \mathrm{~Hz}$ and $2940 \mathrm{~Hz}$ and are either the third through eighth harmonic of $360 \mathrm{~Hz}$, or the highest adjacent powerline harmonic.

Figure 3-45 is a summary of magnetic field strength over the same frequency region as measured in the Robena Coal Mine (a11 $600 \mathrm{~V} \mathrm{dc}$ ) and the Grace Iron Mine (diesel-powered haulage) .

A comparison of the magnetic noise from $1 \mathrm{kHz}$ to $3 \mathrm{kHz}$ in the three mines shows:

1. McElroy is quieter than Robena.

a. The highest logarithmic average of section noise measured one meter from a cable in McElroy is $51 \mathrm{~dB}$ relative to $1 \mu \mathrm{A} / \mathrm{m}$ (power center). The noise in Robena at an "air split" on a haulageway is $16 \mathrm{~dB}$ higher and at a car pull during operation is $21 \mathrm{~dB}$ higher than this $51 \mathrm{~dB}$ value.

b. The quietest 1ocation in McElroy is $26 \mathrm{~dB}$ quieter than the quietest location in Robena.

2. McElroy is noisier than Grace.

a. Most of the McElroy measurements in the section were noisier than the noisiest Grace measurement (the diesel-powered Load-Haul-Dump (LHD) vehicle) by as much as $10 \mathrm{~dB}$. 
b. The quietest location in McElroy is $12 \mathrm{~dB}$ noisier than the quietest location in Grace.

The magnetic noise from $1 \mathrm{kHz}$ to $3 \mathrm{kHz}$ in the three mines compared to the noise measured on the surface above McE1roy shows :

1. A11 measurements in Robena were higher by 15 to $78 \mathrm{~dB}$.

2. Most measurements in McElroy were higher by 14 to $33 \mathrm{~dB}$.

3. The LHD measurement in Grace was higher by $22 \mathrm{~dB}$.

\section{5 .2 Summary of $3 \mathrm{kHz}$ to $180 \mathrm{kHz}$ Data}

Figures 3-46 and 3-47 are given to show how fieldstrength levels at McElroy compare with levels in some other mines (i.e., Grace, Robena, and Itmann Mines). Figure 3-46 shows levels near operating equipment while figure 3-47 shows levels in haulageways. The curves are shown to $200 \mathrm{kHz}$, but the $\pm 2 \mathrm{~dB}$ uncertainty is valid on $1 \mathrm{y}$ from 3 to $180 \mathrm{kHz}$. The Robena curves are shown to $100 \mathrm{kHz}$. 


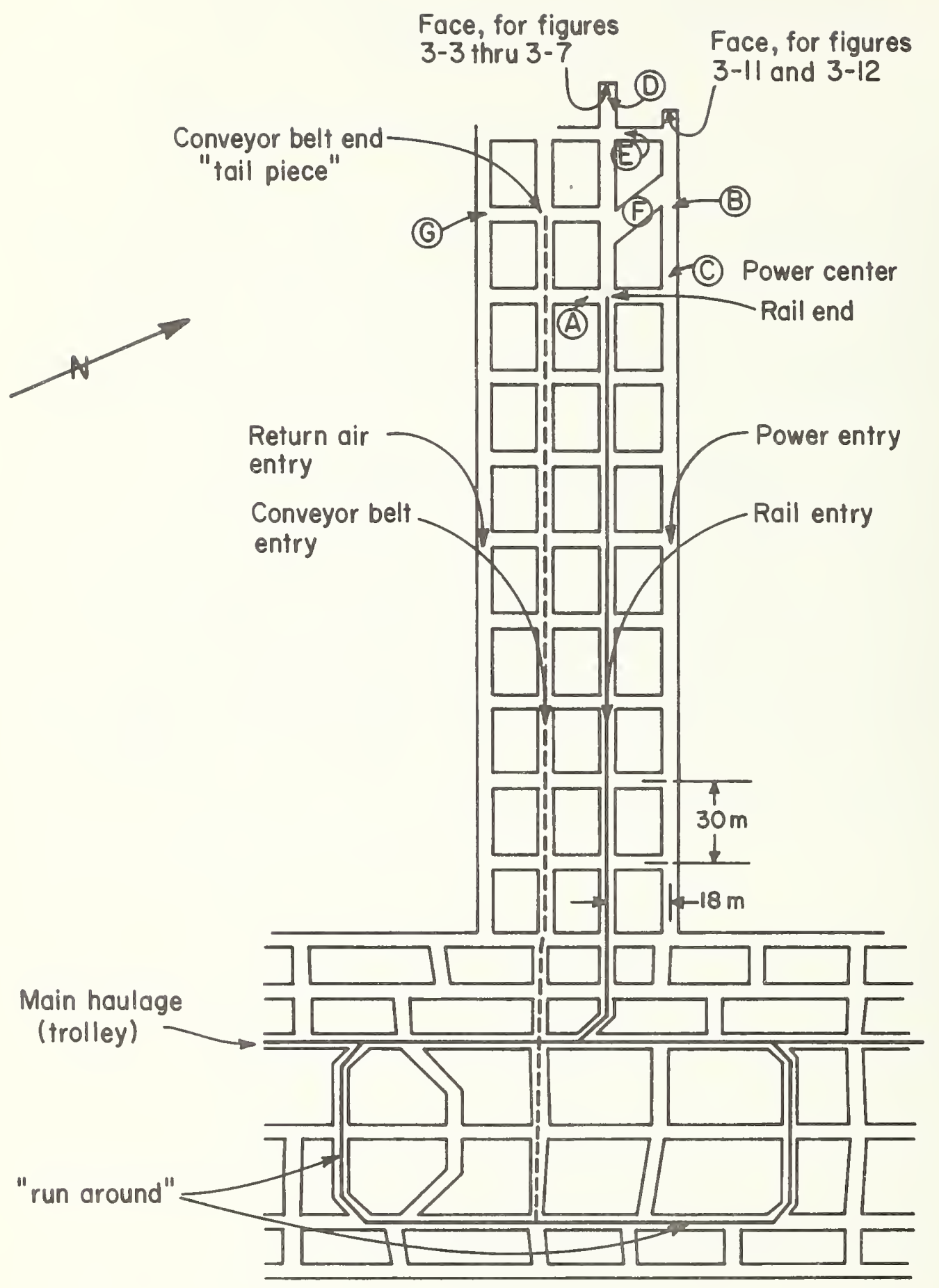

Figure 3-1 Map of McElroy Coal Mine, section 1-left, 1-north for April 10, 1973, the first day of measurements. 


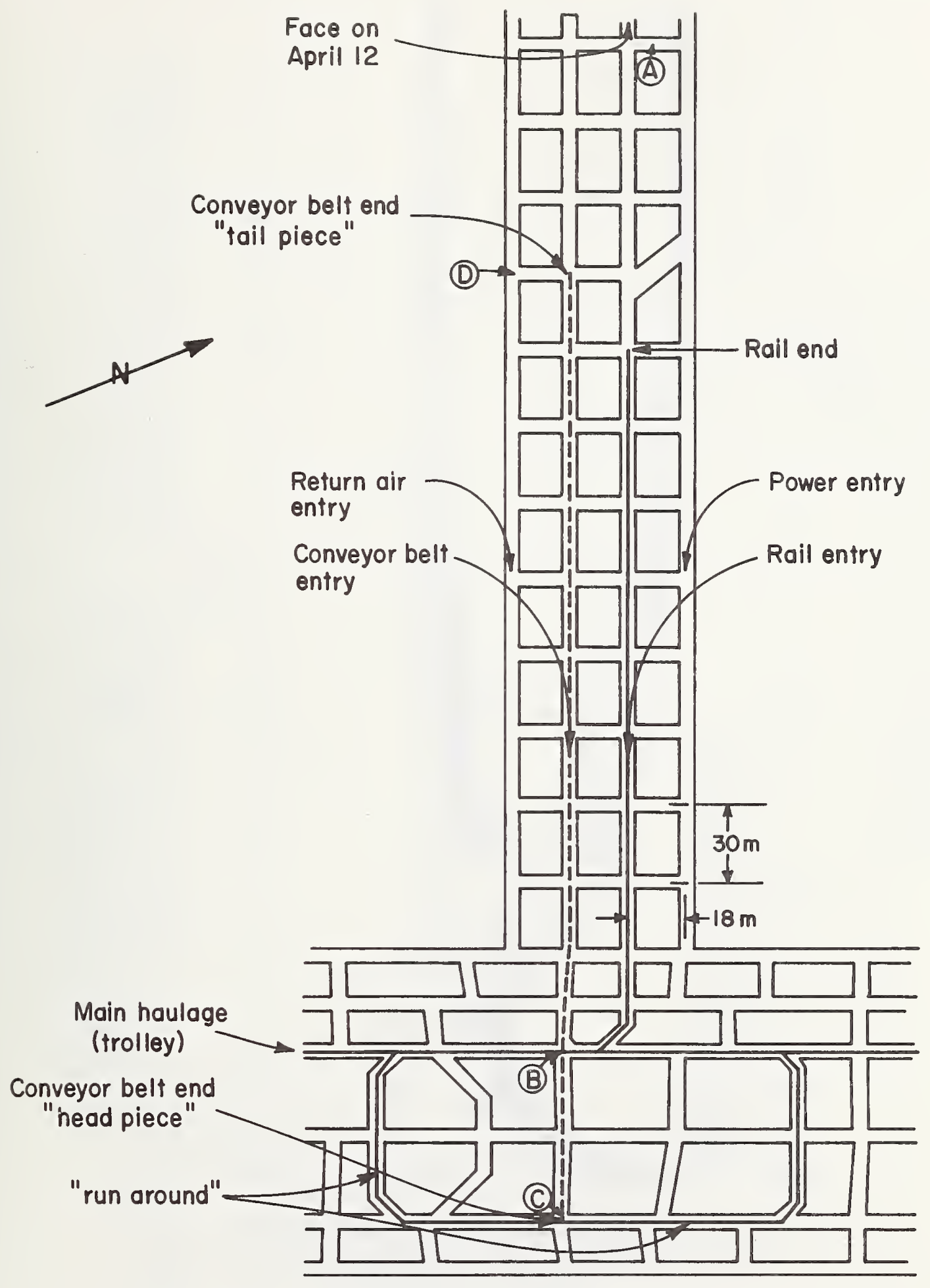

Figure 3-2 Map of McElroy Coal Mine, section 1-left, 1-north for April 12, 1973, the second day of measurements. 


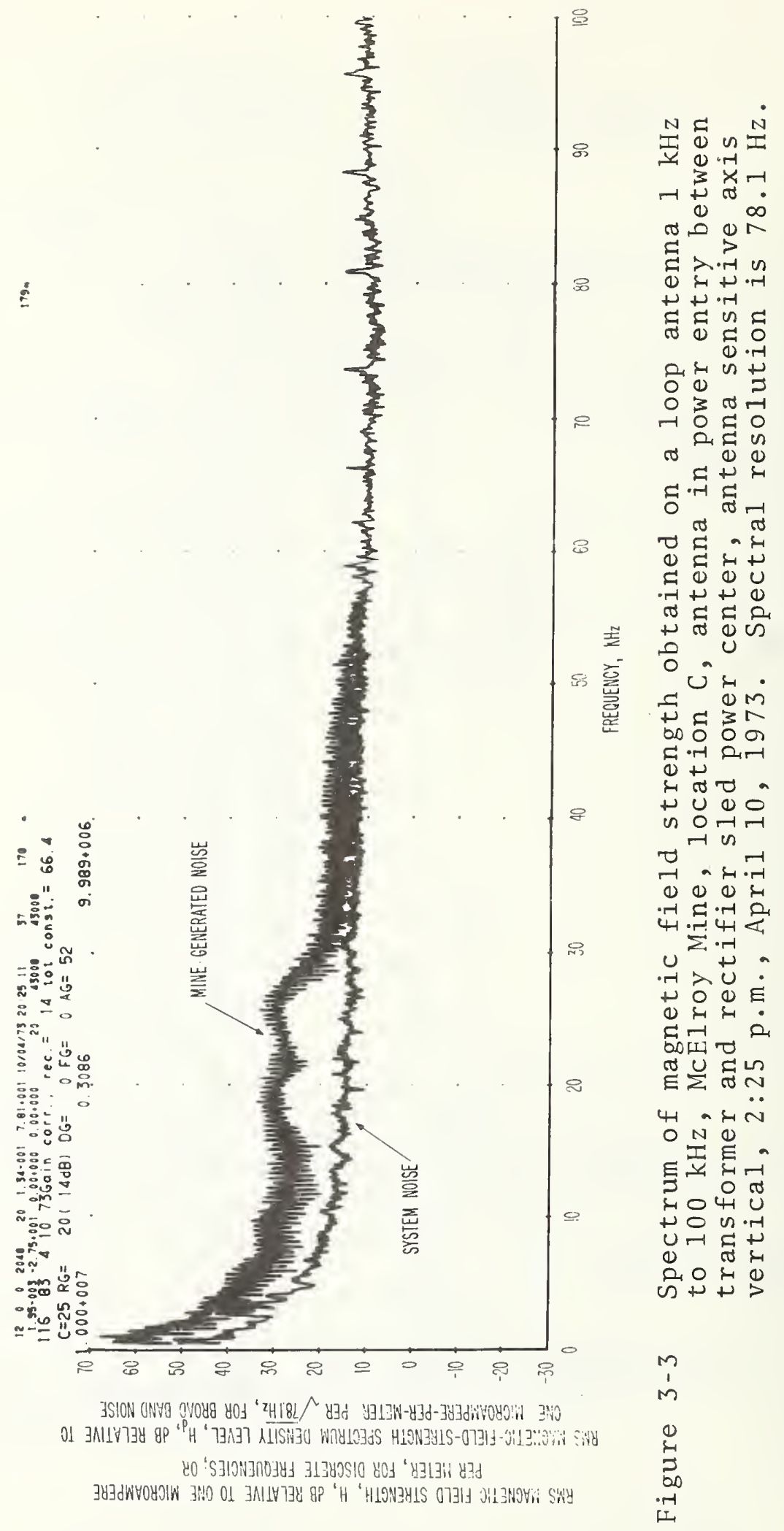




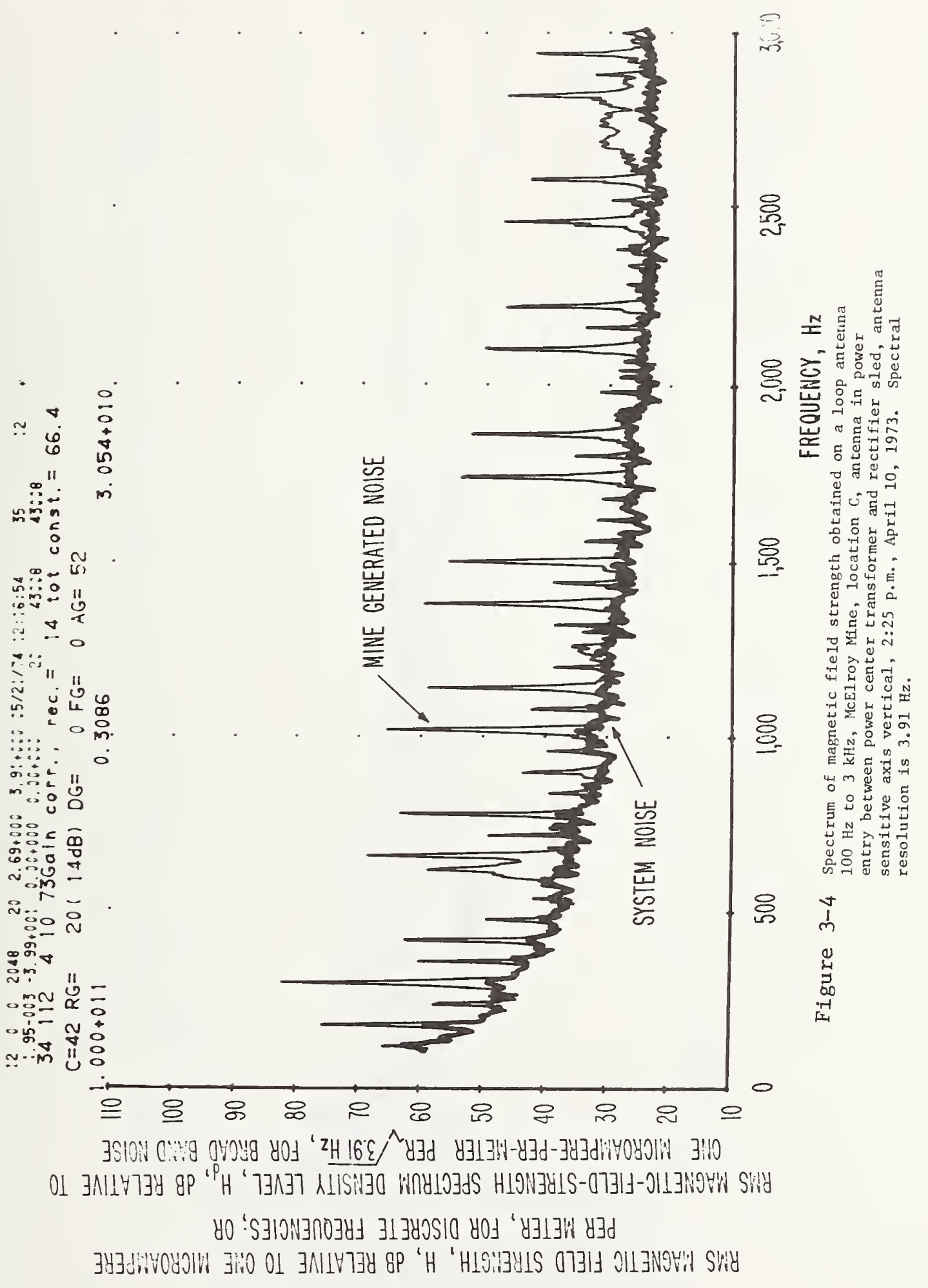




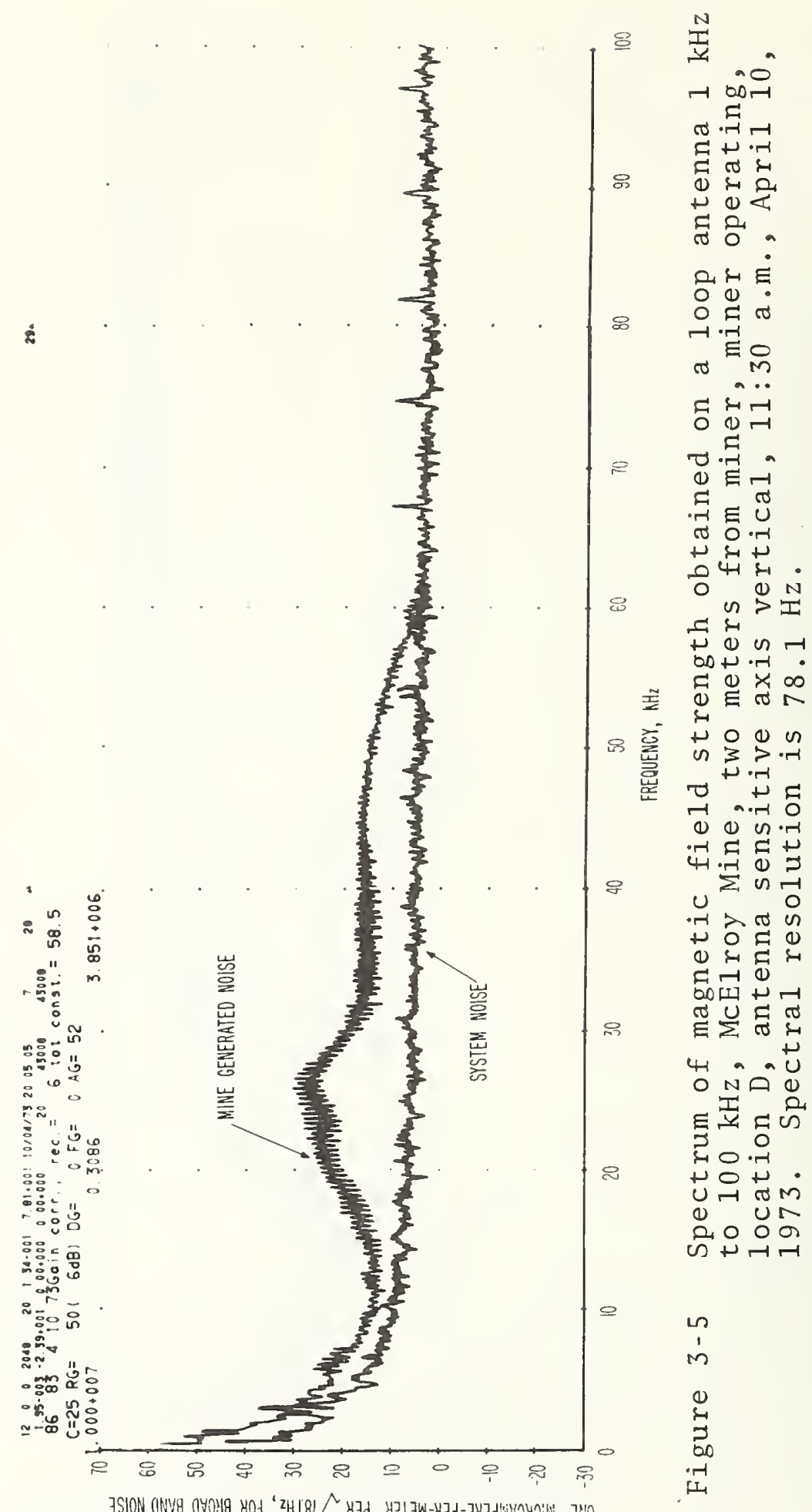

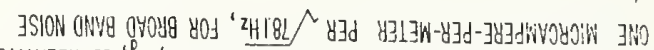

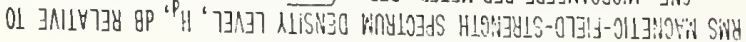

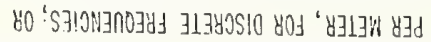

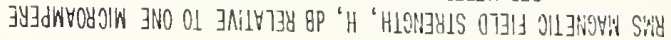




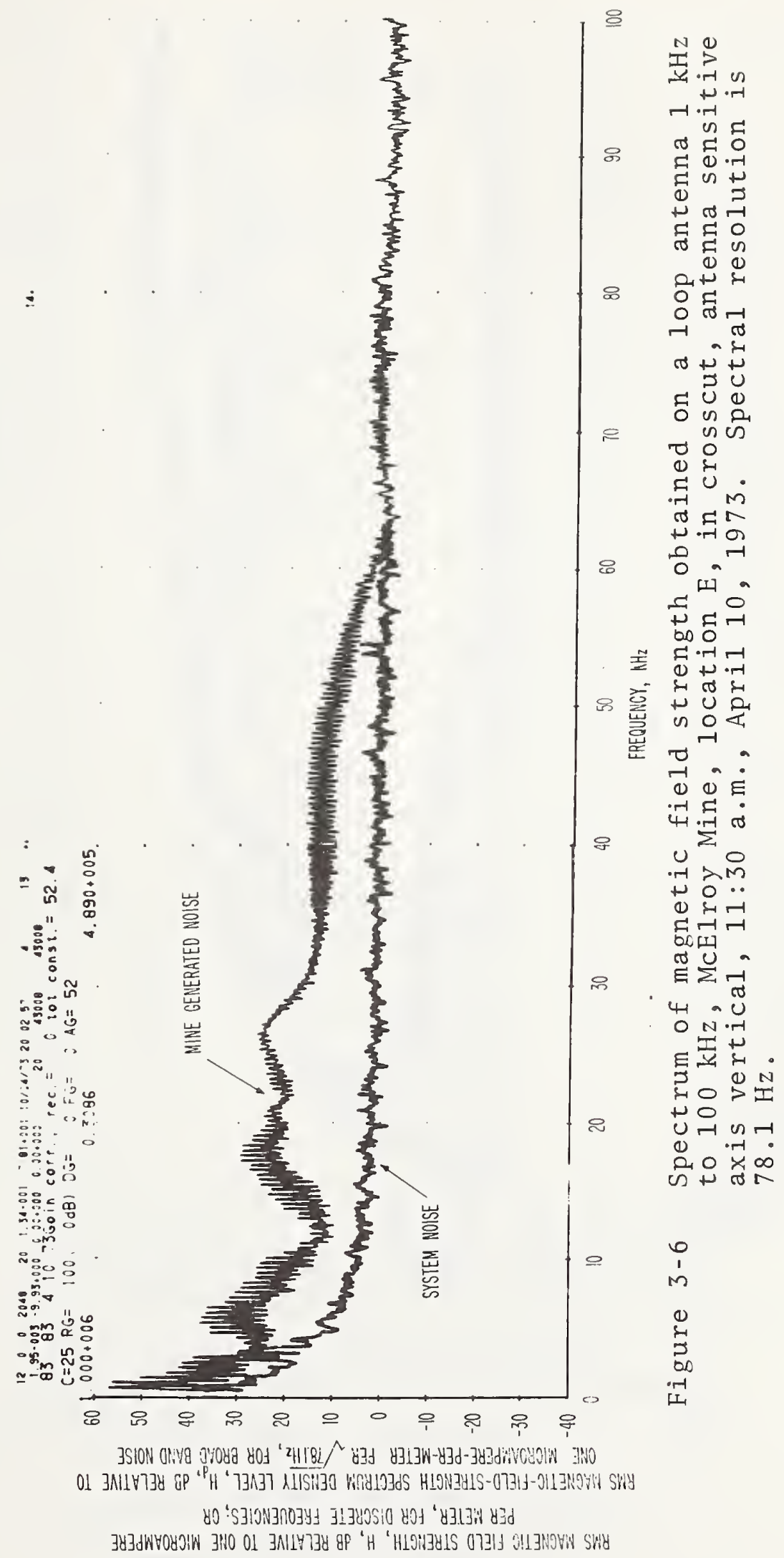




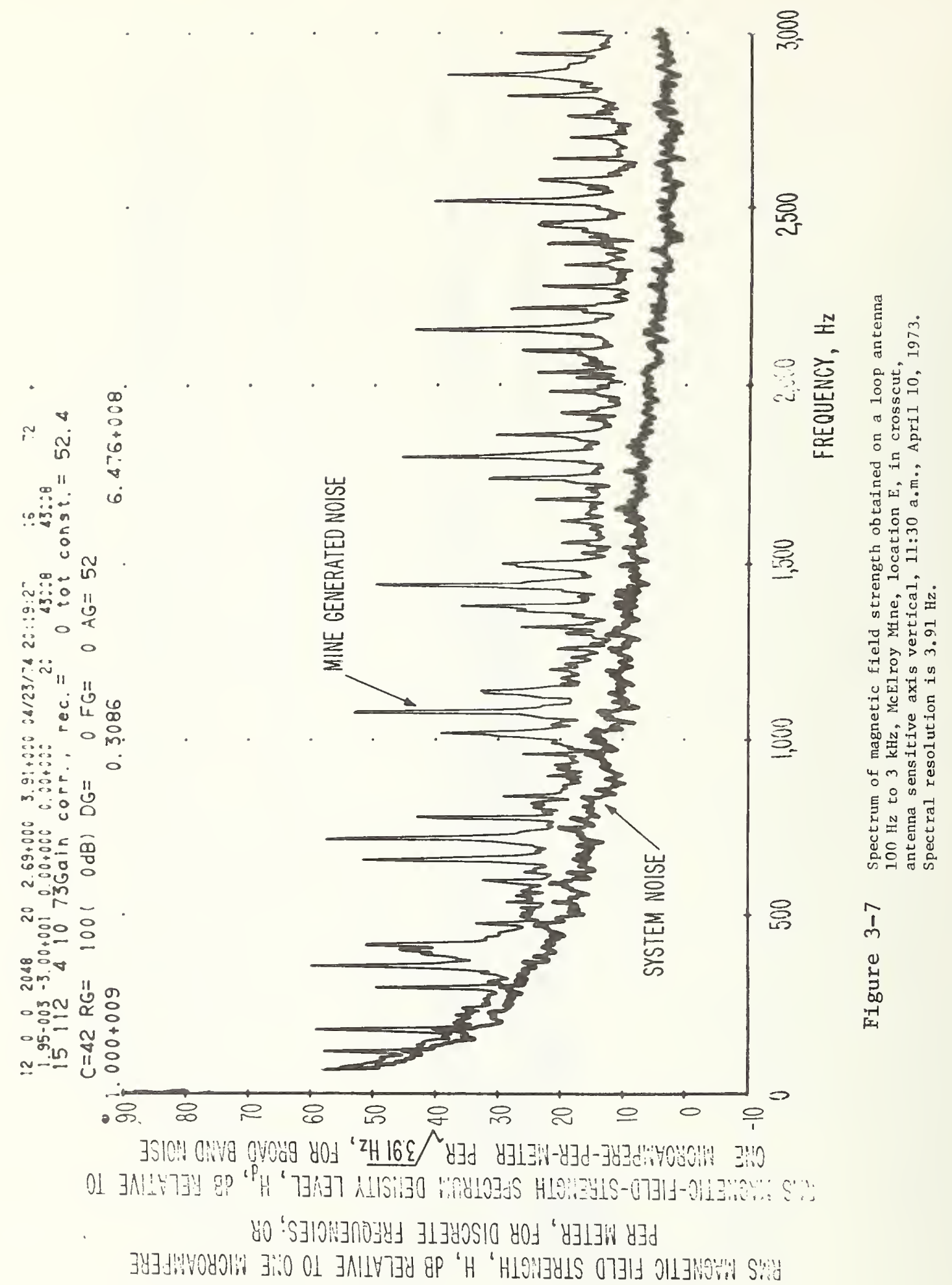




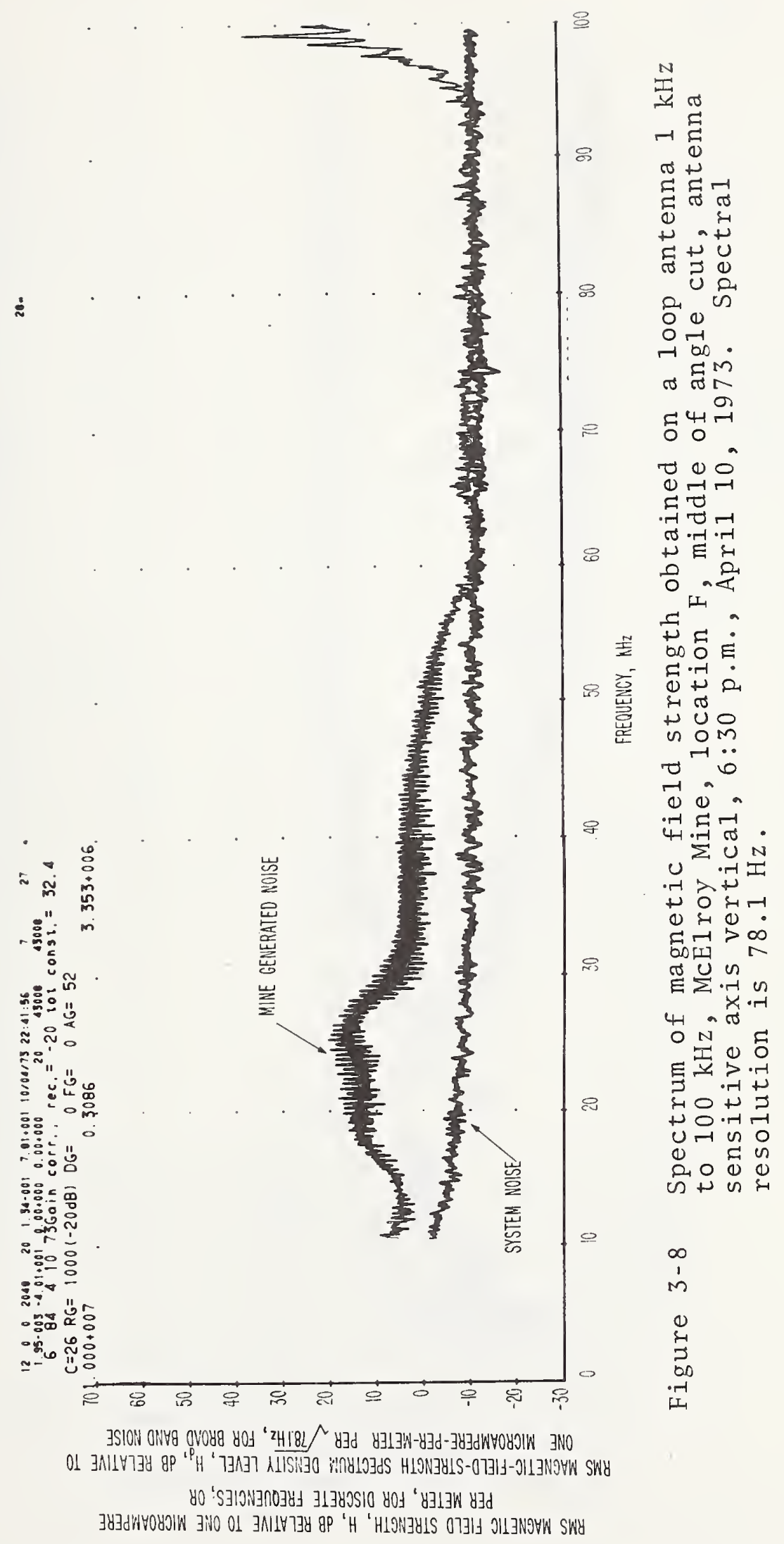




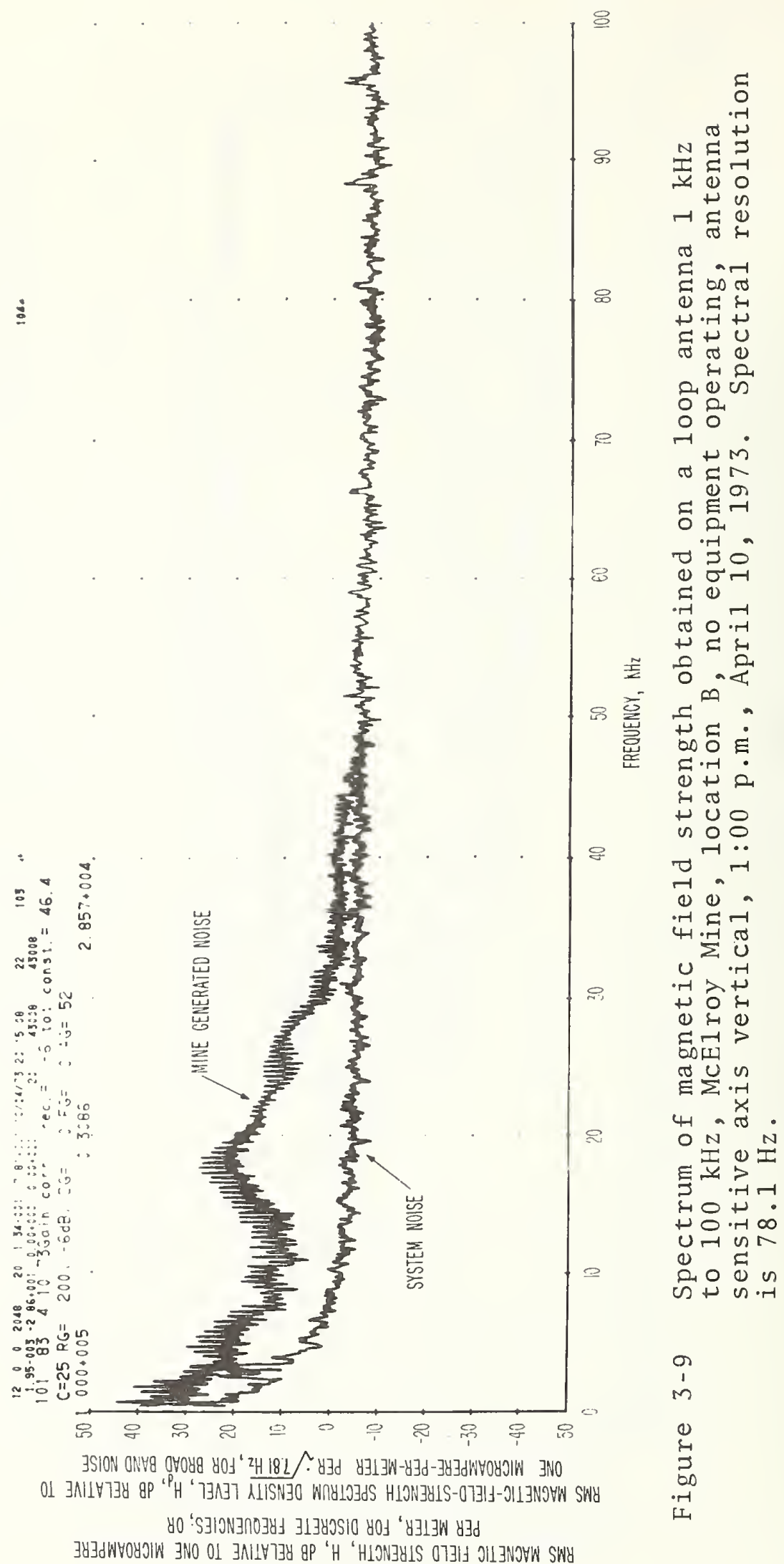




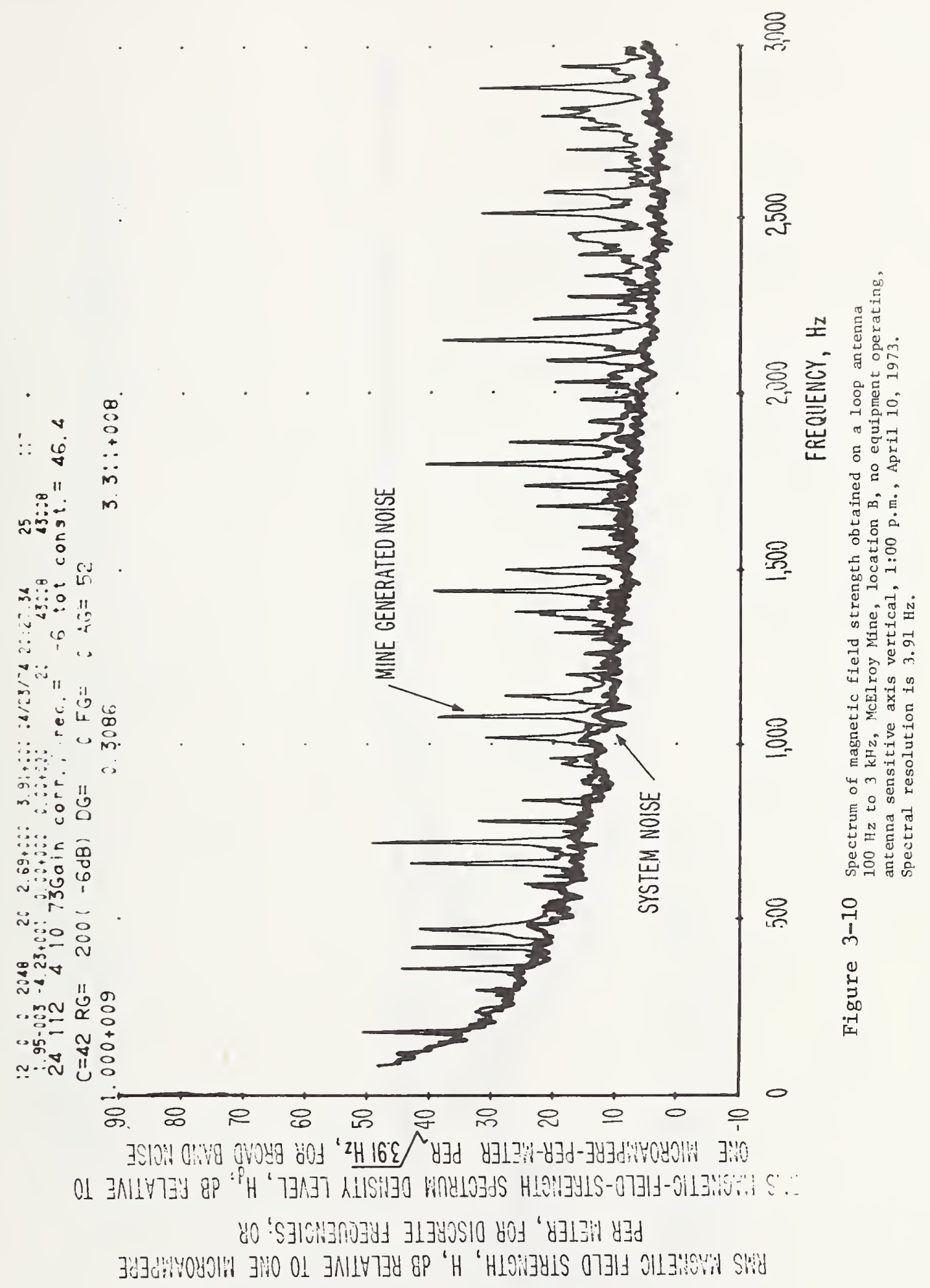




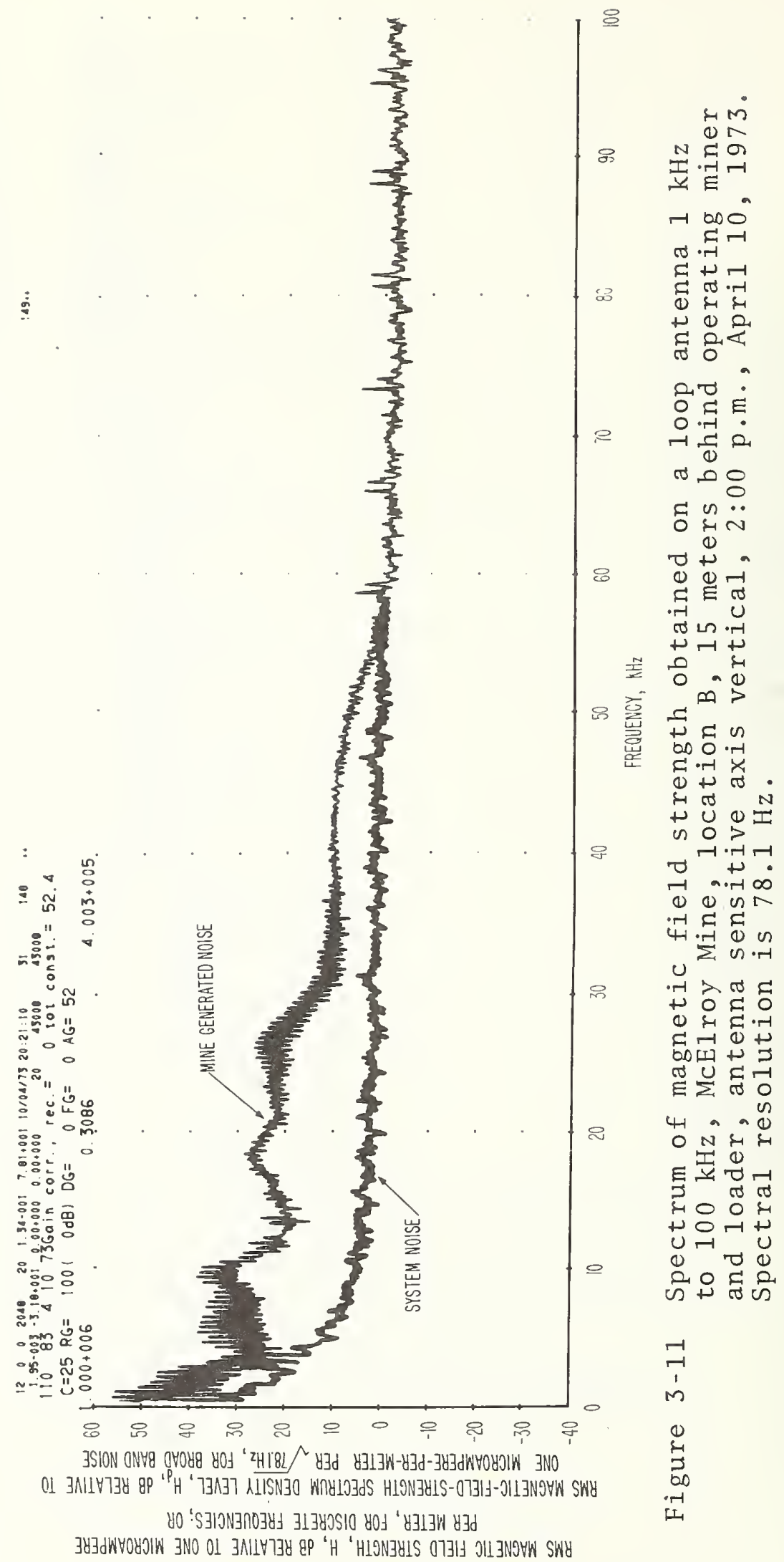




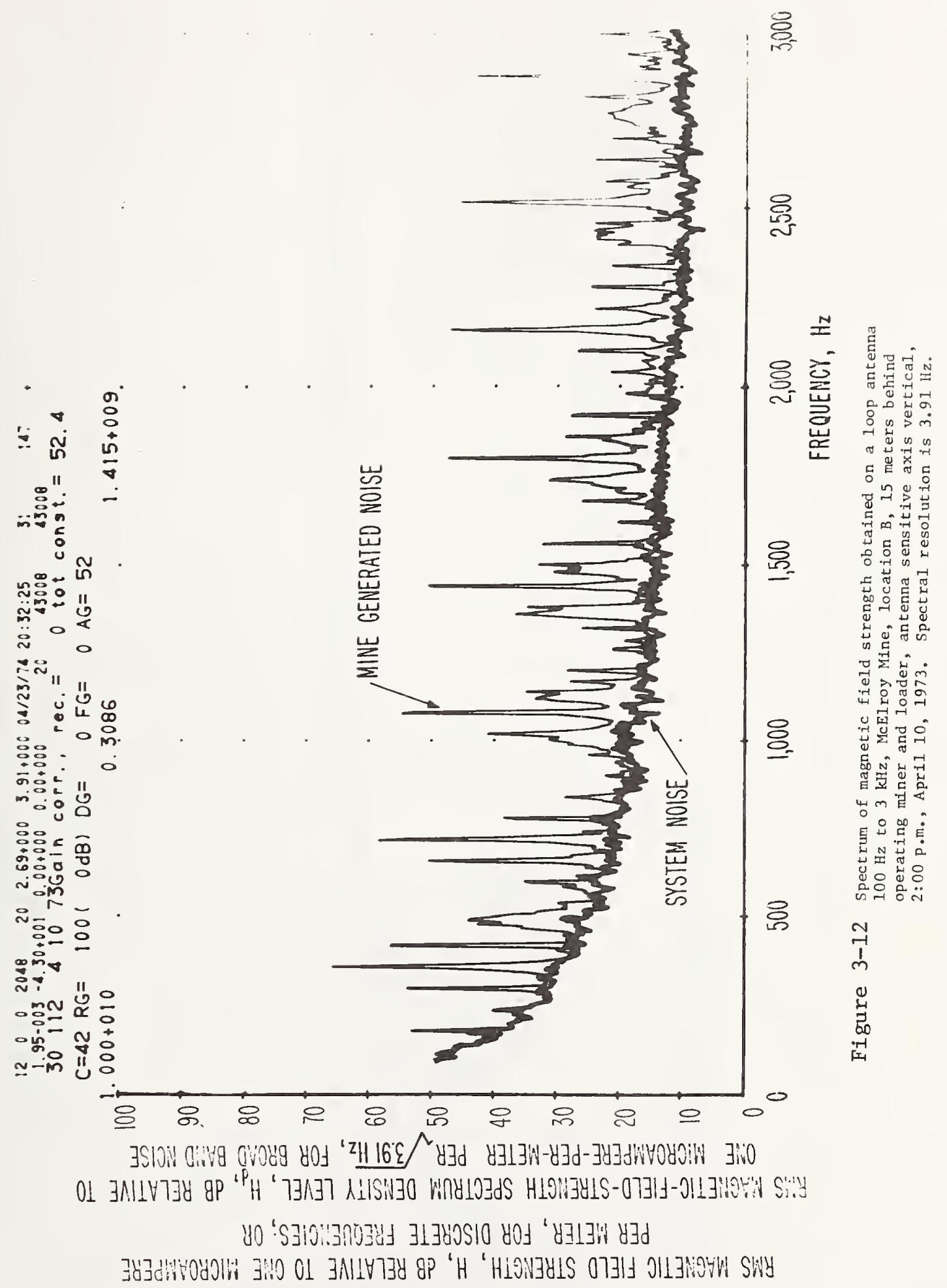




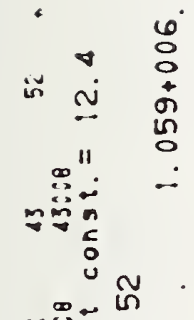

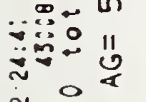

$\therefore$ 앙

패"

空

范: 0

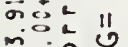

migo

영드

क्षे

īm

a

30응

흥ㅇㅇ

i

응 응

岁

‥ 궝

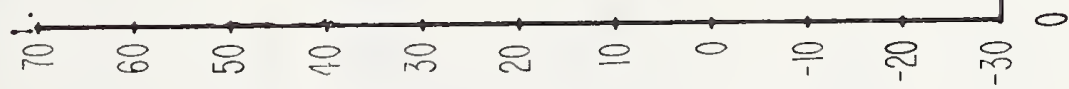

是

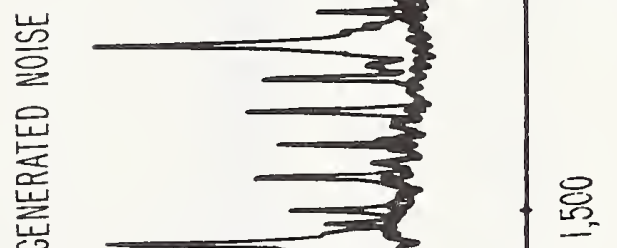

㕸

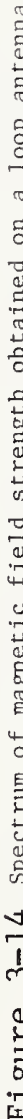

崖

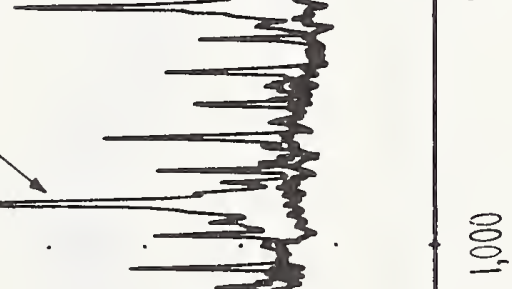

8

:

등료옥

व)

䒕 5 준

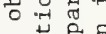

풍.

달의 검

पे

品

검당

엉

뇜

I

政

톨

山以

o in

至 N

욤듀

m

范

䍃

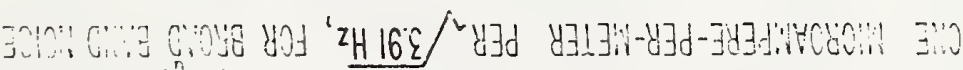

01 zhis

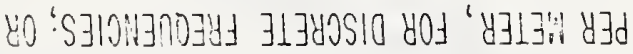

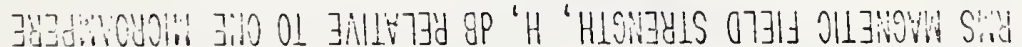




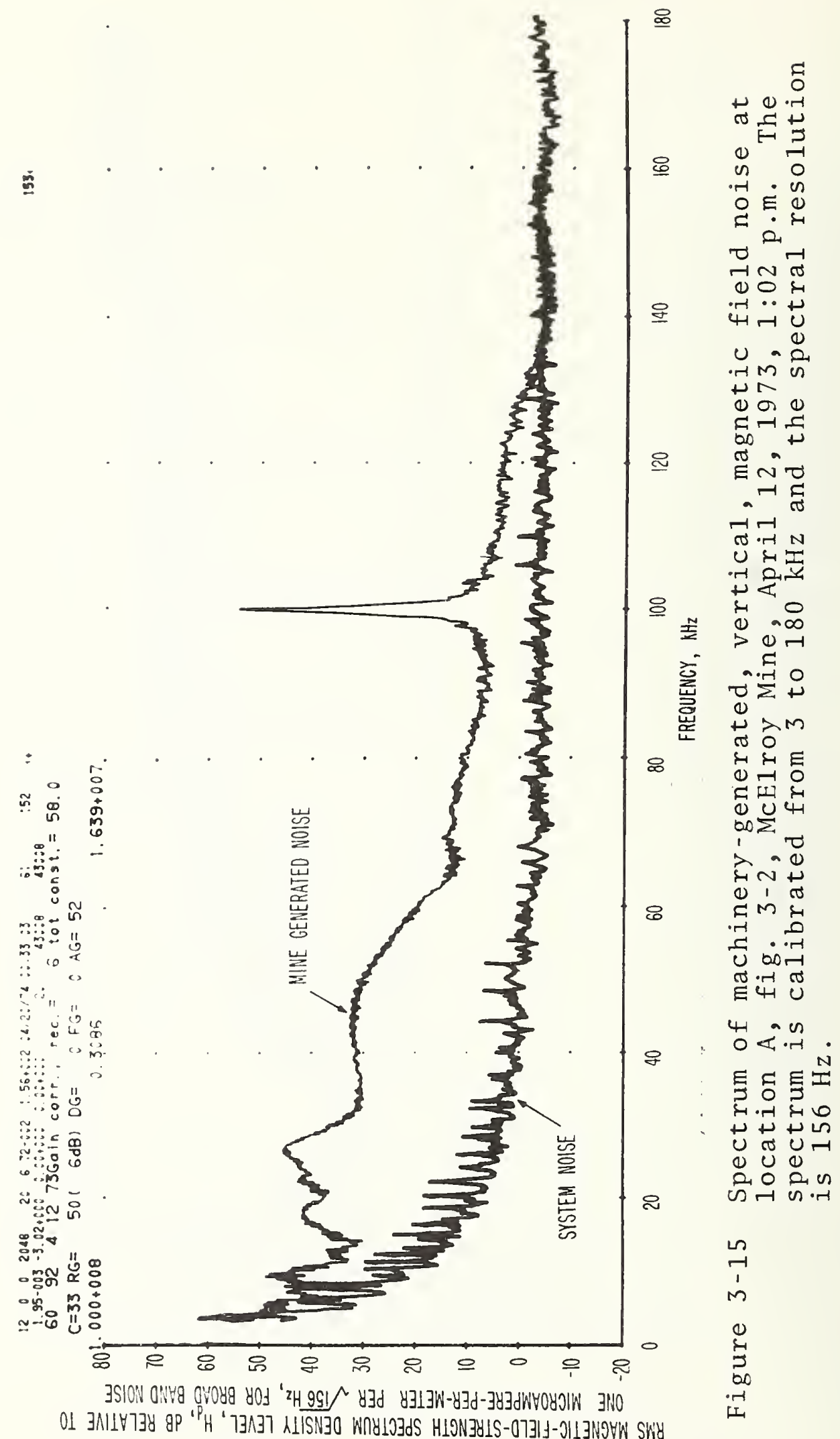

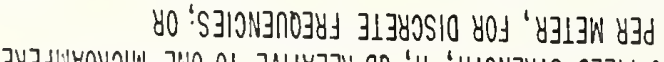

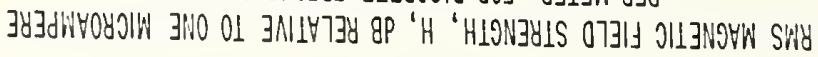




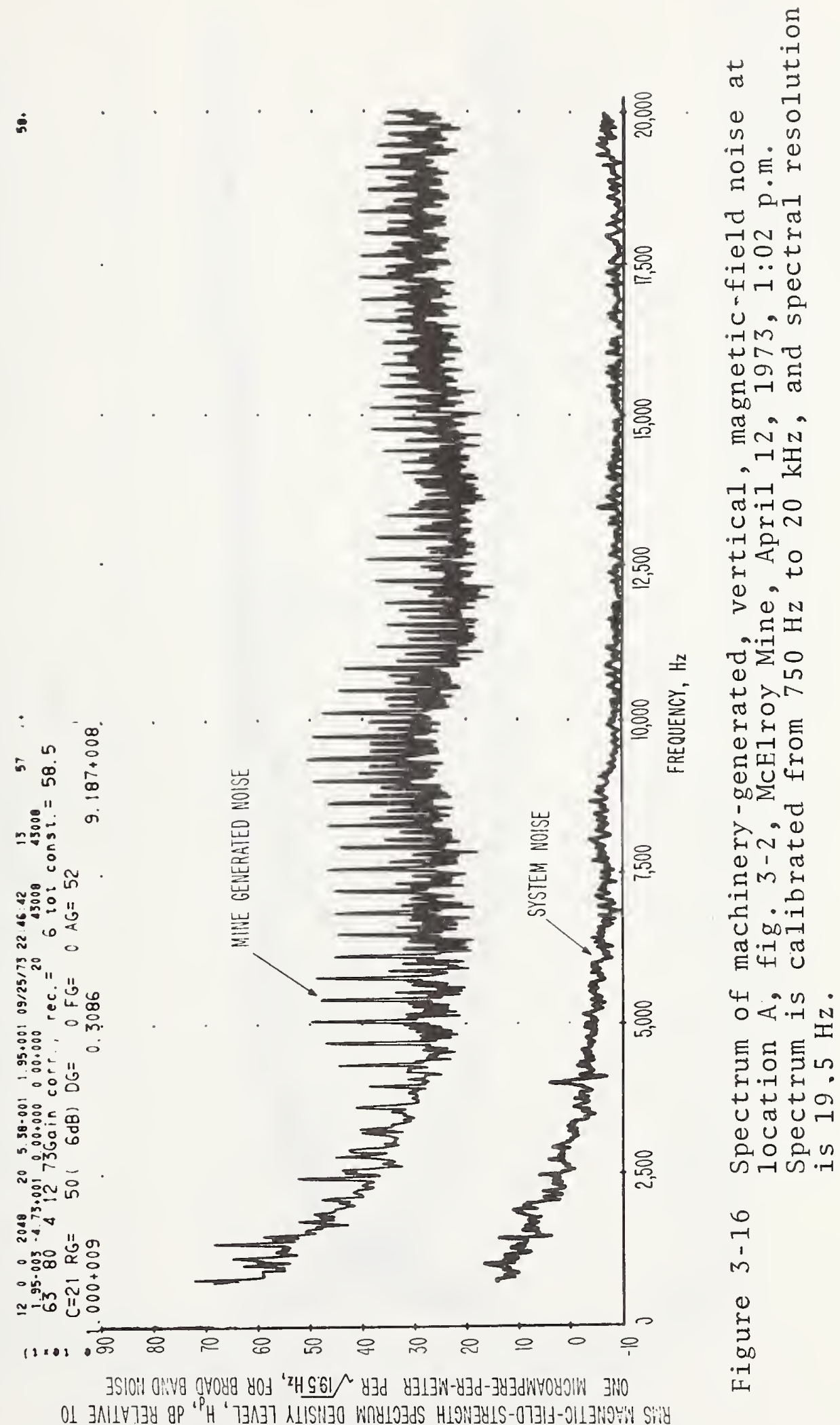

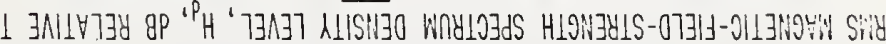

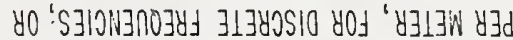

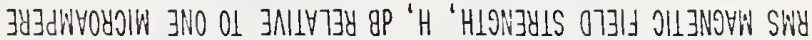




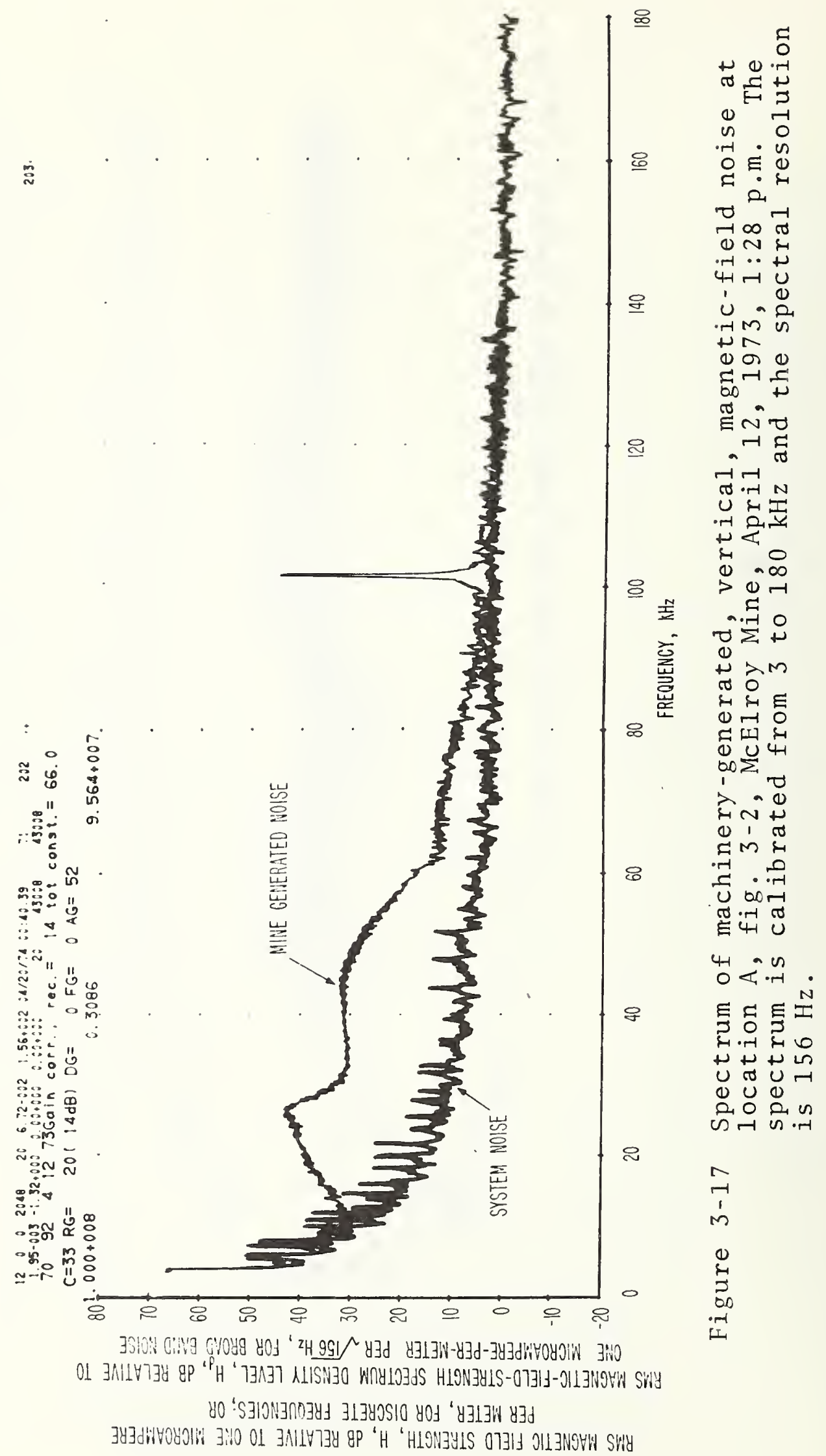




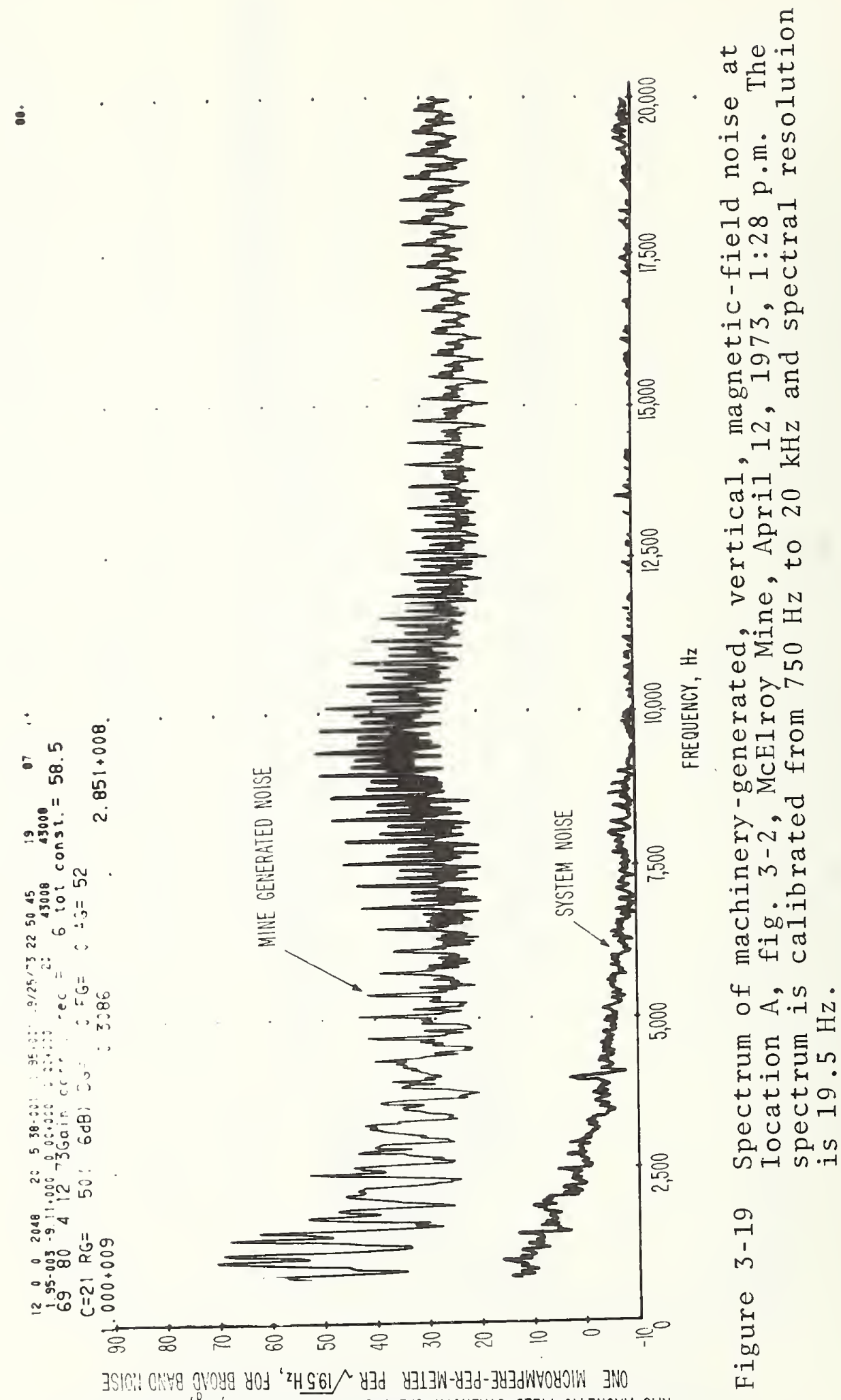

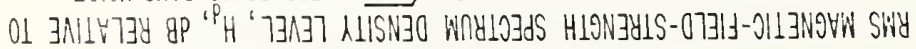

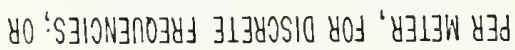

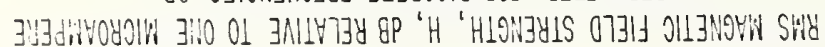




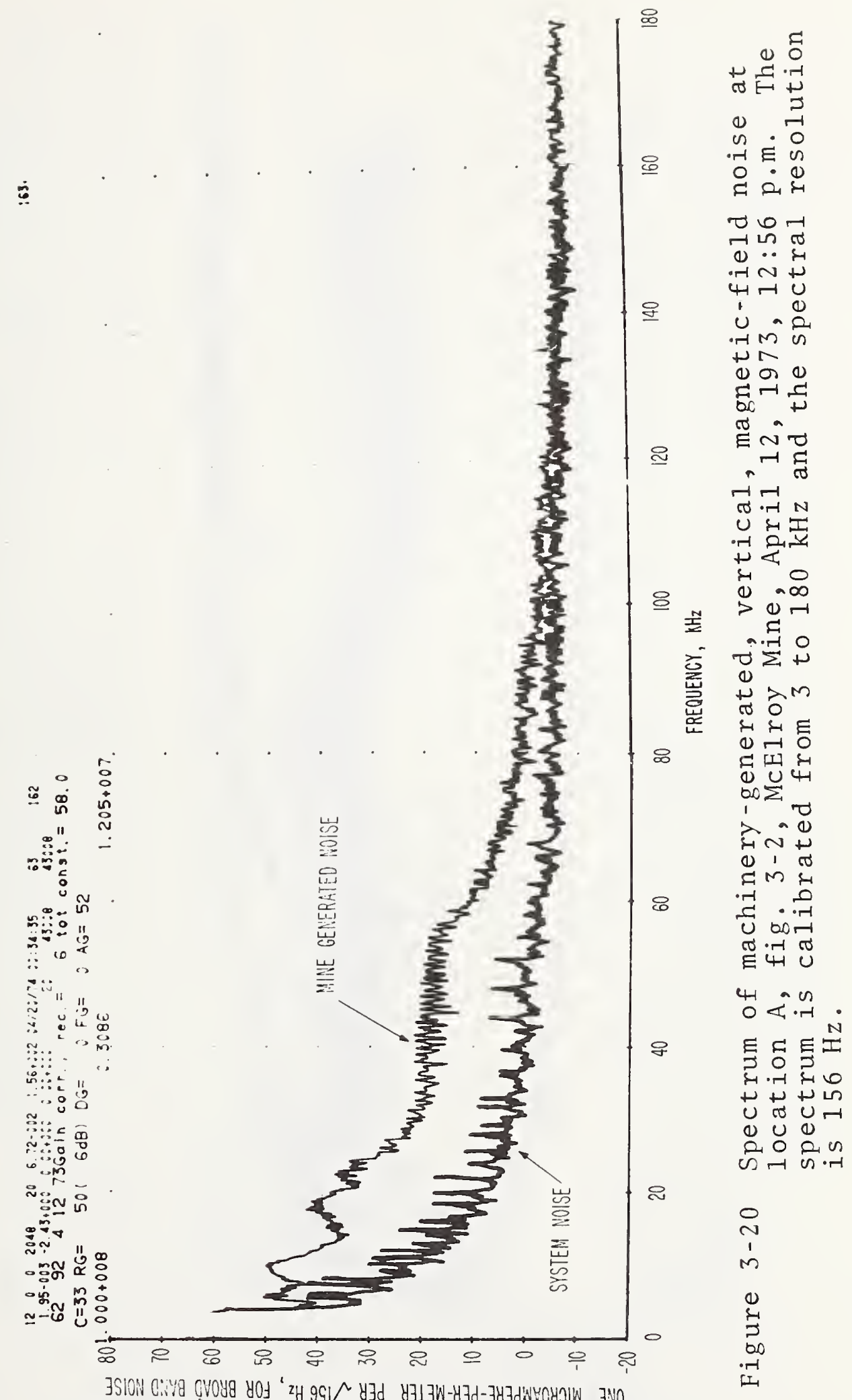

ol 3 ML1

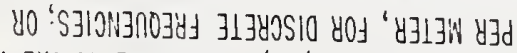

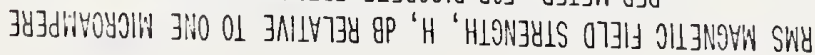


茂兄 +o (1)

की I I

岂 No

ant

₹.

1 에

U્य $m$

-1 0

क्षै है

द $\sum 4$

N $>$ व

. N

का क

어

峲

岂

प)

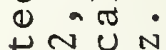

NUN

\& $m$

(1) $\rightarrow 0$

(1) को

ac. 3

14 出

ते

$0<0 \leftleftarrows$

c 00

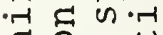

다이

匹

हाँ

40

0 -

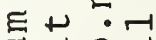

गे

400

U in 过

(1) . . .. 0

कि $\begin{aligned} & 0 \\ & \text { क }\end{aligned}$

i:

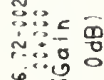

กิ

오응

萬

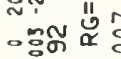

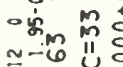

这

$\therefore$
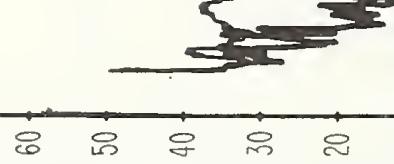

f

-1
1
1
0
$\vdots$
$\vdots$
00
-1
-1

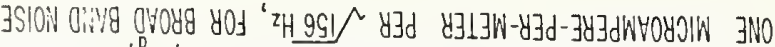

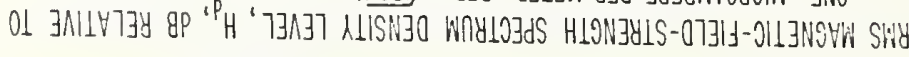

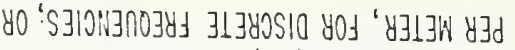

JyJdir. 


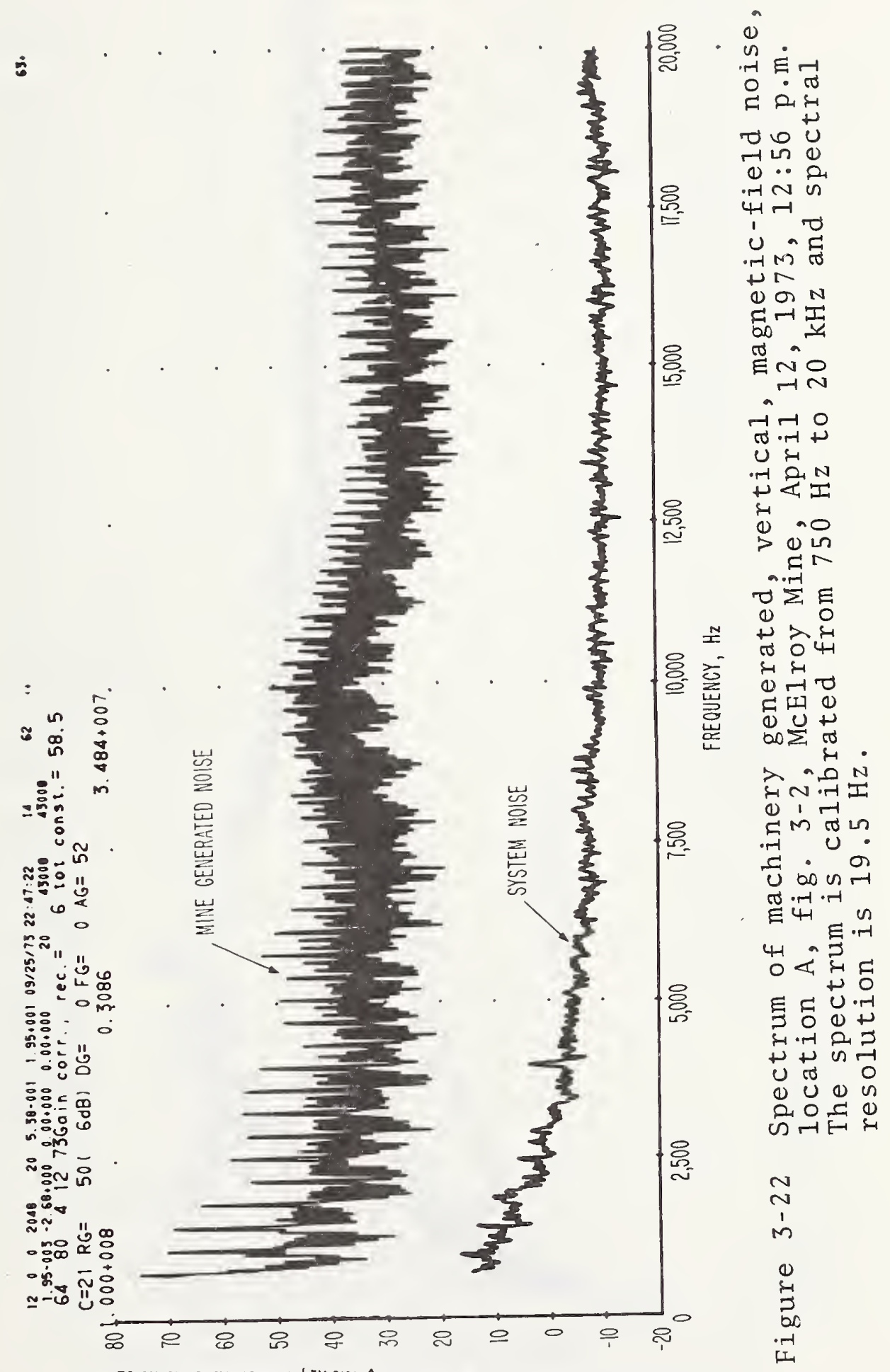

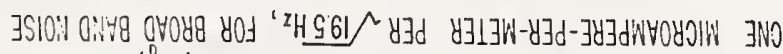

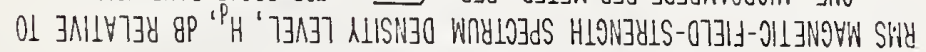

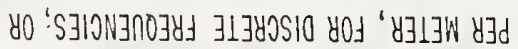

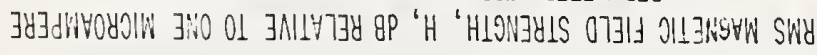




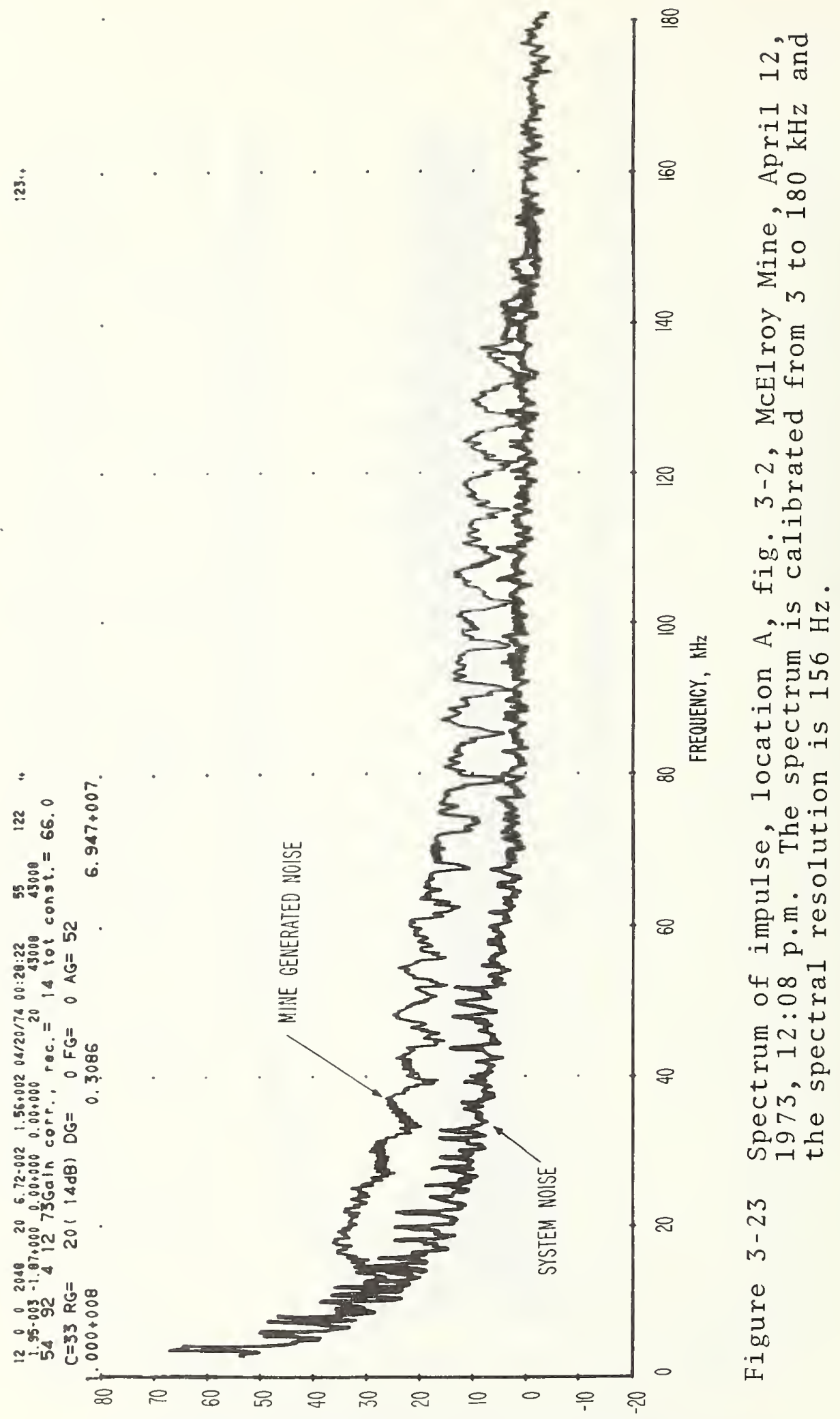

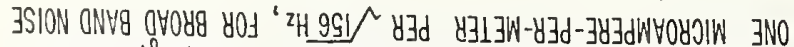

01 JN11

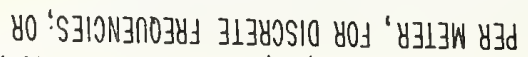

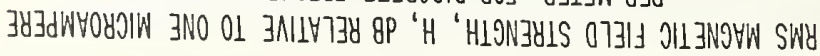




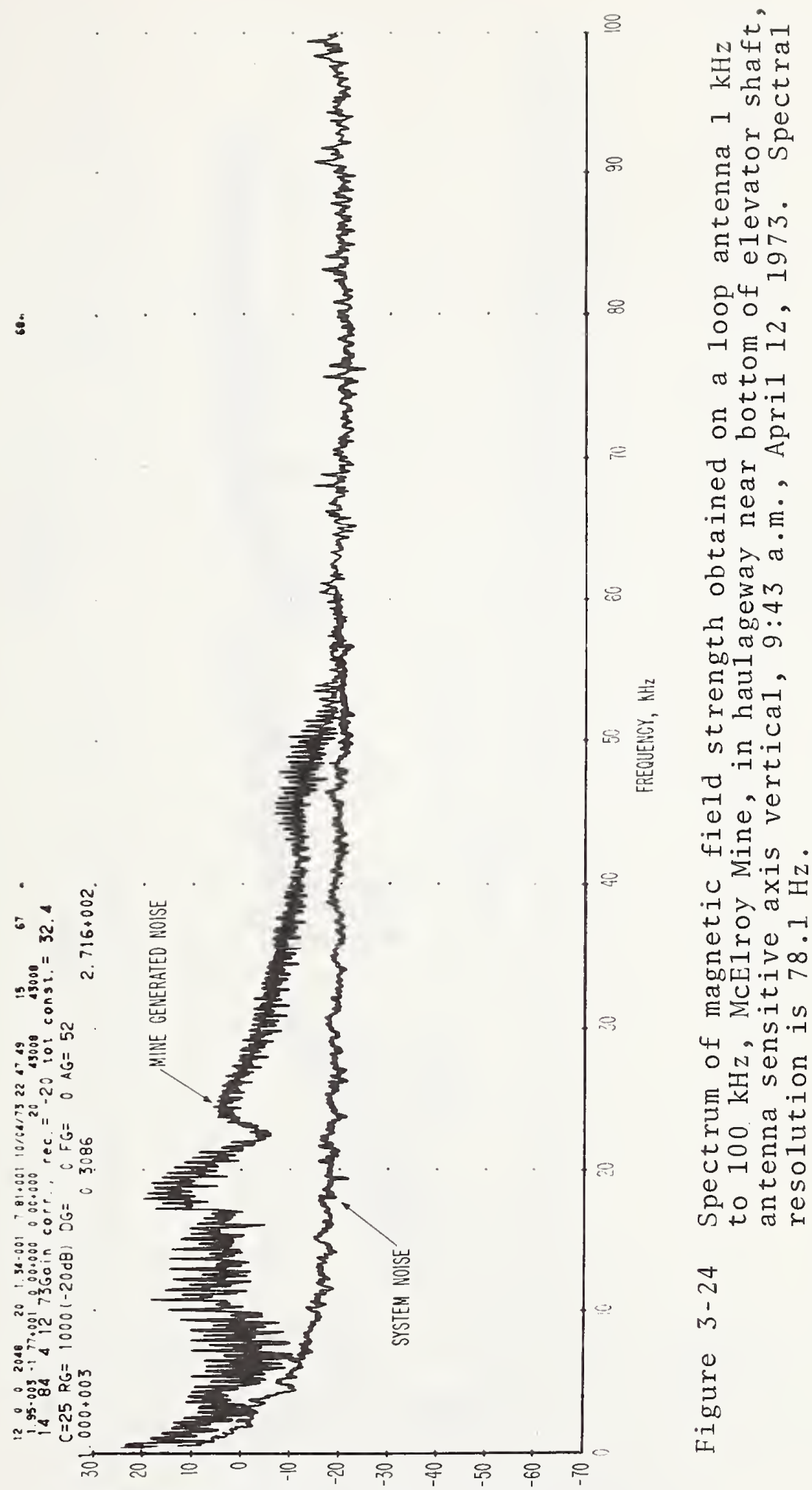

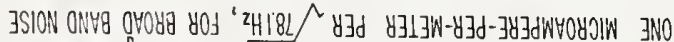
OL JN1Y7zy gP "

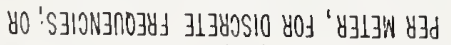

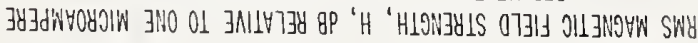




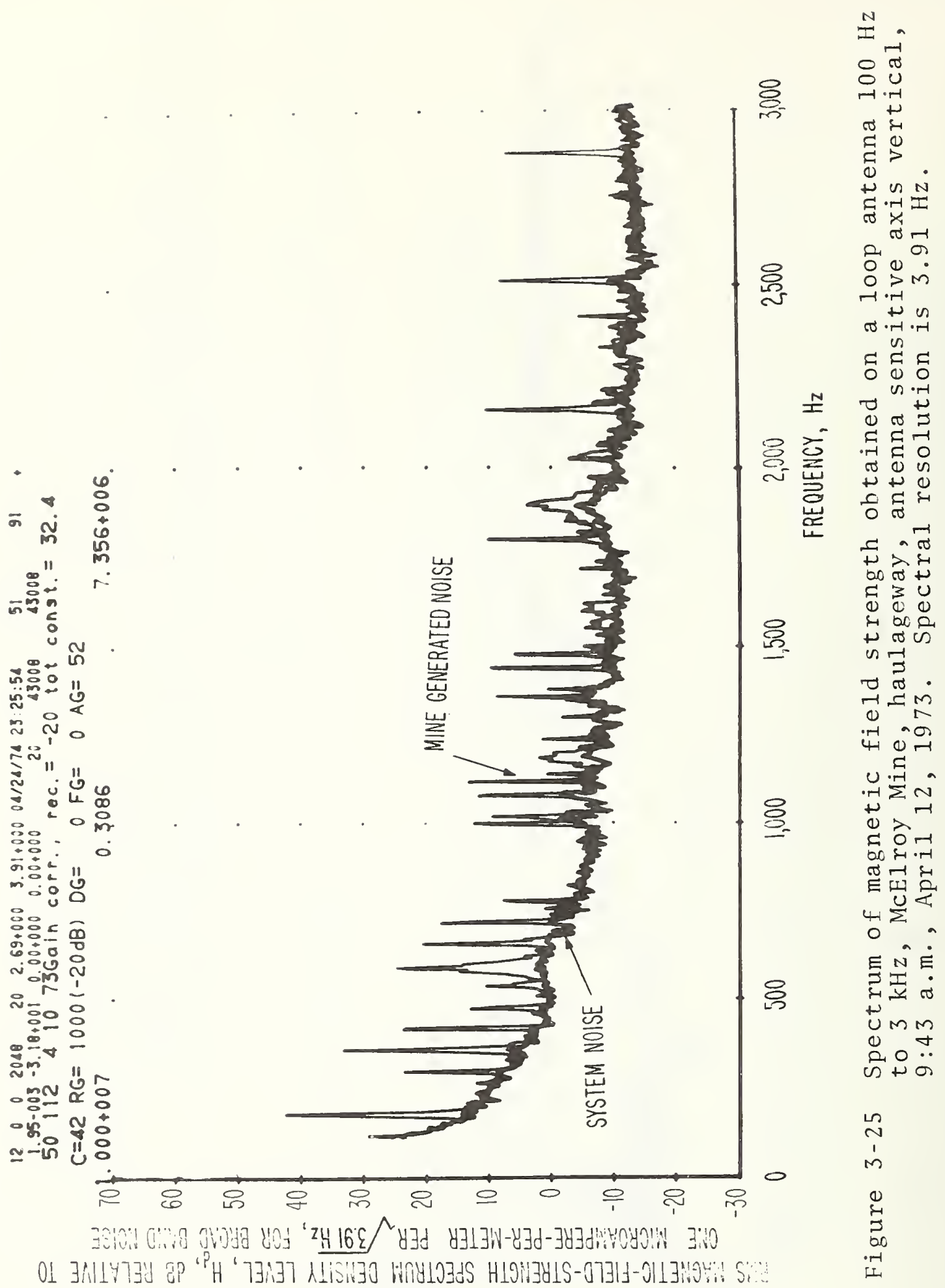

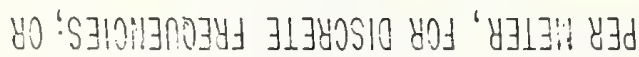

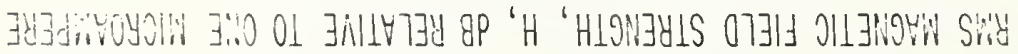




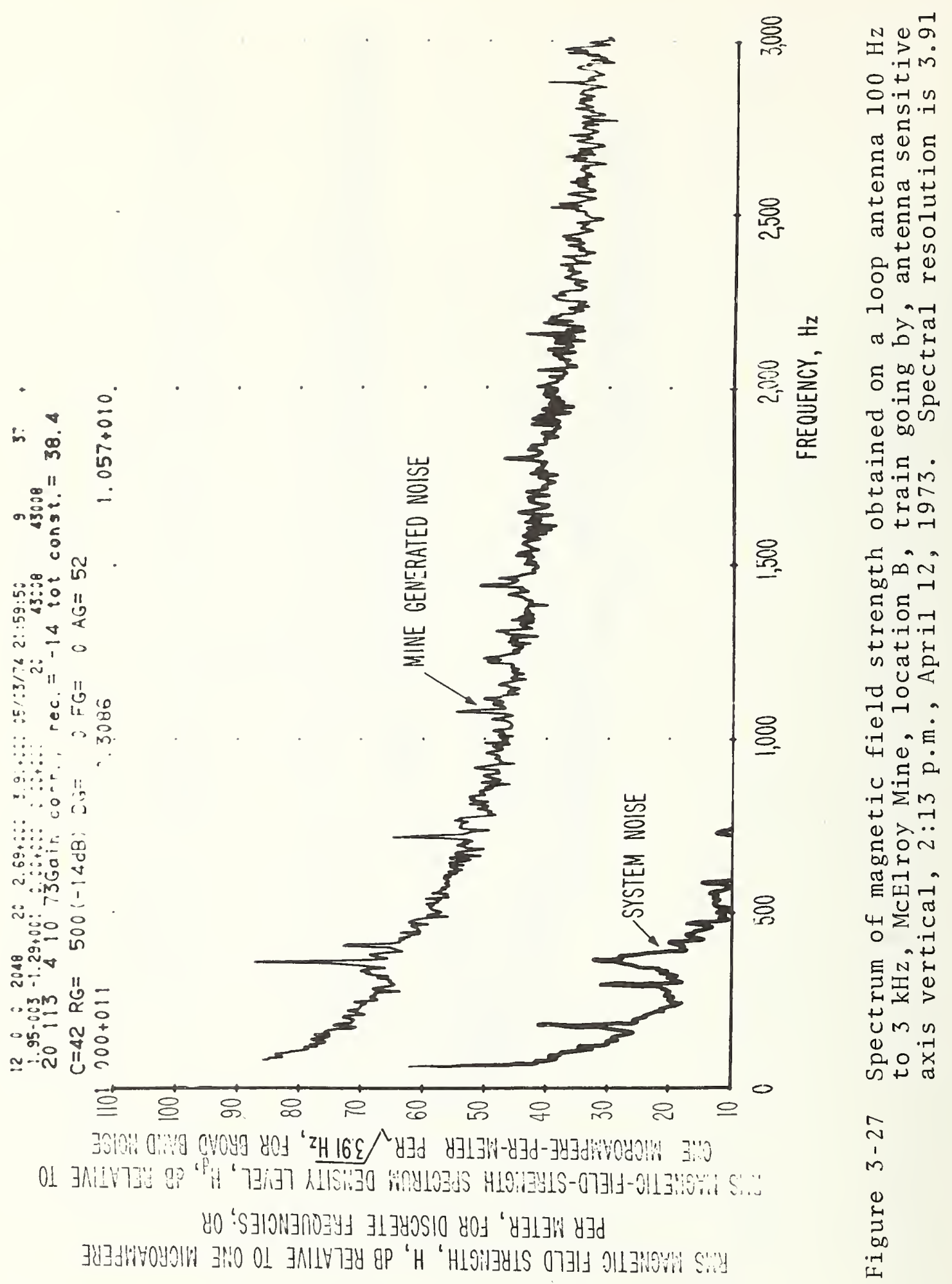




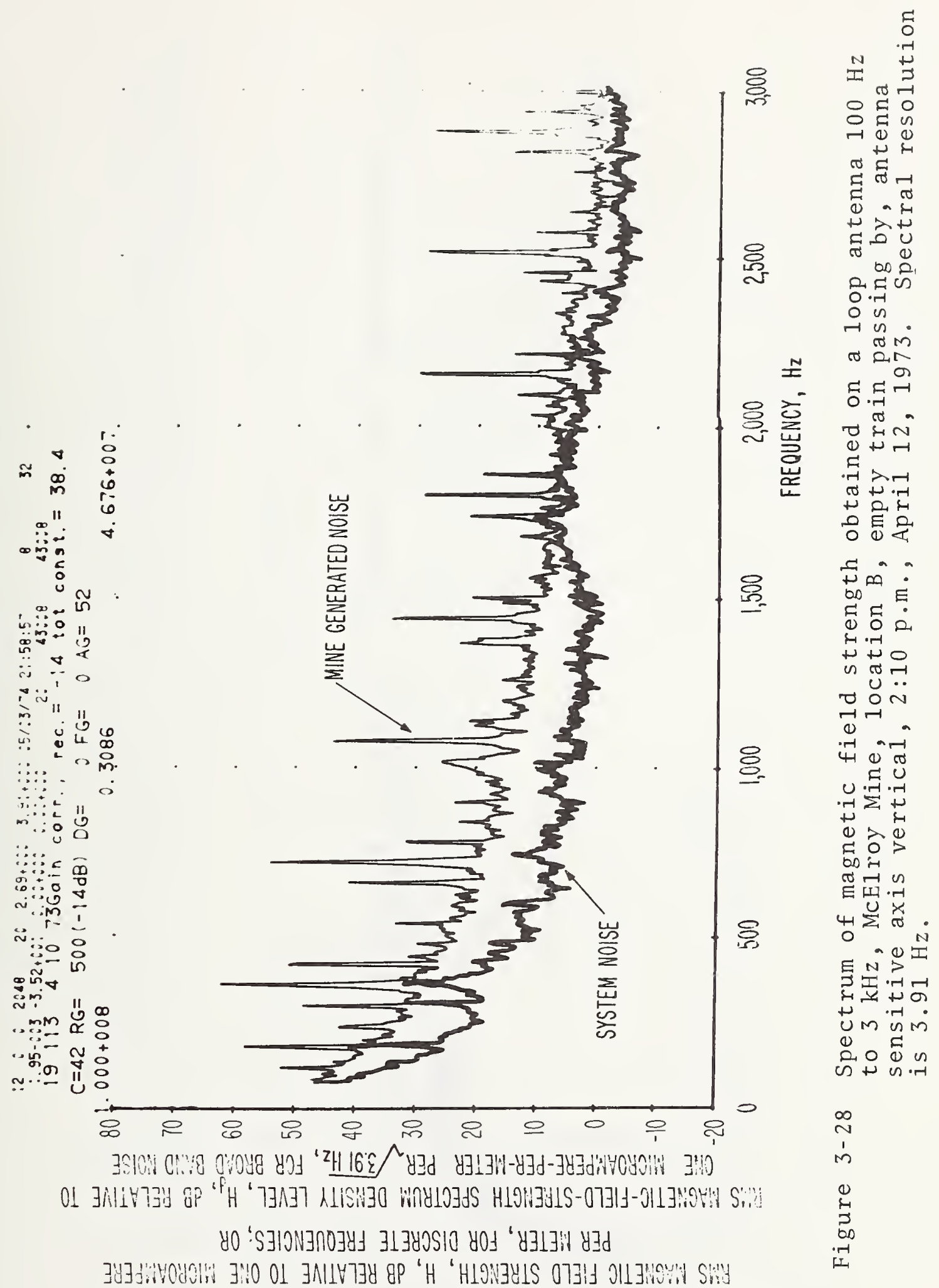




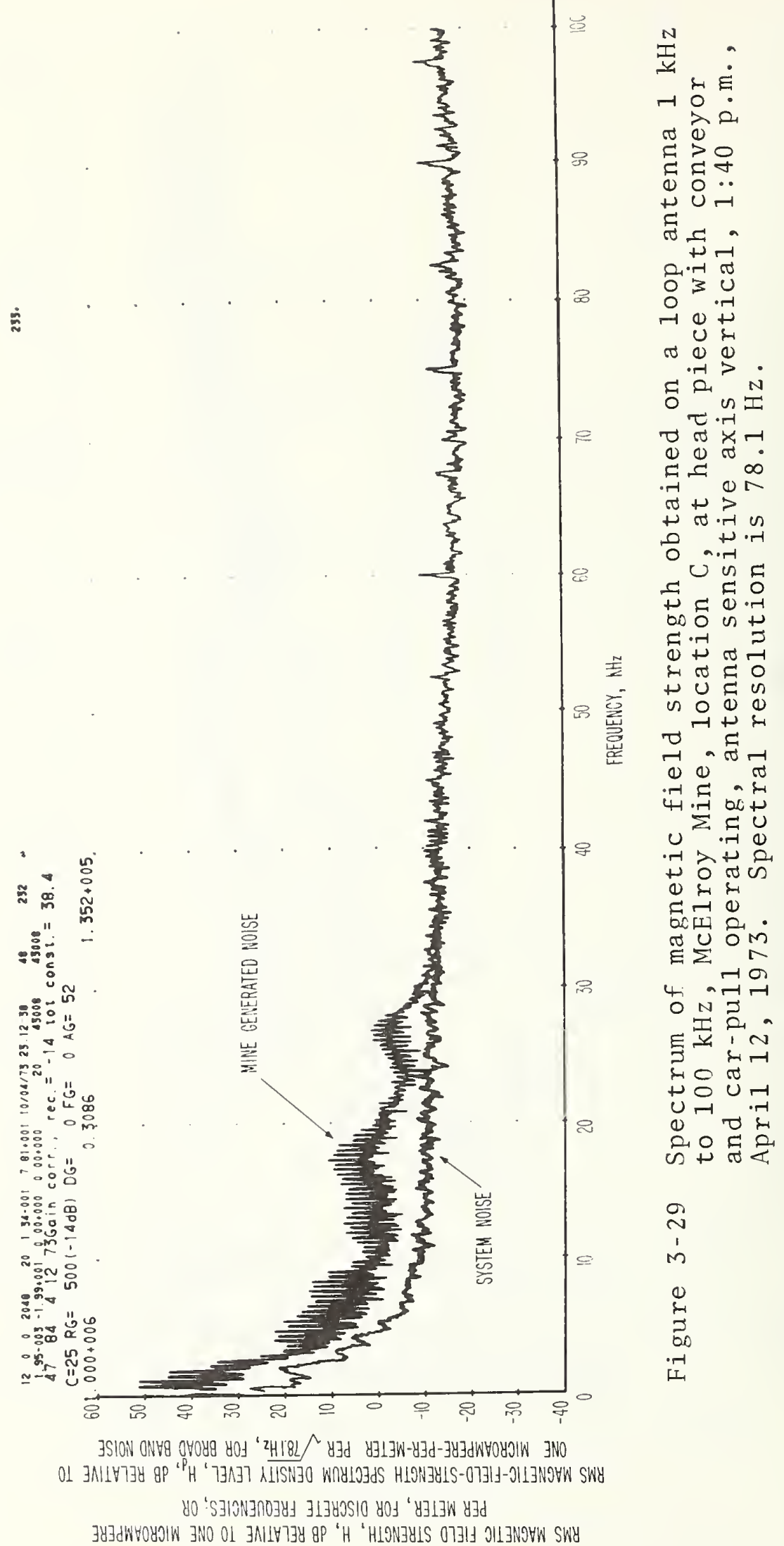




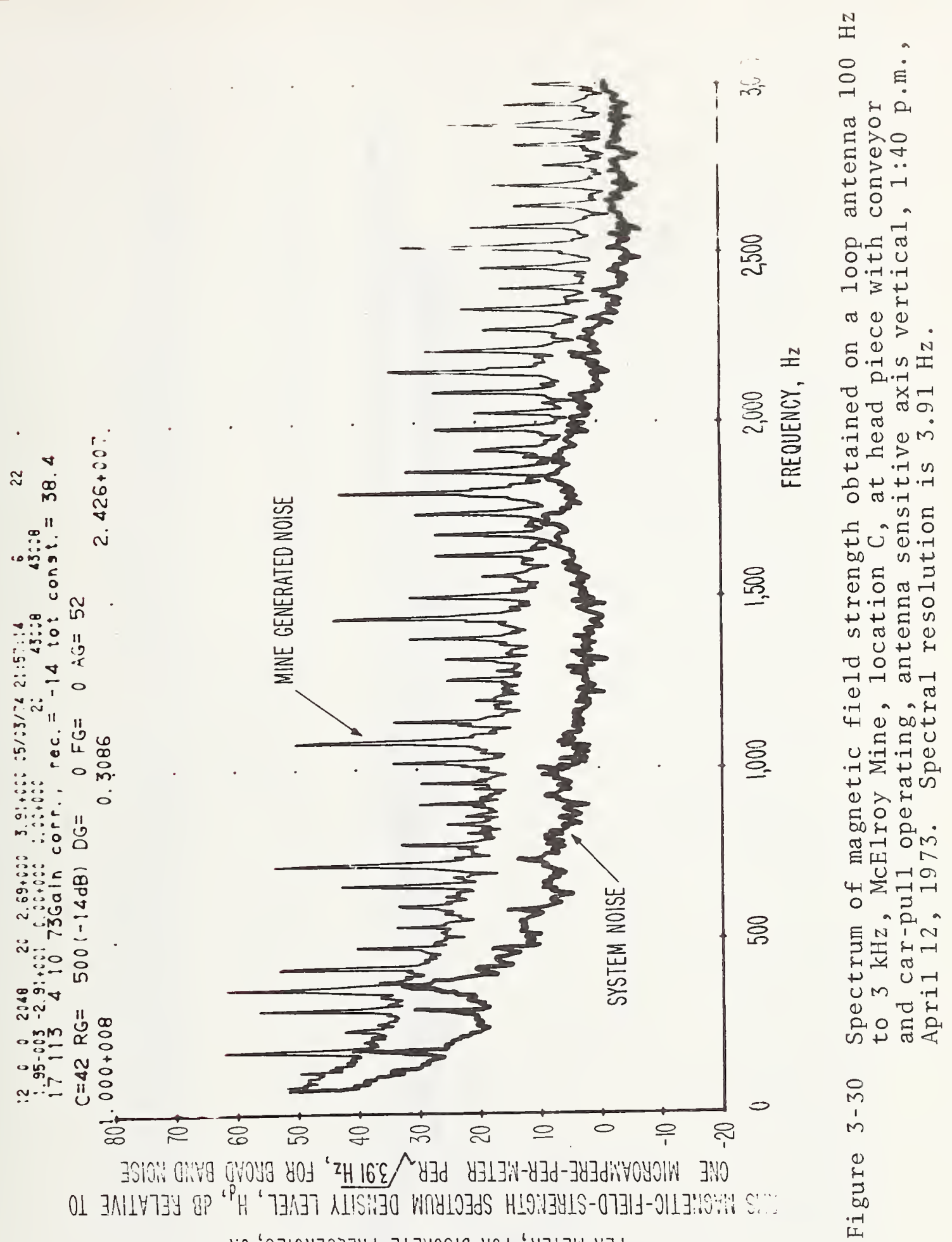

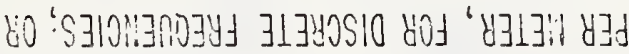

Jug d. 


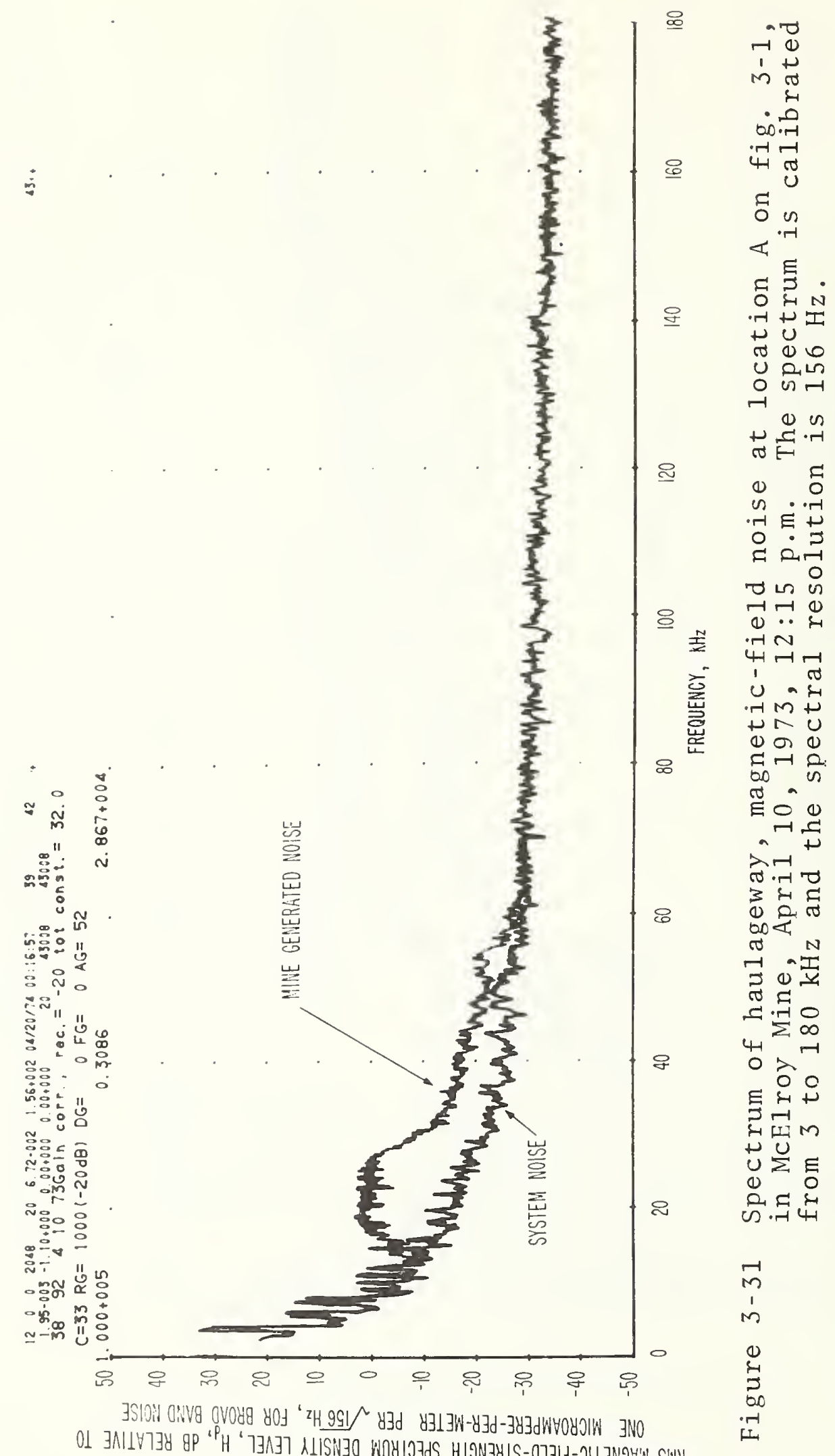

эу

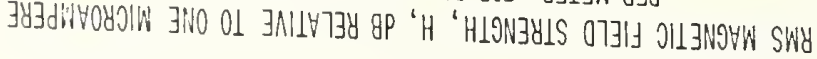




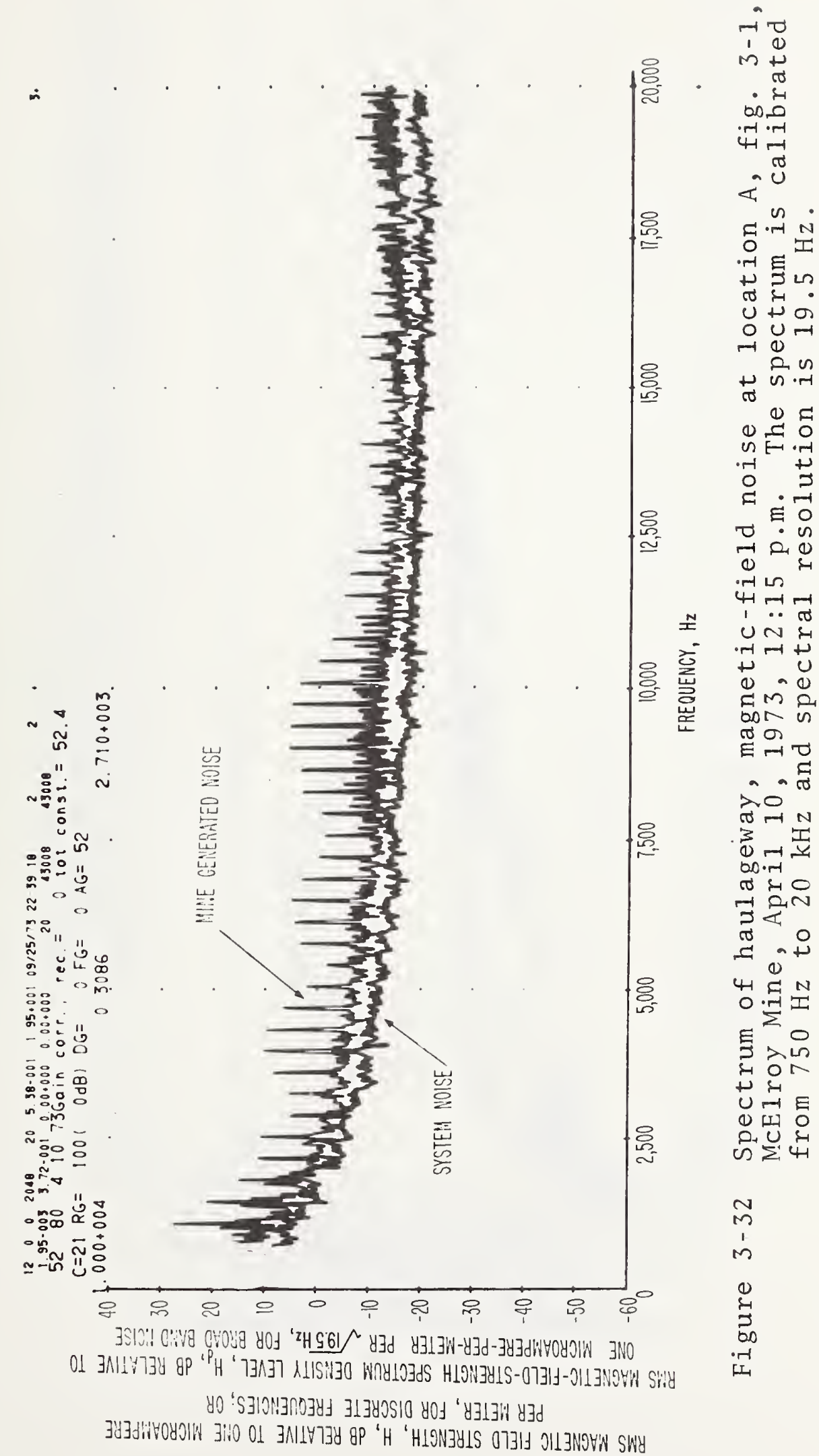




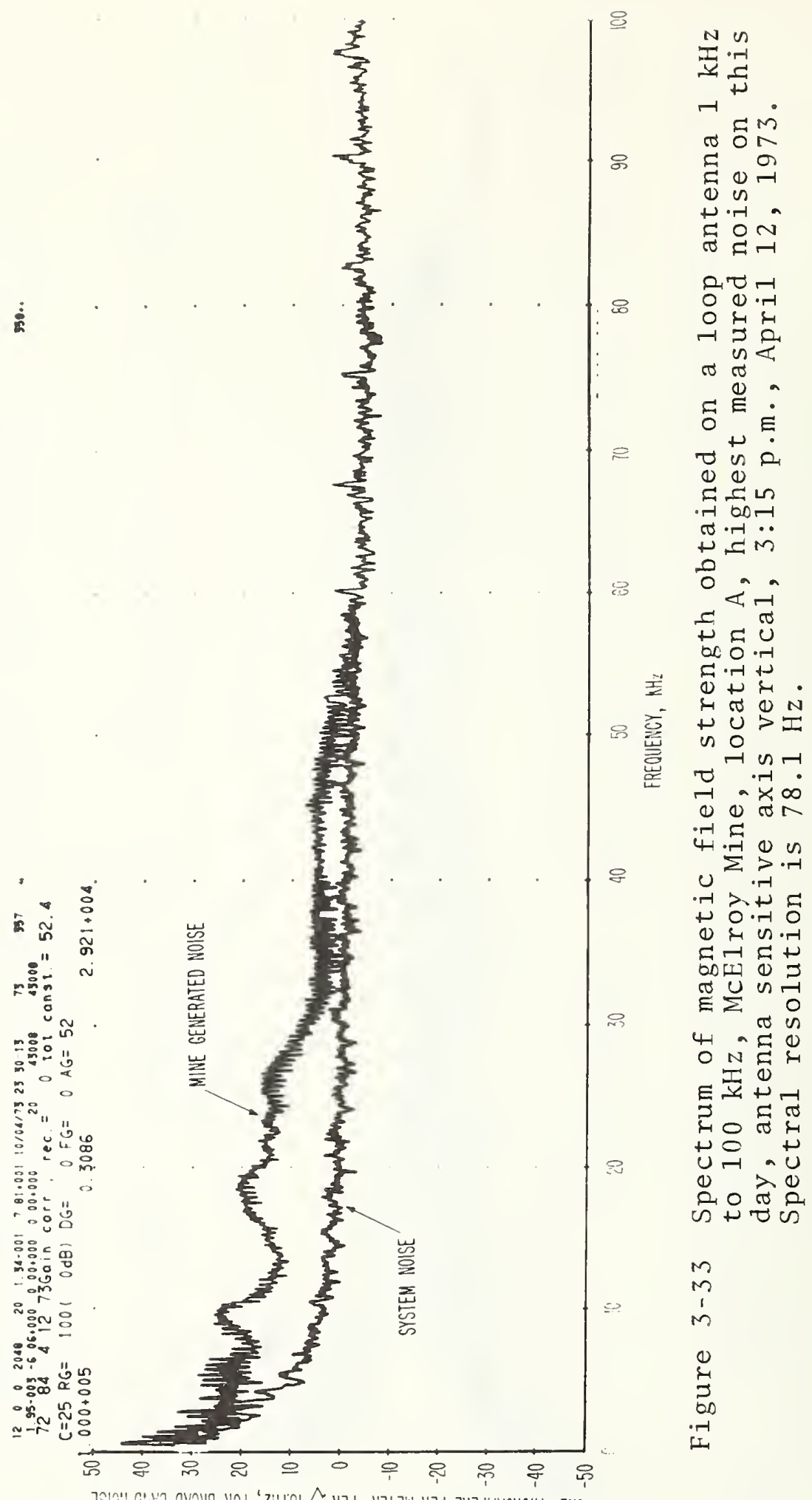

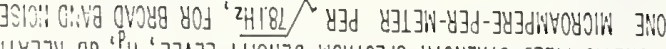

1 JNILB]

y0 5310 ?

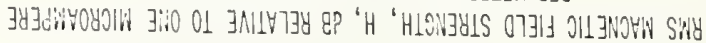




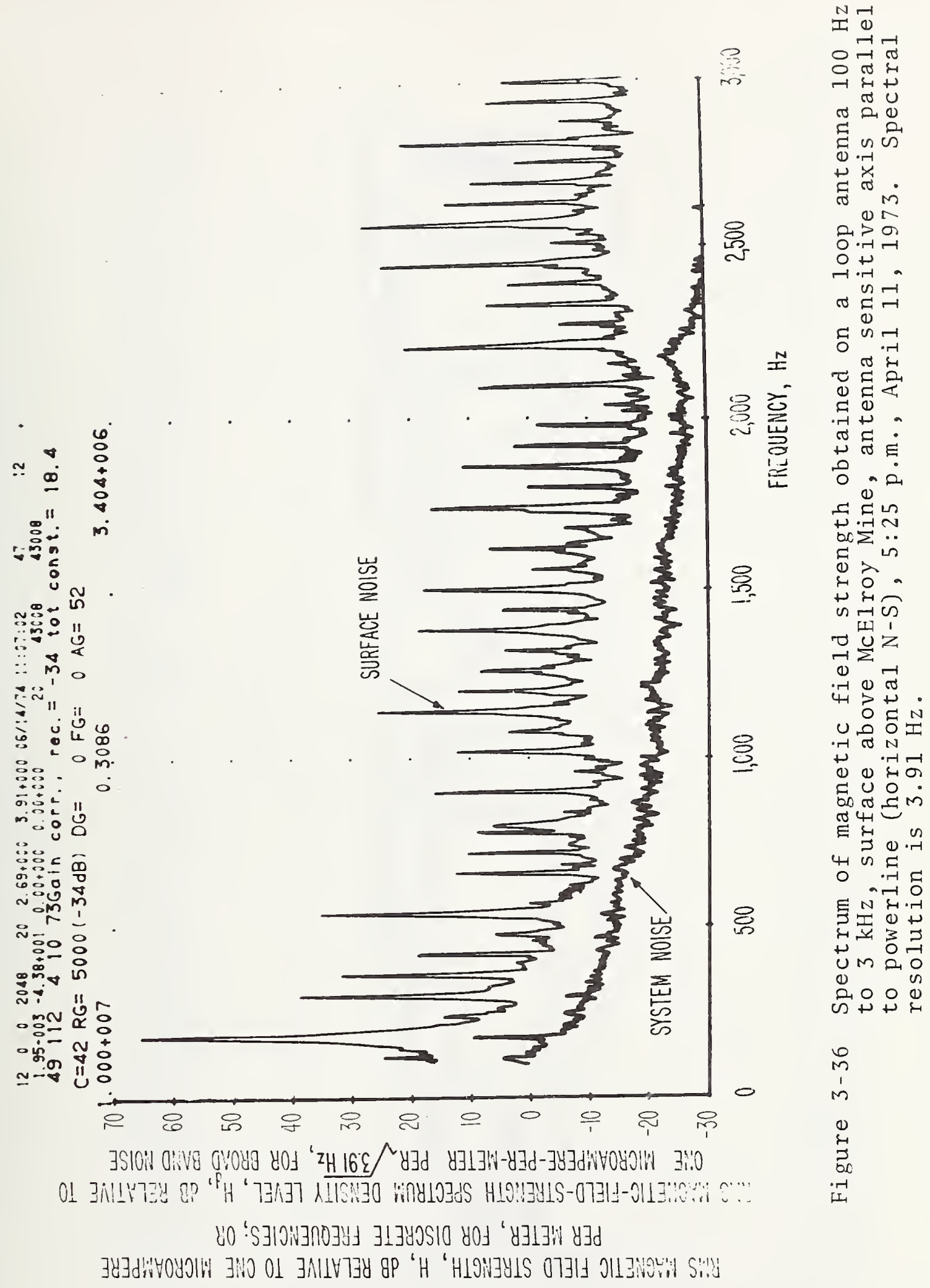




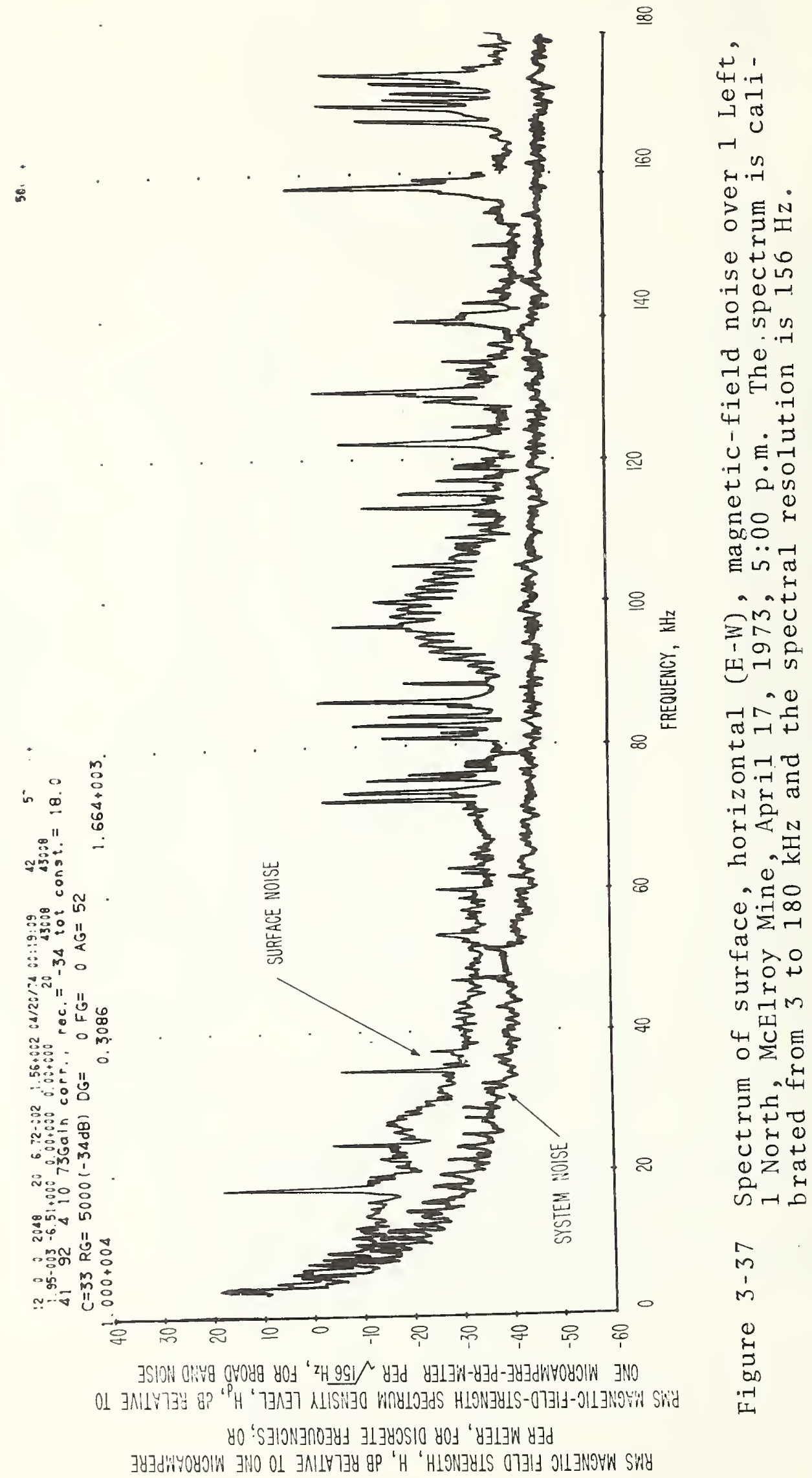




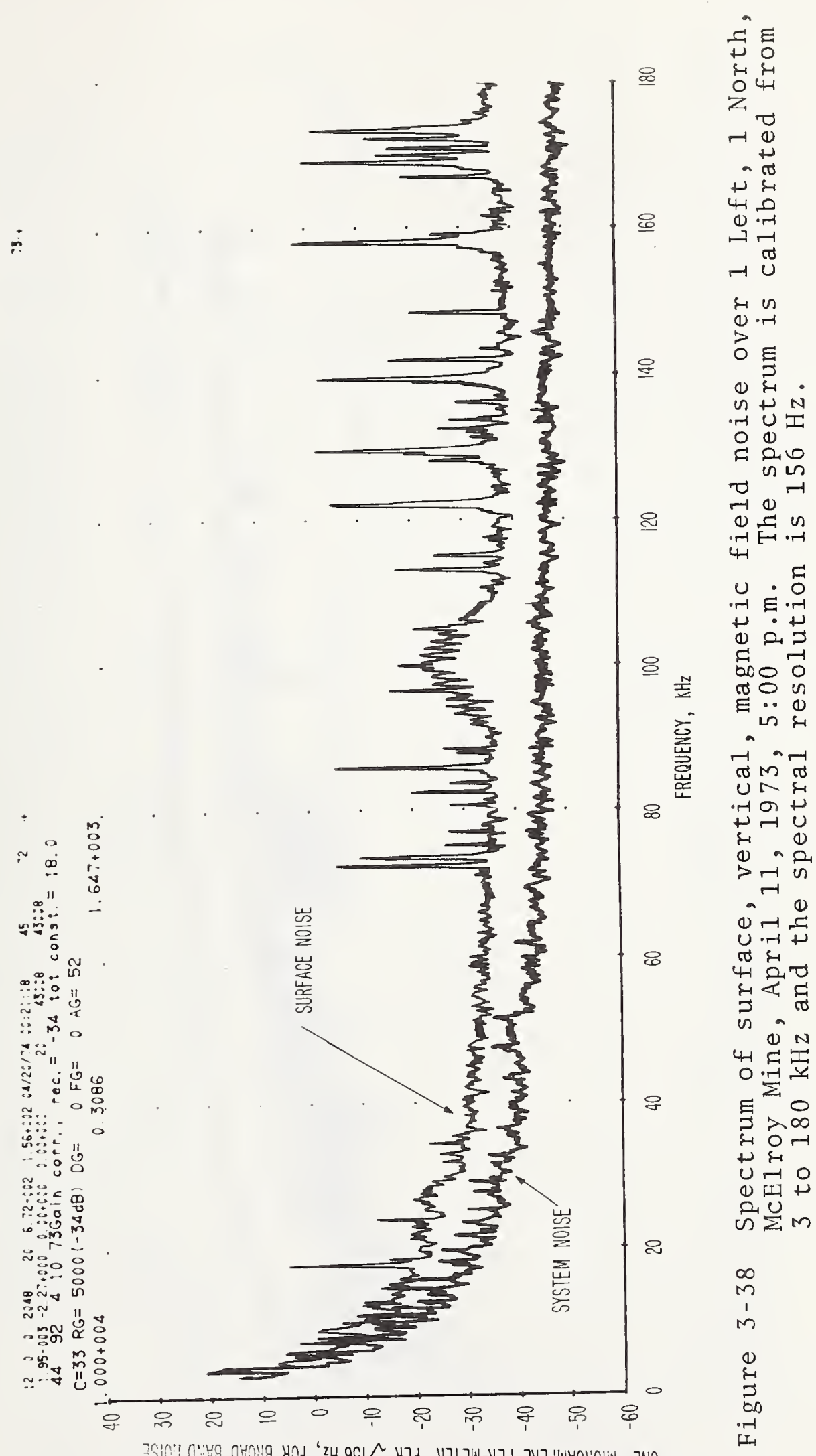

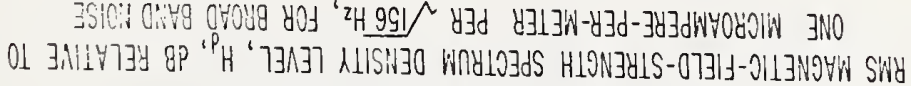

yo 'S

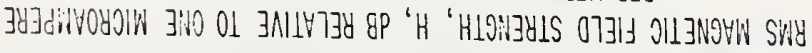




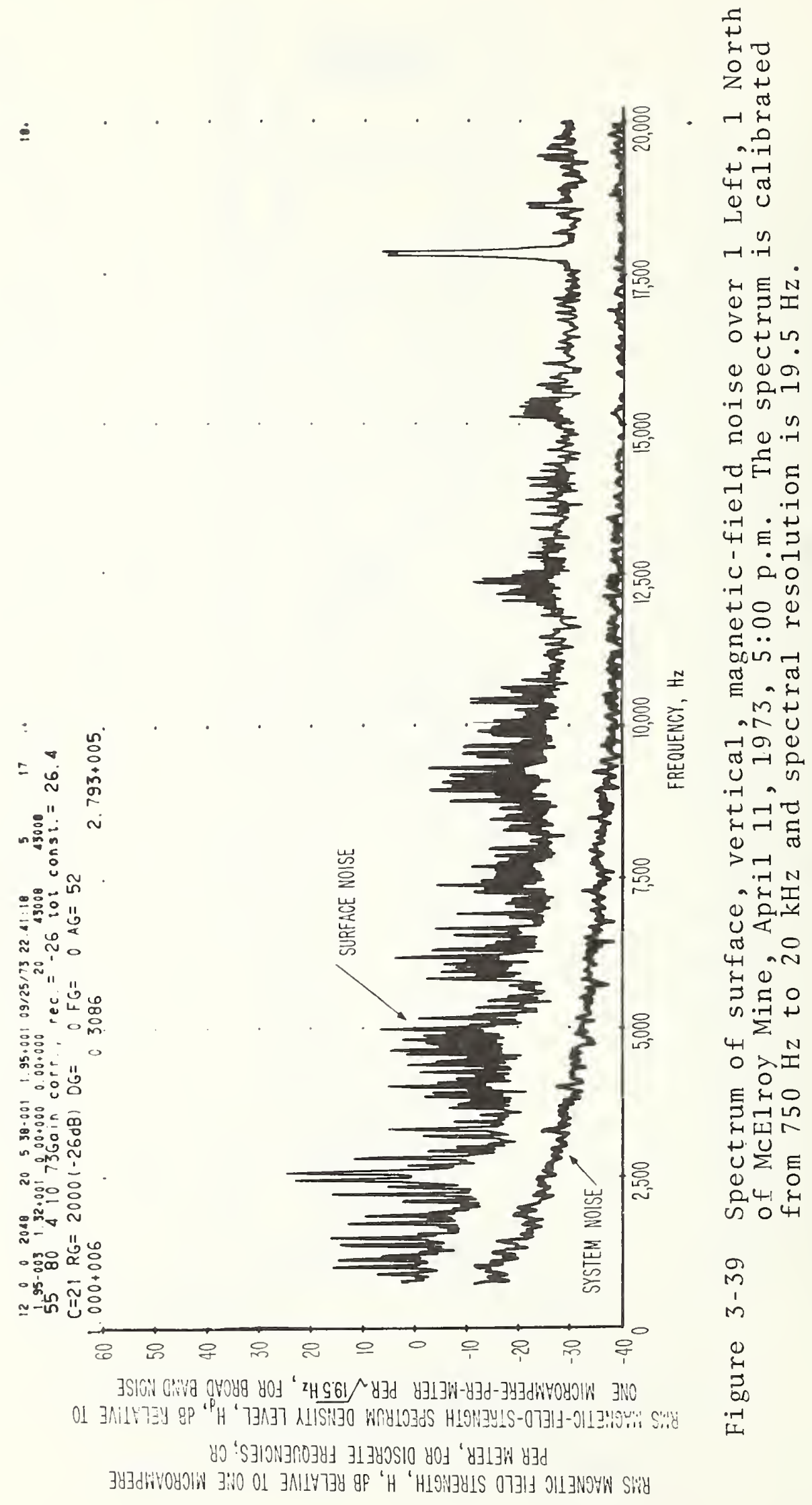




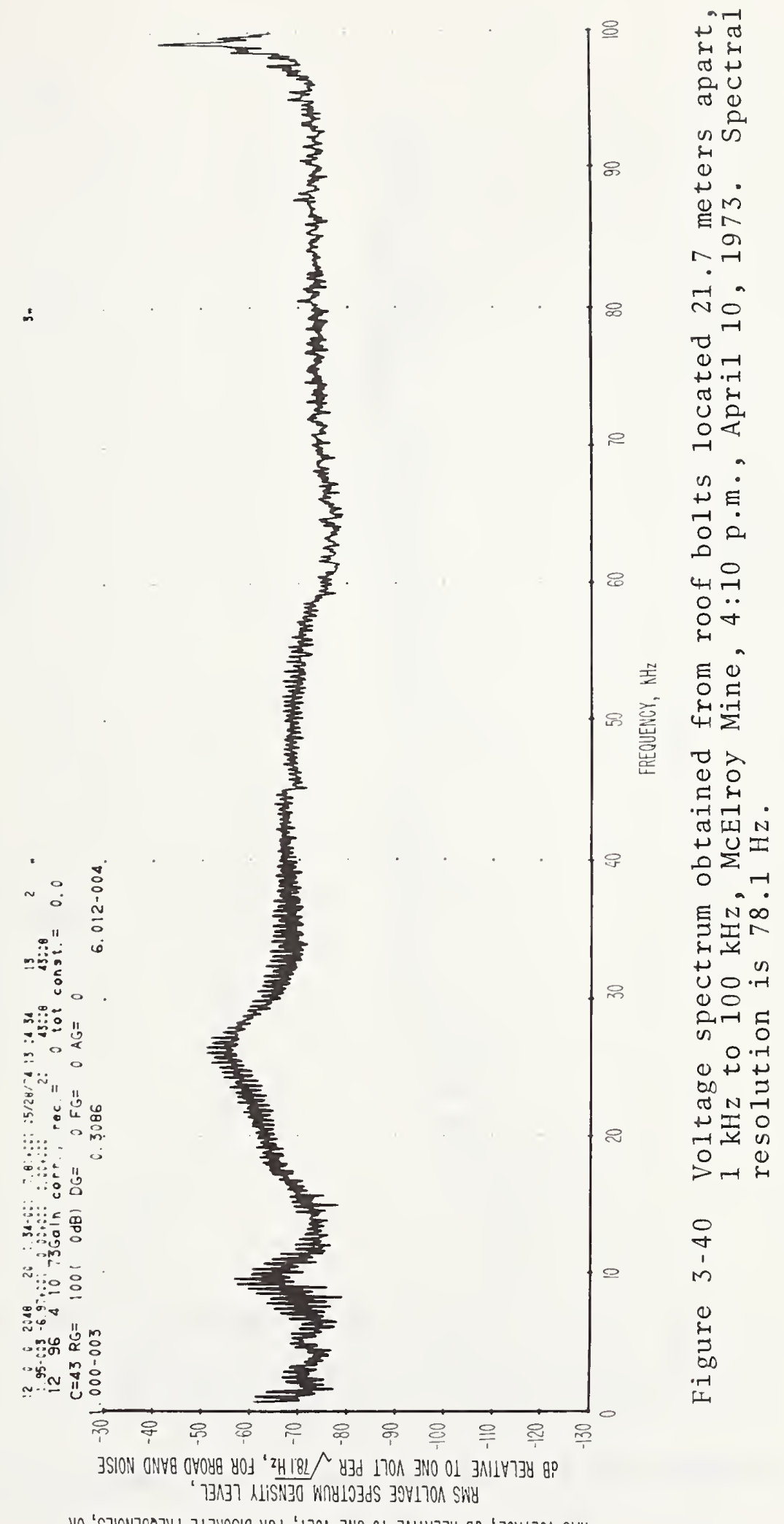

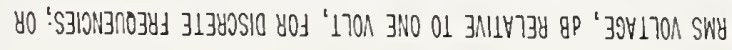




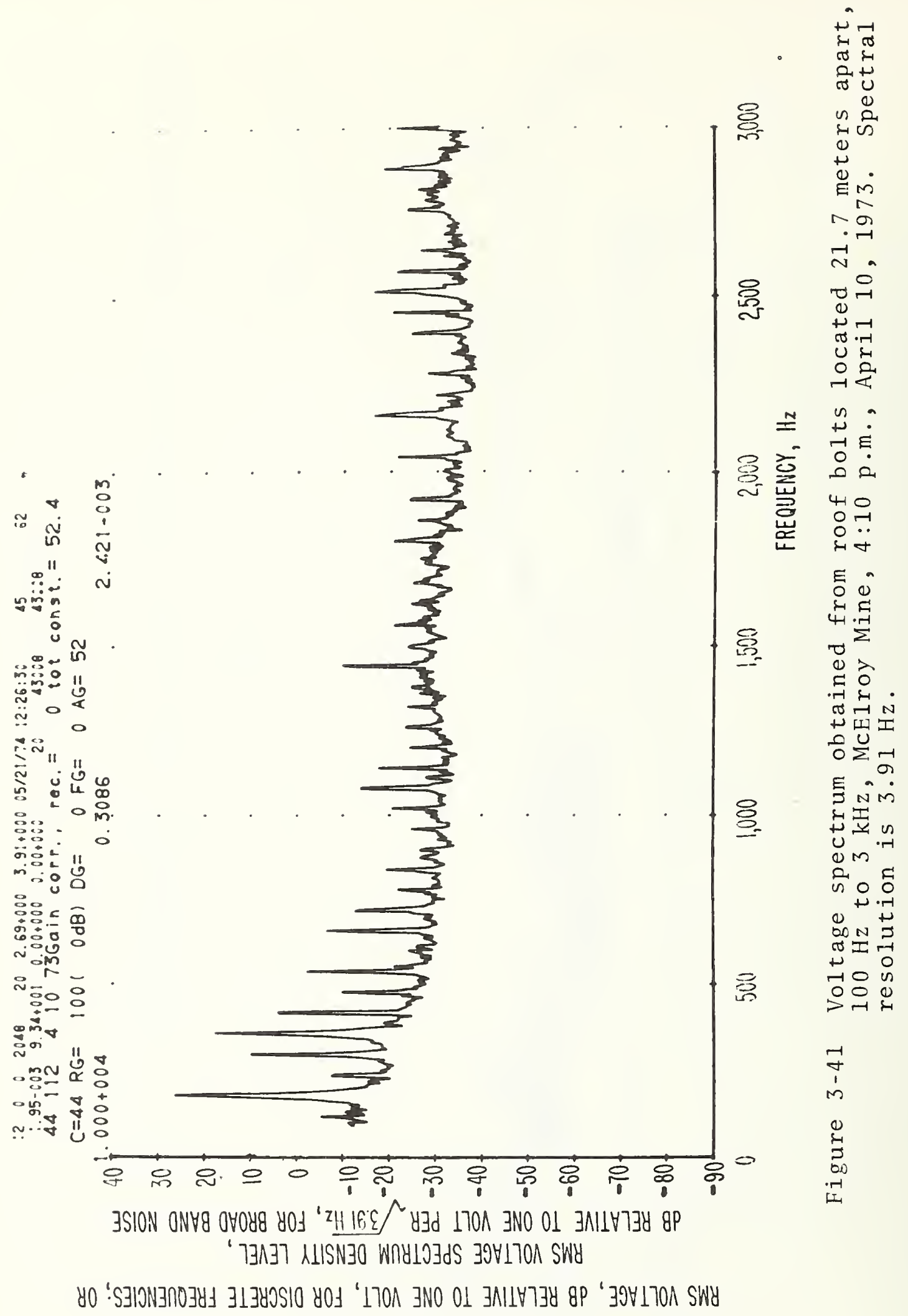




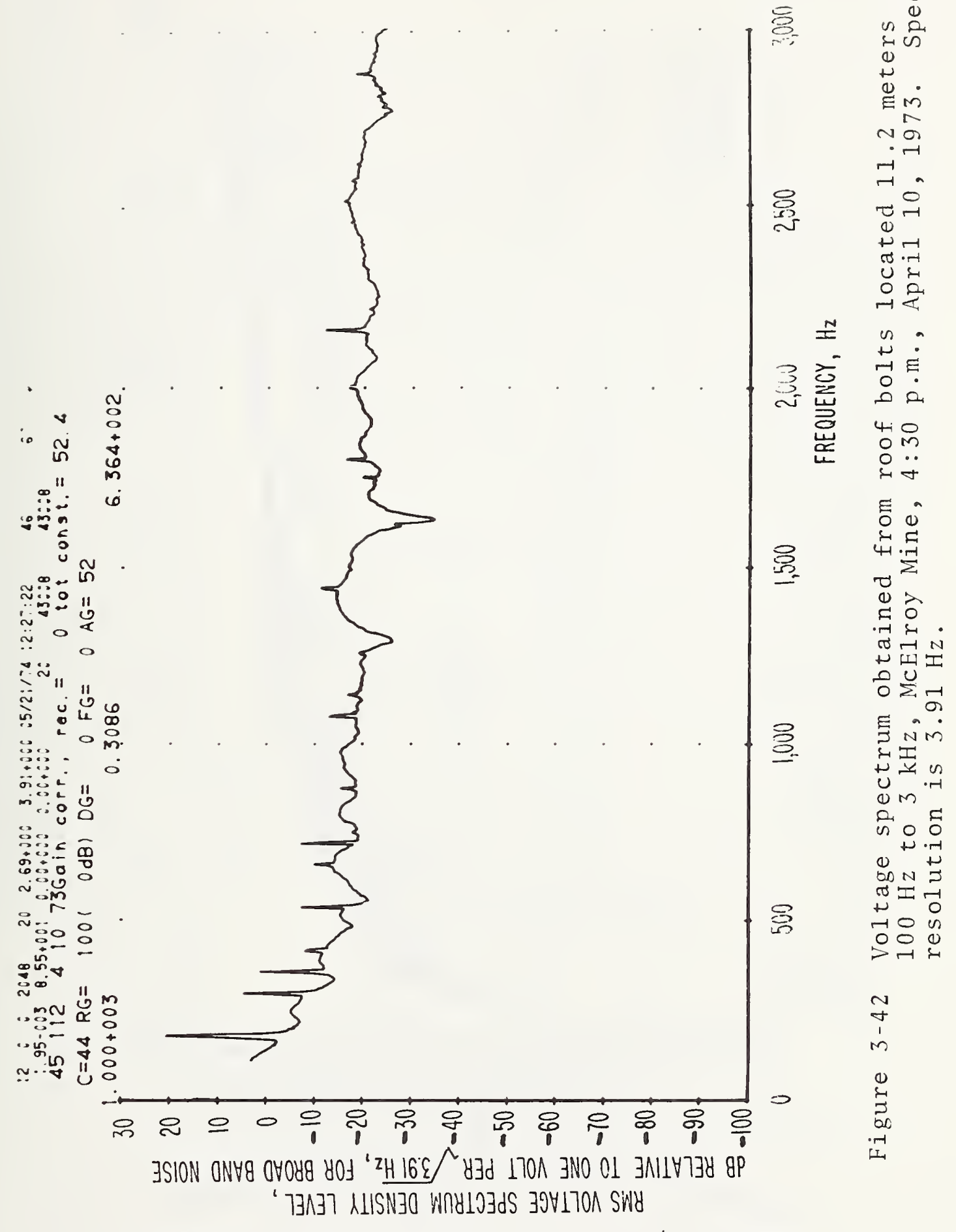

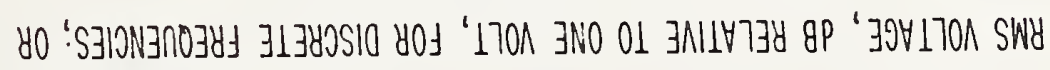




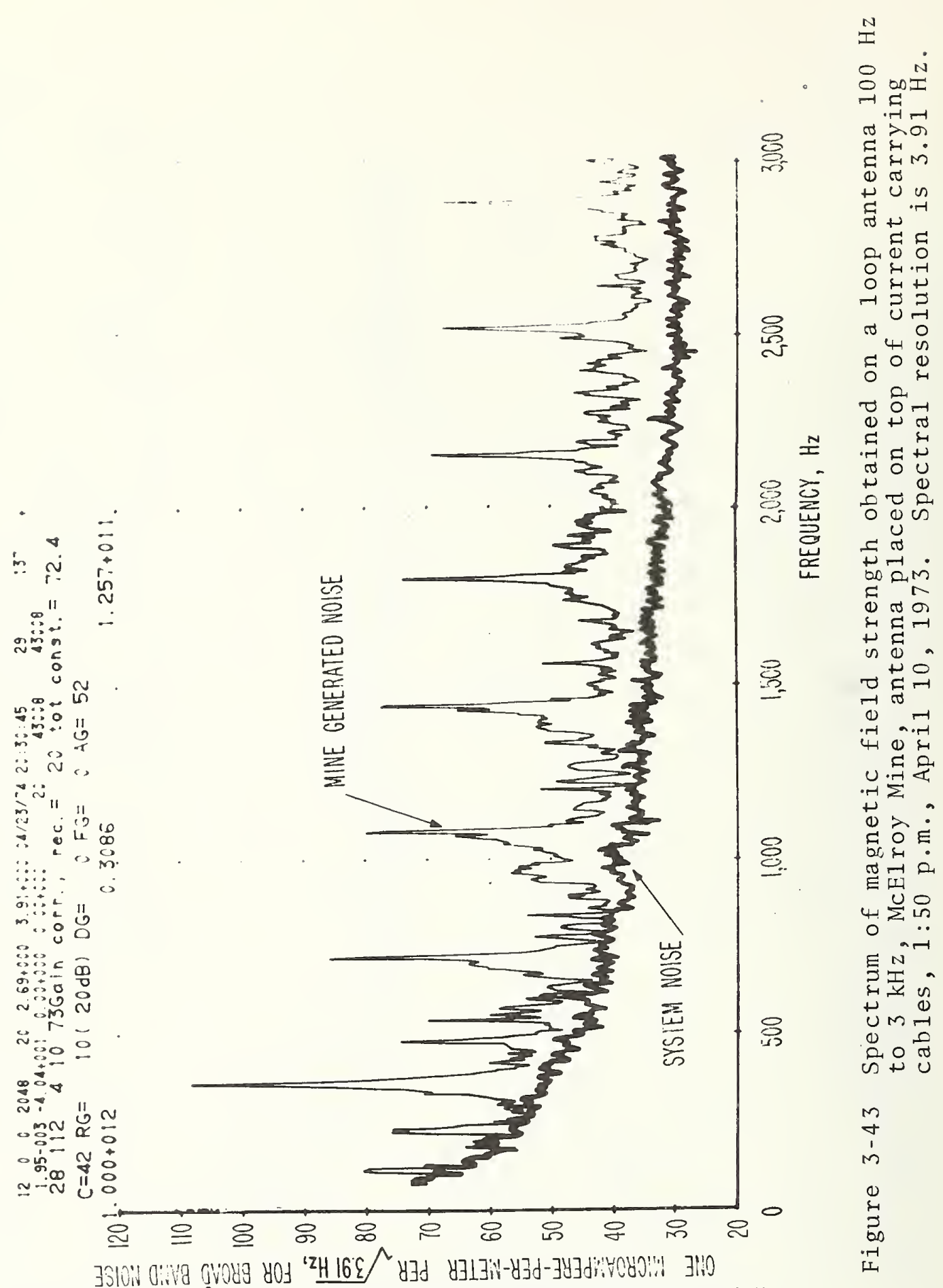

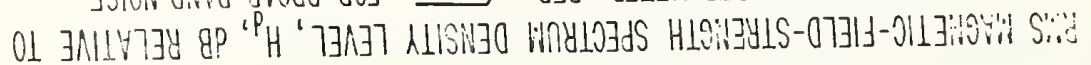

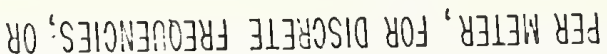

zyadinoyJin zivo 01 Jilly 


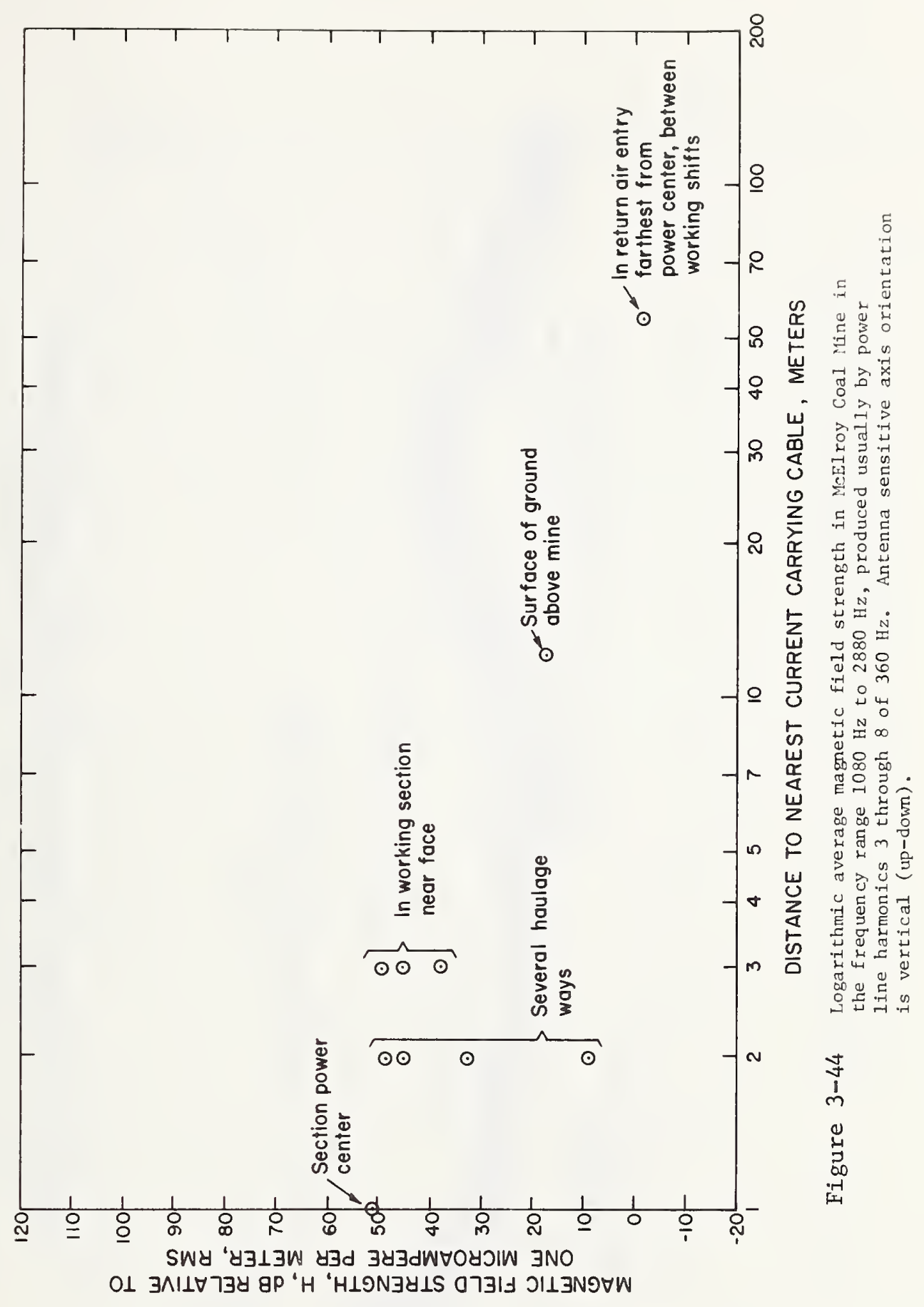




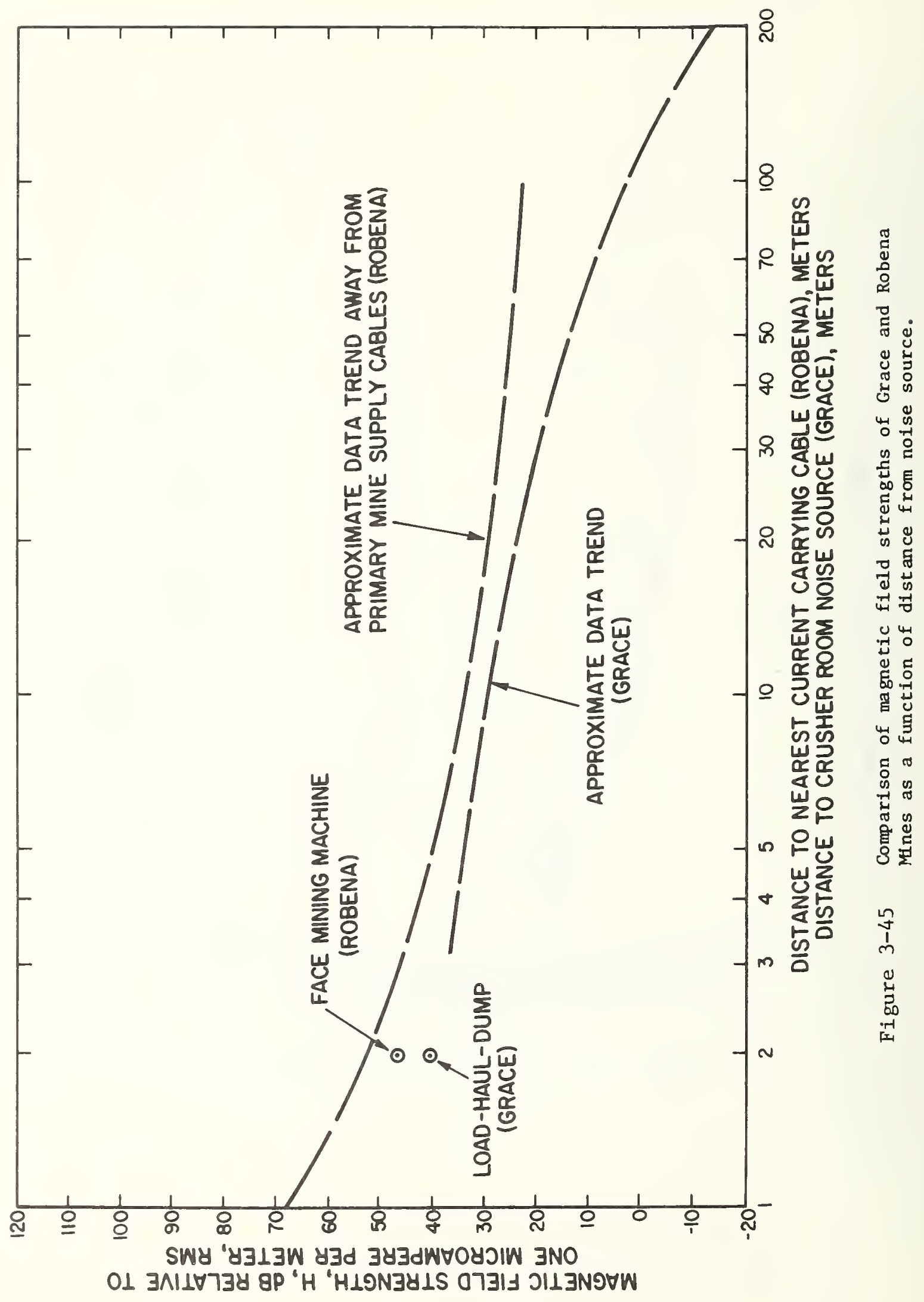




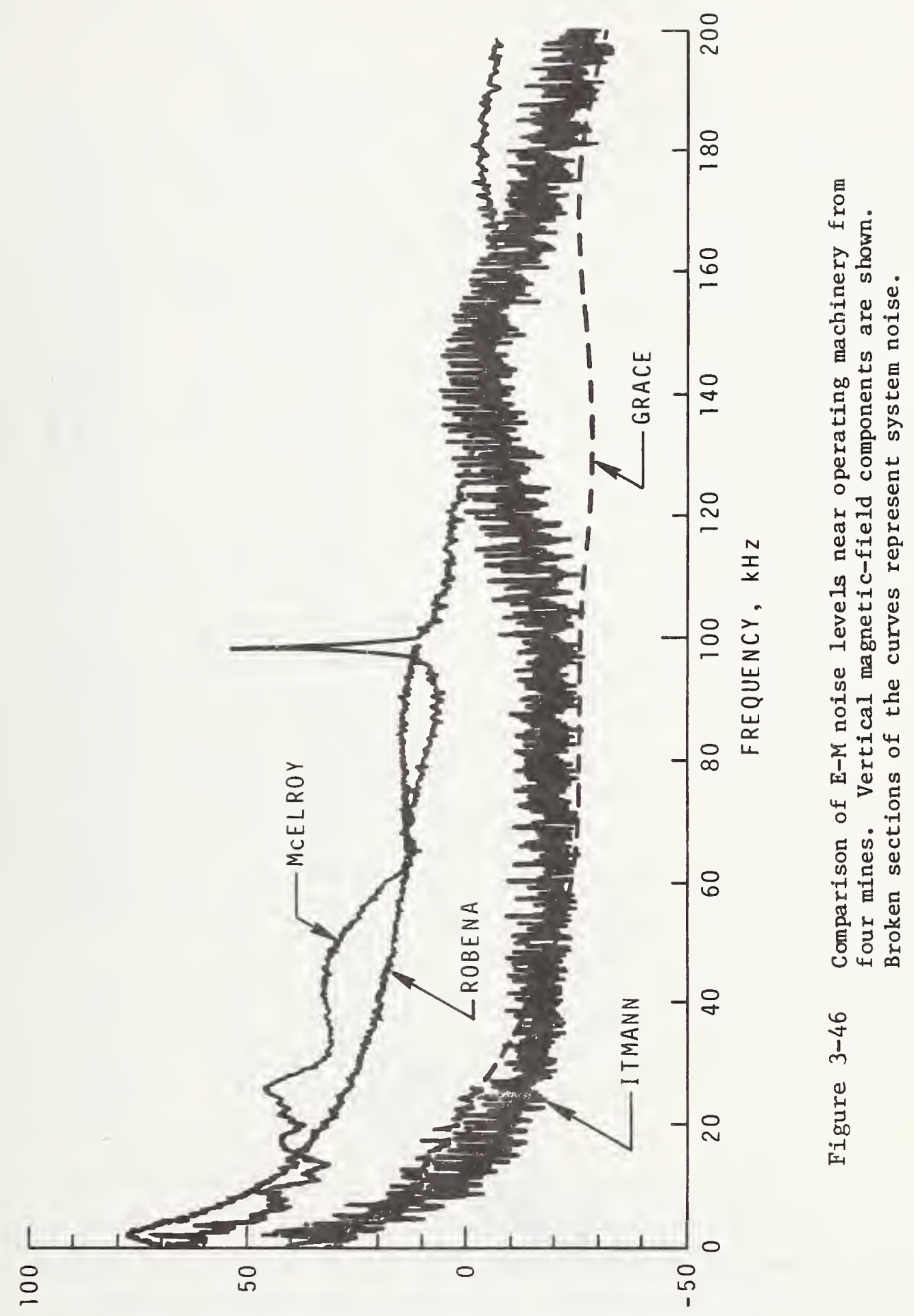

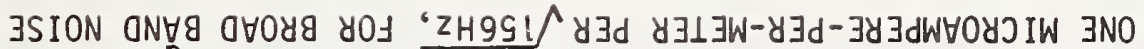

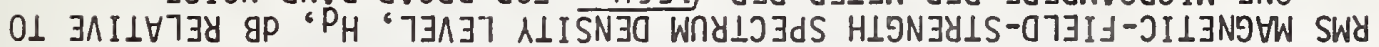

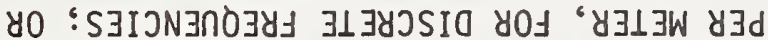

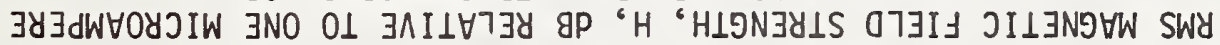




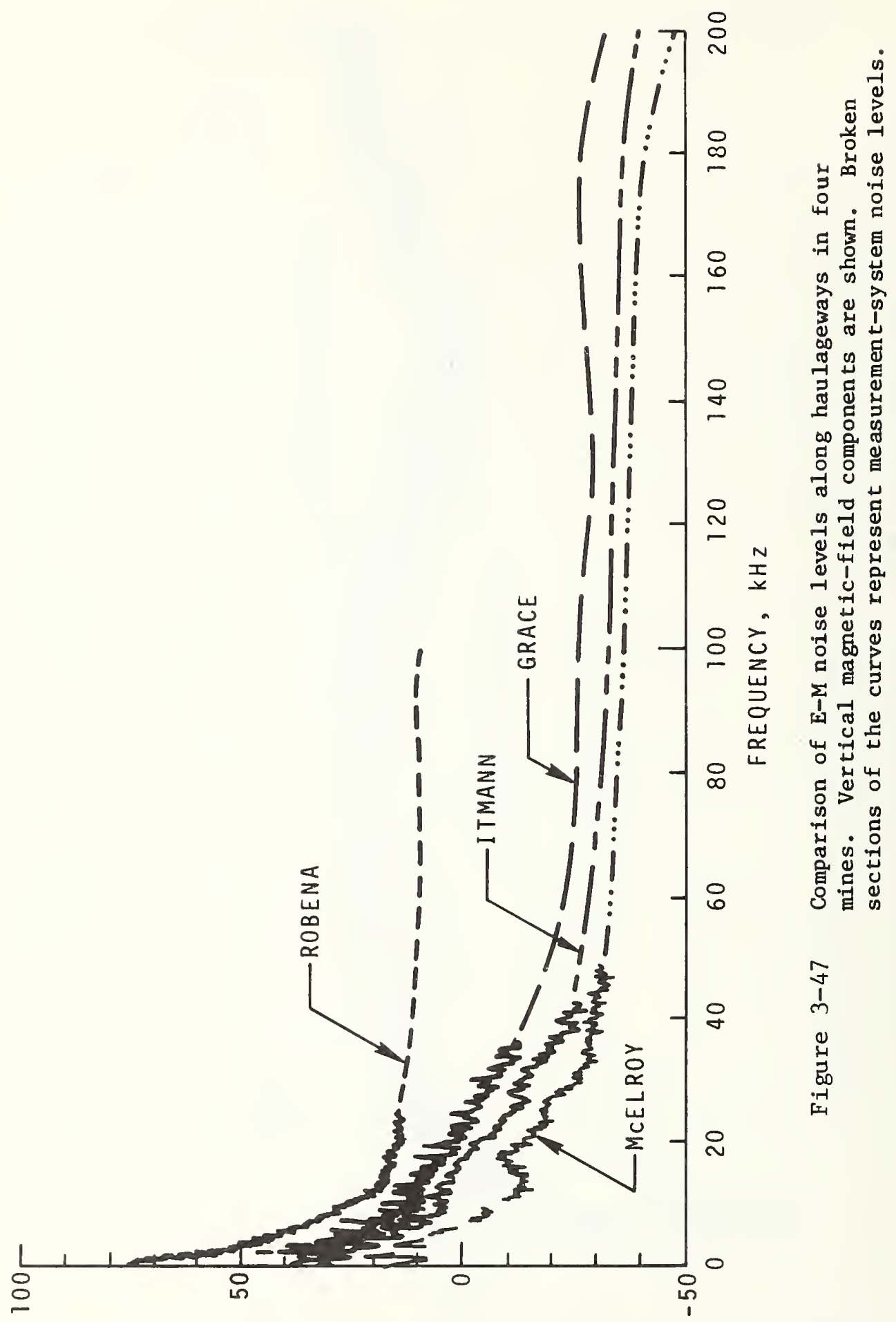

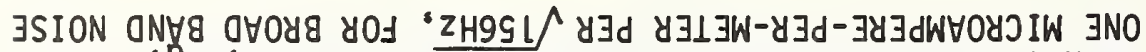

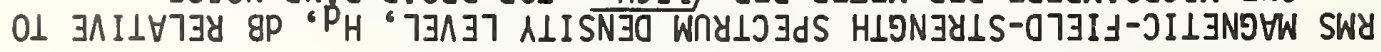
YO

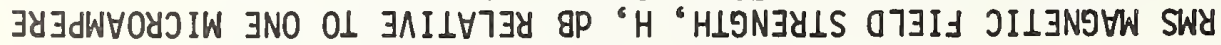


4. AMPLITUDE PROBABILITY DISTRIBUTION MEASUREMENTS

\subsection{Introduction and Uncertainties}

Statistical representations are required since the variations of field strength are, in general, random. The amplitude probability distribution (APD) of the received noise envelope is one of the most useful statistical descriptions of the noise process for the design and evaluation of a telecommunications system operating in a noisy environment $[5,6,7]$.

By plotting the cumulative APD on Rayleigh graph paper, one can show clearly the fraction of time that the noise envelope exceeds various levels. Rayleigh graph paper is chosen with scales such that a Rayleigh distribution (i.e., envelope distribution of Gaussian noise) plots as ${ }^{*}$ a straight line with slope of $-1 / 2$. Noise with rapid large changes in amplitude (e.g., impulsive noise) then has a much steeper slope, typically -4 or -5 , depending on the impulsiveness of the noise and the receiver bandwidth.

With the exception of the roof-support bolt measurements, all APD measurements are reported in absolute quantities.

The estimated limits of error for the APD noise measurements are $\pm 5 \mathrm{~dB}$. Several sources of error that are critical to the overall accuracy of our measurements are listed below: 1. Use of a discrete, digital level counter (levels are $6 \mathrm{~dB}$ apart) contributes $\pm 1-\mathrm{dB}$ quantization error limit. One-decibel step attenuators are used to achieve the \pm one decibel.

2. The system, i.e., recording, data transcribing, and data processing, has a calibration uncertainty of $\pm 0.5 \mathrm{~dB}[3]$.

3. The estimated uncertainty involved in using the portable and the laboratory tape recorders for record and playback is $\pm 0.5 \mathrm{~dB}$ due to harmonic distortion, flutter, dropout, cross-taik, etc. 
4. The gain instability during measurements, gain changes between measurements and calibration, and the non-1inearity of electromagnetic interference and field strength (EIFS) meters and mixers, all combined, contribute $\pm 0.5 \mathrm{~dB}$ uncertainty.

5. The gain instability and non-linearity of the digital level counter, the tuned frequency converter, the amplifier, and attenuators, all combined, contribute $\pm 0.5 \mathrm{~dB}$ uncertainty.

6. Connector losses and BNC cable losses, particularly at higher frequencies above $100 \mathrm{kHz}$, contribute $\pm 2.0 \mathrm{~dB}$ uncertainty.

Some additional uncertainty beyond the stated measurement system uncertainty is caused by the in-mine environment. Care was taken to provide at least one meter separation from metallic objects wherever possible. However, coal, rock, or earth was sometimes immediately adjacent to a loop antenna. In all observed cases, this had no effect at frequencies up to $1 \mathrm{MHz}$. Above $1 \mathrm{MHz}$, earth and other reflections did in some cases cause \pm 1 dB variations, even with a shielded, balanced loop antenna. An estimate is that an additional $\pm 5 \mathrm{~dB}$ uncertainty might be advisable. However, due to the complexity of the shielded loop in the mine environment, this uncertainty cannot be rigorous $1 y$ bounded without substantial additional analysis.

\subsection{Results}

\subsubsection{Introduction}

APD measurements were made on Apri1 10 and 12, 1973, during operation in the McFlroy Coal Mine located near Moundsville, West Virginia. Descriptions of McElroy Mine are given in section 1.2 . APD measurements were made at four locations. The first set of APD measurements of about eleven different frequencies was made on Apri1 10, 1973, at 
location B in figure 3-1. The second set of APD measurement of about eight different frequencies was made on April 10, 1973, at location A in figure 3-1. In these two sets of APD measurements, both the vertical and horizontal components of magnetic field were measured.

The third set of APD measurements of about nine frequencies was made on April 12, 1973, at location B in figure 3-2. The fourth set of APD measurements of about nine frequencies was made on April 12, 1973, at location A in figure 3-2. In these two sets of APD measurements, only the vertical components of magnetic field were measured.

In addition to these four sets of measurements, APD measurements were made during a quiet time at locations $A$ and $B$ in figure 3-1. APD measurements between roof-support bolts were performed on April 10, 1973, at location B in figure $3-1$.

\subsubsection{Measurement Results}

Figures 4-1 through 4-11 show the APD's of vertical components of magnetic field noise and figures 4-12 through 4-23 show the APD's of horizontal components (NE-SW) of magnetic field noise measured at location $B$ of figure 3-1 on April 10, 1973. APD's measured at quiet time at location B of figure 3-1 are shown in figures 4-24 through 4-27. Here only the vertical component of magnetic noise was measured at four frequencies ranging from $10 \mathrm{kHz}$ to $150 \mathrm{kHz}$. Above $250 \mathrm{kHz}$, the magnetic noise measured in the mine was below the system noise (i.e., $60 \mathrm{~dB}$ or more below one microampere per meter) since EIFS meter readings with and without an antenna were the same.

Figures 4-28 through 4-36 show APD's of the vertical component of magnetic field noise and figures 4-37 through 4-43 show APD's of the horizontal component of magnetic field noise measured at location A in figure 3-1 on April 10, 
1973. APD measurements made at a quiet time at location $A$ in figure 3-1 are also shown in figures 4-44 through 4-48. Again, only the vertical component of magnetic noise was measured at five frequencies ranging from $10 \mathrm{kHz}$ to $160 \mathrm{kHz}$. Above $250 \mathrm{kHz}$, the magnetic noise measured in the mine was below the system noise (i.e.,60 dB or more below one microampere per meter) since EIFS meter readings with and without an antenna were the same.

Figures 4-49 through 4-58 show the APD's of magnetic field noise measured at location $B$ in figure 3-2. Figures 4-59 through 4-68 show the APD's of magnetic field noise measured at location A in figure 3-2 on April 12, 1973. Only the vertical component of the magnetic field was measured at ten frequencies ranging from $10 \mathrm{kHz}$ to $32 \mathrm{kHz}$.

Figures 4-69 through 4-70 show results of the roofsupport bolt measurements made at location $B$ in figure 3-1 on April 10, 1973. The separation between the two roofsupport bolts was 3 meters. The APD's were measured using non-shielded copper wire clipped to the roof-support bolts. It is not easy to analyze what was measured using non-shielded copper wire. It was a combination of electric field through a dipole with a lossy surrounding medium (i.e., coal), of magnetic field through a lossy loop antenna, and of voltage induced by current flowing through the medium between the roof bolts. Therefore, relative voltage is the parameter given. The rms value is arbitrarily assigned the value $0 \mathrm{~dB}$.

\subsubsection{RMS and Average Values}

The APD's are integrated to give rms and average values of the field strength, according to the equations

$$
\mathrm{H}_{\text {avg }}=-\int_{0}^{\infty} \mathrm{H} \mathrm{dp}(\mathrm{H})
$$


and

$$
\mathrm{H}_{\mathrm{rms}}=\left(-\int_{0}^{\infty} \mathrm{H}^{2} \mathrm{dp}(\mathrm{H})\right)^{\frac{1}{2}},
$$

where $H$ represents the magnetic field strength of the noise, and $\mathrm{p}$ is the probability that the measured field strength exceeds the value $H$. These quantities are also dependent upon the measurement bandwidth, the length of the data run, and possibly other parameters. Finite series are actually used for the numerical integration. The rms and average values so arrived at are identified on each graph and are time averages (23 minutes) of these time-dependent parameters. If the tapes are played into ordinary rms-reading meters, the meter readings will vary 10 to $20 \mathrm{~dB}$ over fractions of a second depending on the averaging time constants of the meter. The rms value is directly relatable to noise power.

\subsubsection{Summary Curves}

Excursions of field strength between 0.001 and 99 percent, as well as rms and average values, are shown in figures 4-71 through 4-78. The predetection bandwidth for these APD measurements either is $1 \mathrm{kHz}$ or is normalized to $1 \mathrm{kHz}$. Figures 4-1 through 4-11 (vertical, near the power distribution center) are summarized on figure 4-71; figures 4-12 through 4-23 horizontal, near the power distribution center) are summarized on figure 4-72; figures 4-24 through 4-27 (vertical, quiet time, near the power distribution center) are summarized on figure 4-73. Figures 4-28 through 4-36 (vertical, near end of rail haulage) are summarized on figure 4-74; figures 4-37 through 4-43 (horizontal, near end of rail haulage) are summarized on figure 4-75; figures 4-44 through 4-48 (vertical, quiet time near end of rail haulage) are summarized on figure 4-76. Figures 4-49 through 4-58 (near intersection of main haulage and conveyor belt) are summarized in figure 4-77. 
Figures 4-59 through 4-68 (near operating continuous miner) are summarized on figure 4-78. Magnetic field strength generally decreases monotonically with increasing frequency at $20 \mathrm{~dB}$ per decade. Some long-term fluctuations in values occur because of different operating conditions during different times of the day. Although 20 minutes was determined to be a sufficient time to give validity to the statistics in a mine-section environment where the work cycle is two to four minutes, 20 minutes may not be sufficient in other locations where longer cycles may exist. Perhaps this should be considered further. 


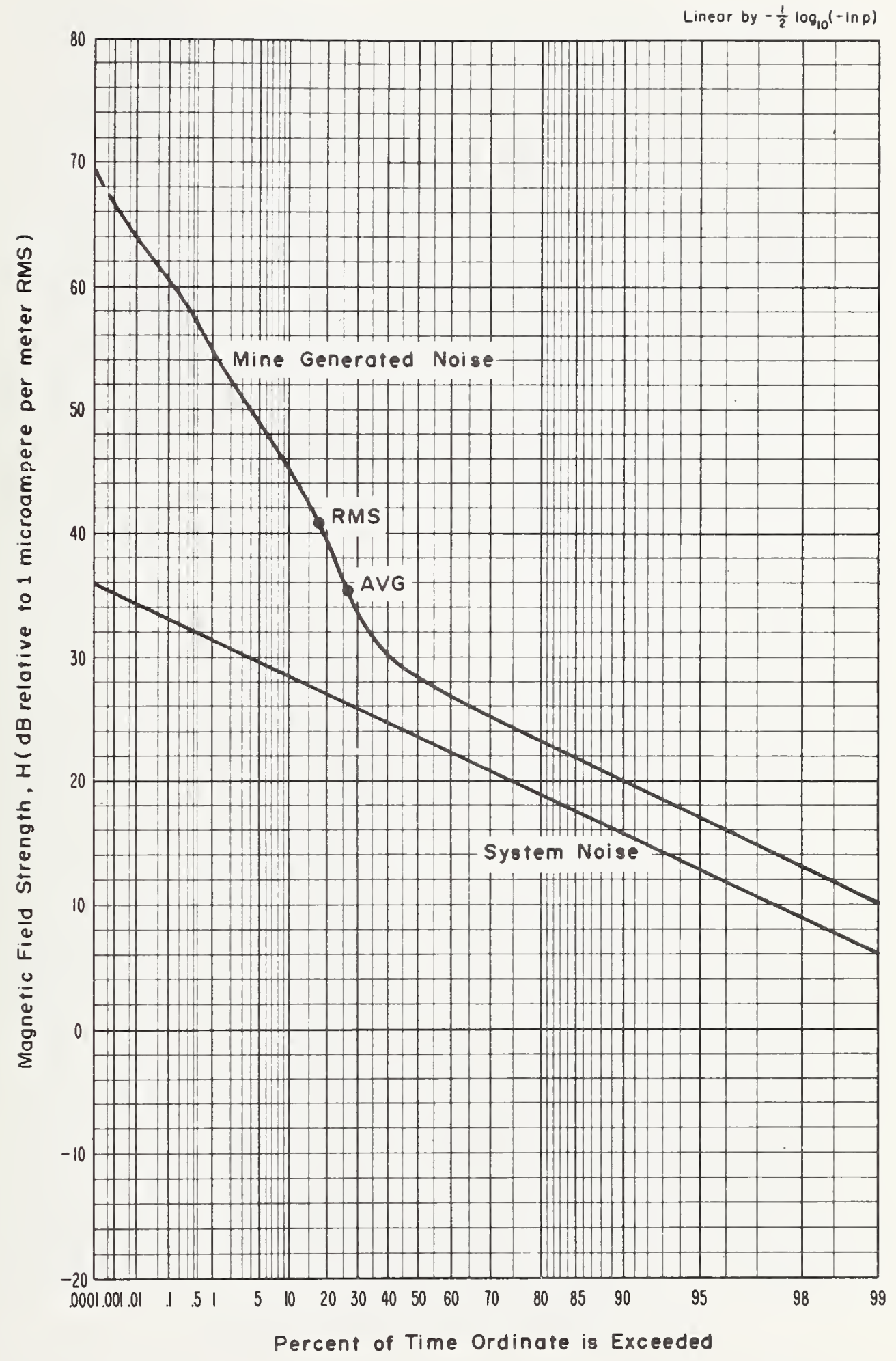

Figure 4-I APD, $10 \mathrm{kHz}$, vertical component, $1.0 \mathrm{kHz}$ predetection bandwidth, April 10,1973, 11:40 a.m., McElroy Mine. 


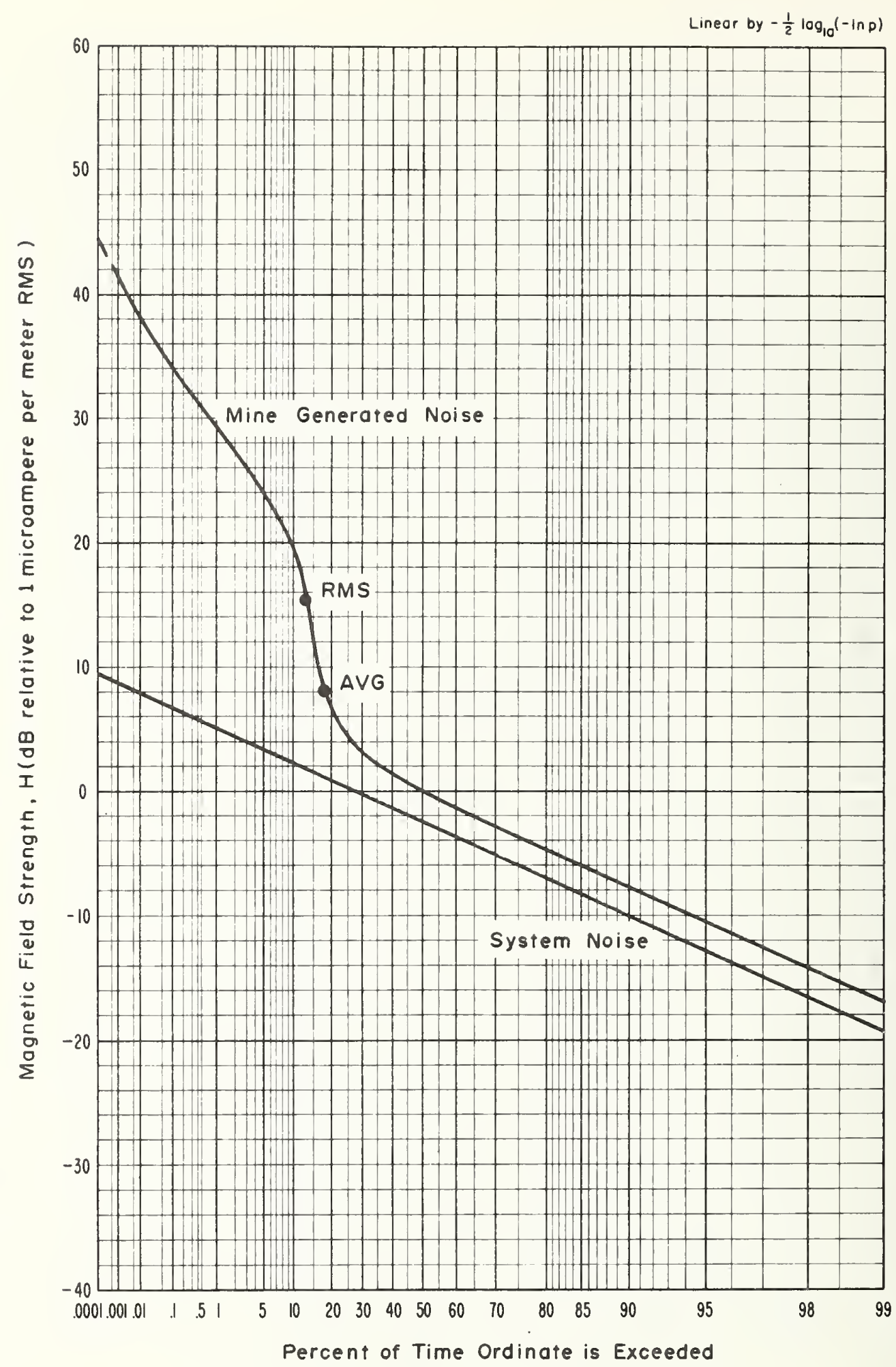

Figure 4-2 APD, $30 \mathrm{kHz}$, vertical component, $1.0 \mathrm{kHz}$ predetection bandwidth, April 10, 1973, 1:10 p.m., McElroy Mine. 


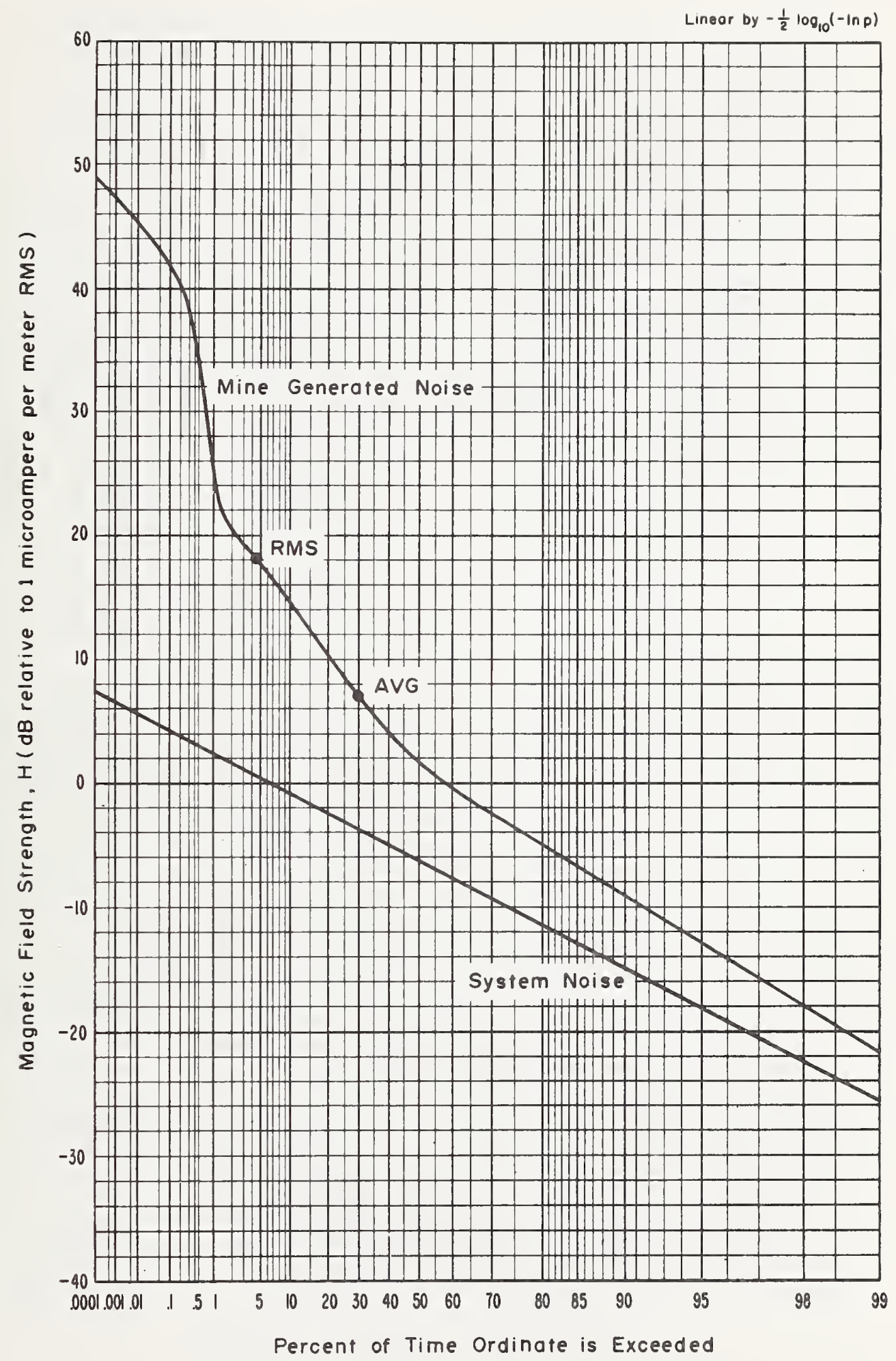

Figure 4-3 APD, $70 \mathrm{kHz}$, vertical component, $1.0 \mathrm{kHz}$ predetection bandwidth, April 10, 1973, 2:20 p.m., McElroy Mine. 


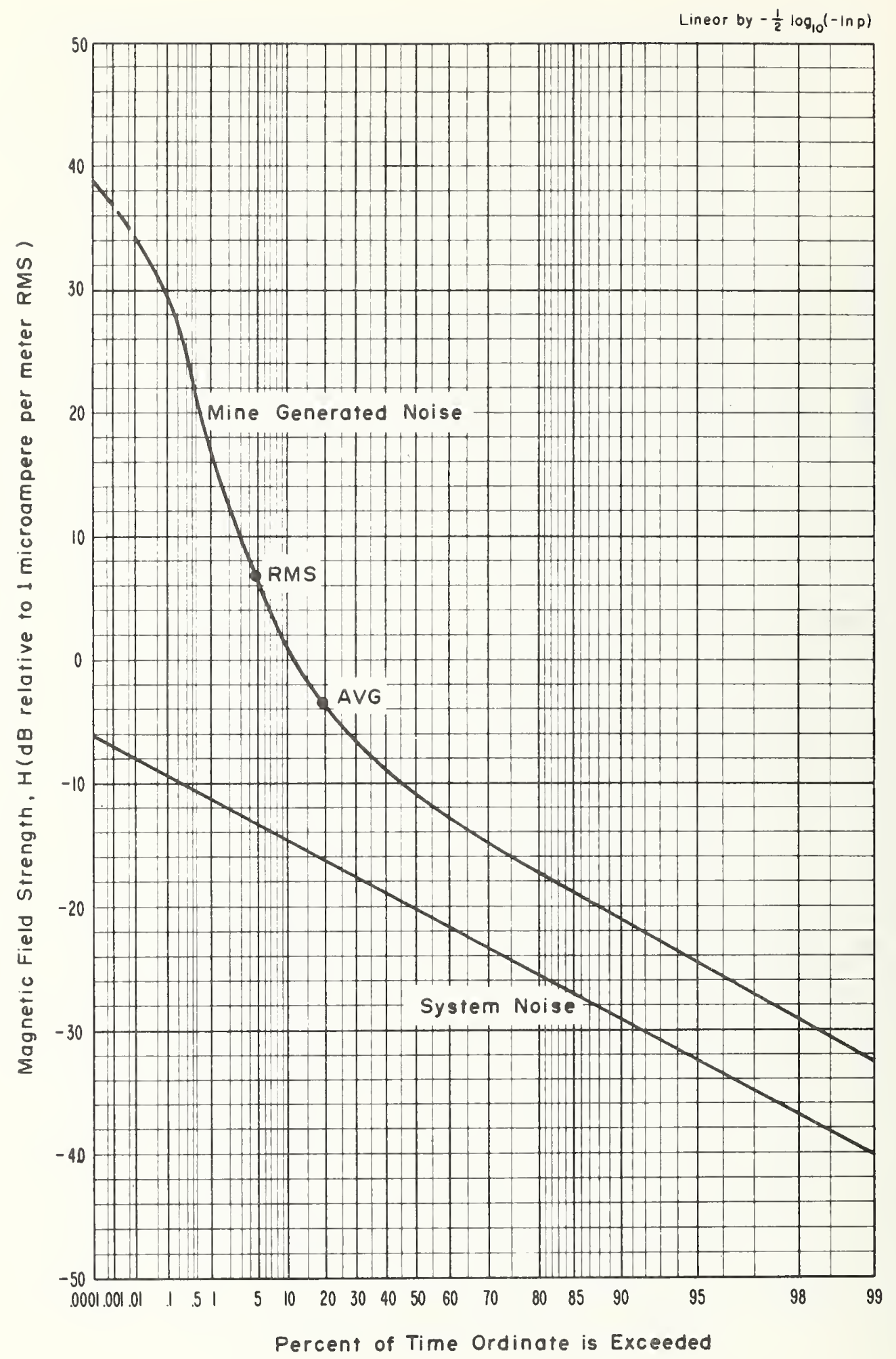

Figure 4-4 APn, $130 \mathrm{kHz}$, vertical component, $1.0 \mathrm{kHz}$ predetection bandwidth, April 10, 1973, 3:25 p.m., McElroy Mine. 


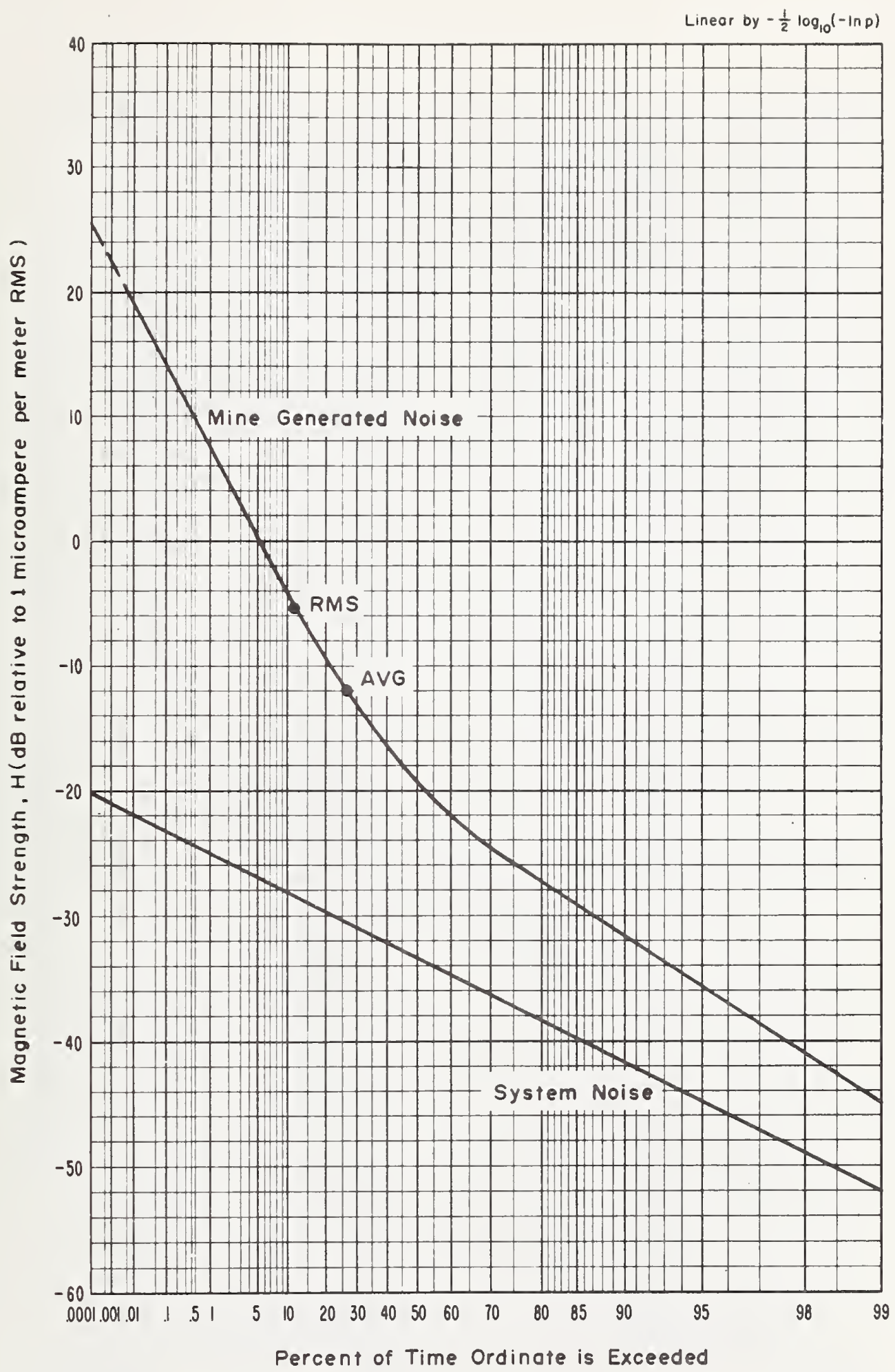

Figure 4-5 APD, $160 \mathrm{kHz}$, vertical component, $1.0 \mathrm{kHz}$ predetection bandw1dth, April 10, 1973, 5:30 p.m., McElroy Mine. 


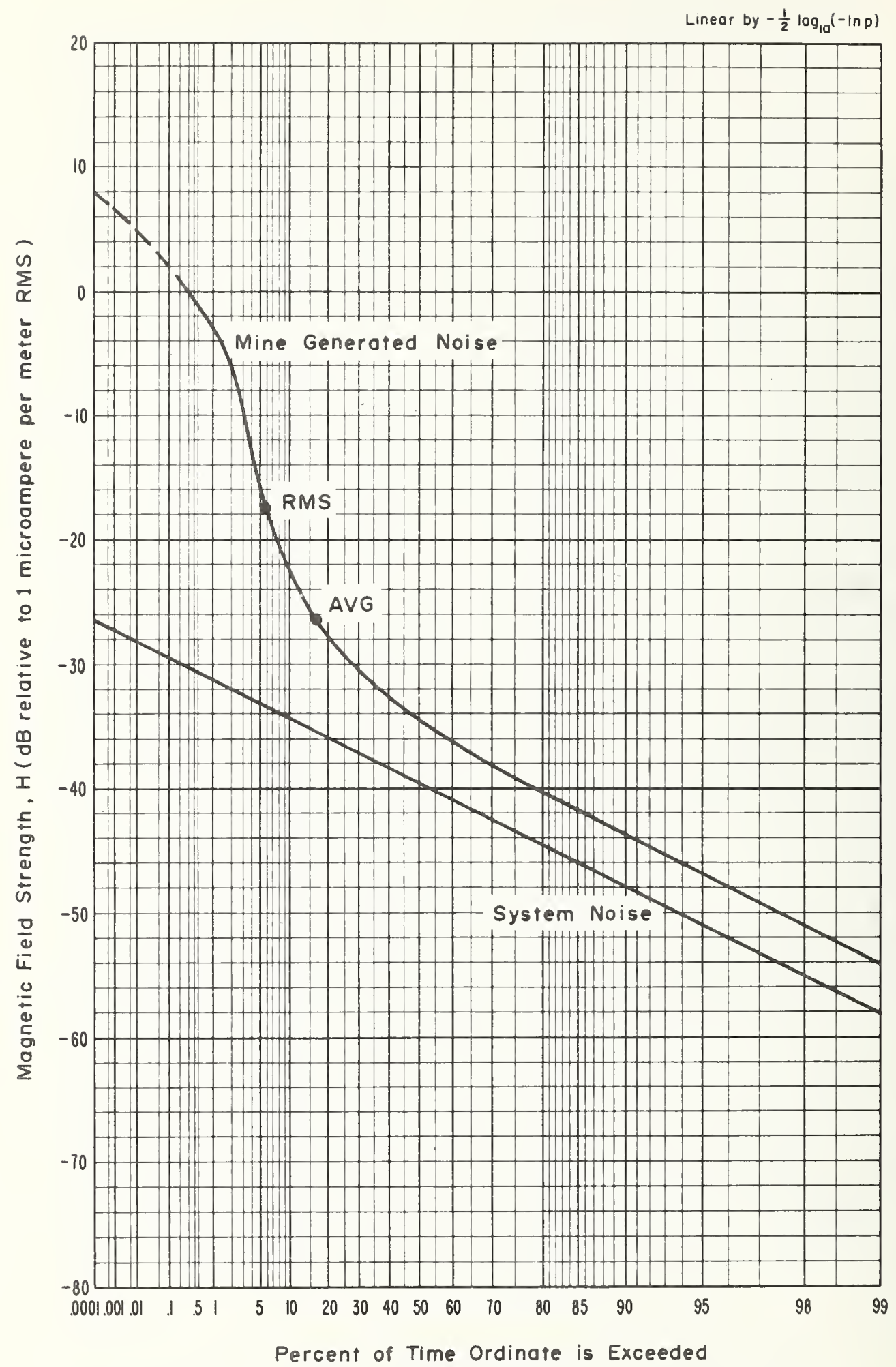

Figure 4-6 APD $250 \mathrm{kHz}$, vertical component, $1.0 \mathrm{kHz}$ predetection bandwidth, Apr 11 10, 1973, 6:35 p.m., McElroy Mine. 


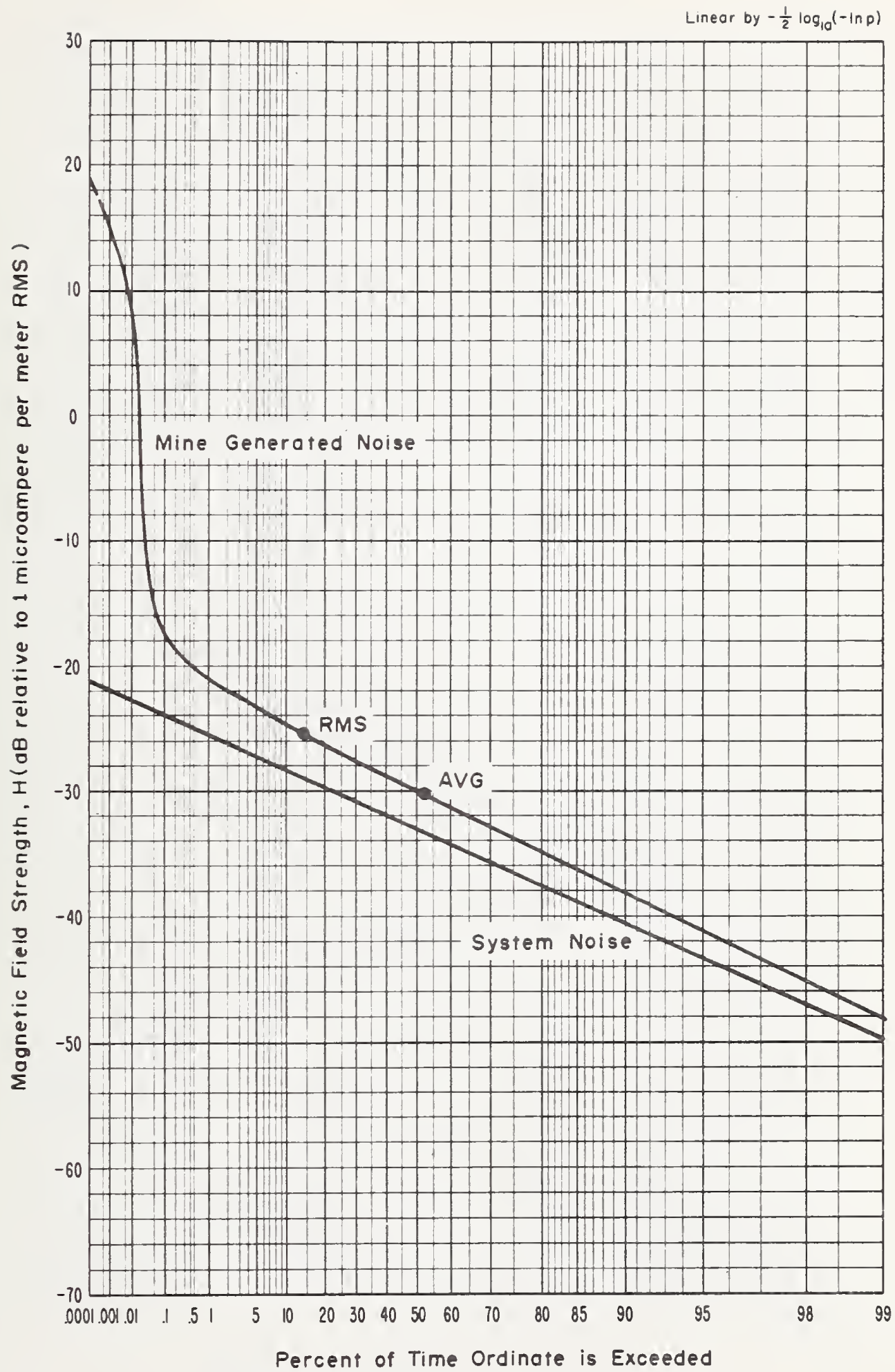

Figure 4-7 APD, $500 \mathrm{kHz}$, vertical component, $1.2 \mathrm{kHz}$ predetection bandwidth, April 10,1973, 11:40 a.m., McElroy Mine. 


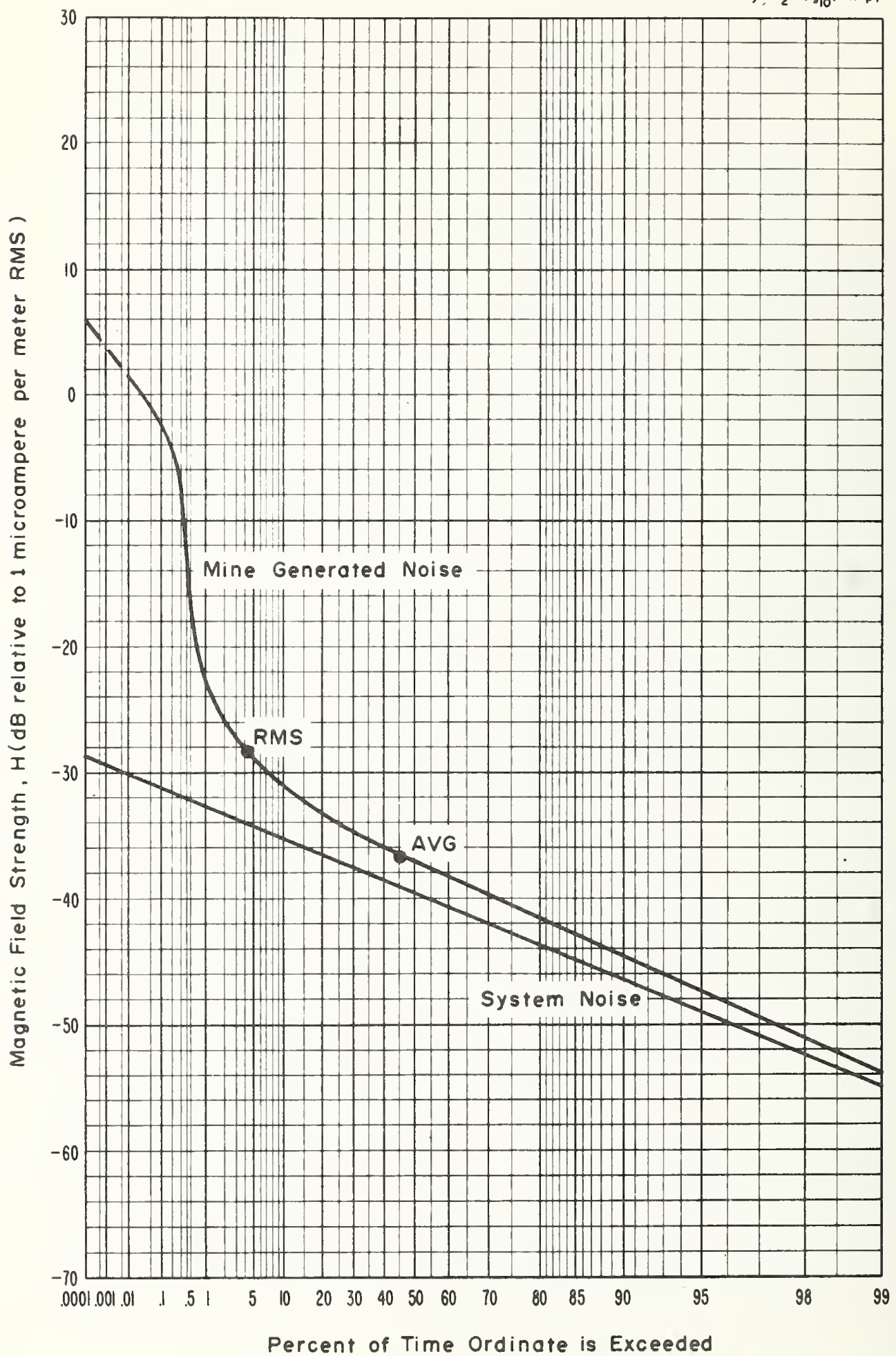

Figure 4-8 APD, $1 \mathrm{MHz}$, vertical component, $1.2 \mathrm{kHz}$ predetection bandwidth, April 10, 1973, 1:10 p.m., McElroy Mine. 


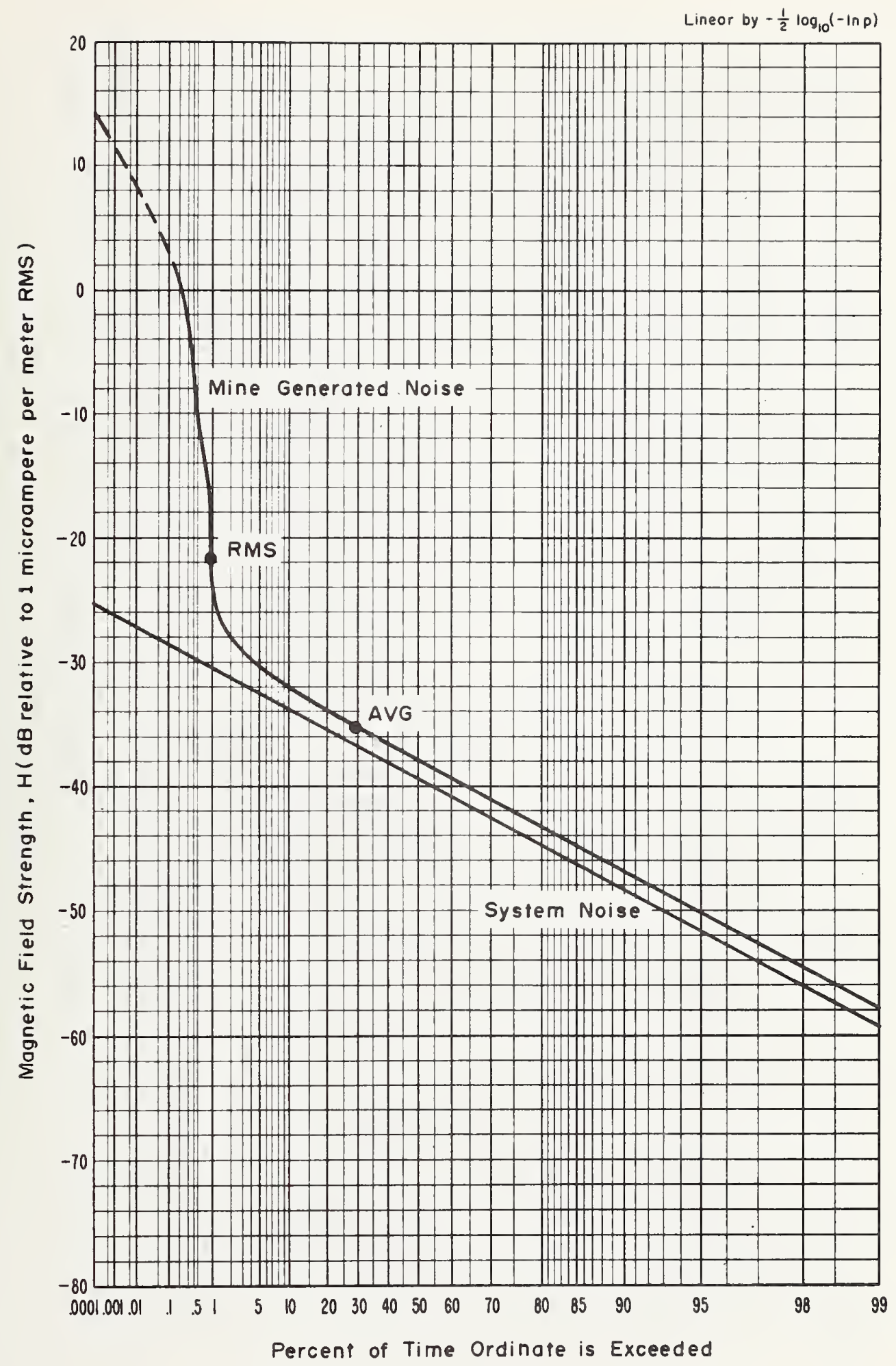

Figure 4-9 APD, $2 \mathrm{MHz}$, vertical component, $1.2 \mathrm{kHz}$ predetection bandwidth, April 10, 1973, 2:20 p.m., McElroy Mine. 


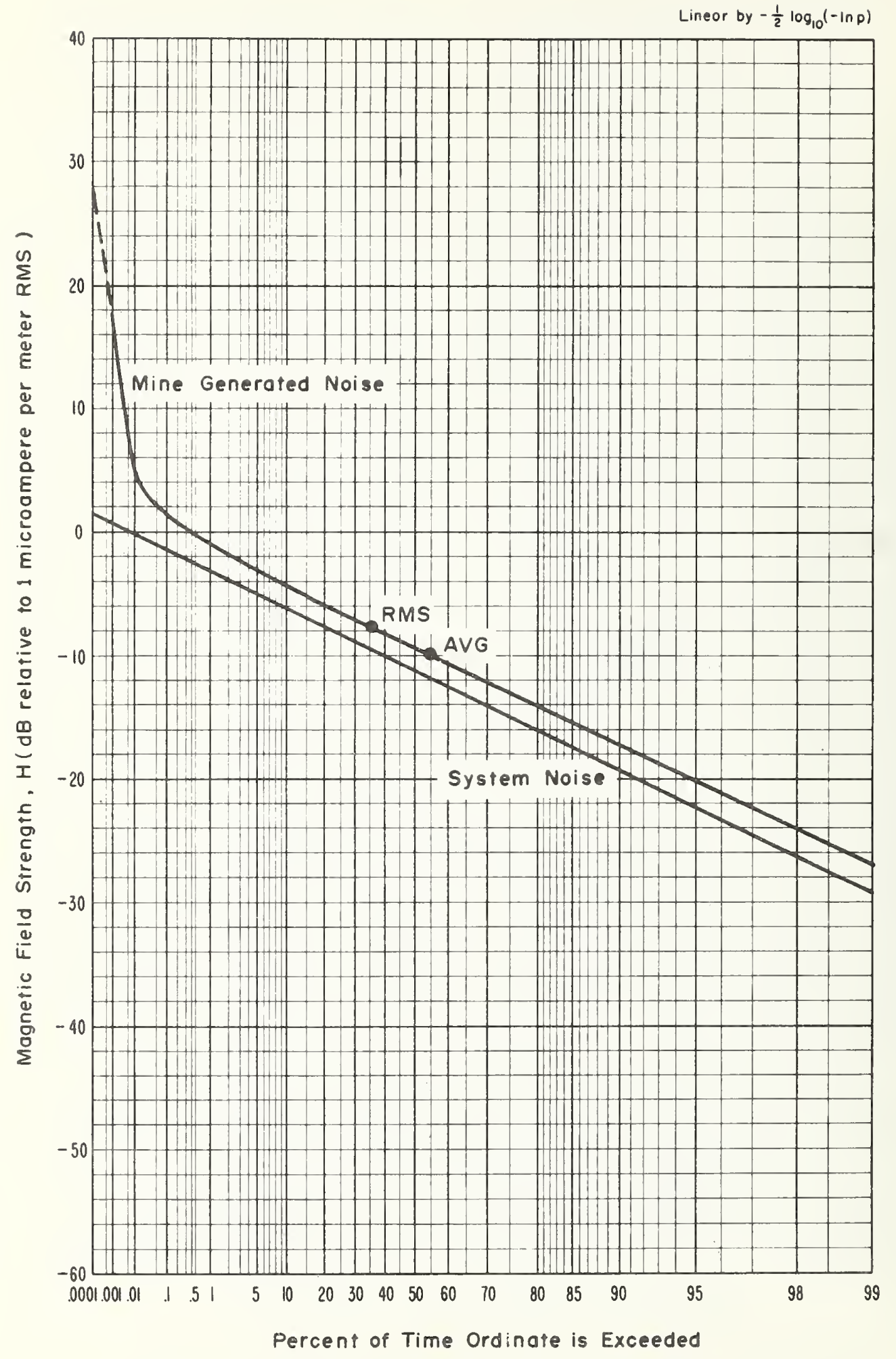

Figure 4-10 APD, $6 \mathrm{MHz}$, vertical component, $1.2 \mathrm{kHz}$ predetection bandwidth, April 10, 1973, 3:25 p.m., McElroy Mine. 


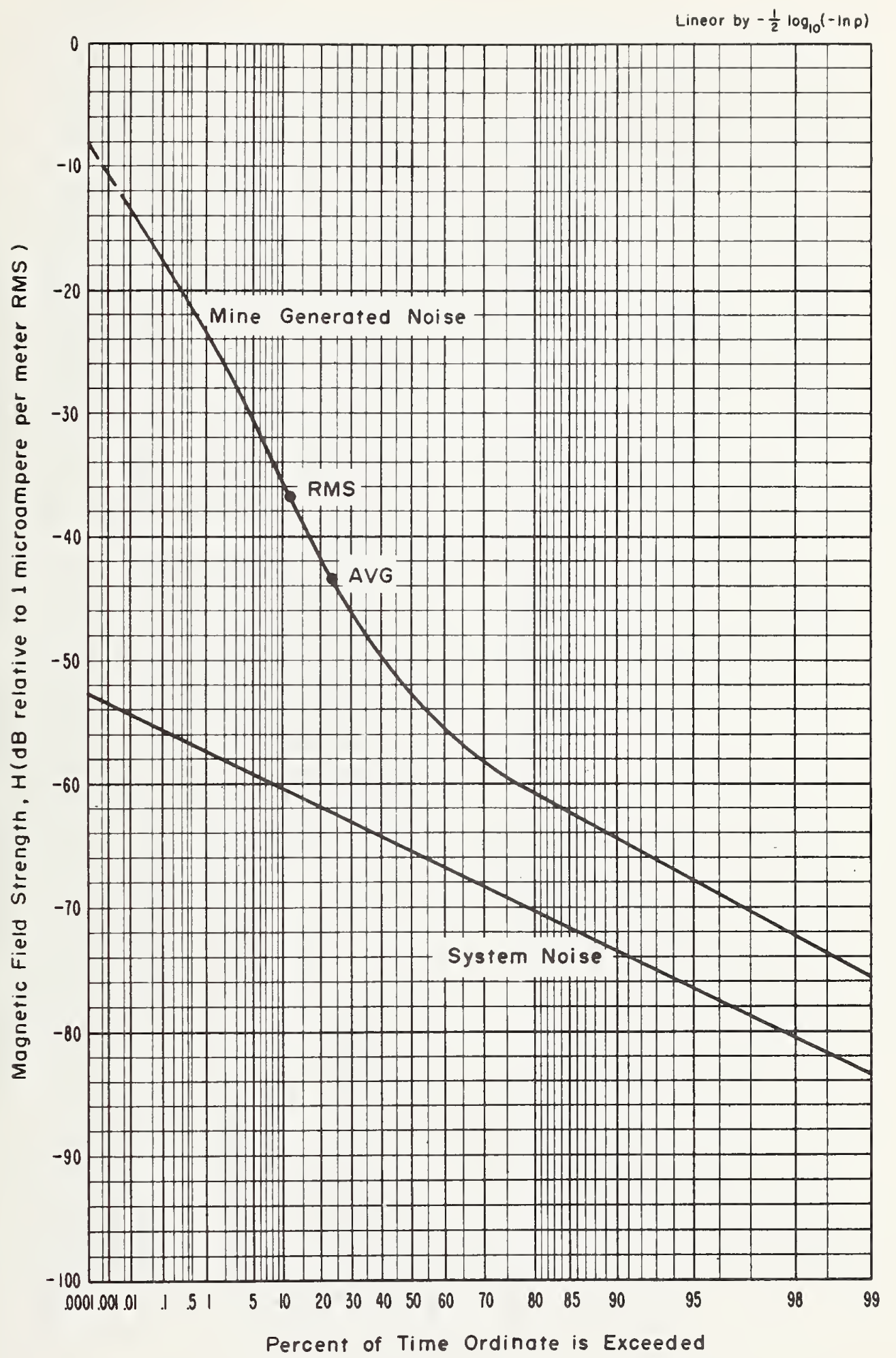

Figure 4-II APD, $14 \mathrm{MHz}$, vertical component, $1.2 \mathrm{kHz}$ predetection bandwidth, Apr11 10, 1973, 5:30 p.m., McElroy Mine. 


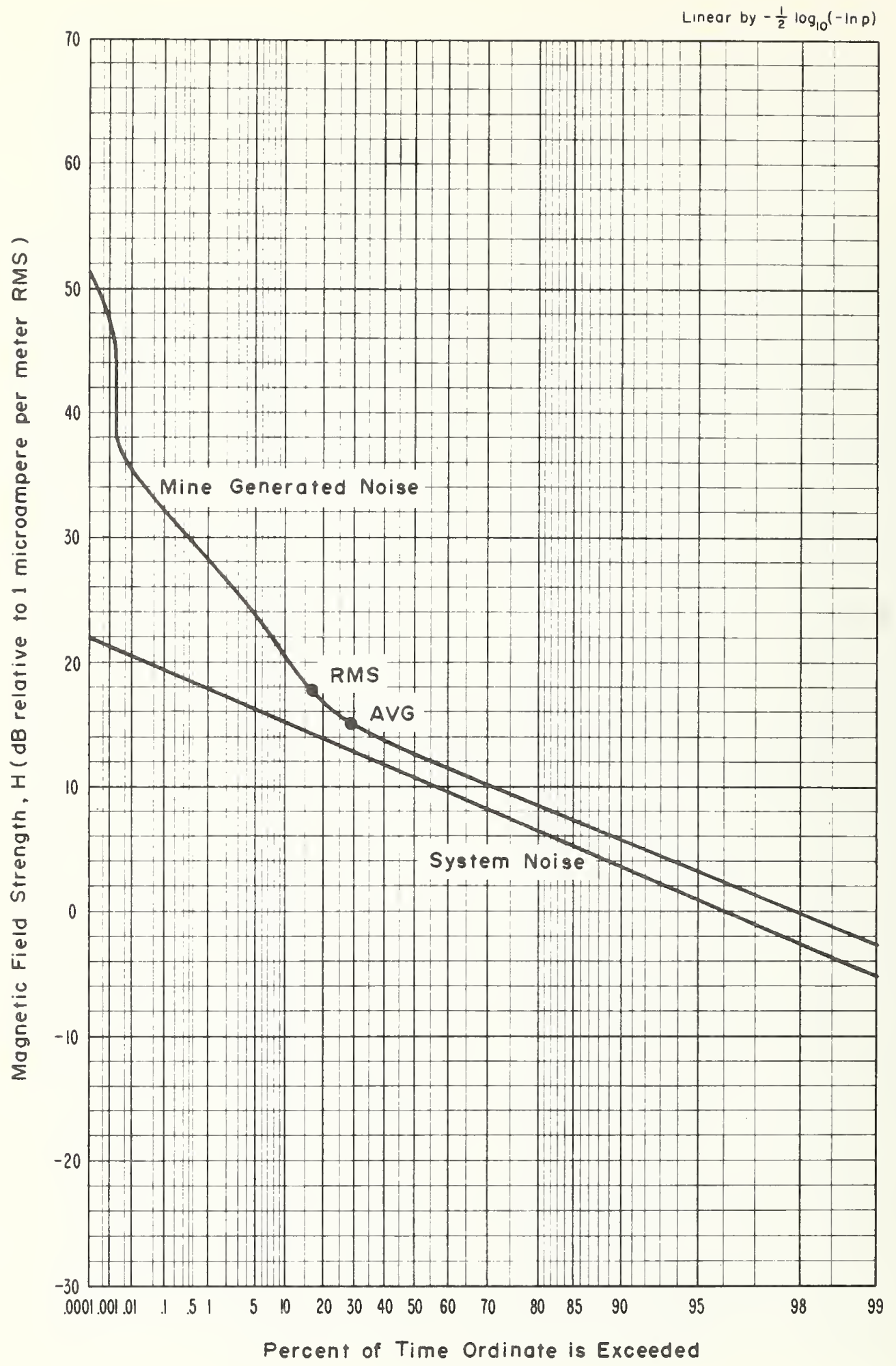

Figure 4-12 APD, $10 \mathrm{kHz}$, horizontal component (NE-SW), $1.0 \mathrm{kHz}$ predetection bandwidth, April 10, 1973, 12:20 p.m., McEl roy Mine. 


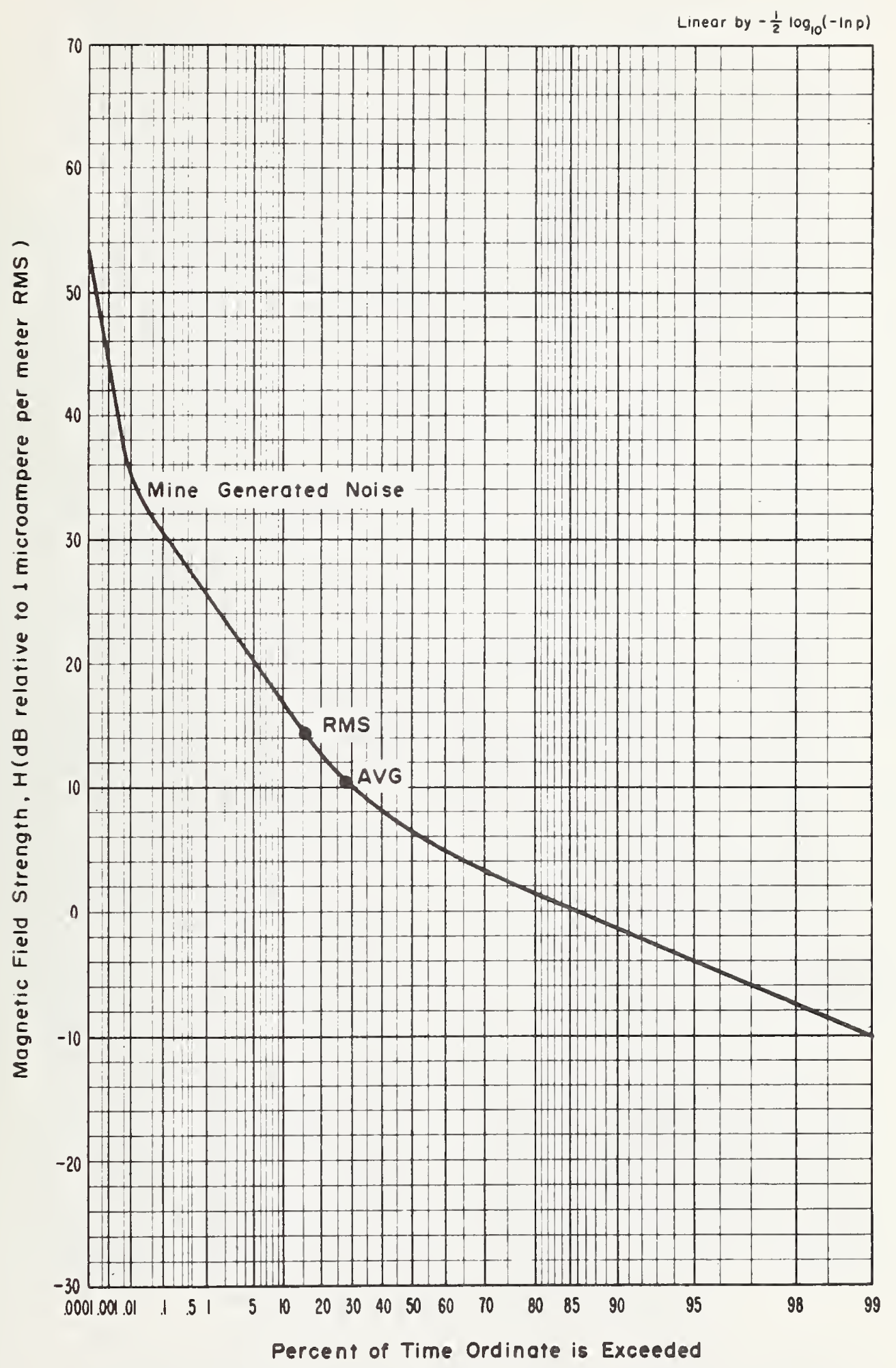

F1gure 4-13 APD, $30 \mathrm{kHz}$, horizontal component, (NE-SW), $1.0 \mathrm{kHz}$ predetection bandw1dth, Apr11 10, 1973, 1:50 p.m., MCElroy Mine. 


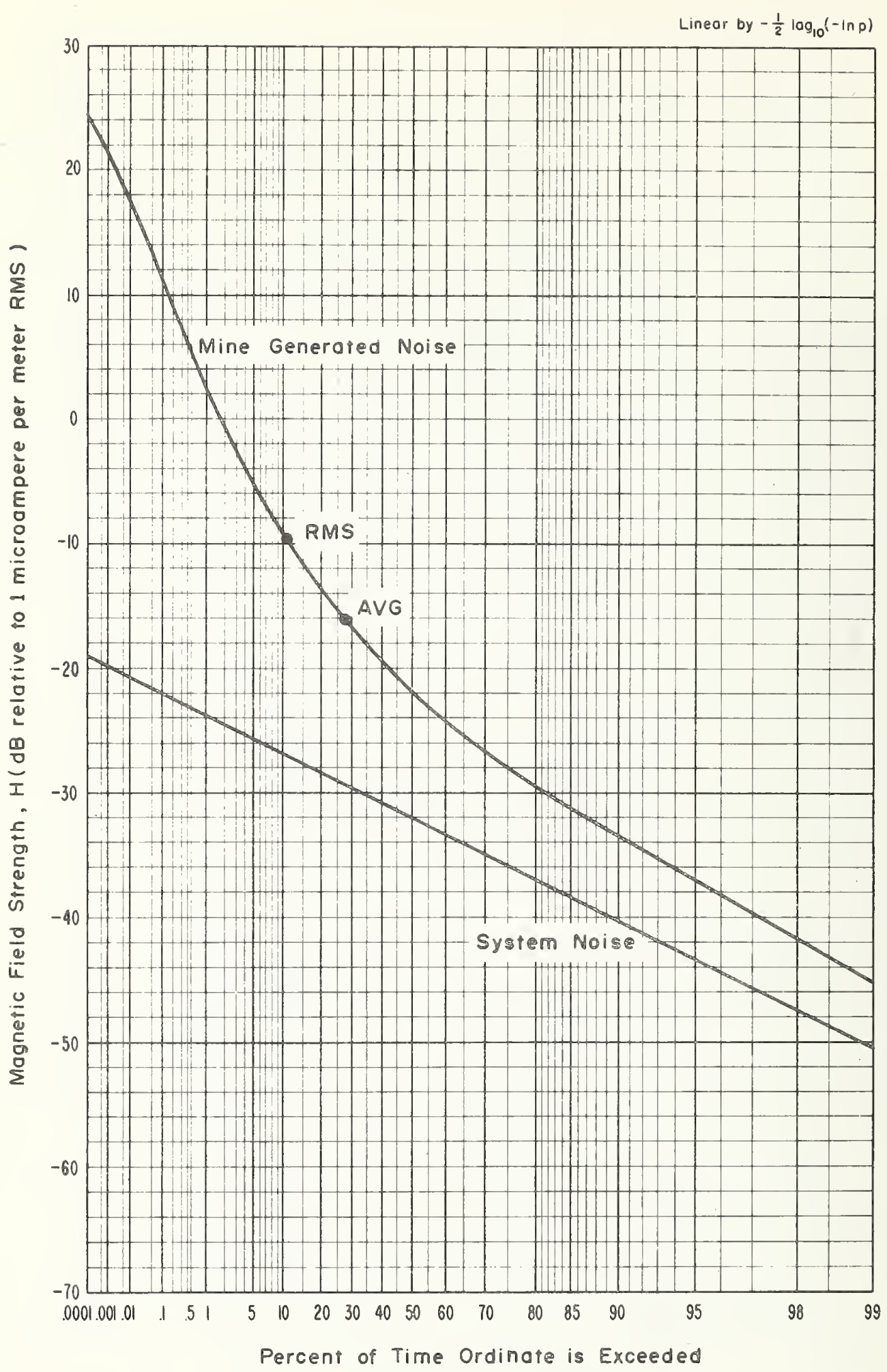

Figure 4-14 APD, $70 \mathrm{kHz}$, hortzontal component (NE-SW), $1.0 \mathrm{kHz}$ predetection bandwidth, April 10, 1973, 2:50 p.m., MeElroy Mine. 


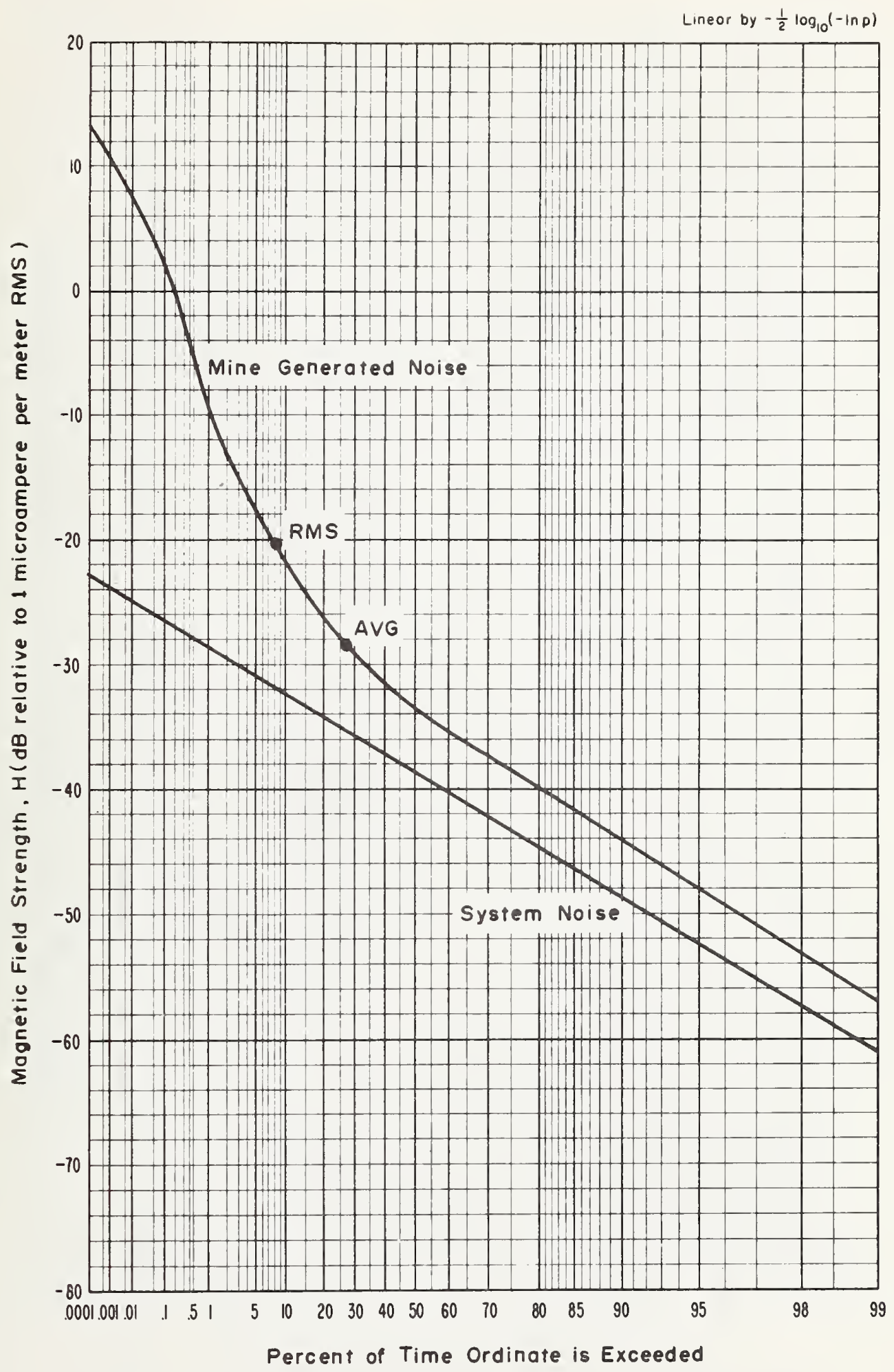

Figure 4-15 APD, $130 \mathrm{kHz}$, horizontal component (NE-SW), $1.0 \mathrm{kHz}$ predetection bandwidth, April 10, 1973, 5:00 p.m., McElroy Mine. 


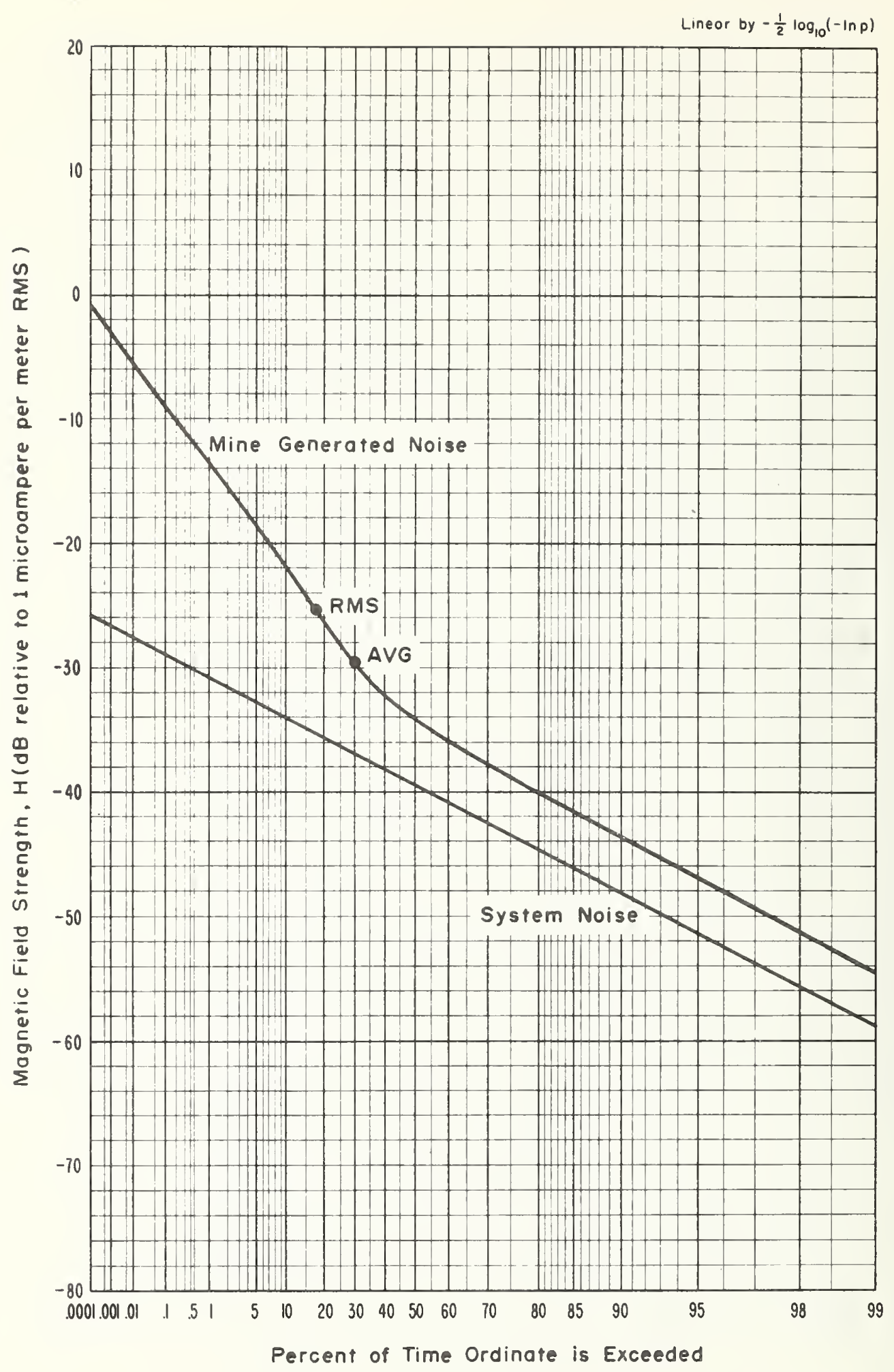

Figure 4-16 APD, $160 \mathrm{kHz}$, horizontal component(NE-SW), $1.0 \mathrm{kHz}$ predetection bandwidth, Apr 11 10, 1973, 6:00 p.m., McElroy Mine. 


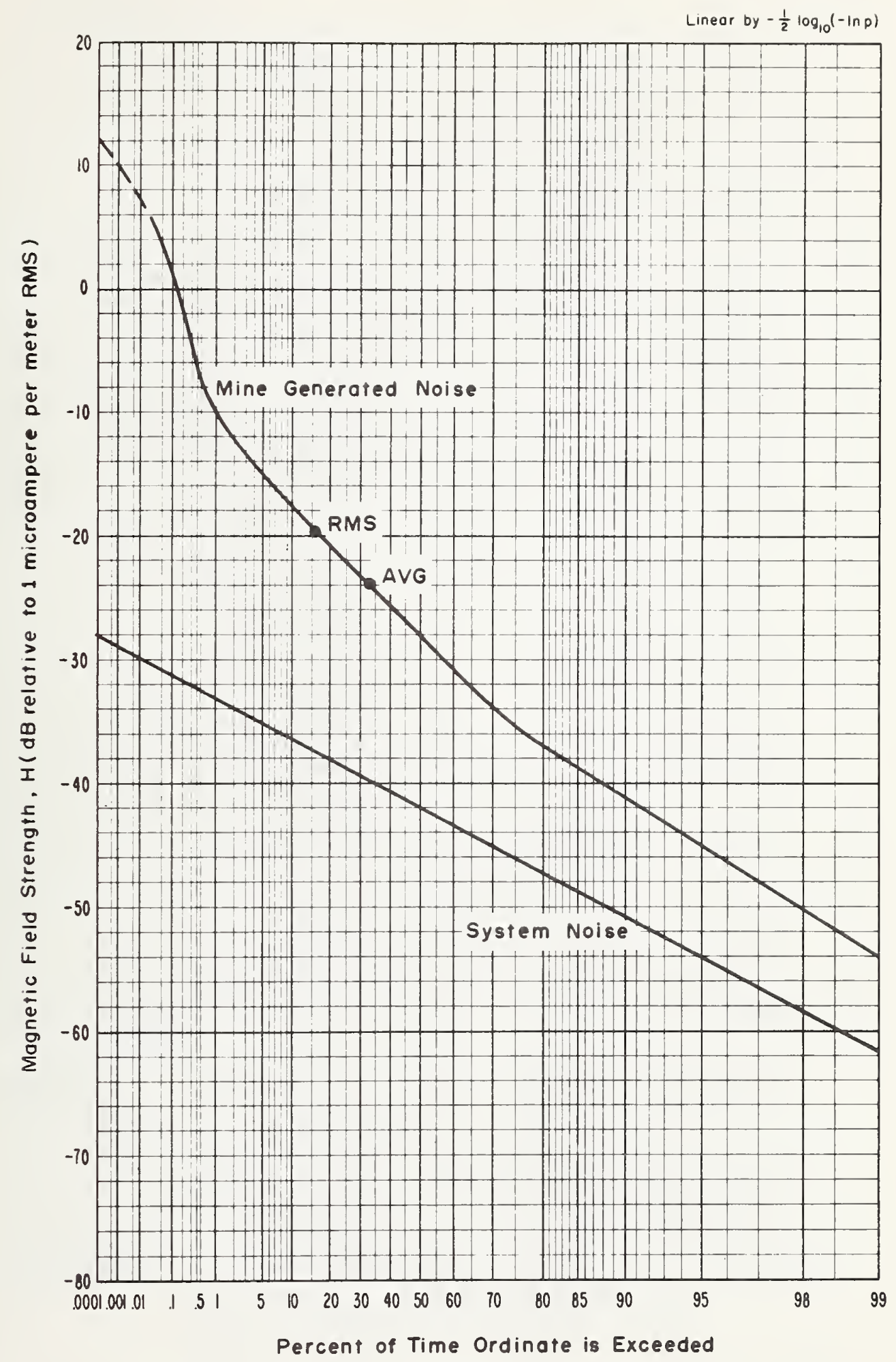

Figure 4-17 APD, $250 \mathrm{kHz}$, horizontal component (NE-SW), $1.0 \mathrm{kHz}$, predetection bandwidth, April 10, 1973, 7:00 p.m., McElroy Mine. 


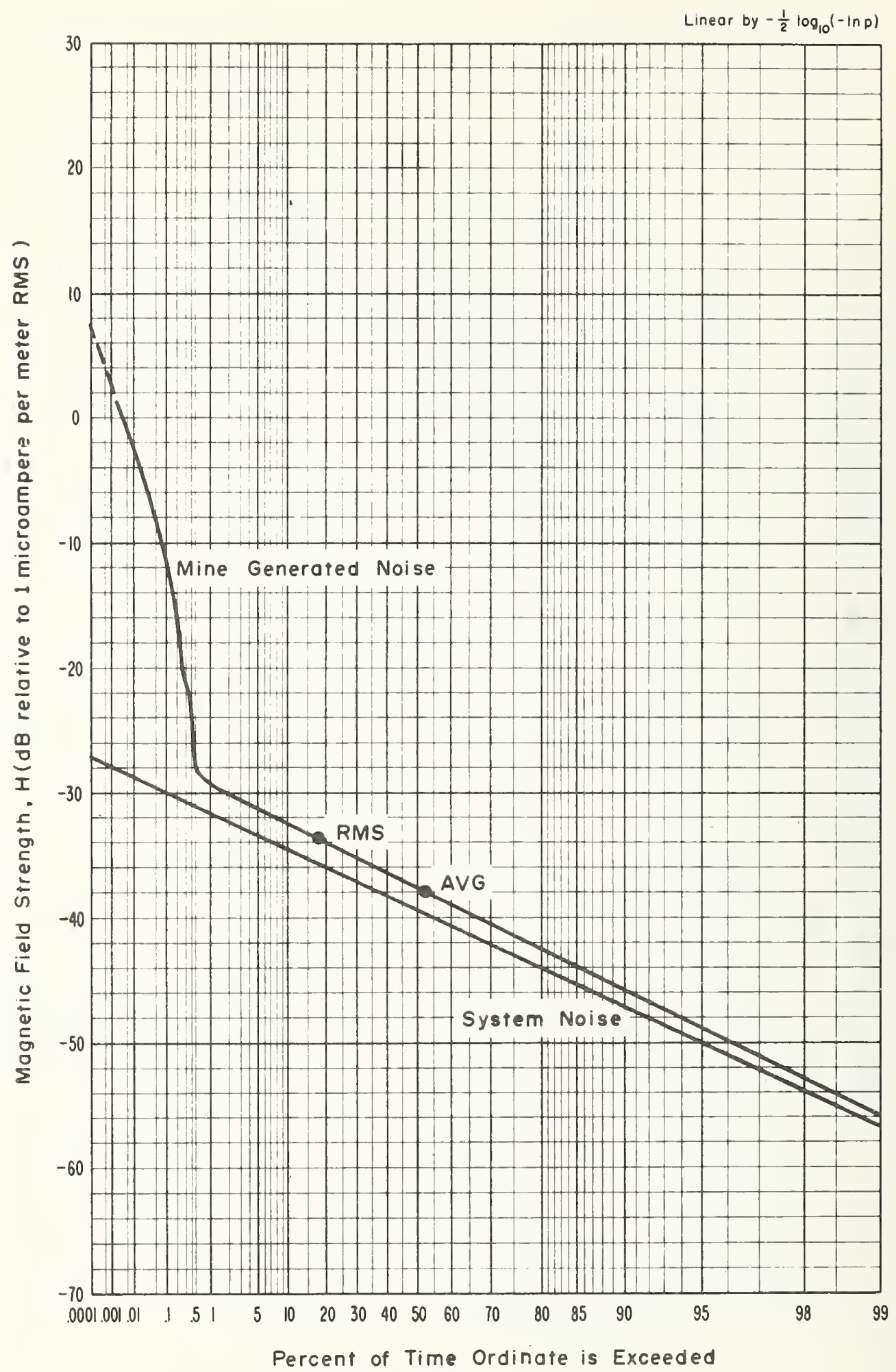

Figure 4-18 APD, $500 \mathrm{kHz}$, horizontal component (NE-SW), $1.2 \mathrm{kHz}$ predetection bandwidth, April 10,1973, 12:20 p.m., McElroy Mine. 


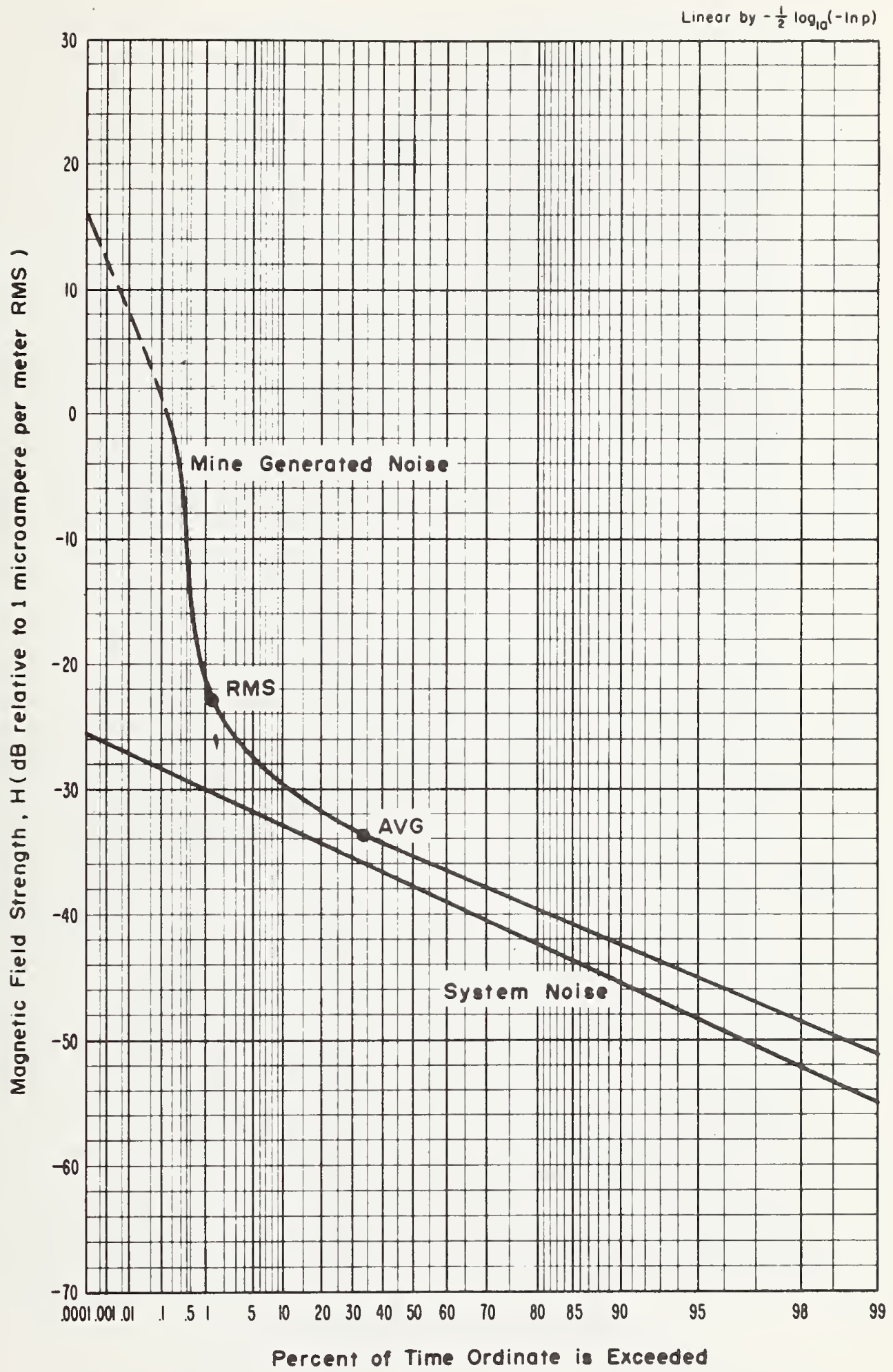

F1gure 4-19 APD, $1 \mathrm{MHz}$, hor1zontal component (NE-SW), $1.2 \mathrm{kHz}$ predetection bandwidth, Apr11 10, 1973, 1:50 P.m., McEl roy Mine. 


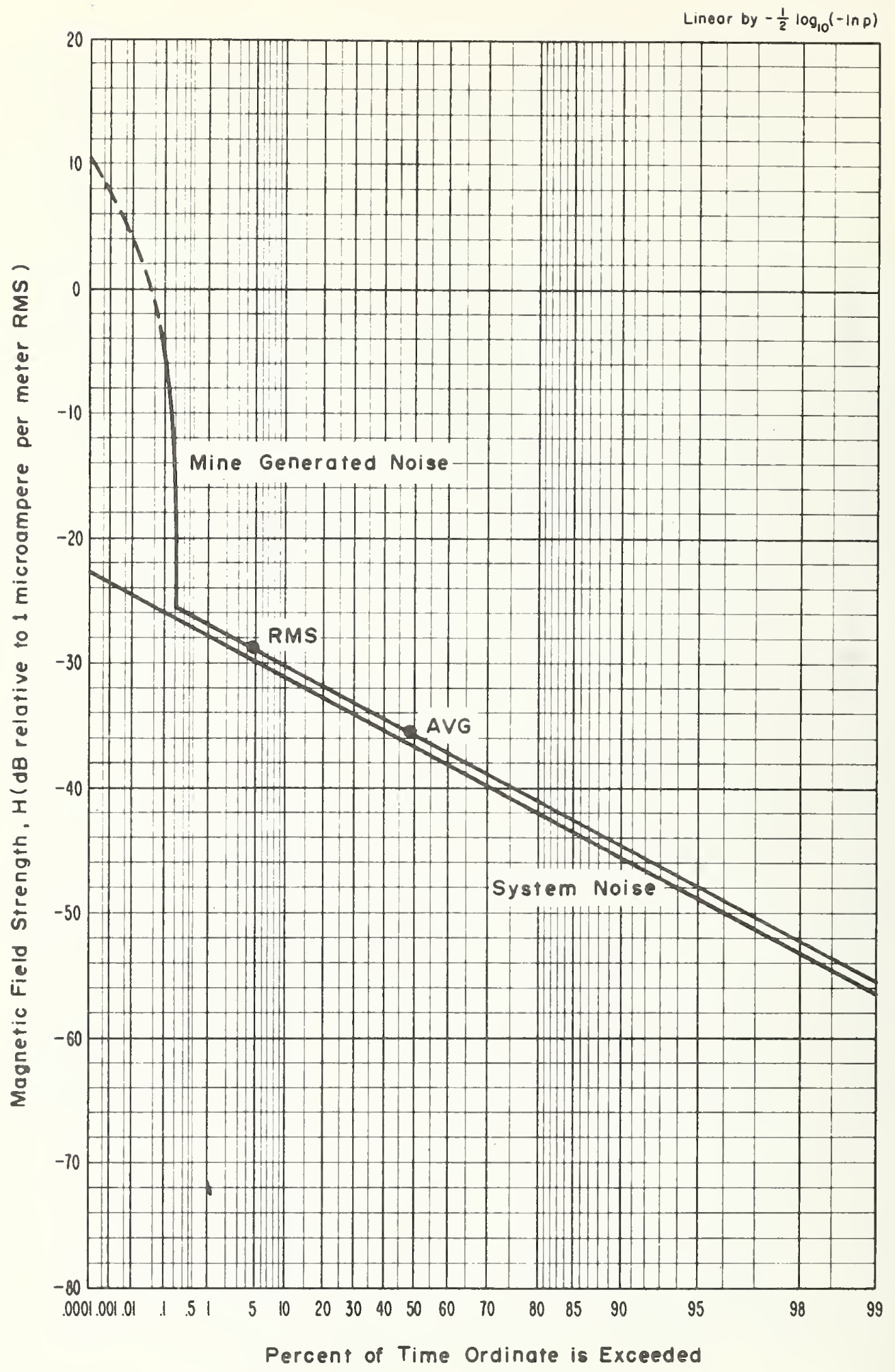

Figure 4-20 APD, $2 \mathrm{MHz}$, horizontal component (NE-SW), $1.2 \mathrm{kHz}$ predetection bandwidth, Apr11 10, 1973, 2:50 p.m., McElroy Mine. 


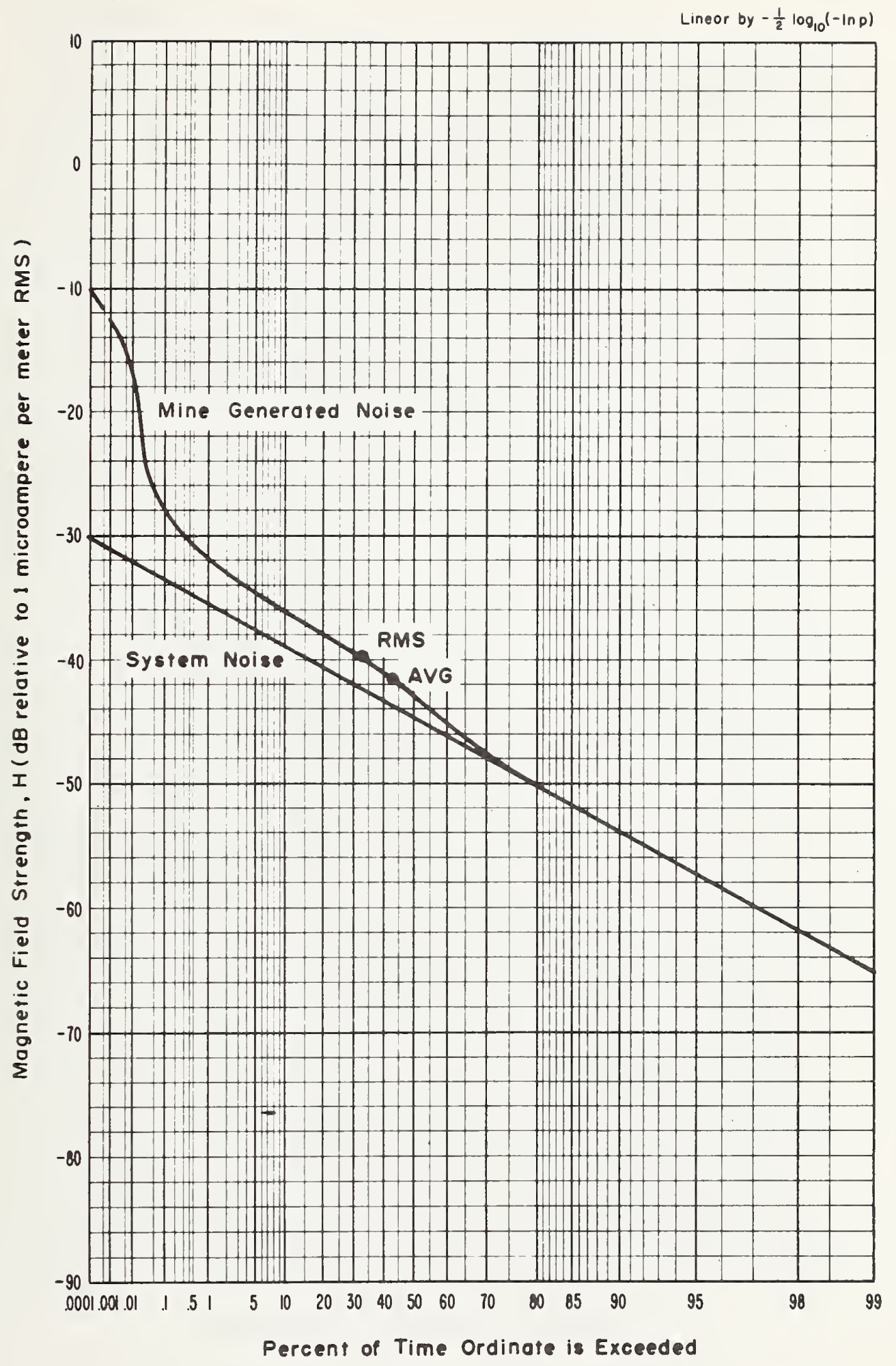

Flgure 4-2l APD, $6 \mathrm{MHz}$, hor1zontal component (NE-SW), $1.2 \mathrm{kHz}$ predetection bandw1dth, April 10, 1973, 5:00 p.m., McE1roy Mine. 


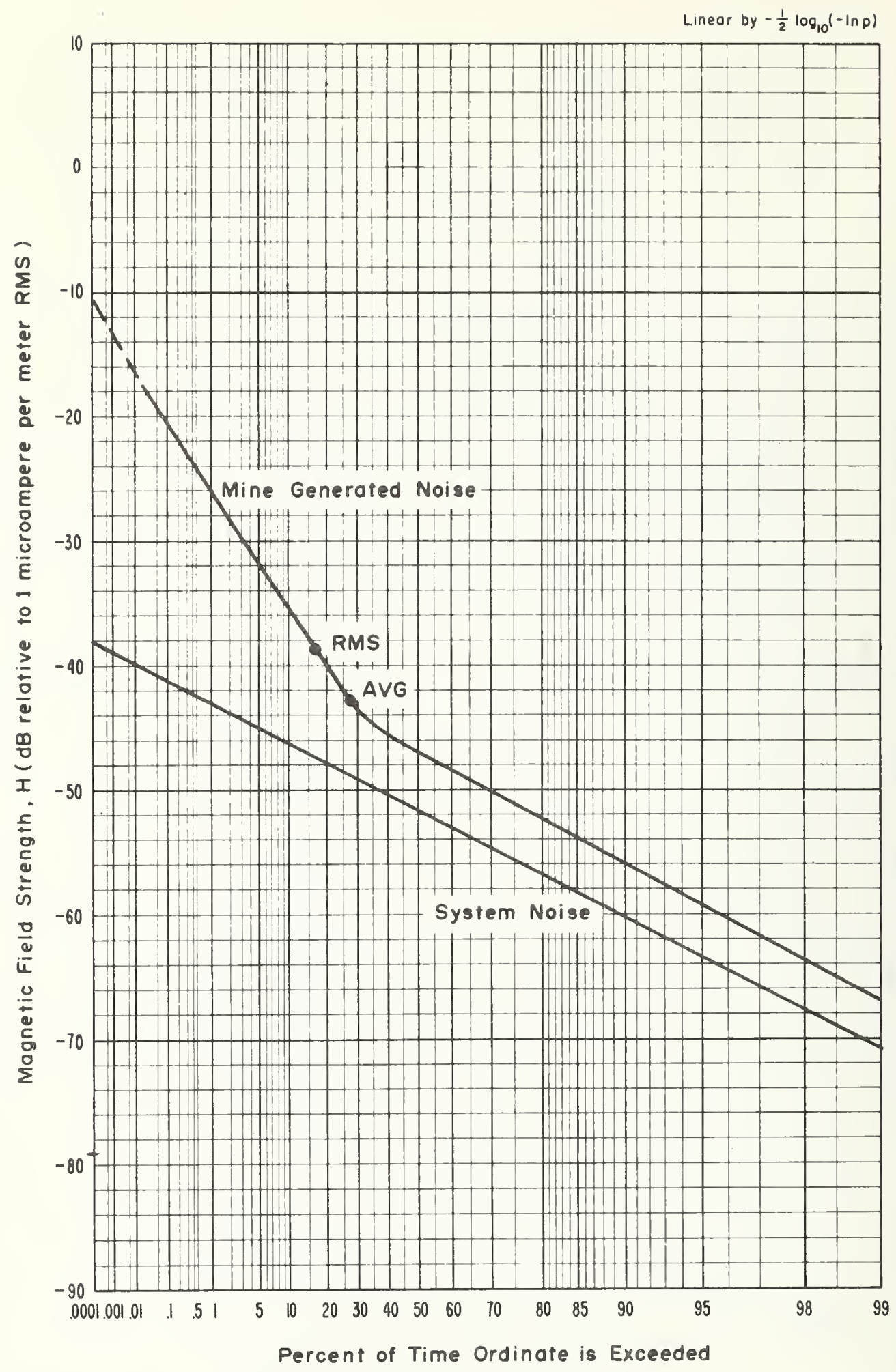

Figure 4-22 APD, $14 \mathrm{MHz}$, horizontal component (NE-SW), $1.2 \mathrm{kHz}$ predetection bandwidth, April 10, 1973, 6:00 p.m., McElroy Mine. 


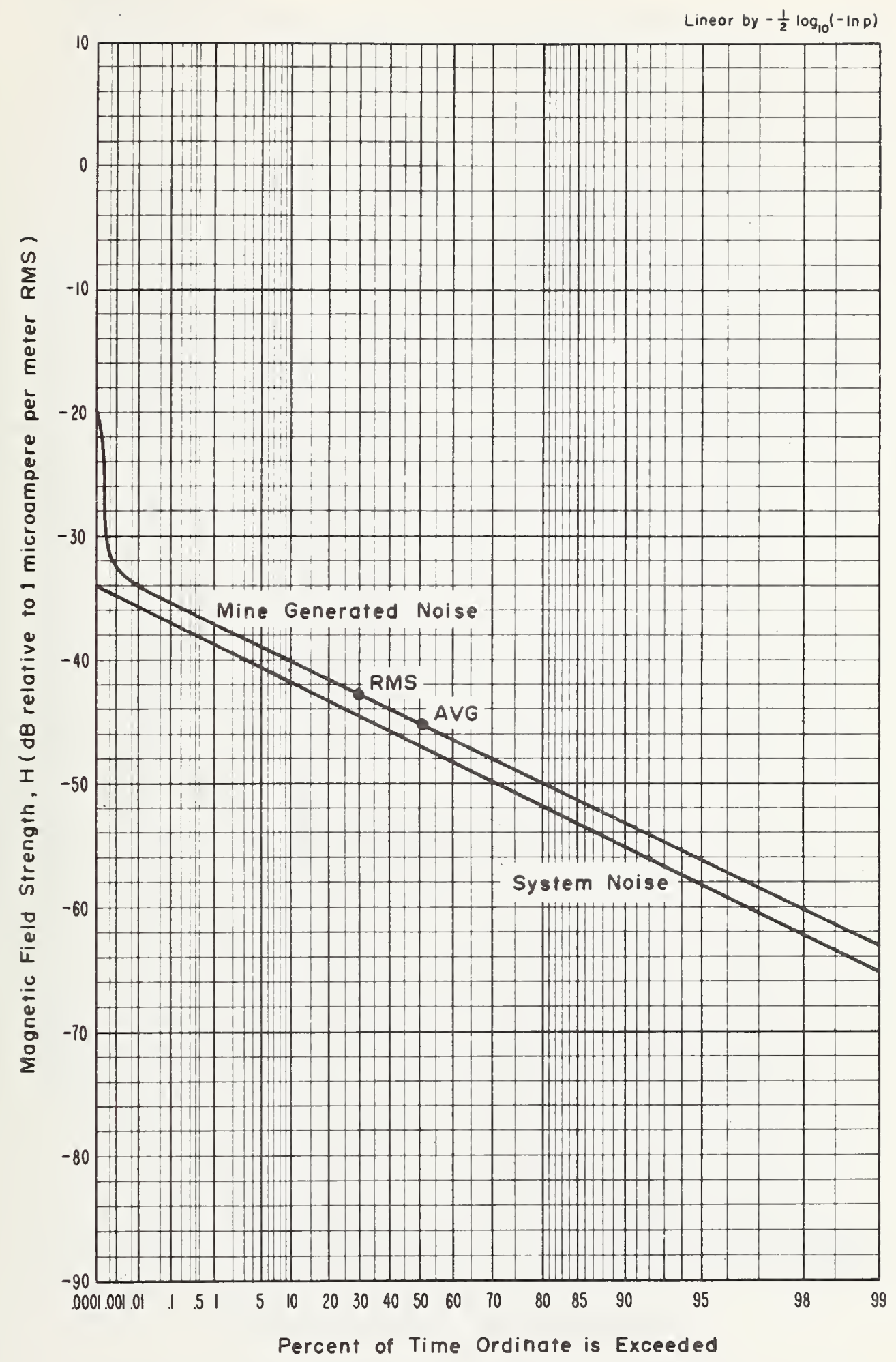

Figure 4-23 APD, $32 \mathrm{MHz}$, horlzontal component (NE-SW), $1.2 \mathrm{kHz}$ predetection bandwidth, Apr11 10, 1973, 7:00 p.m., McElroy Mine. 


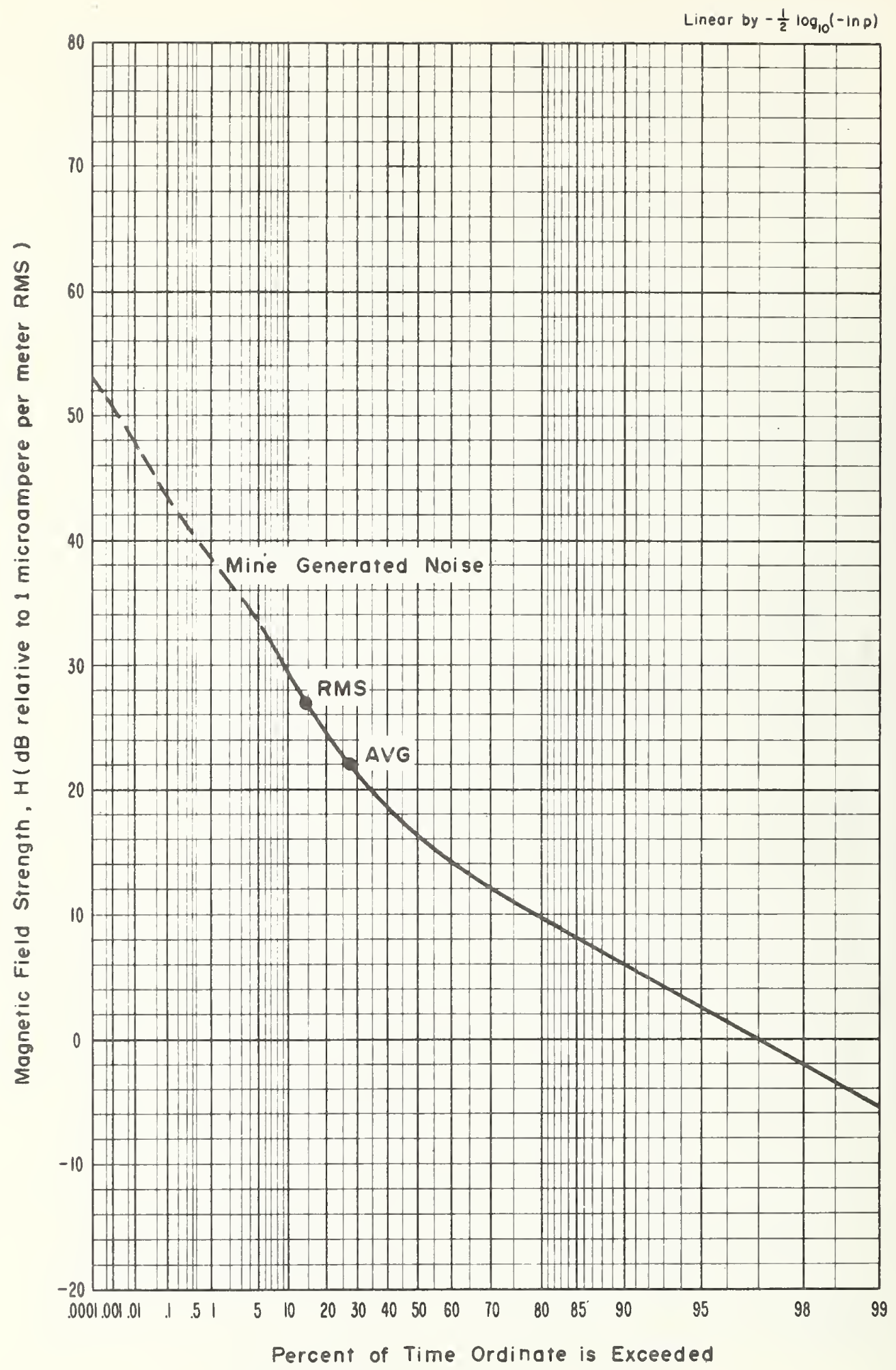

Figure 4-24 APD, $10 \mathrm{kHz}$, vertical component, $1.0 \mathrm{kHz}$ predetection bandwidth, April 10,1973, 4:00 p.m., quiet time measurements, McEl roy Mine. 


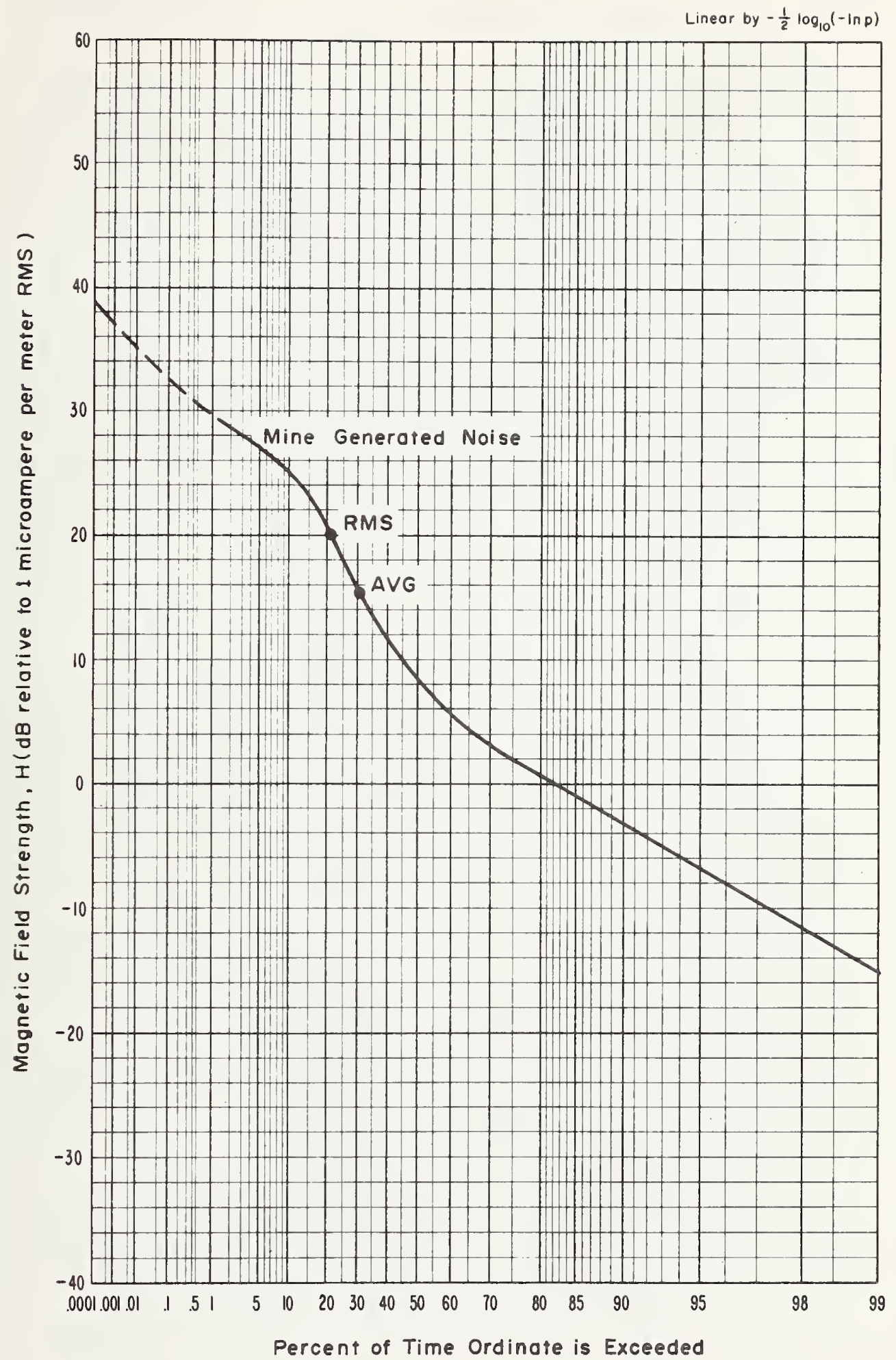

Figure 4-25 APD, $30 \mathrm{kHz}$, vertical component, $1.0 \mathrm{kHz}$ predetection bandwidth, April 10,1973, 4:10 p.m., qulet t1me measurements, McElroy Mine. 


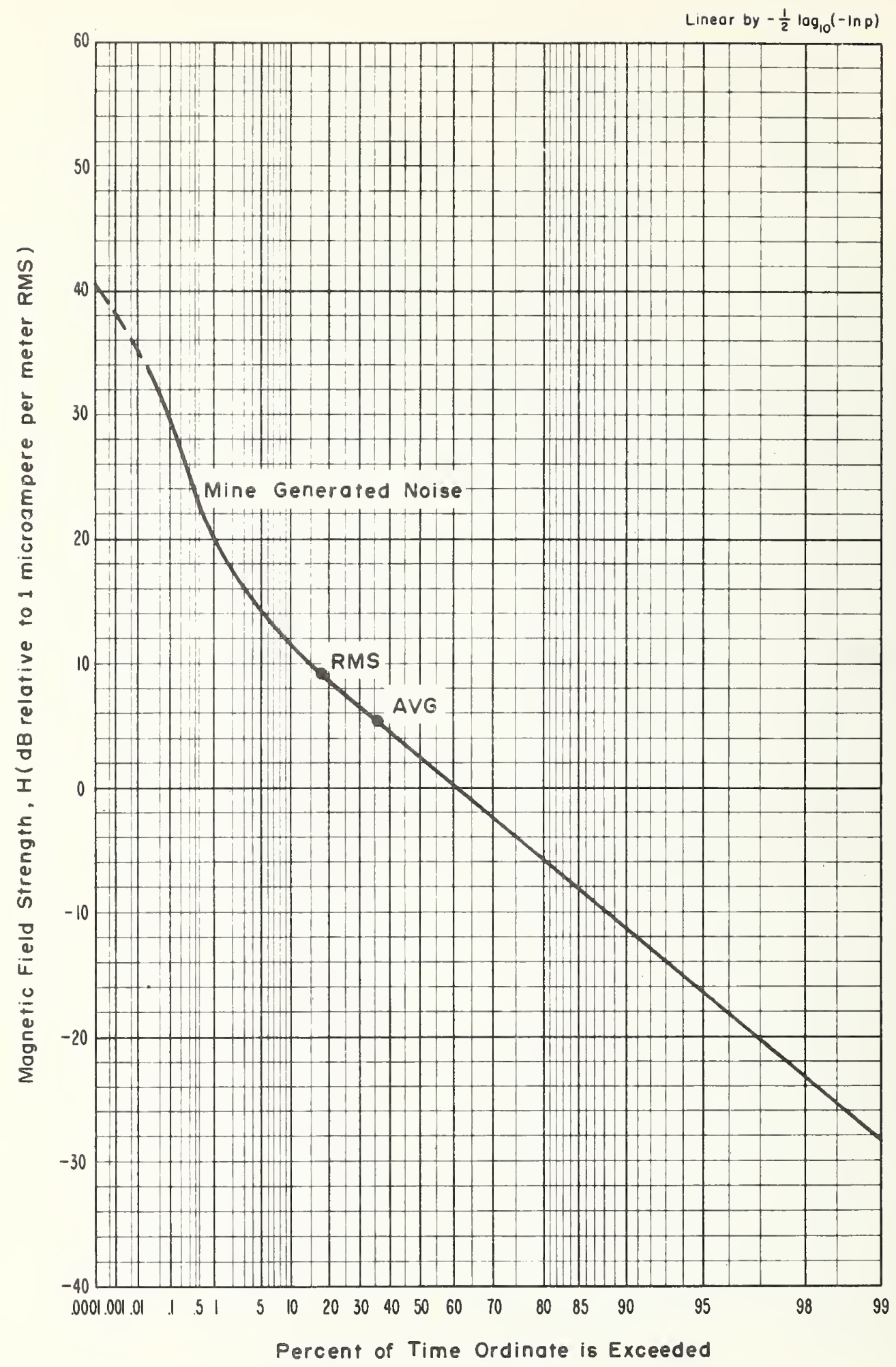

Figure 4-26 APD, $70 \mathrm{kHz}$, vertical component, $1.0 \mathrm{kHz}$ predetection bandwidth, April 10, 1973, quiet time measurements, McEl roy Mine. 


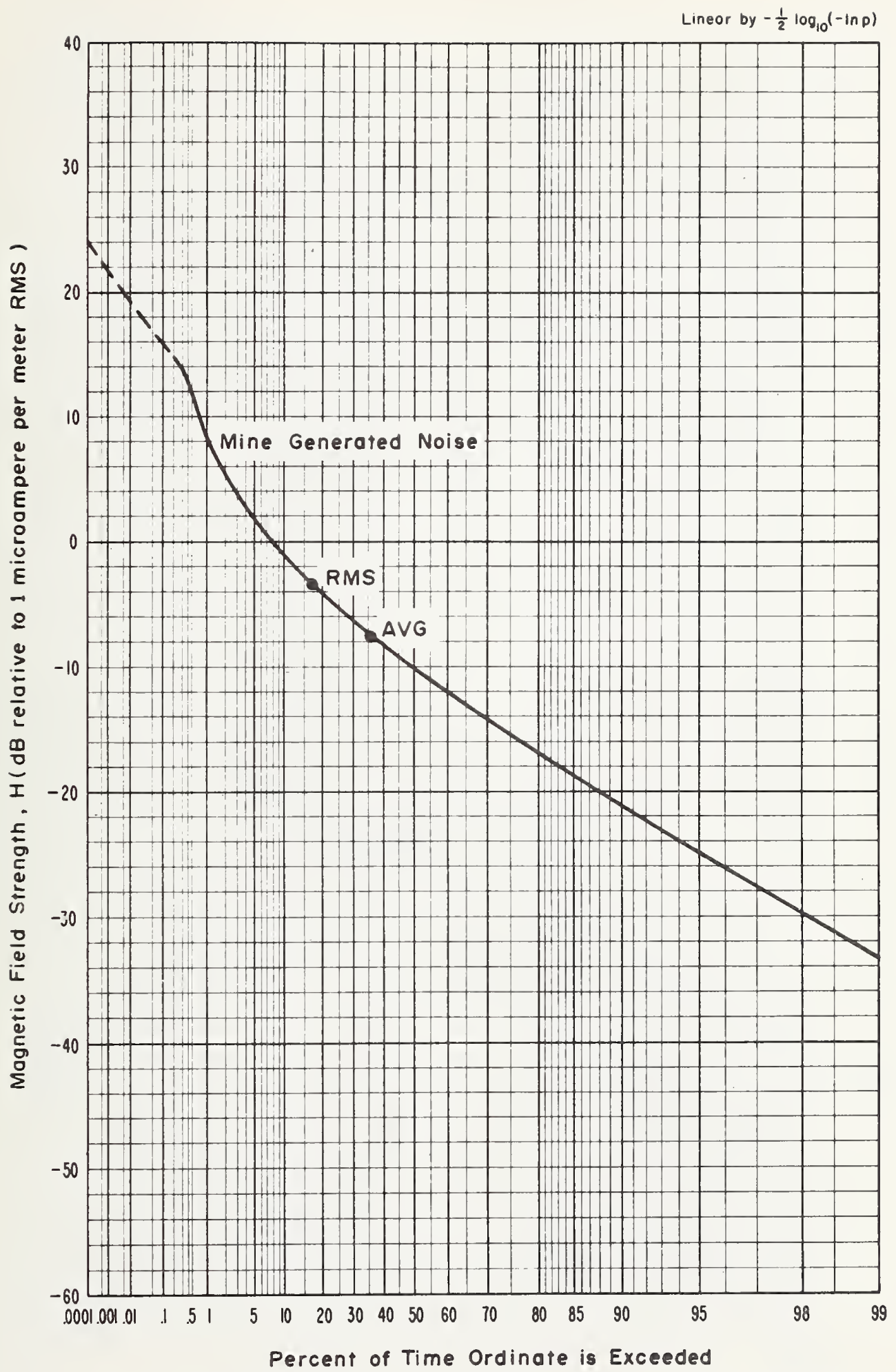

Figure 4-27 APD, $130 \mathrm{kHz}$, vertical component, $1.0 \mathrm{kHz}$ predetection bandwidth, April 10,1973, 4:30 p.m., qulet time measurement, McElroy Mine. 


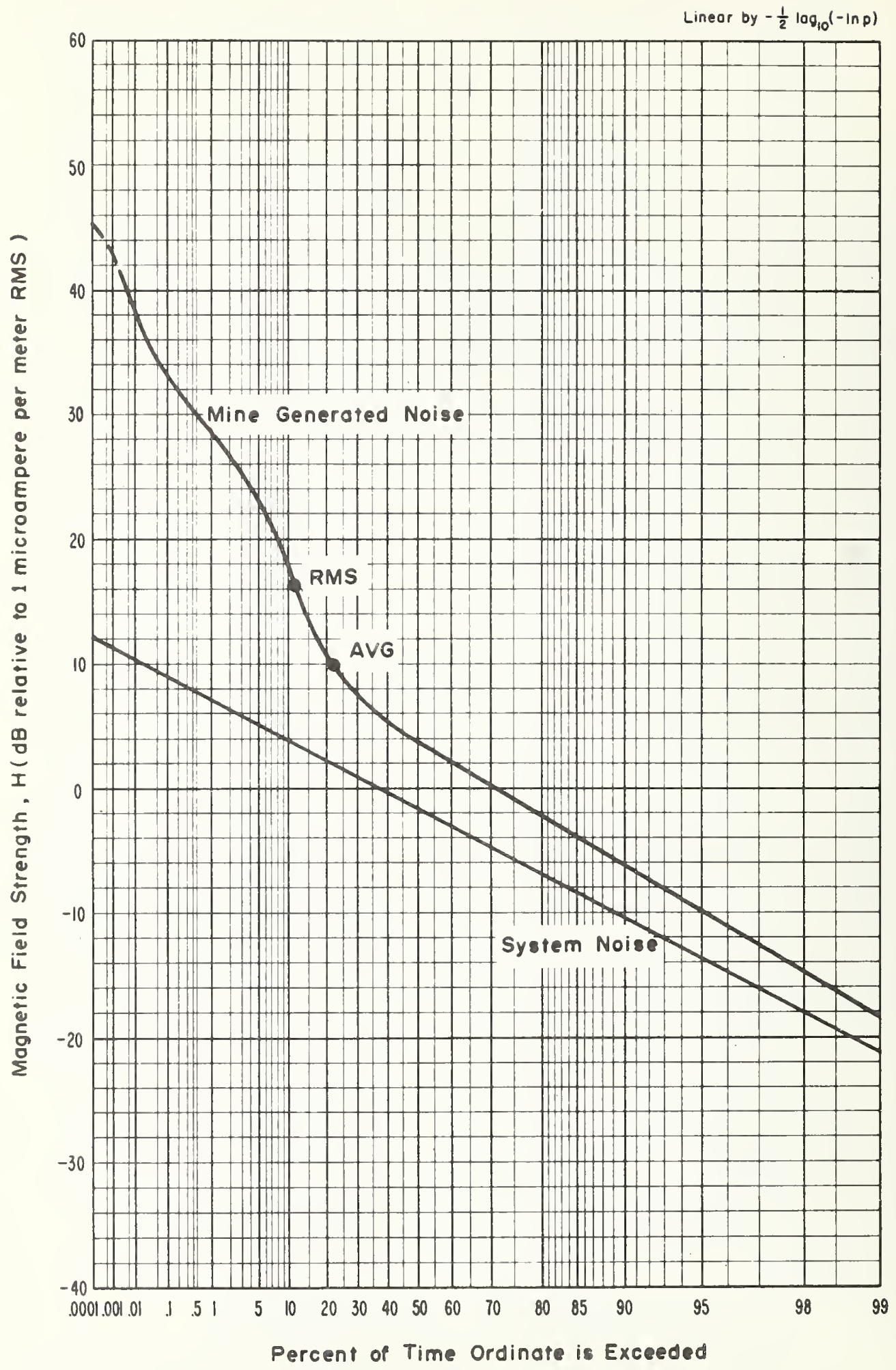

Figure 4-28 APD, $10 \mathrm{kHz}$, vertical component, $1.0 \mathrm{kHz}$ predetection bandwldth, April 10, 1973, 1:00 p.m., McElroy M1ne. 


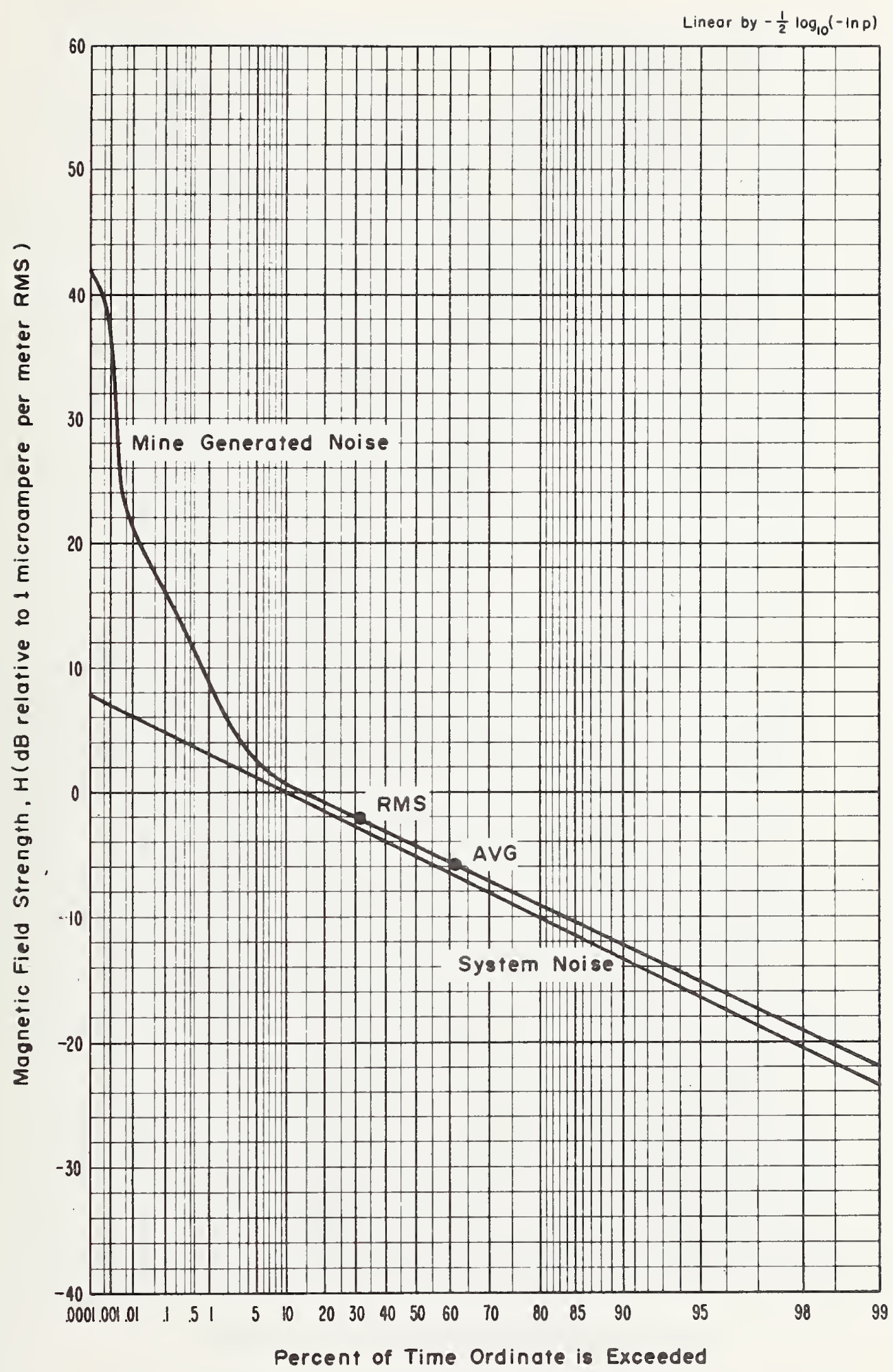

F1gure 4-29 APD, $30 \mathrm{kHz}$, vertical component, $1.0 \mathrm{kHz}$ predetection bandwidth, April 10, 1973, 2:30 p.m., McElroy Mine. 


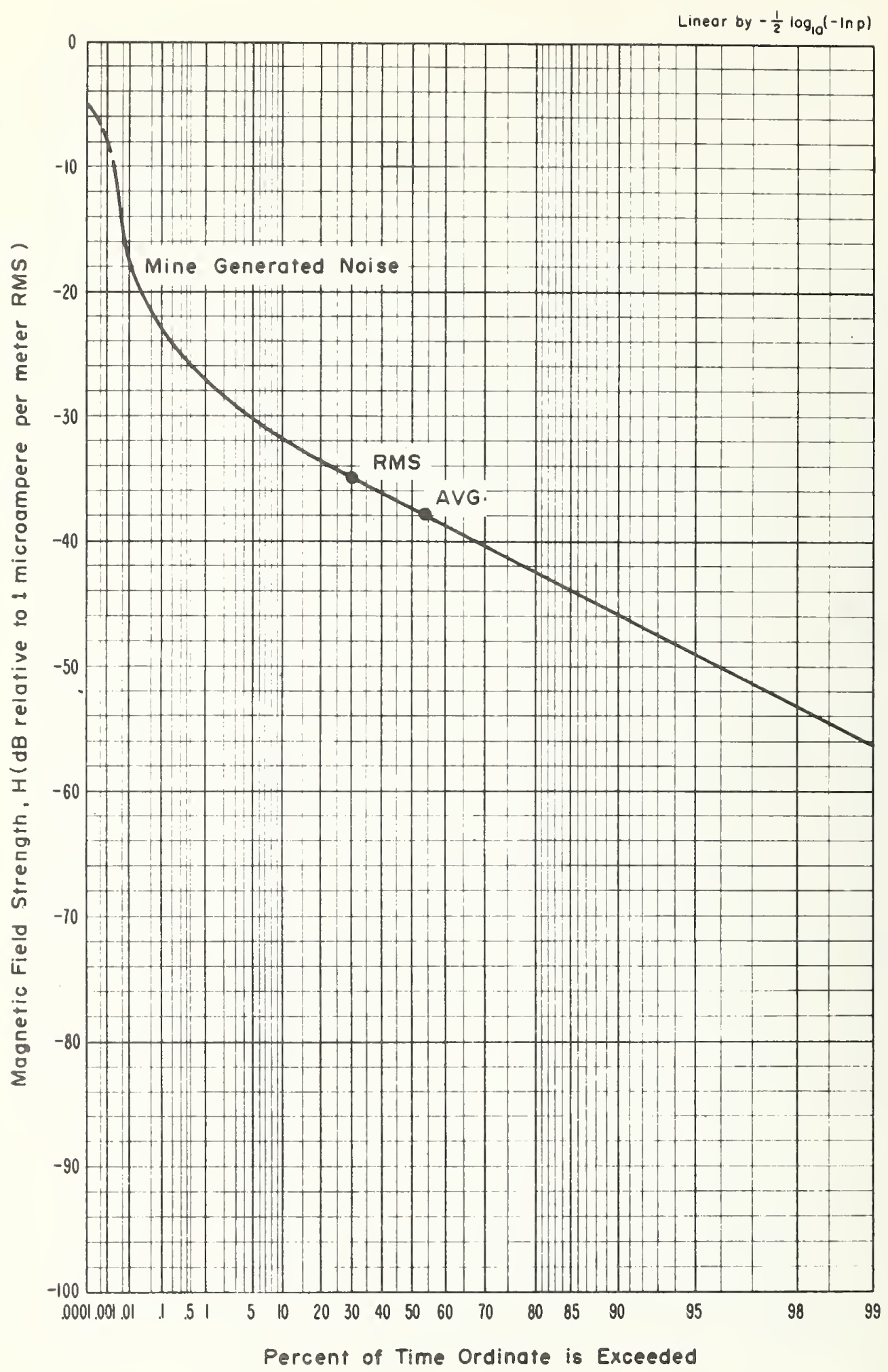

Figure 4-30 APD, $70 \mathrm{kHz}$, vertical component, $1.0 \mathrm{kHz}$ predetection bandwidth, April 10, 1973, 5:15 p.m., McElroy Mine. 


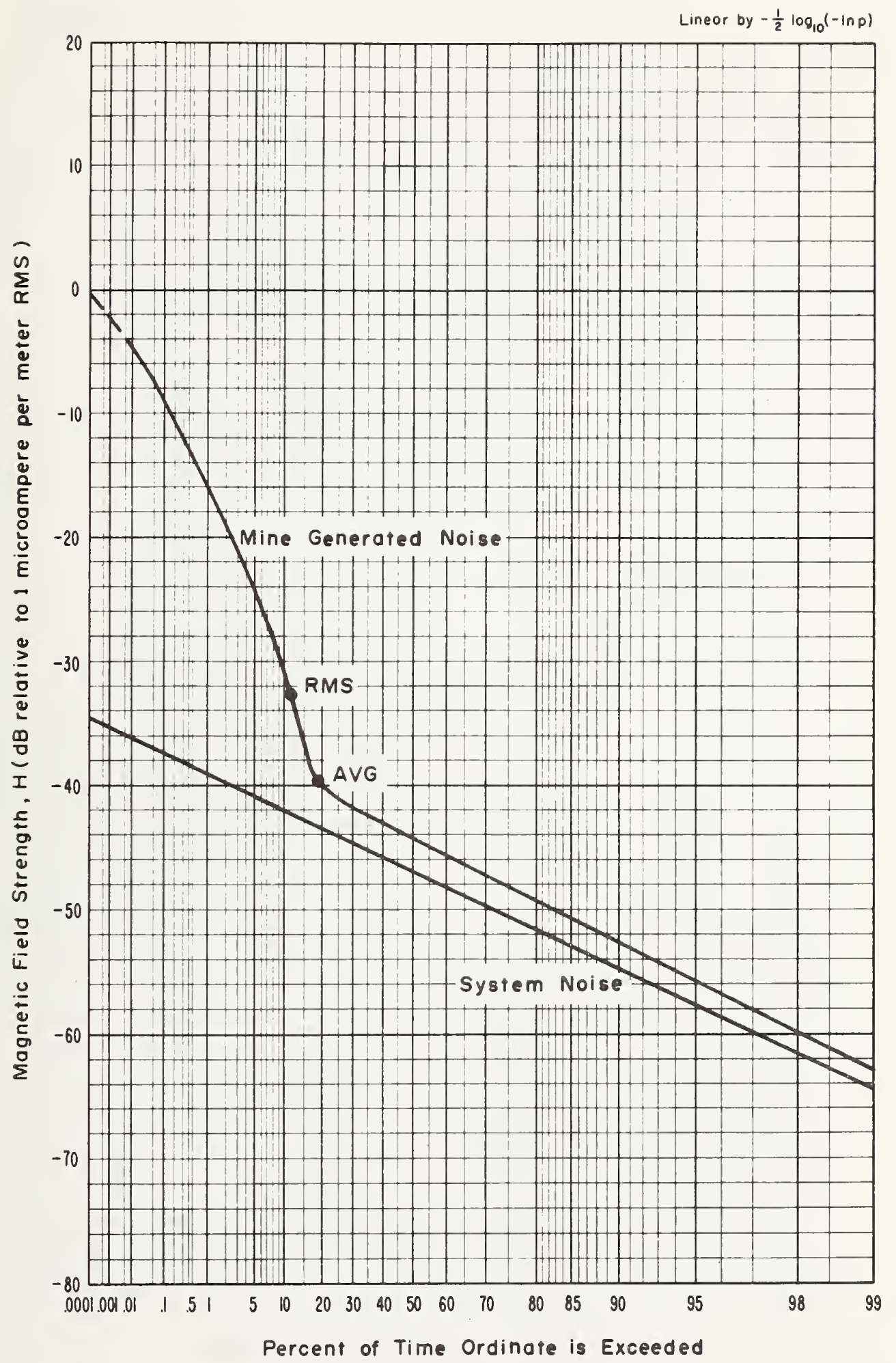

Figure 4-31 APD, $130 \mathrm{kHz}$, vertical component, $1.0 \mathrm{kHz}$ predetection bandwldth, Apr11 10, 1973, 7:30 p.m., McElroy Mine. 


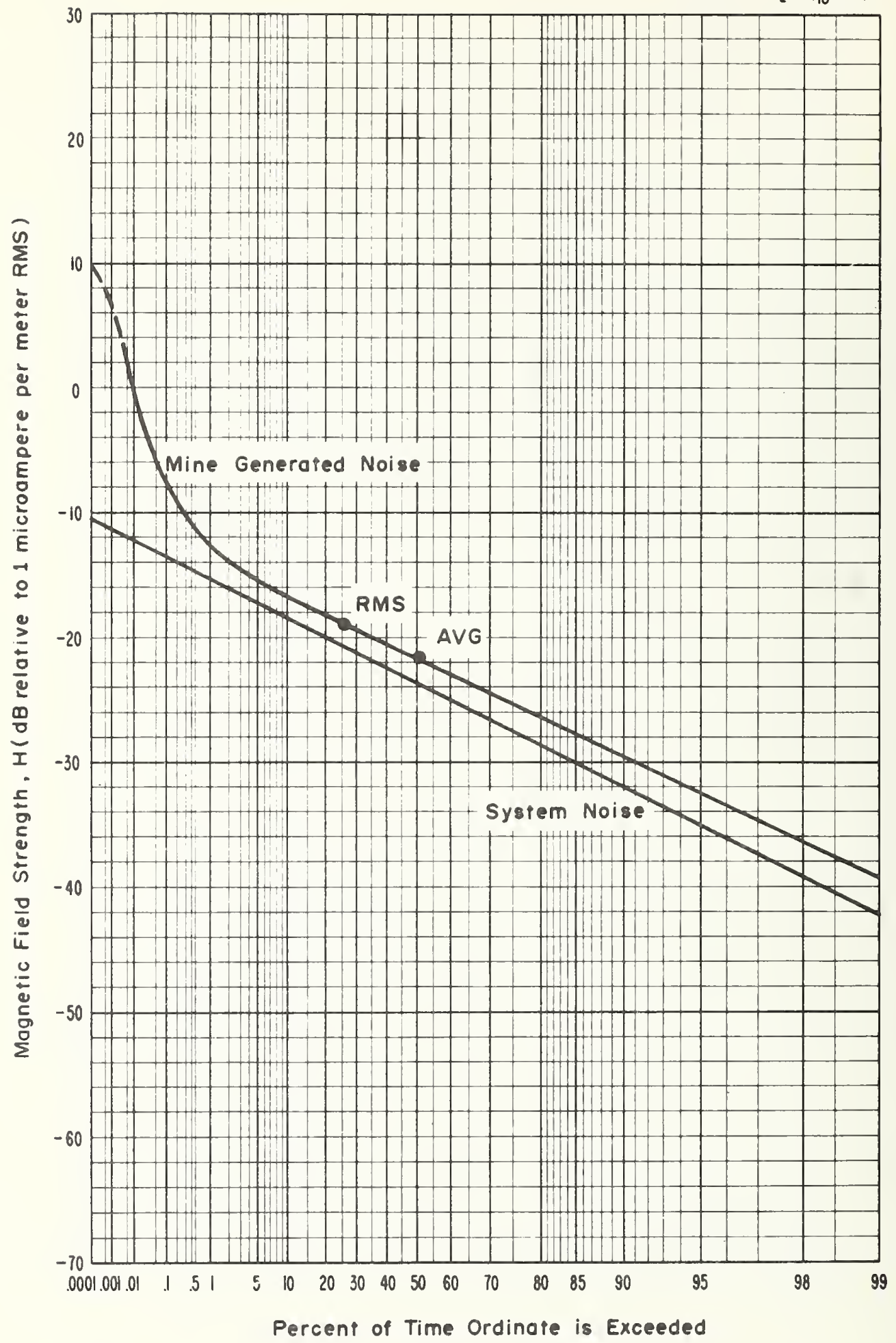

Figure 4-32 APD, $160 \mathrm{kHz}$, vertical component, $1.0 \mathrm{kHz}$ predetection bandwIdth, April 10, 1973, 6:45 p.m., McElroy Mine. 


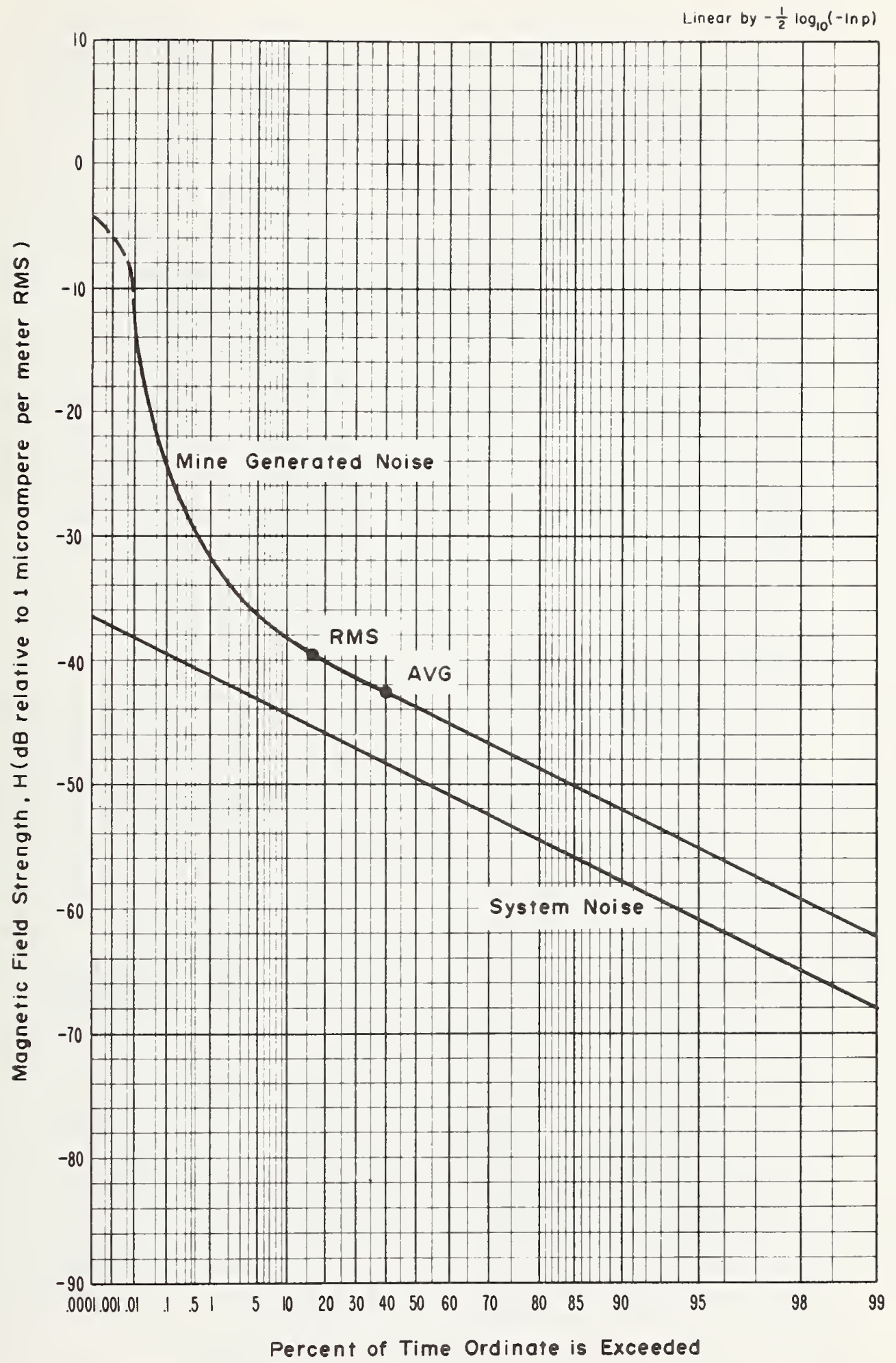

Figure 4-33 APD, $250 \mathrm{kHz}$, vertical component, $1.2 \mathrm{kHz}$ predetection bandwidth, April 10, 1973, 7:30 p.m., McElroy Mine. 


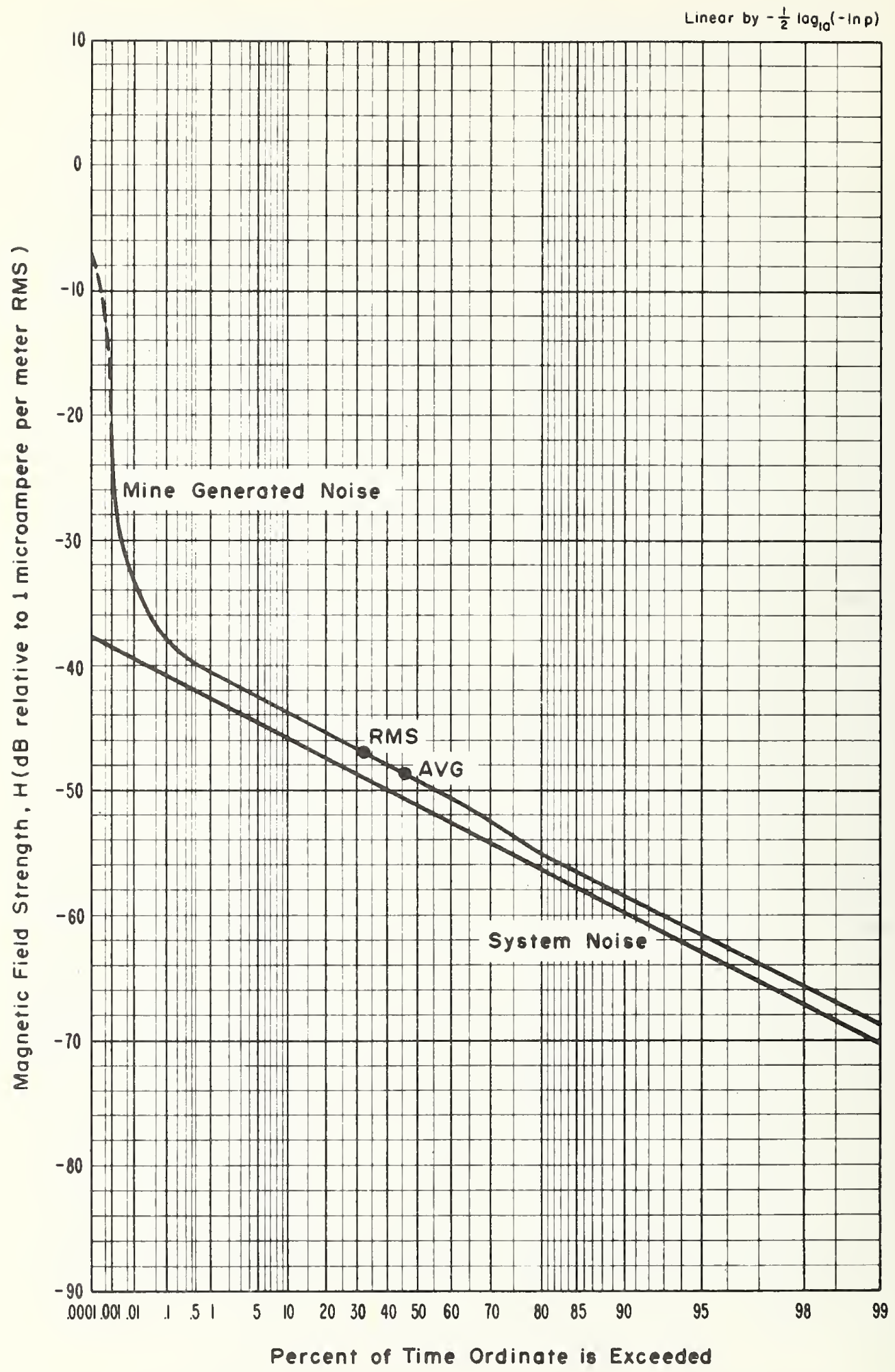

Figure 4-34 APD, $500 \mathrm{kHz}$, vertical component, $1.2 \mathrm{kHz}$ predetection bandwldth, April 10, 1973, 1:00 p.m., McElroy Mine. 


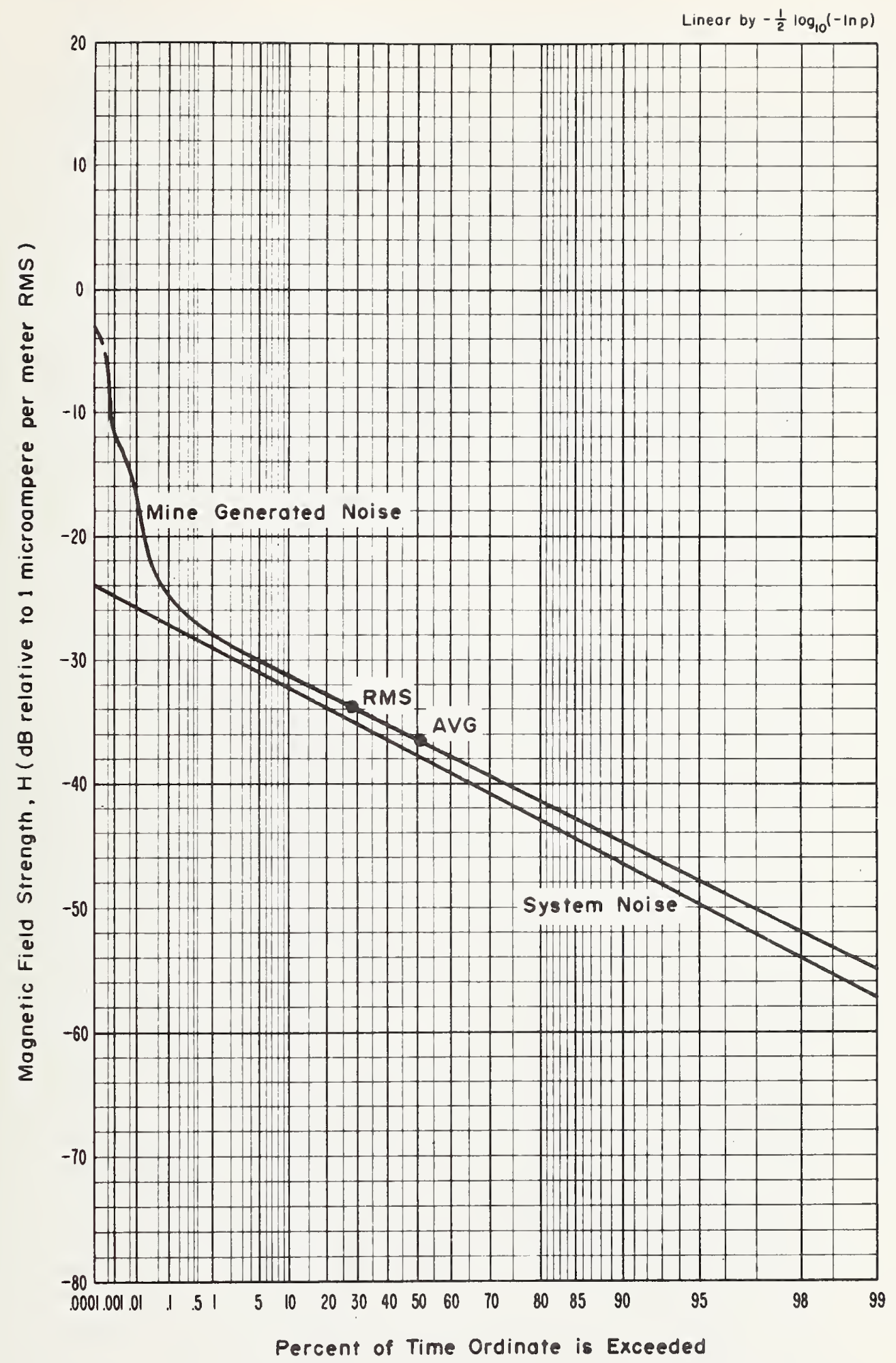

Figure 4-35 APD, $1 \mathrm{MHz}$, vertical component, $1.2 \mathrm{kHz}$ predetection bandwidth, April 10,1973, 2:30 p.m., McElroy Mine. 


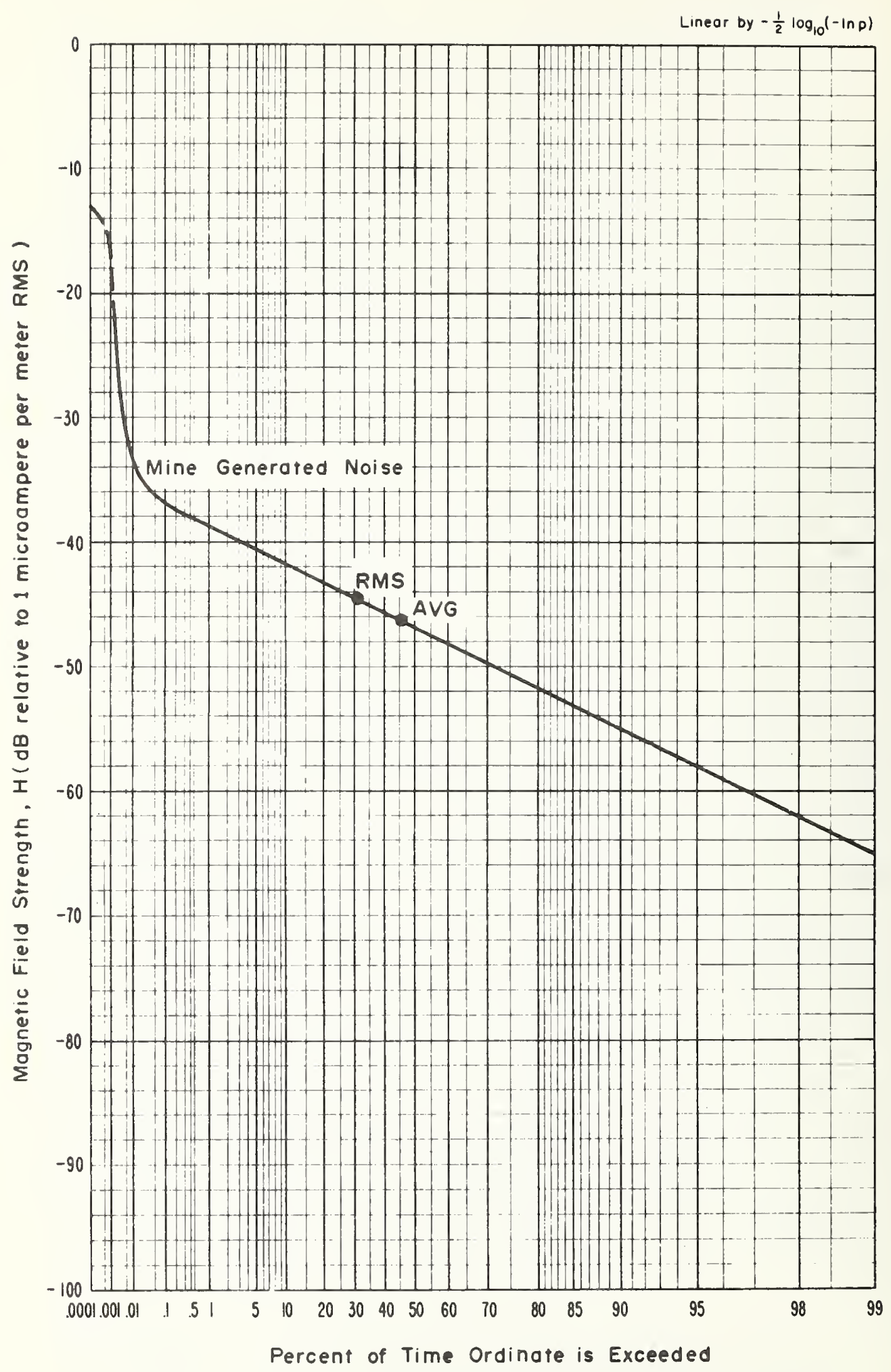

Figure 4-36 APD, $2 \mathrm{MHz}$, vertical component, $1.2 \mathrm{kHz}$ predetection bandwidth, Apri1 10, 1973, 5:15 p.m., McElroy Mine. 


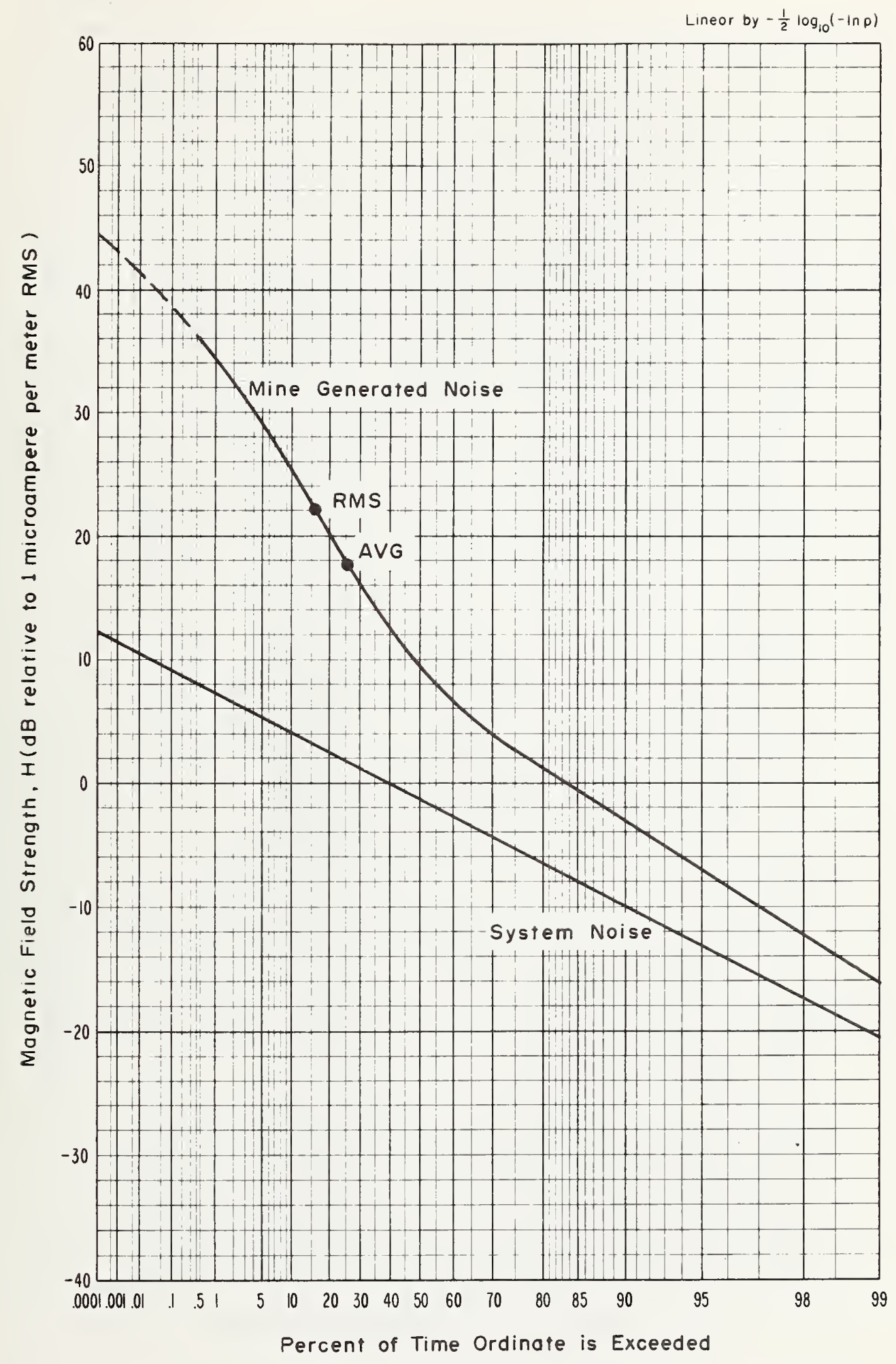

Figure 4-37 APD, $10 \mathrm{kHz}$, horizontal component (N-S), $1.0 \mathrm{kHz}$ predetection bandwidth, April 10,1973, 1:30 p.m., McE1roy Mine. 


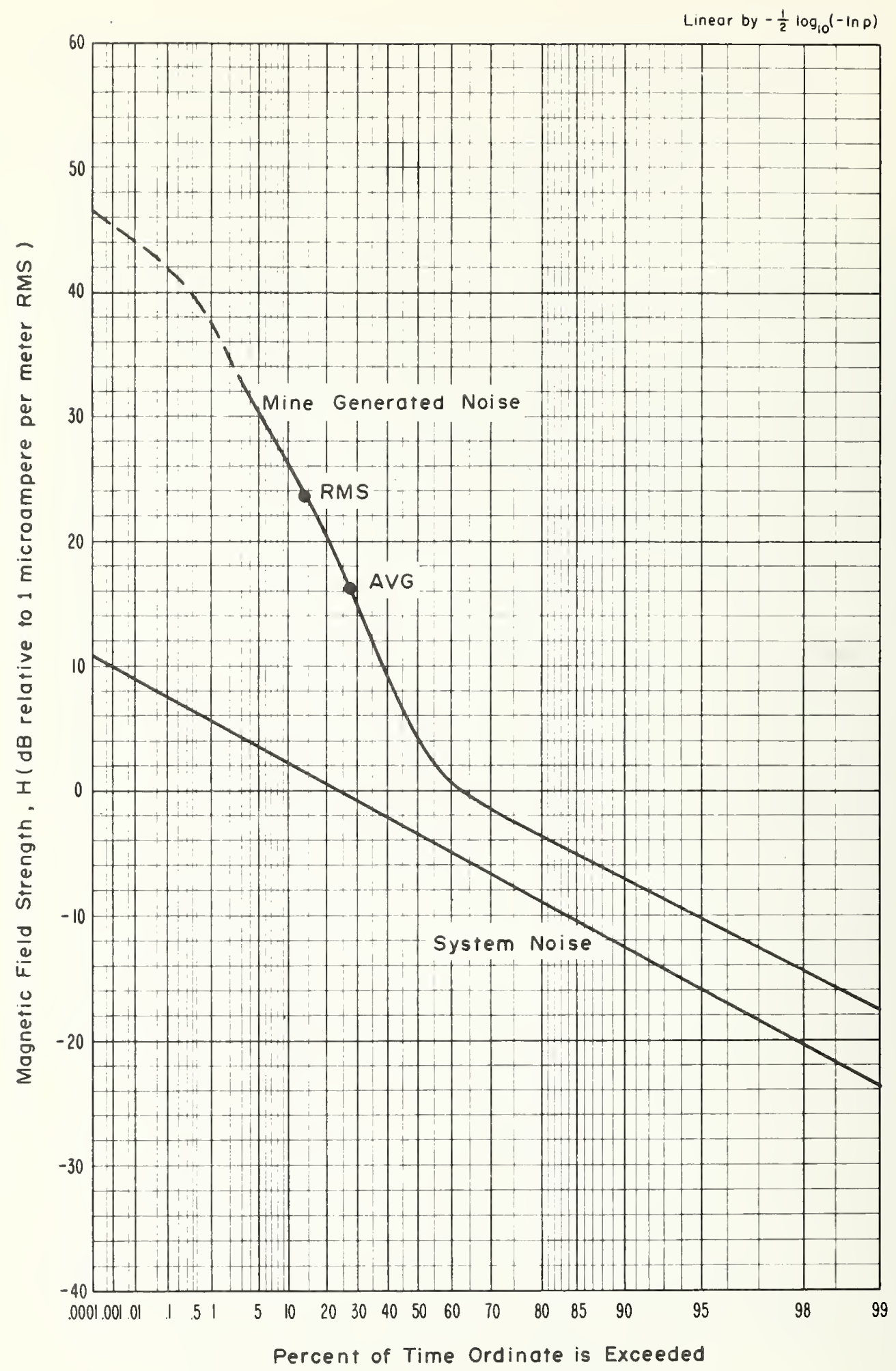

Figure 4-38 APD, $30 \mathrm{kHz}$, hortzontal component (N-S), $1.0 \mathrm{kHz}$ predetection bandwidth, April 10, 1973, 2:00 p.m., McElroy Mine. 


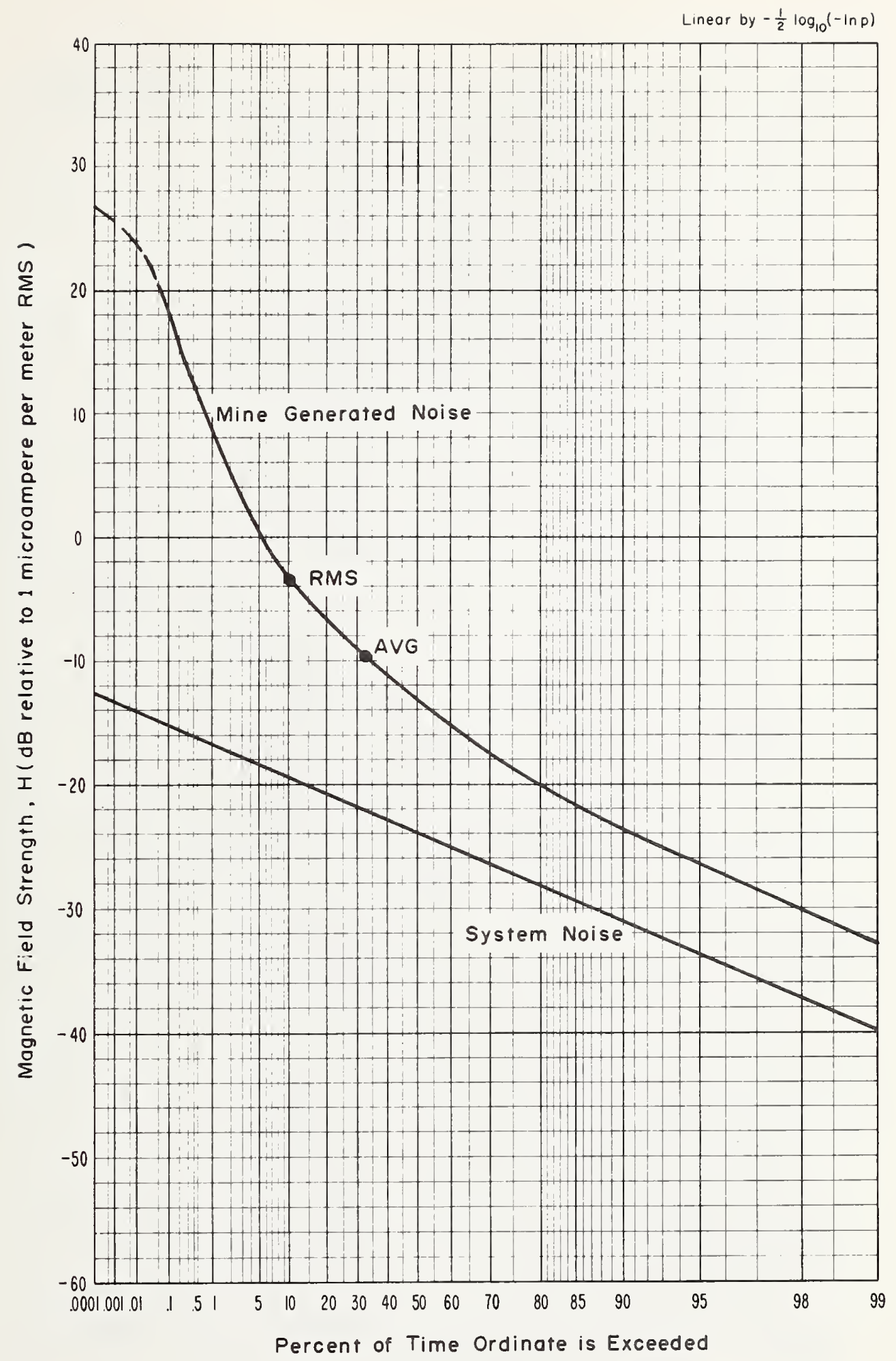

Figure 4-39 APD, $70 \mathrm{kHz}$, horizontal component (N-S), $1.0 \mathrm{kHz}$ predetection bandwidth, April 10, 1973, 6:00 p.m., McElroy Mine. 


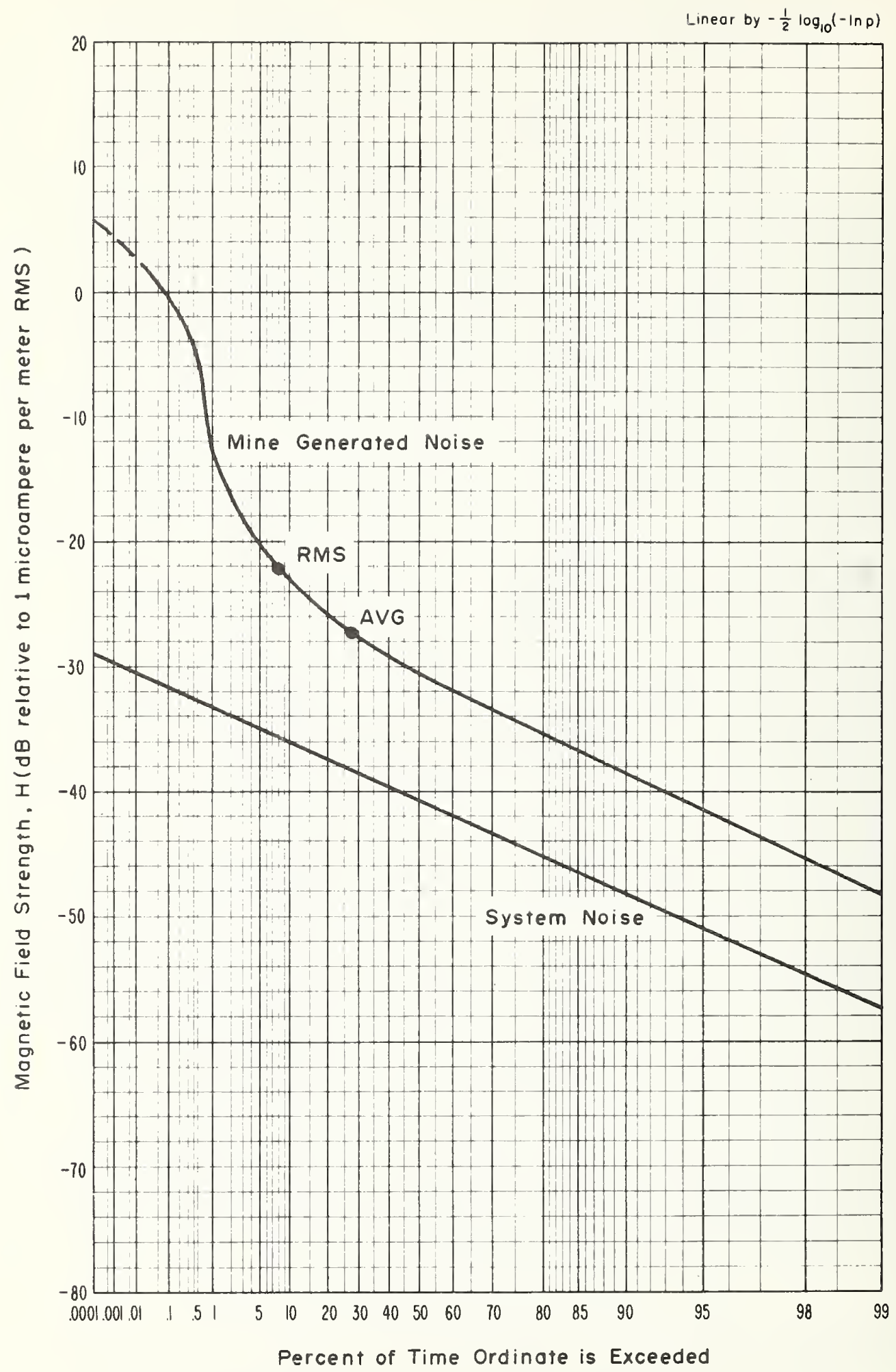

Figure 4-40 APD, $130 \mathrm{kHz}$, horizontal component (N-S), $1.0 \mathrm{kHz}$ predetection bandwidth, April 10, 1973, 6:45 p.m., McElroy Mine. 


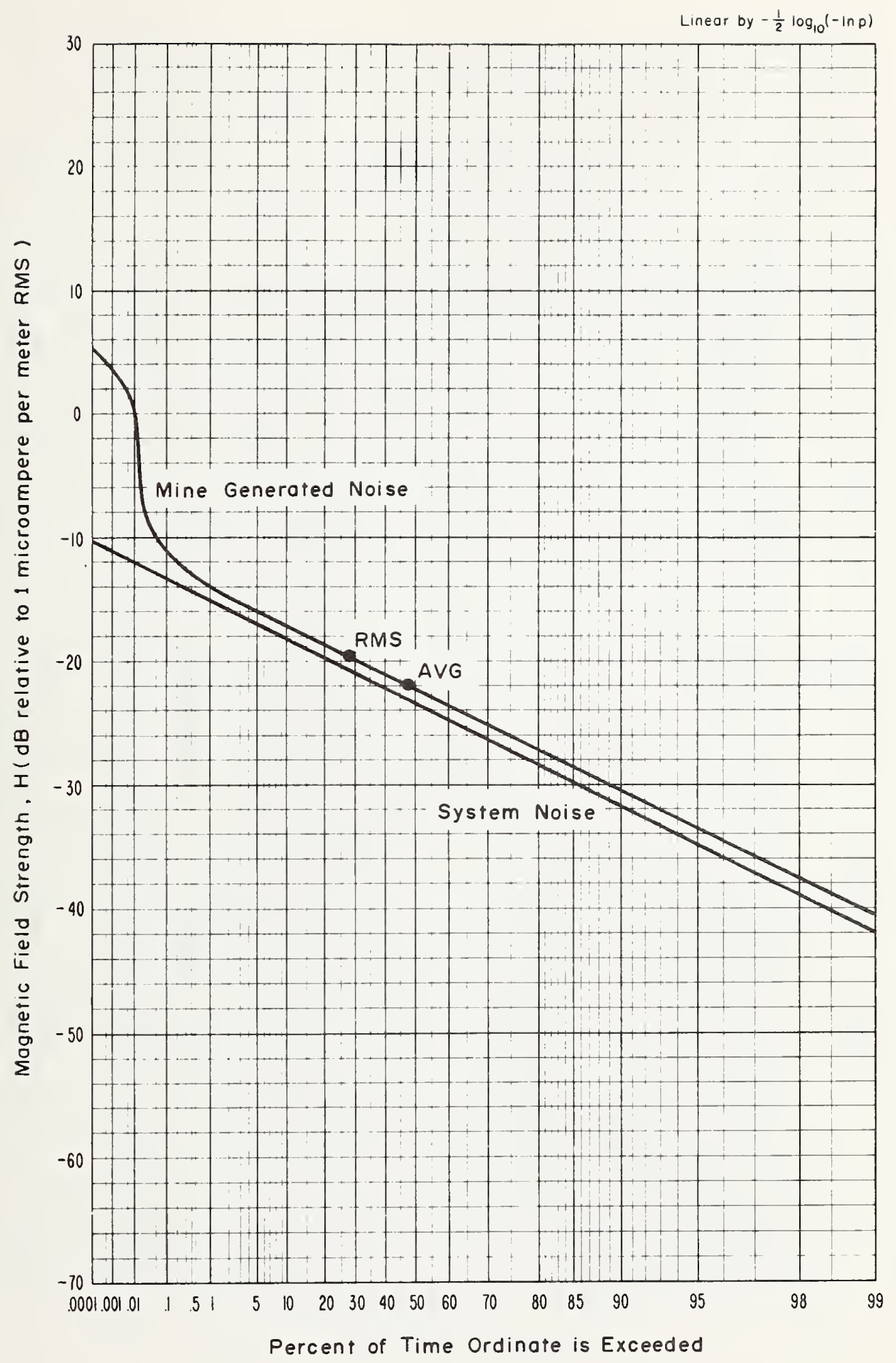

Figure 4-4! APD, $160 \mathrm{kHz}$, horizontal component (N-S), $1.0 \mathrm{kHz}$, predetection bandwidth, April 10,1973,6:00 p.m., McElroy Mine. 


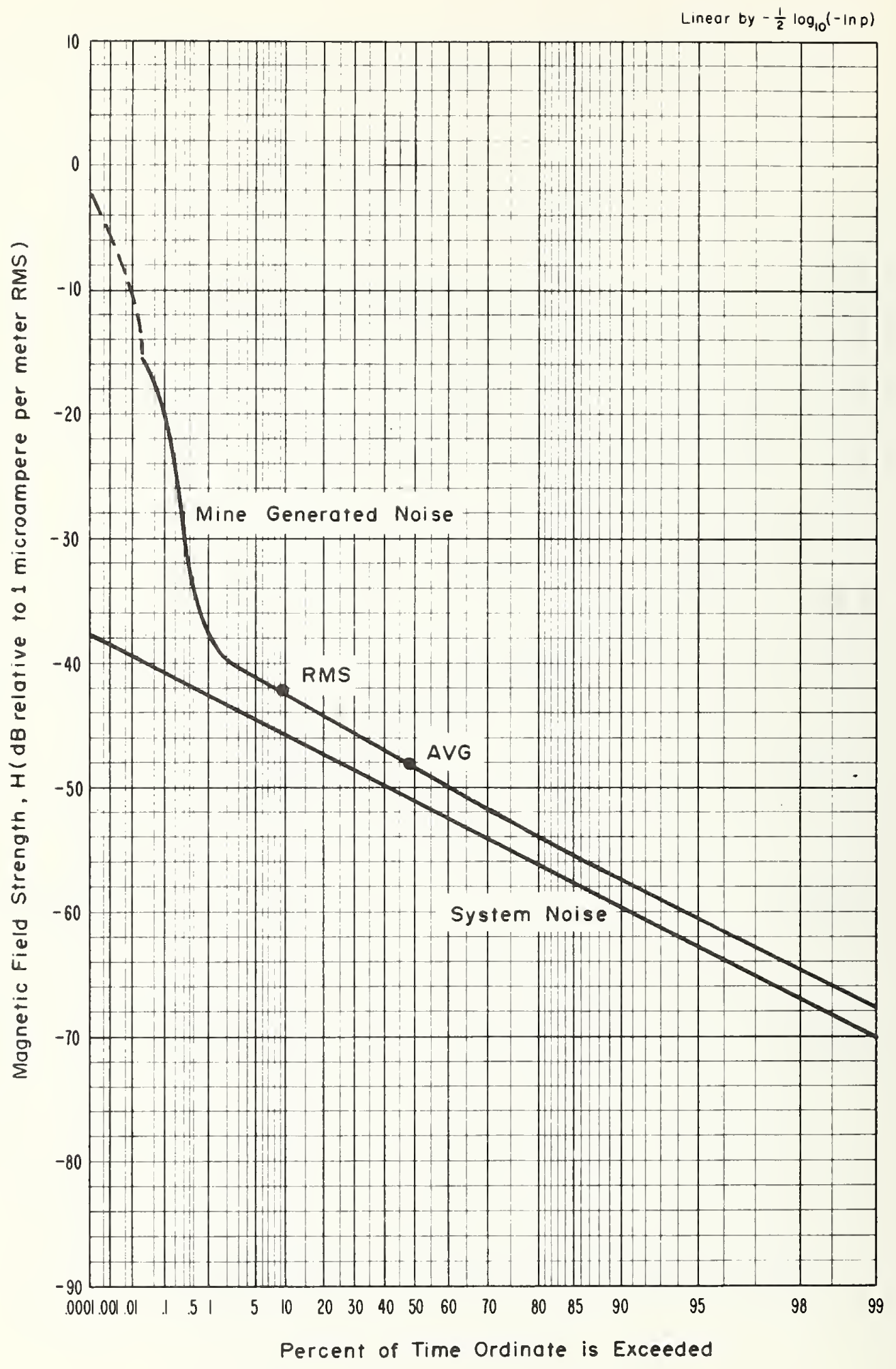

Figure 4-42 APD, $500 \mathrm{kHz}$, horizontal component(N-S), $1.2 \mathrm{kHz}$ predetection bandwldth, April 10, 1973, 1:30 p.m., McElroy Mine. 


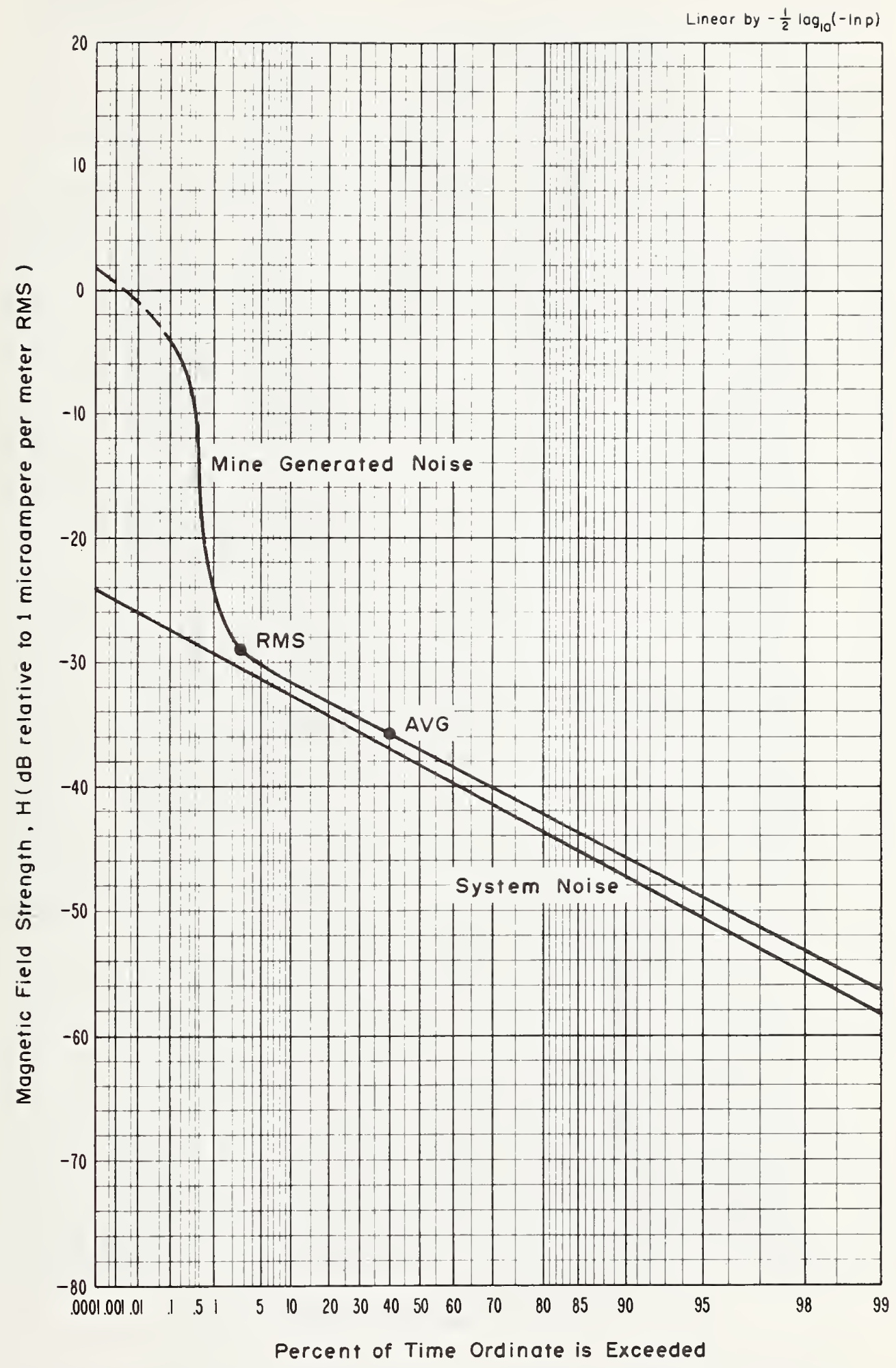

Figure 4-43 APD, I MHz, horizontal component (N-S), $1.2 \mathrm{kHz}$ predetection bandwidth, April 10, 1973, 2:00 p.m., McElroy Mine. 


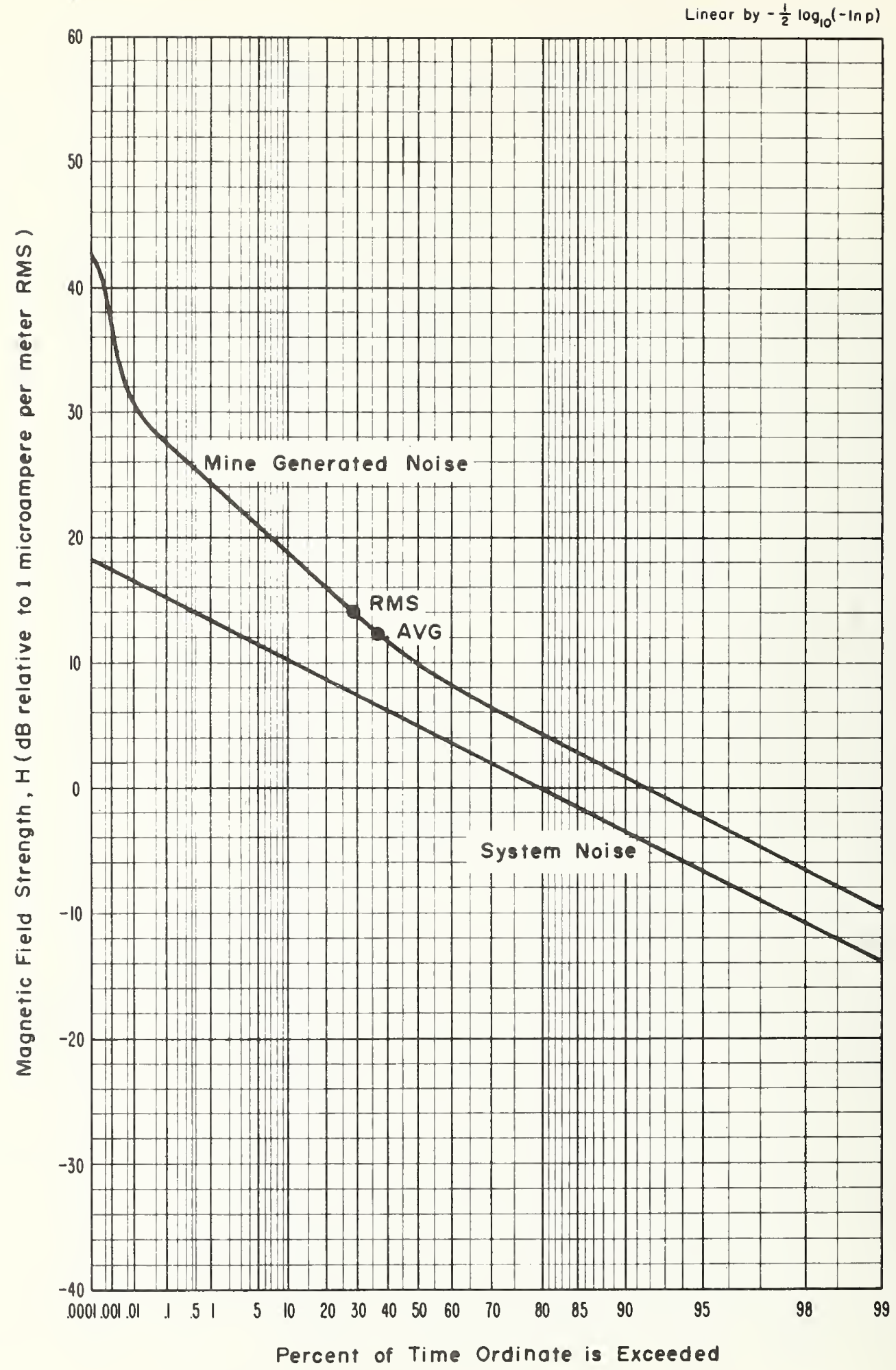

Figure 4-44 APD, $10 \mathrm{kHz}$, vertical component, $1.0 \mathrm{kHz}$ predetection bandwldth, April 10,1973, 4:00 p.m., quiet time measurements, McElroy Mine. 


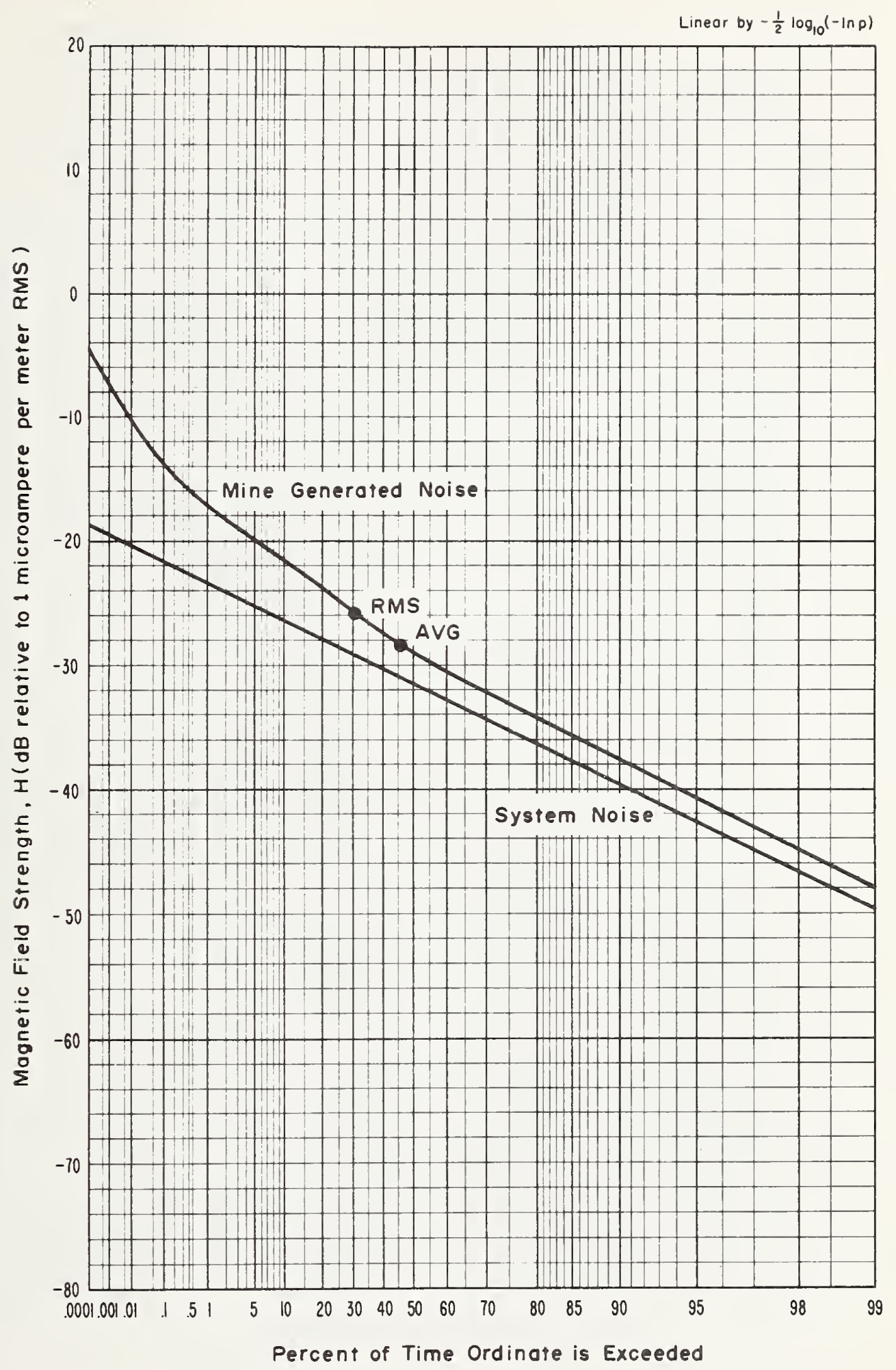

Figure 4-45 APD, $30 \mathrm{kHz}$, vertical component, $1.0 \mathrm{kHz}$ predetection bandwidth, April 10, 1973, 4:05 p.m., quiet time measurements, McElroy Mine. 


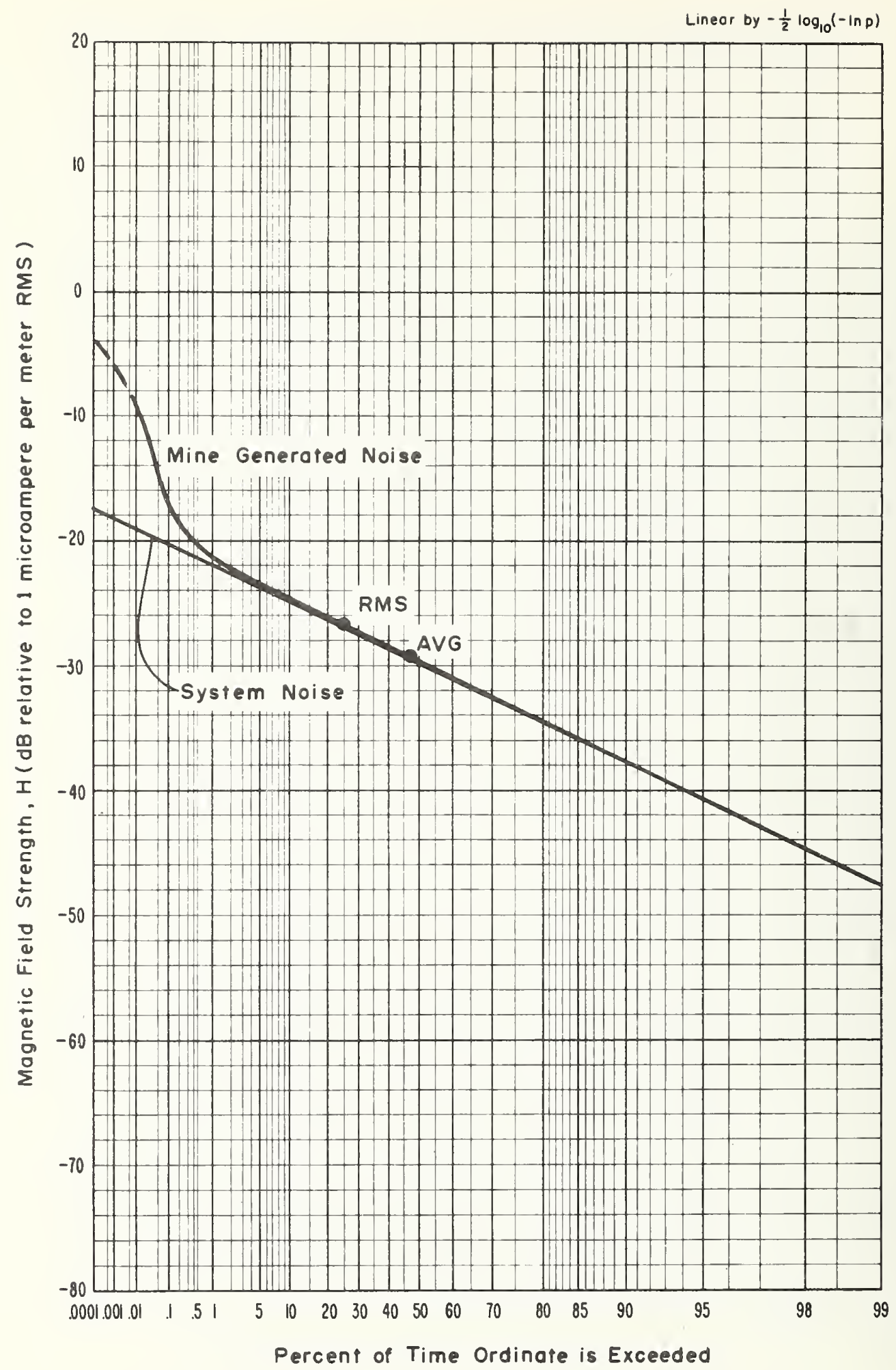

F1gure 4-46 APD, $70 \mathrm{kHz}$, vertical component, $1.0 \mathrm{kHz}$ predetection bandwldth, Apri1 10, 1973, 4:15 p.m., quiet t1me measurements, McEl roy Mine. 


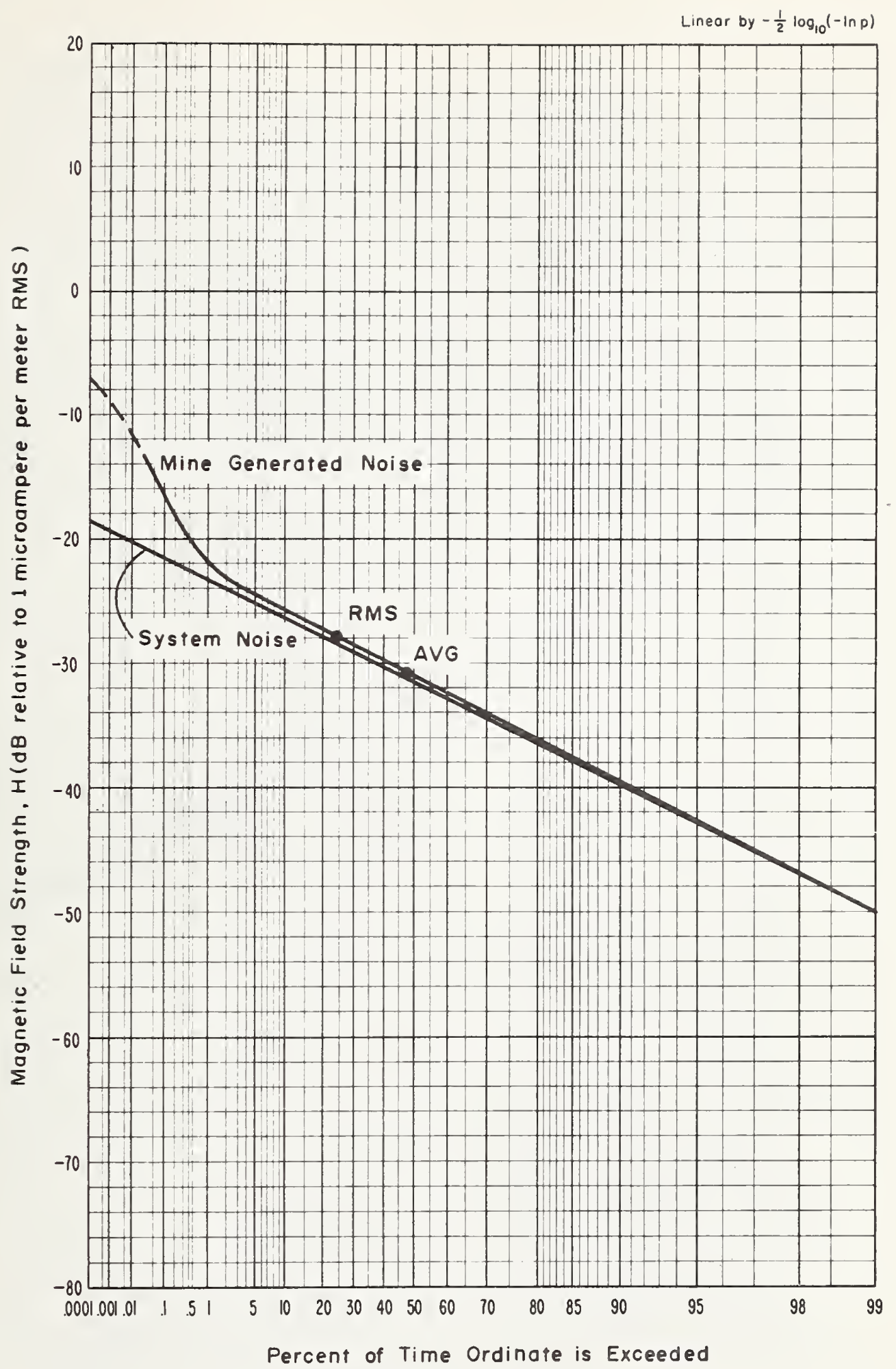

Figure 4-47 APD, $130 \mathrm{kHz}$, vertical component, $1.0 \mathrm{kHz}$ predetection bandwidth, April 10, 1973, 4:20 p.m., quiet time measurements, McElroy Mine. 


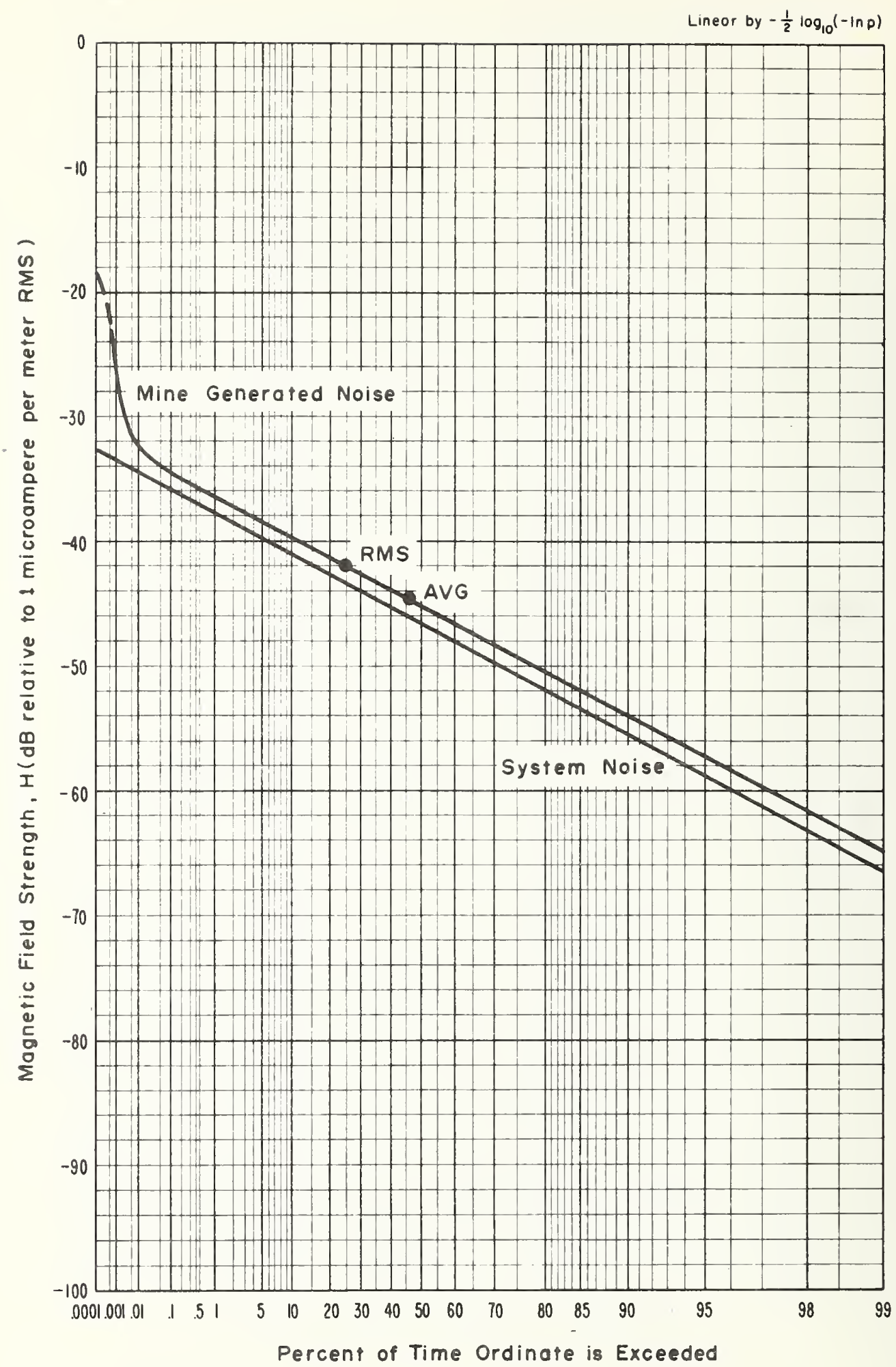

Figure 4-48 APD, $1 \mathrm{MHz}$, vertical component, $1.2 \mathrm{kHz}$ predetection bandwidth, April 10, 1973, 4:05 p.m., quiet time measurements, McElroy Mine. 


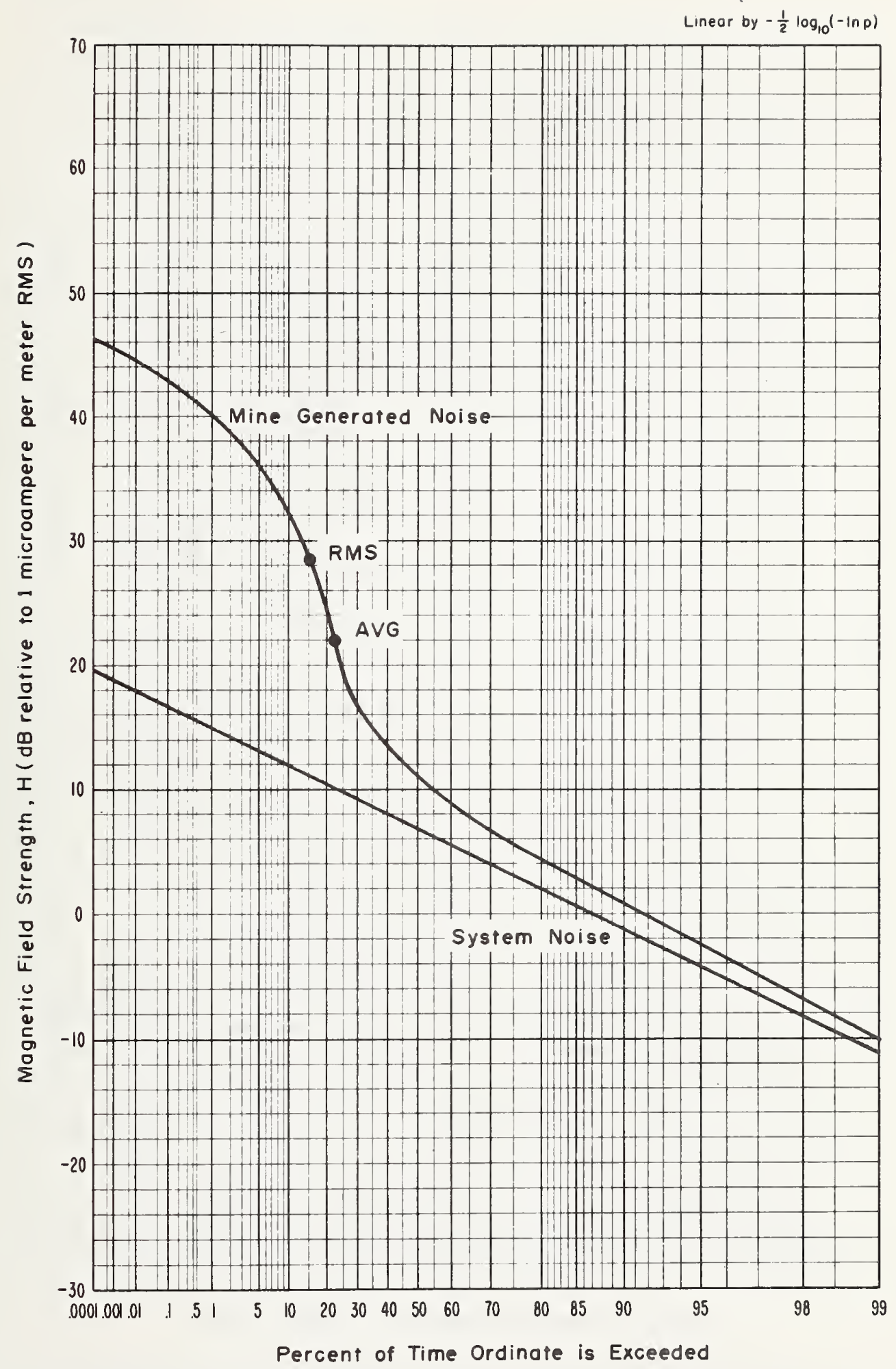

Figure 4-49 APD, $10 \mathrm{kHz}$, vertical component, $1.0 \mathrm{kHz}$ predetection bandwidth, Apr11 12, 1973, 11:50 a.m., McElroy Mine. 


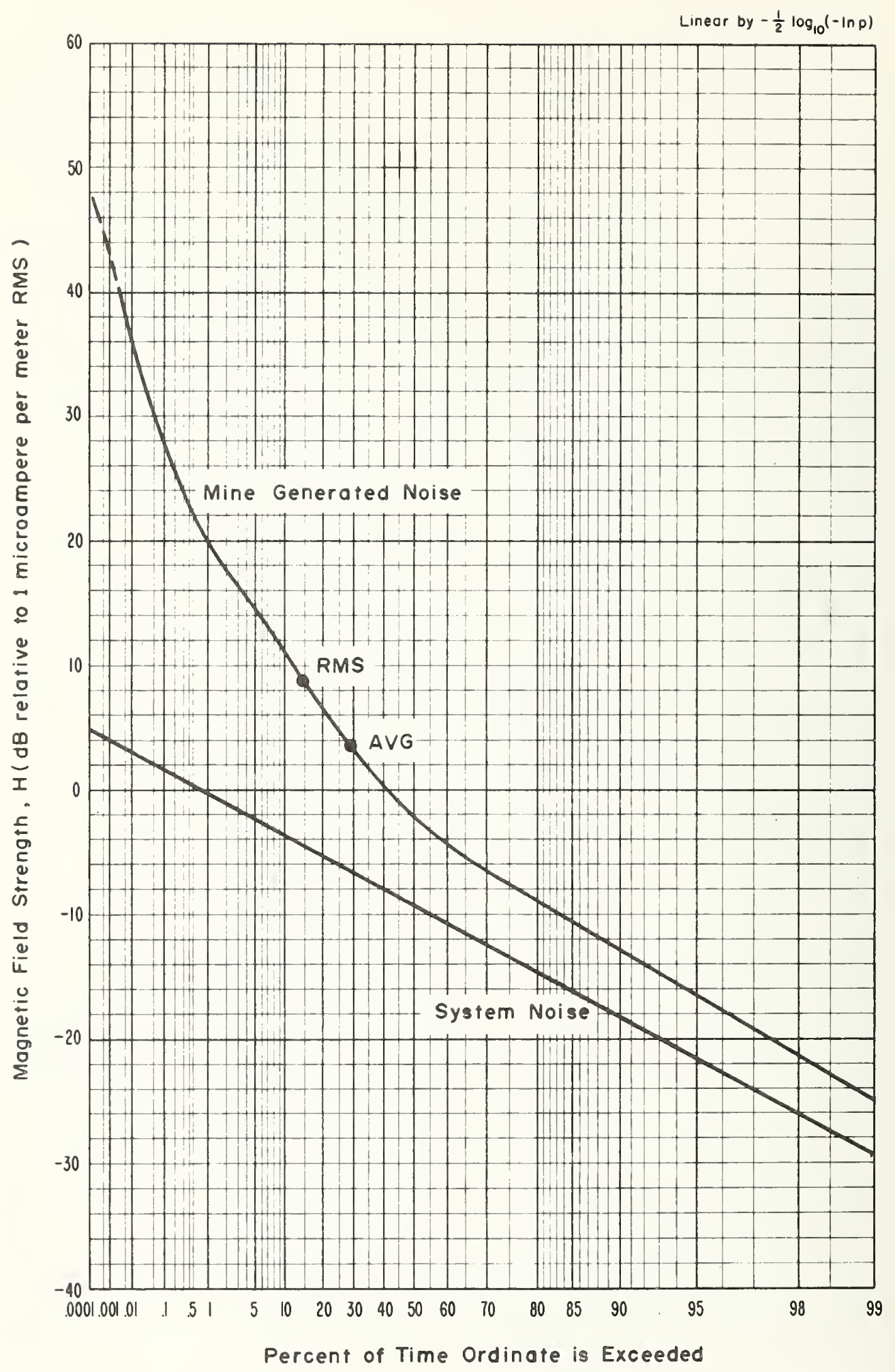

Figure 4-50 APD, $30 \mathrm{kHz}$, vertical component, $1.0 \mathrm{kHz}$ predetection bandwidth, April 12, 1973, 12:25 p.m., McElroy Mine. 


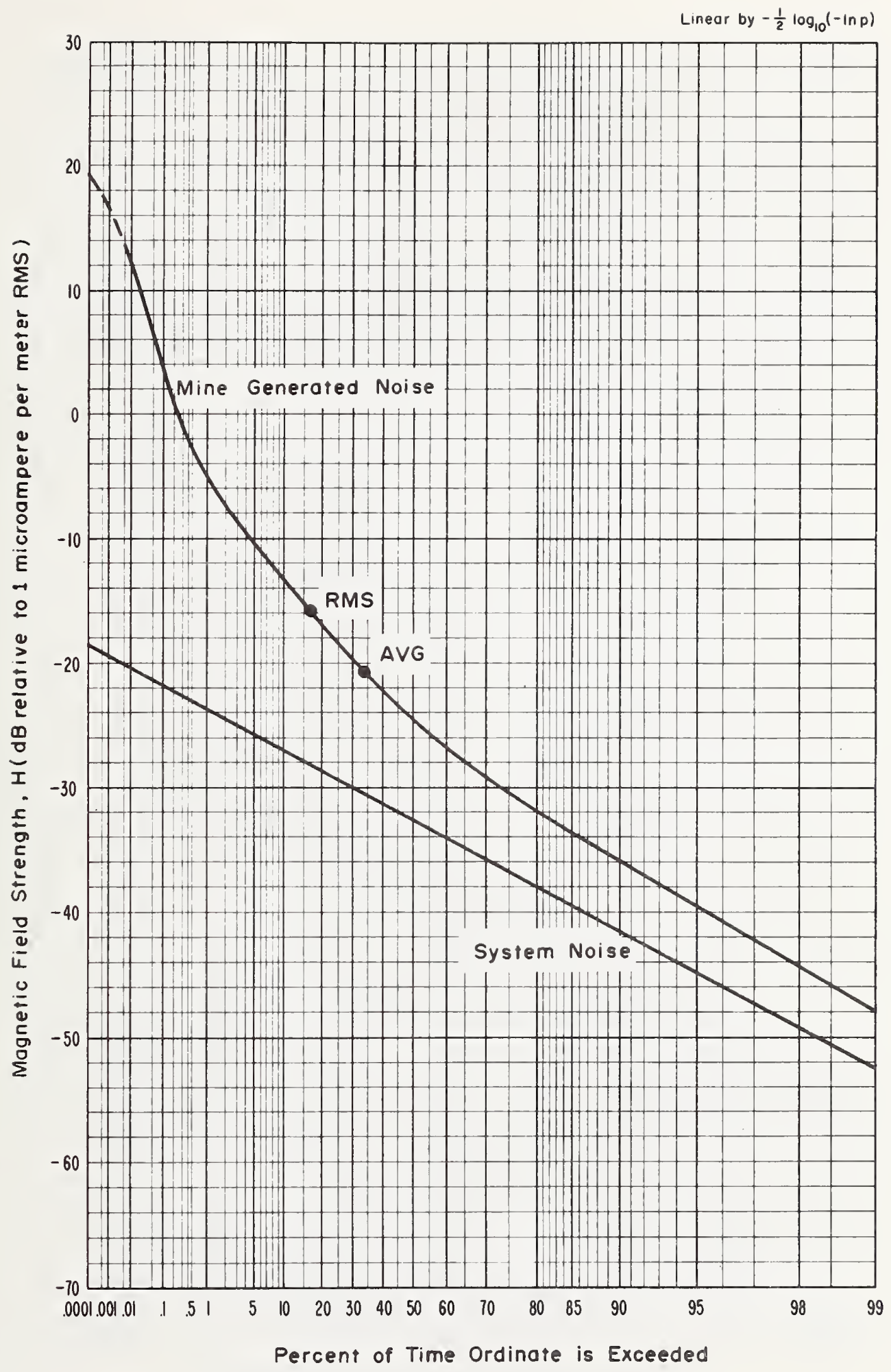

Figure 4-51 APD, $70 \mathrm{kHz}$, vertical component, $1.0 \mathrm{kHz}$ predetection bandwidth, April 12, 1973, 12:50 p.m., McElroy Mine. 


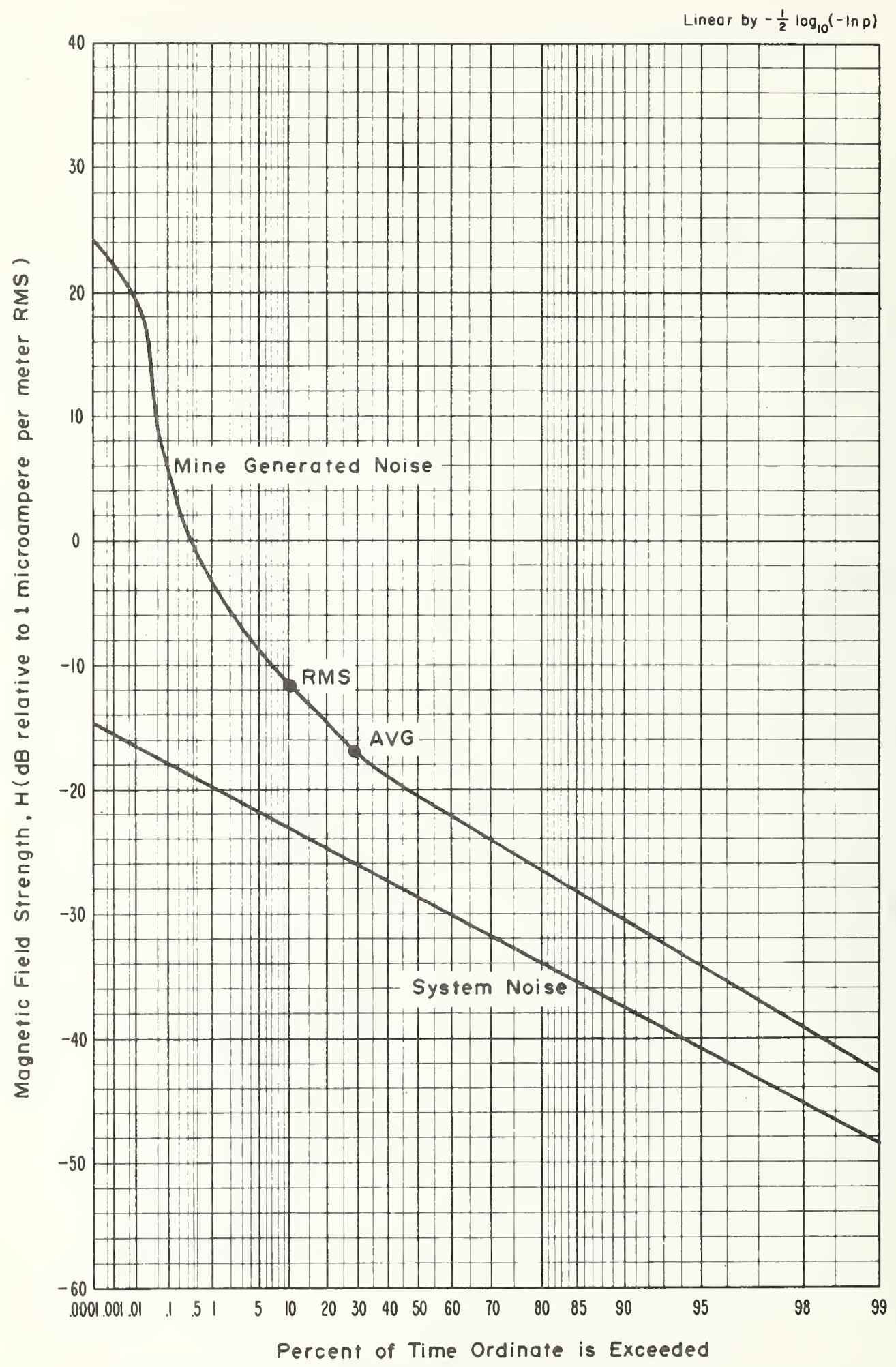

Figure 4-52 APD, $130 \mathrm{kHz}$, vertical component, $1.0 \mathrm{kHz}$ predetection bandw1dth, April 12, 1973, 1:30 p.m., McElroy Mine. 


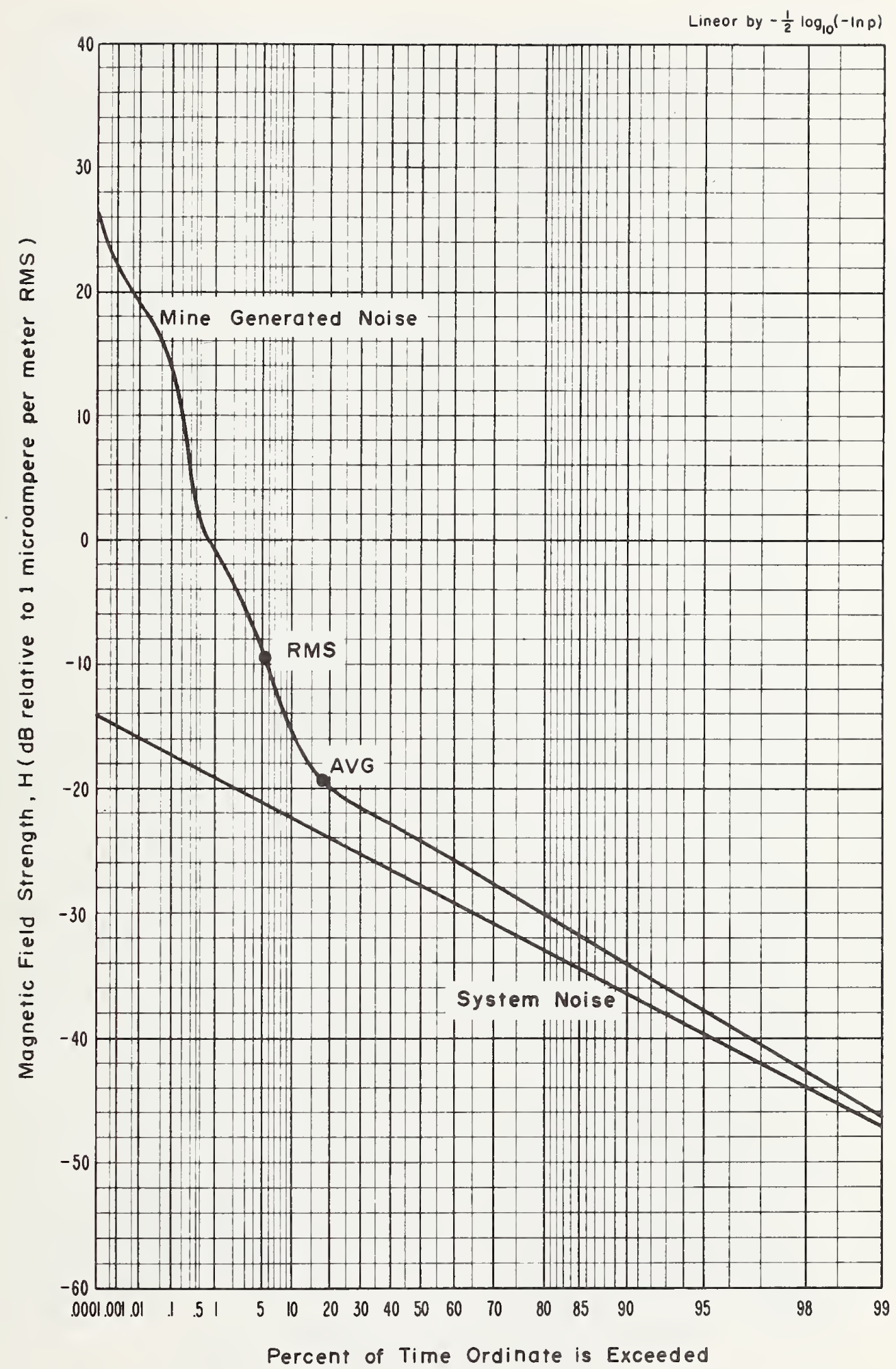

Figure 4-53 APD, $160 \mathrm{kHz}$, vertical component, $1.0 \mathrm{kHz}$ predetection bandwidth, April 12, 1973, 2:10 p.m., McElroy Mine. 


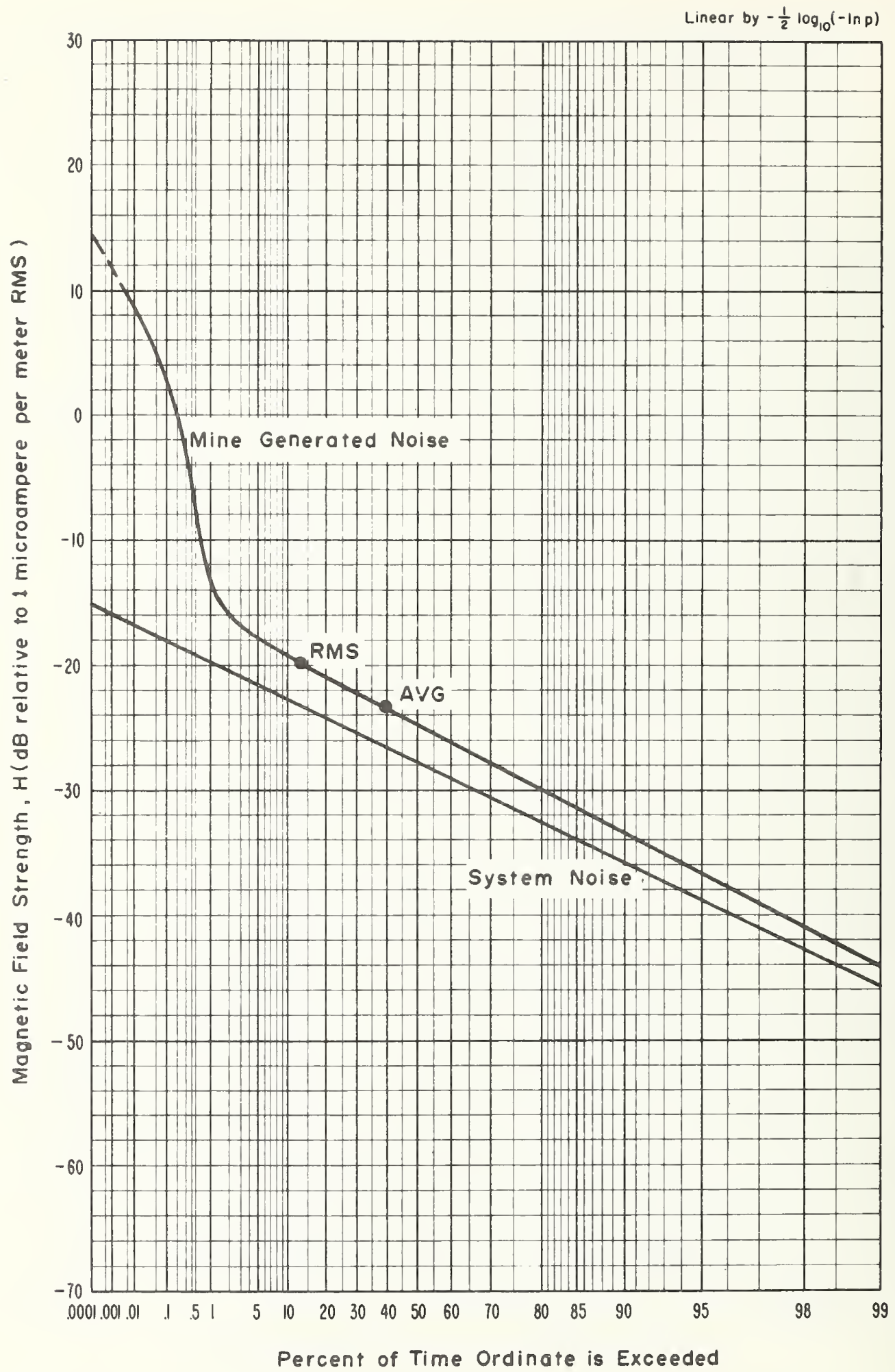

Figure 4-54 APD, $500 \mathrm{kHz}$, vertical component, $1.2 \mathrm{kHz}$ predetection bandwidth, April 12, 1973, 11:50 a.m., McElroy Mine. 


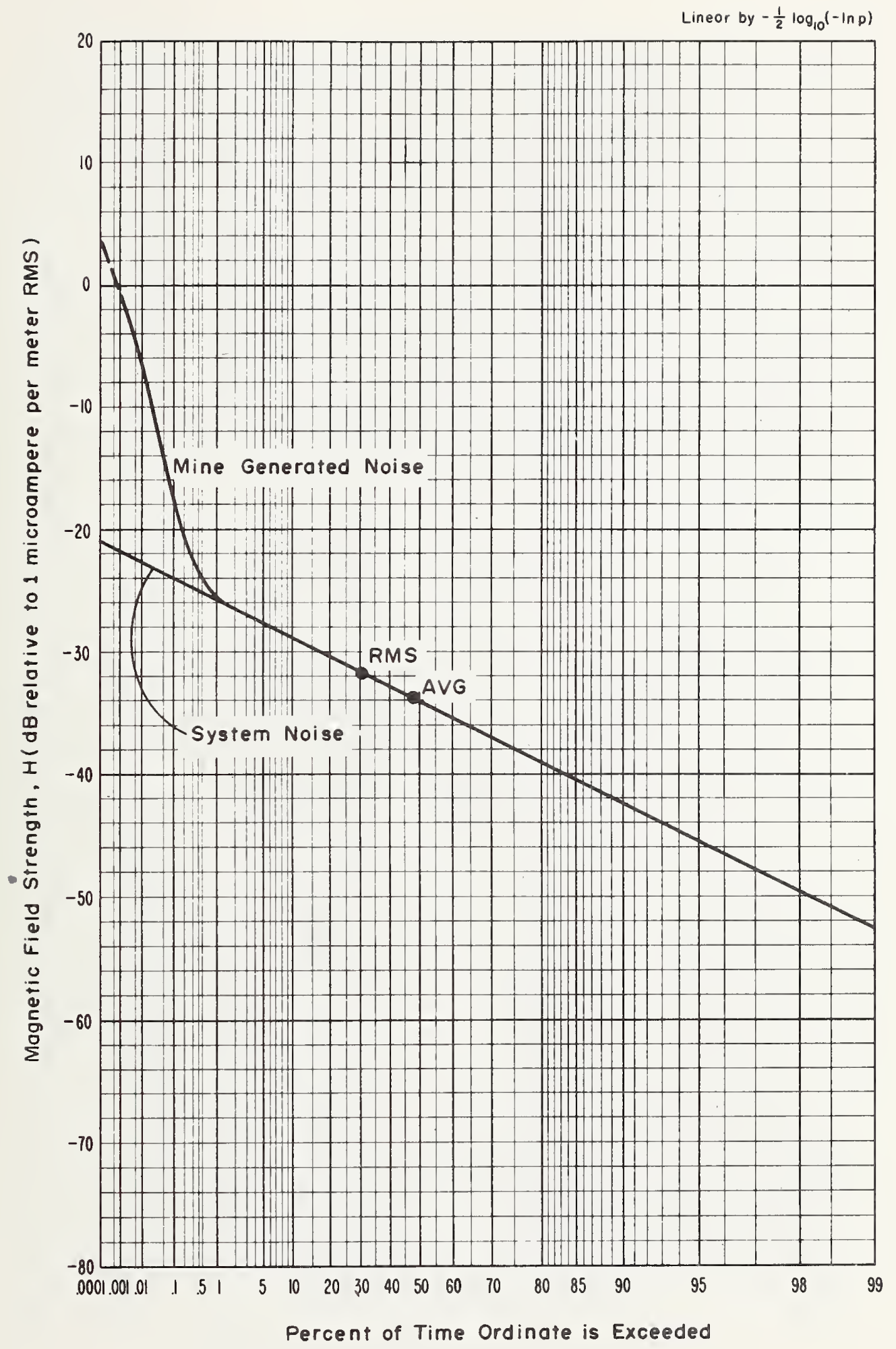

Figure 4-55 APD, $1 \mathrm{MHz}$, vertical component, $1.2 \mathrm{kHz}$ predetection bandwidth, Apr 11 12, 1973, 12:25 p.m., McElroy Mine. 


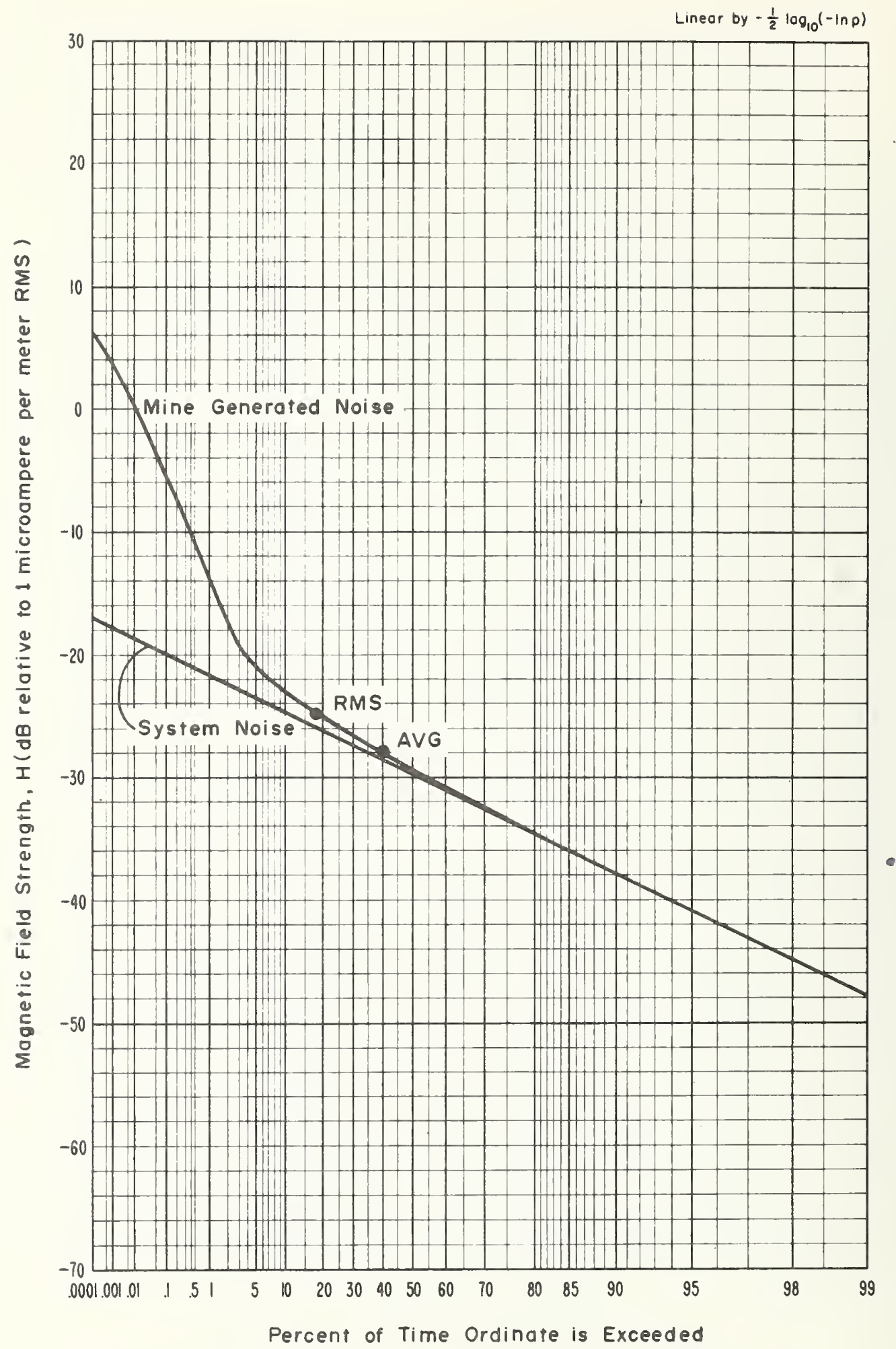

Figure 4-56 APD, $2 \mathrm{MHz}$, vertical component, $1.2 \mathrm{kHz}$ predetection bandwidth, Apr 11 12, 1973, 12:50 p.m., McElroy Mine. 


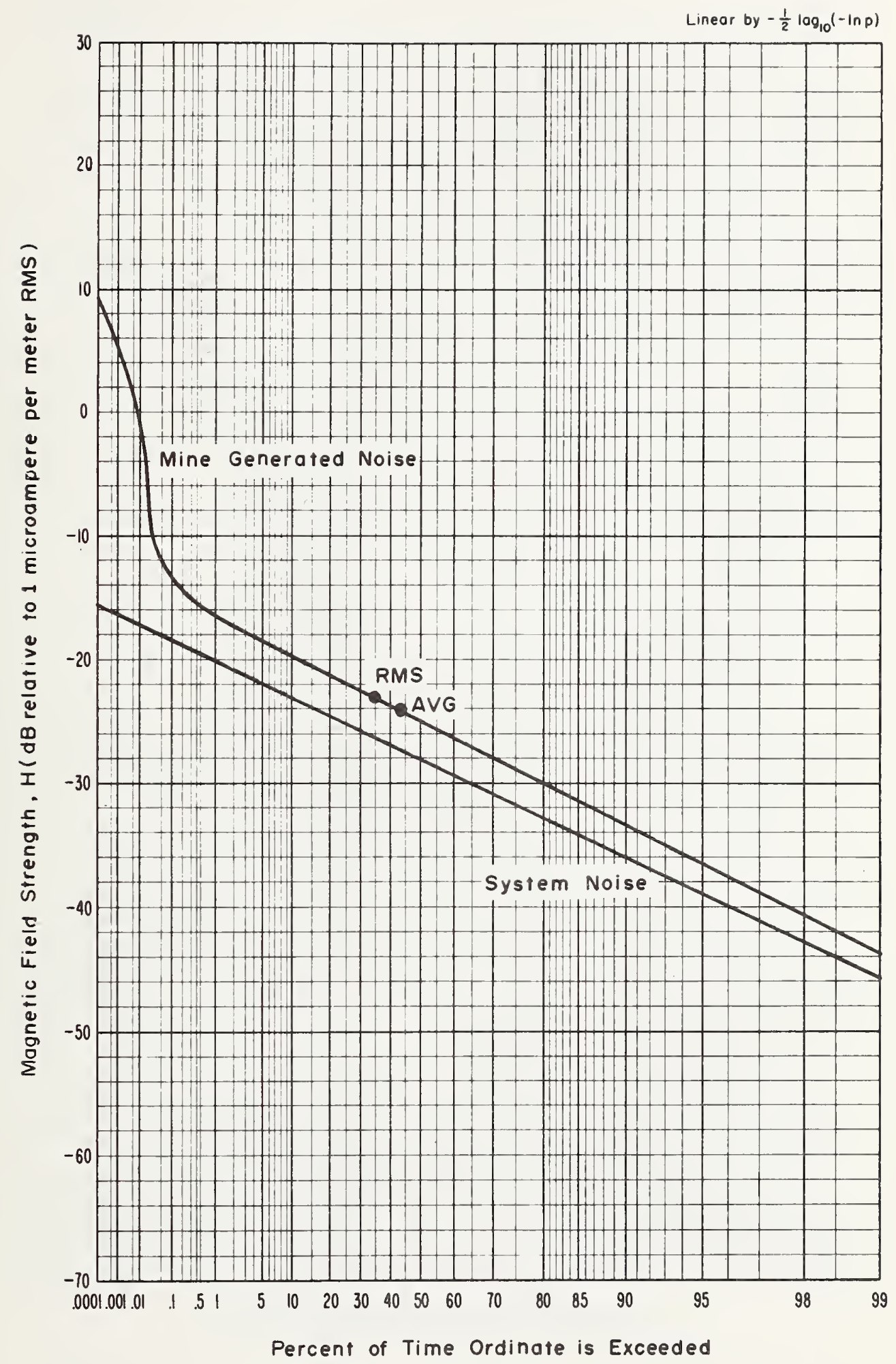

Figure 4-57 APD, $6 \mathrm{MHz}$, vertical component, $1.2 \mathrm{kHz}$ predetection bandwldth, April 12, 1973, 1:30 p.m., McElroy Mine. 


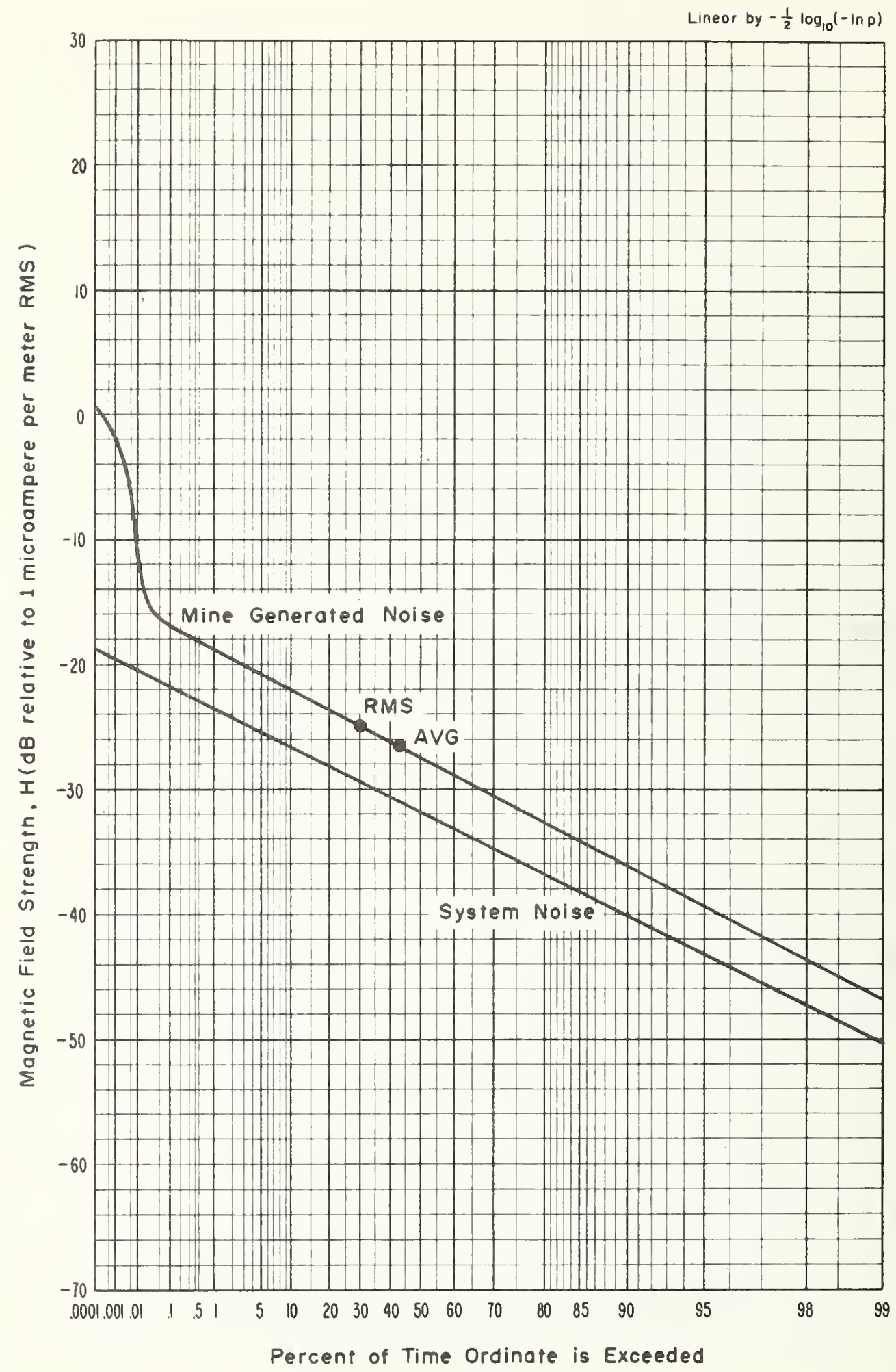

Figure 4-58 APD, $14 \mathrm{MHz}$, vertical component, $1.2 \mathrm{kHz}$ predetection bandwidth, April 12, 1973, 2:10 p.m., McElroy Mine. 


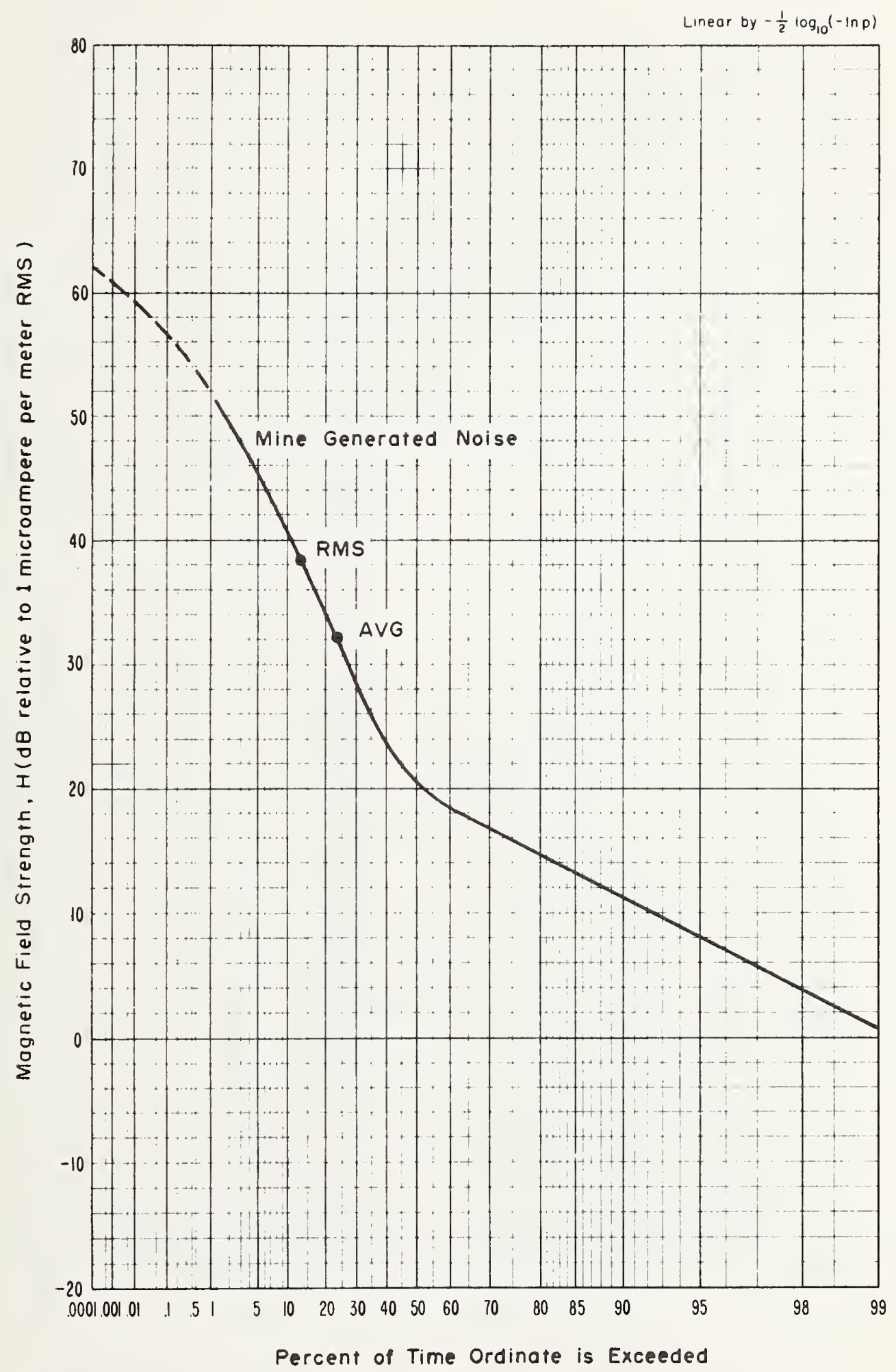

Figure 4-59 APD, $10 \mathrm{kHz}$, vertical component, $1.0 \mathrm{kHz}$ predetection bandwidth, April 12, 1973, 11:30 a.m., McElroy Mine. 


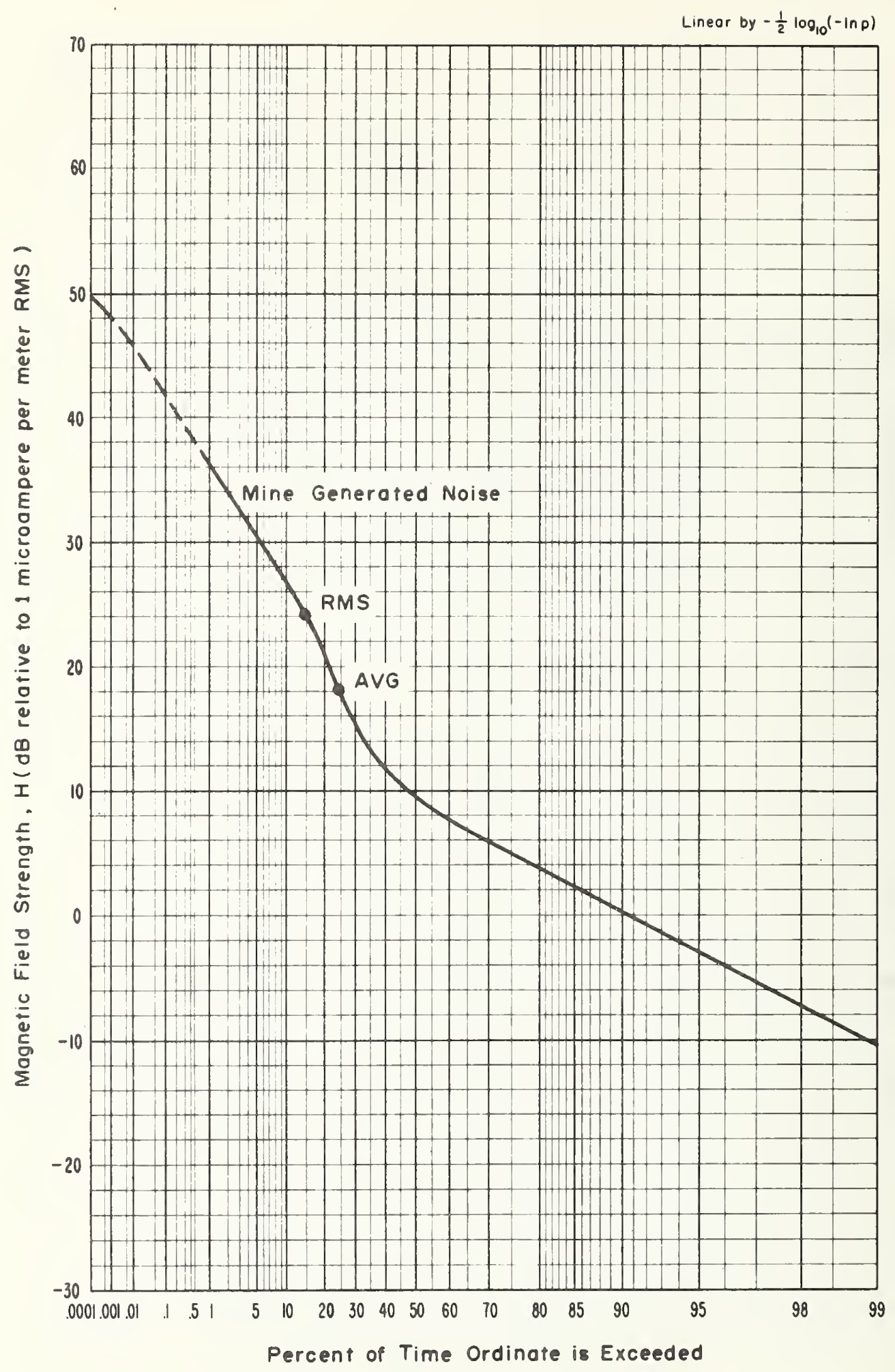

Figure 4-60 APD, $30 \mathrm{kHz}$, vertical component, $1.0 \mathrm{kHz}$ predetection bandwidth, April 12, 1973, 12:15 p.m., McElroy Mine. 


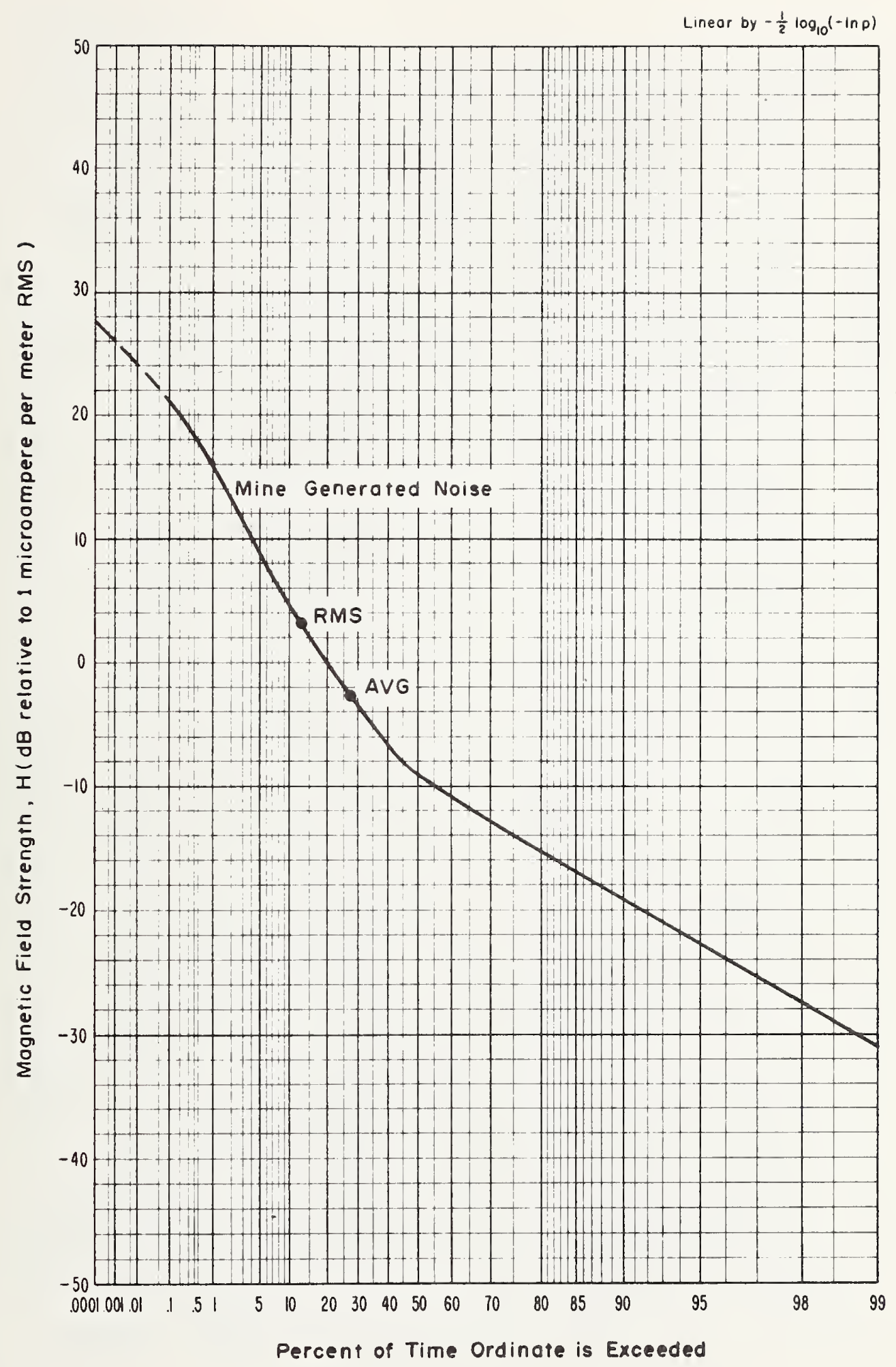

Figure 4-61 APD, $70 \mathrm{kHz}$, vertical component, $1.0 \mathrm{kHz}$ predetection bandwidth, April 12, 1973, 1:00 p.m., McElroy Mine. 


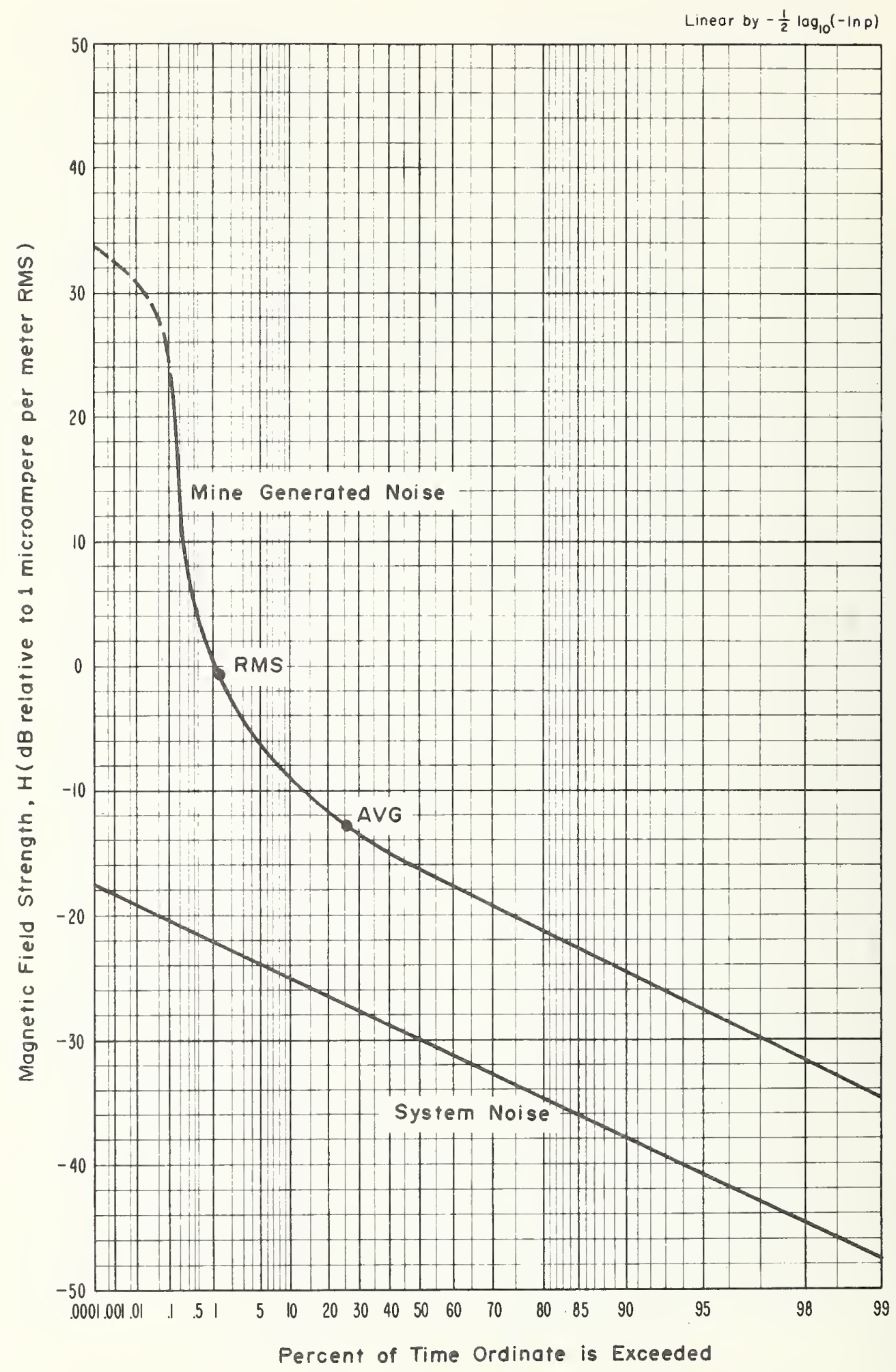

Figure 4-62 APD, $130 \mathrm{kHz}$, vertical component, $1.0 \mathrm{kHz}$ predetection bandwidth, Apr11 12, 1973, 1:30 p.m., McElroy Mine. 


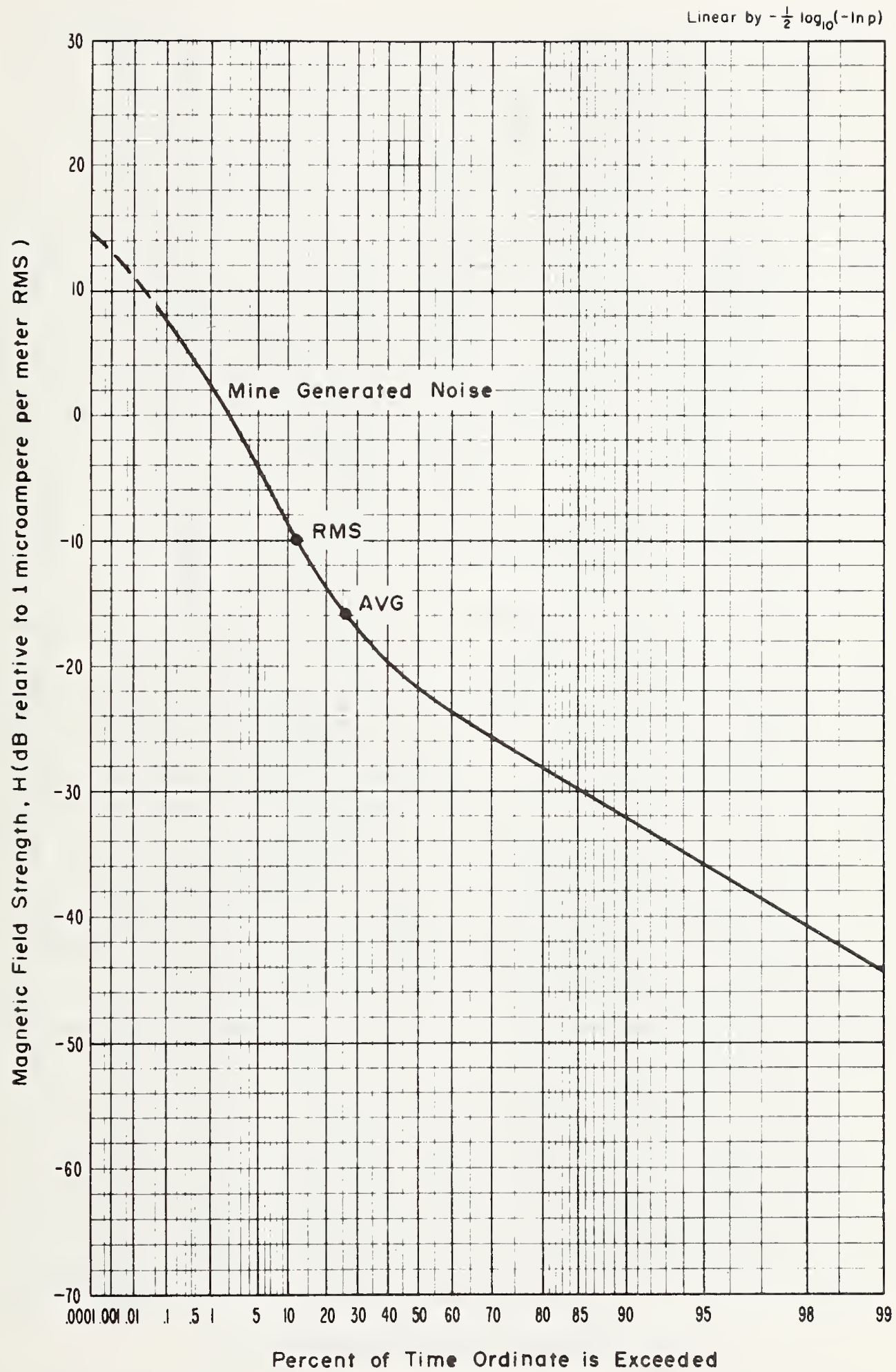

F1gure 4-63 APD, $160 \mathrm{kHz}$, vertical component, $1.0 \mathrm{kHz}$ predetection bandw1dth, Apr11 12, 1973, 2:15 p.m., :celroy Mine. 


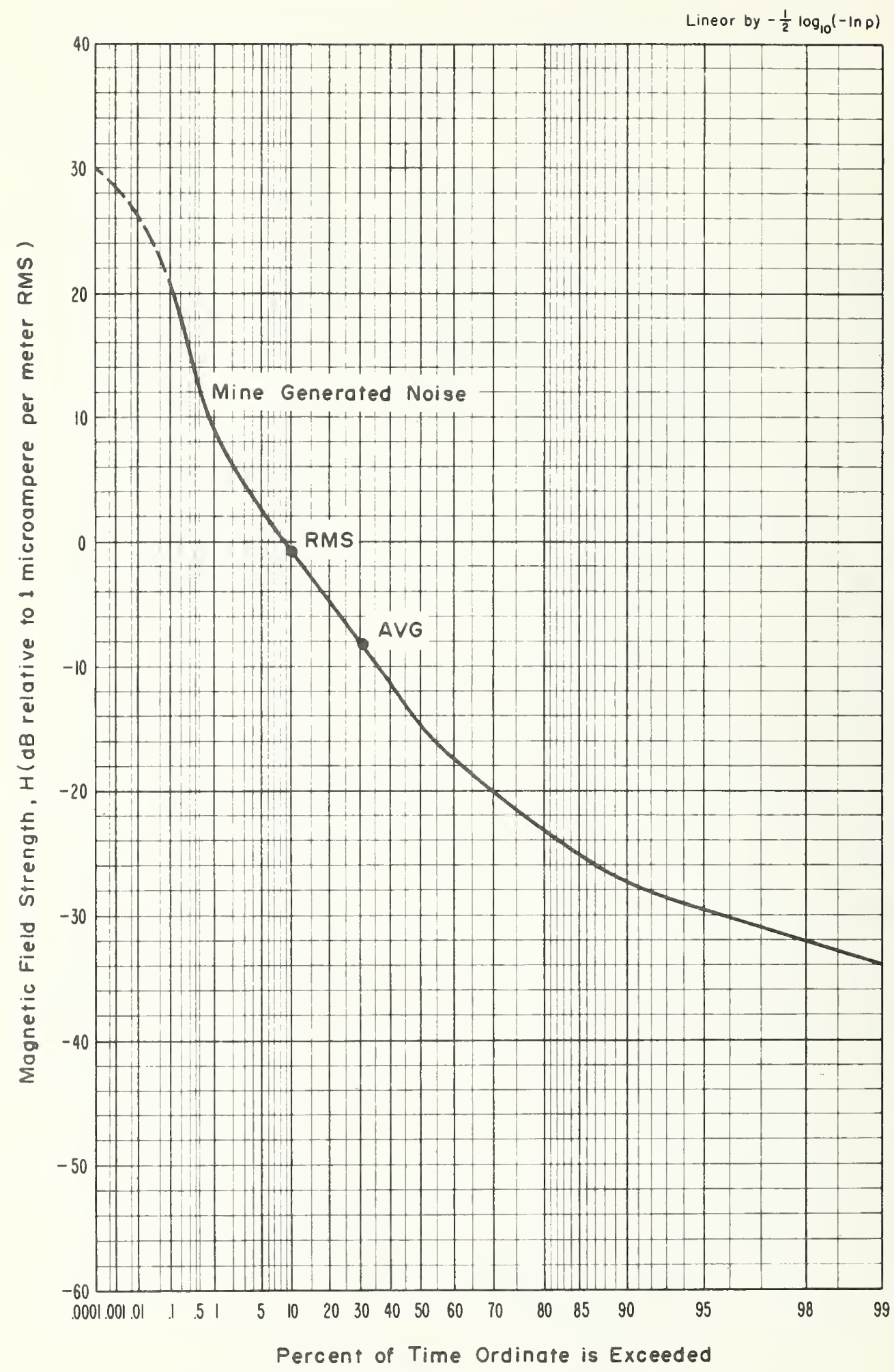

Figure 4-64 APD, $250 \mathrm{kHz}$, vertical component, $1.2 \mathrm{kHz}$ predetection bandwidth, Apr11 12, 1973, 11:30 p.m., McElroy Mine. 


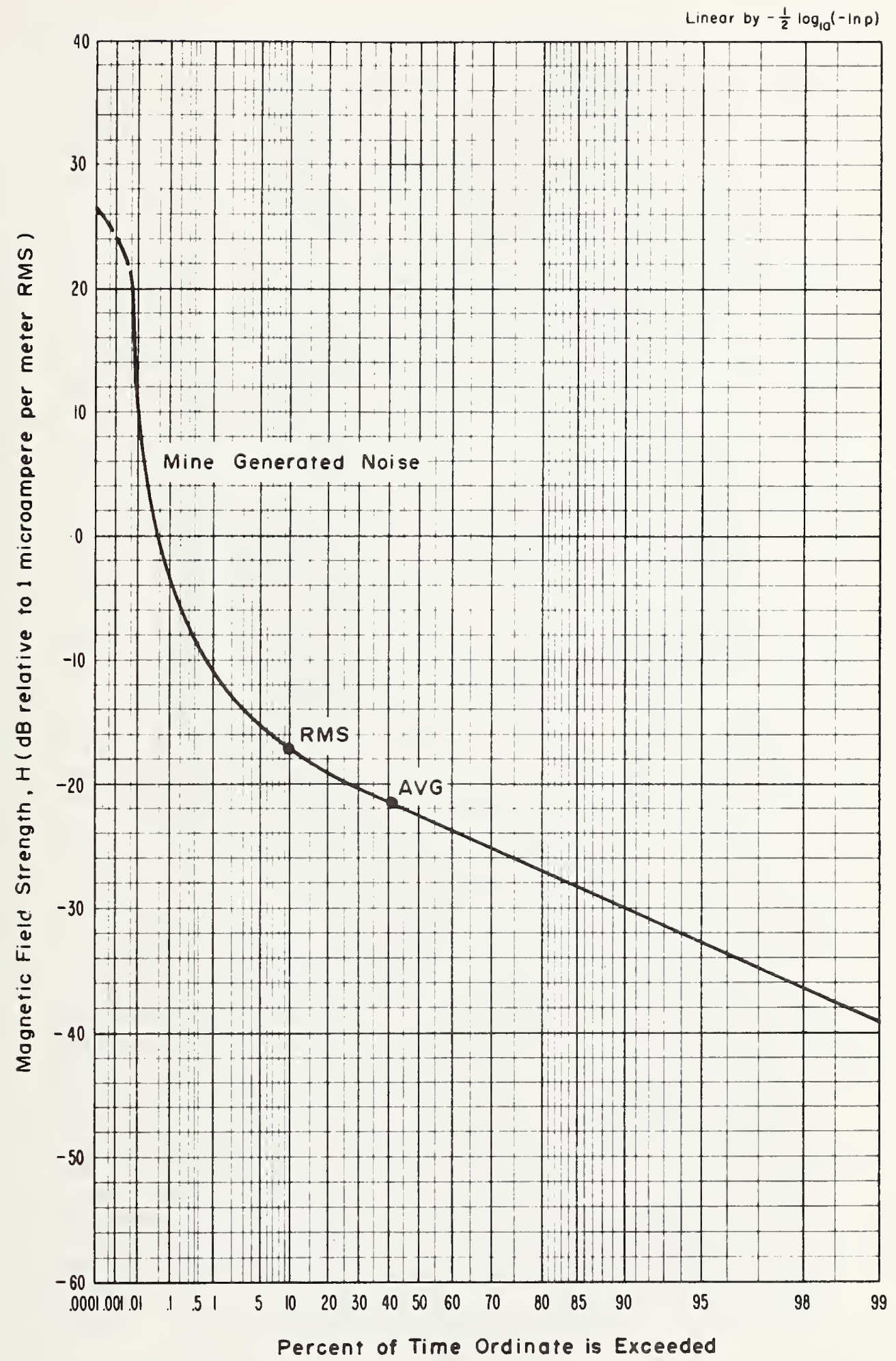

F1gure 4-65 APD, $500 \mathrm{kHz}$, vertical component, $1.2 \mathrm{kHz}$ predetection bandwidth, April 12, 1973, 12:15 p.m., McElroy Mine. 


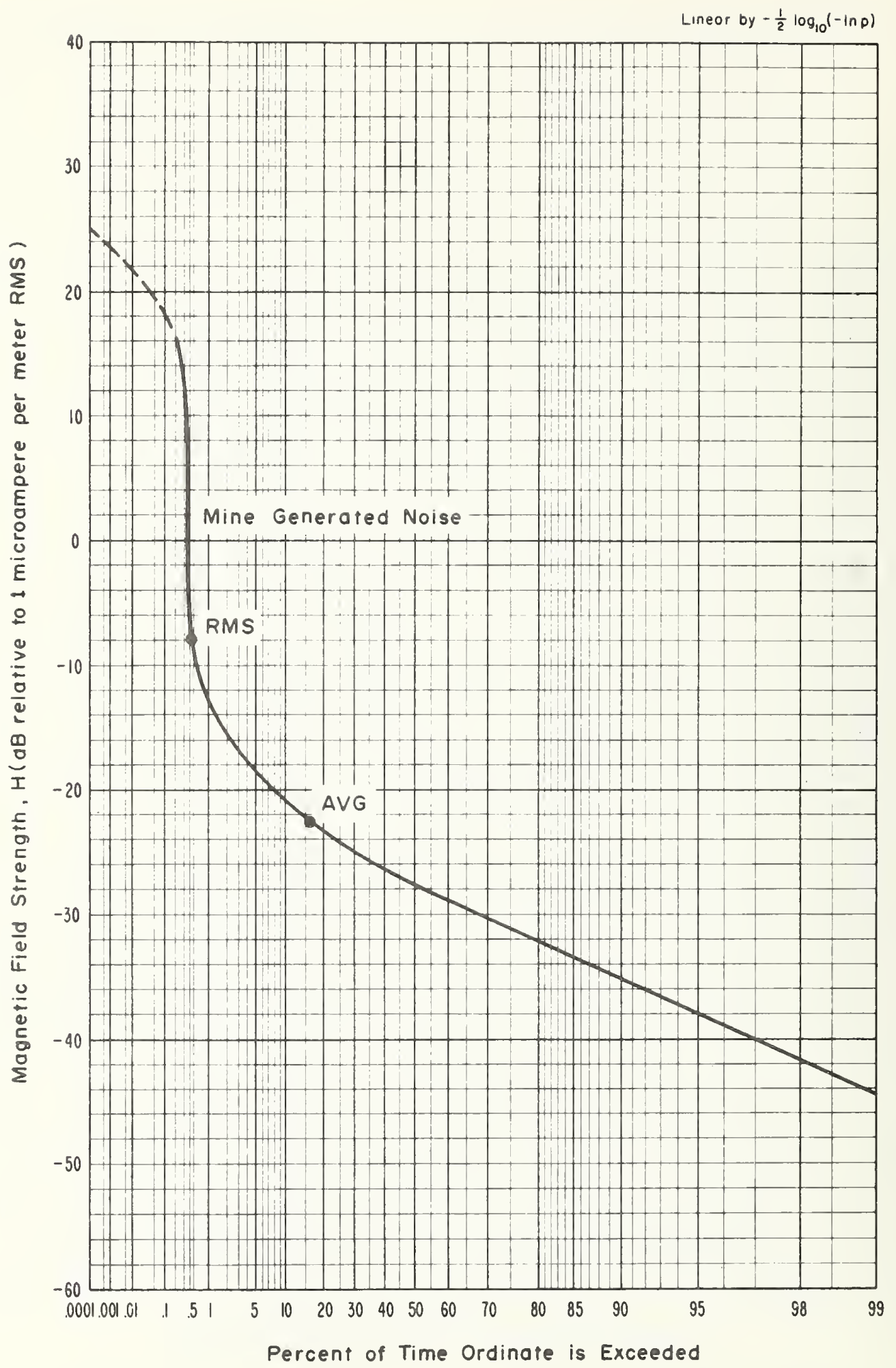

Figure 4-66 APD, $1 \mathrm{MHz}$, vertical component, $1.2 \mathrm{kHz}$ predetection bandwidth, April 12, 1973, 1:00 p.m., McElroy Mine. 


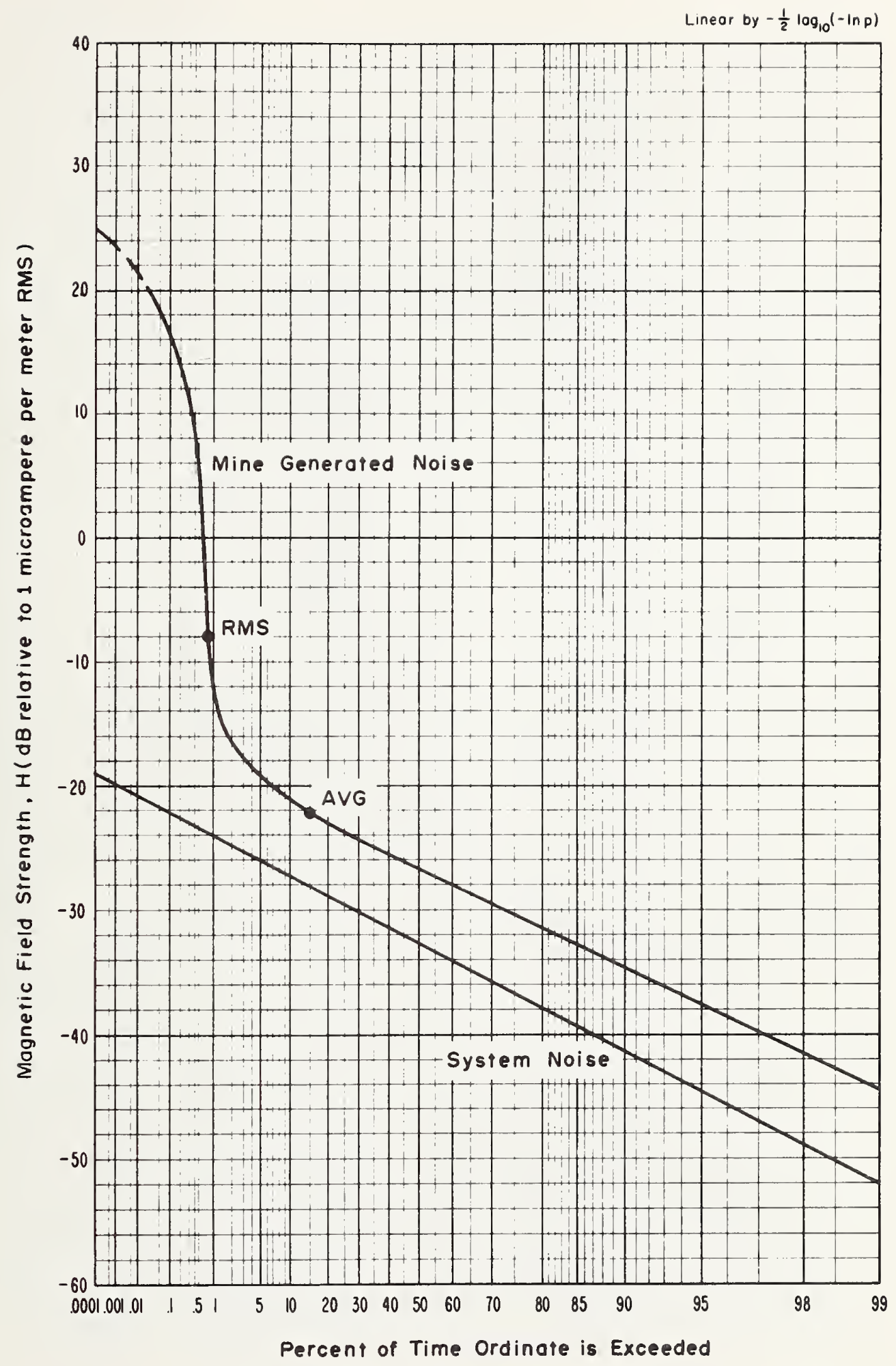

Figure 4-67 APD, $2 \mathrm{MHz}$, vertical component, $1.2 \mathrm{kHz}$ predetection bandw1dth, April 12, 1973, 1:30 p.m., McElroy Mine. 


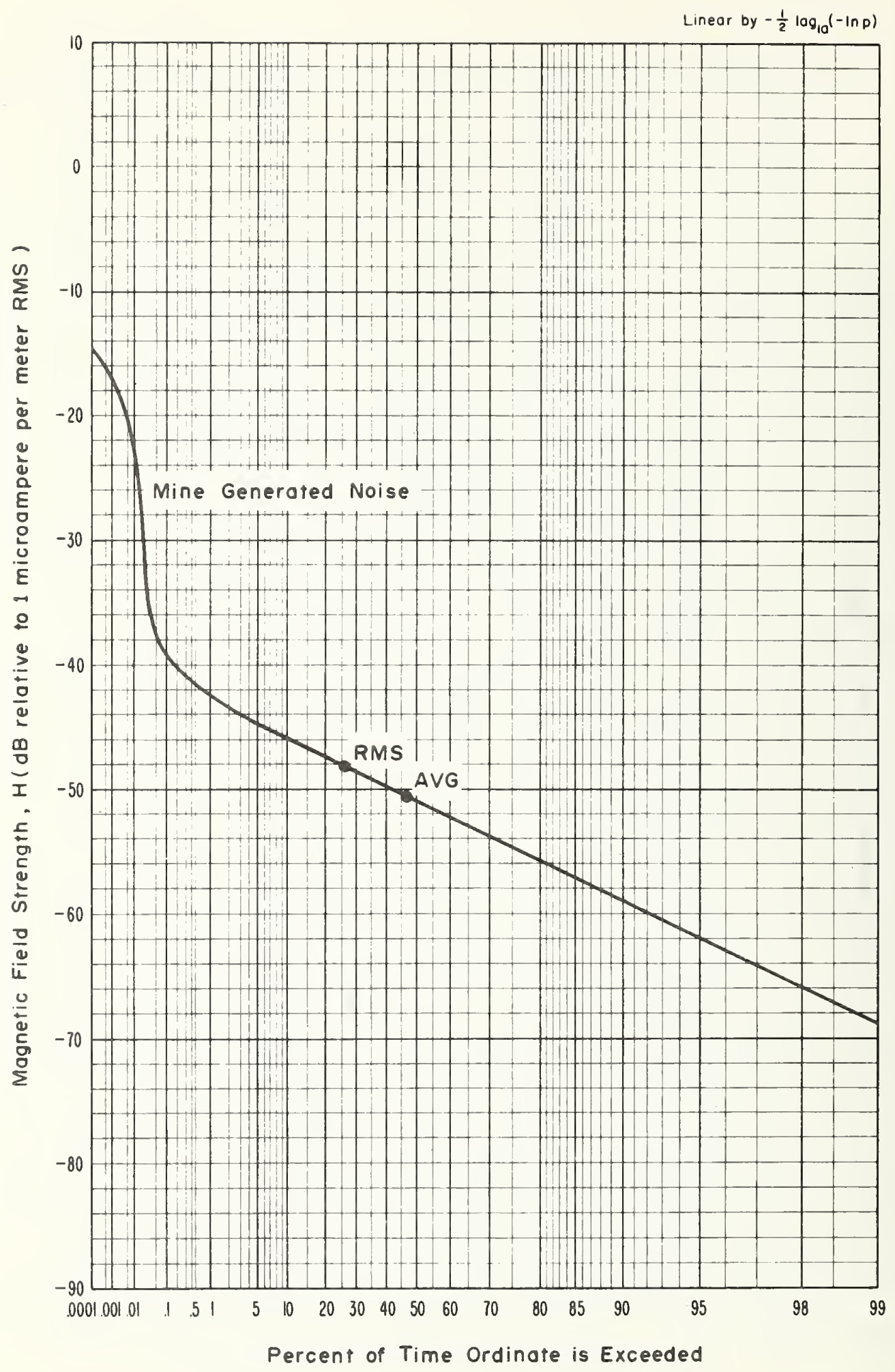

Figure 4-68 APD, $6 \mathrm{MHz}$, vertical component, $1.2 \mathrm{kHz}$ predetection bandwidth, April 12, 1973, 2:15 p.m., McElroy Mine. 


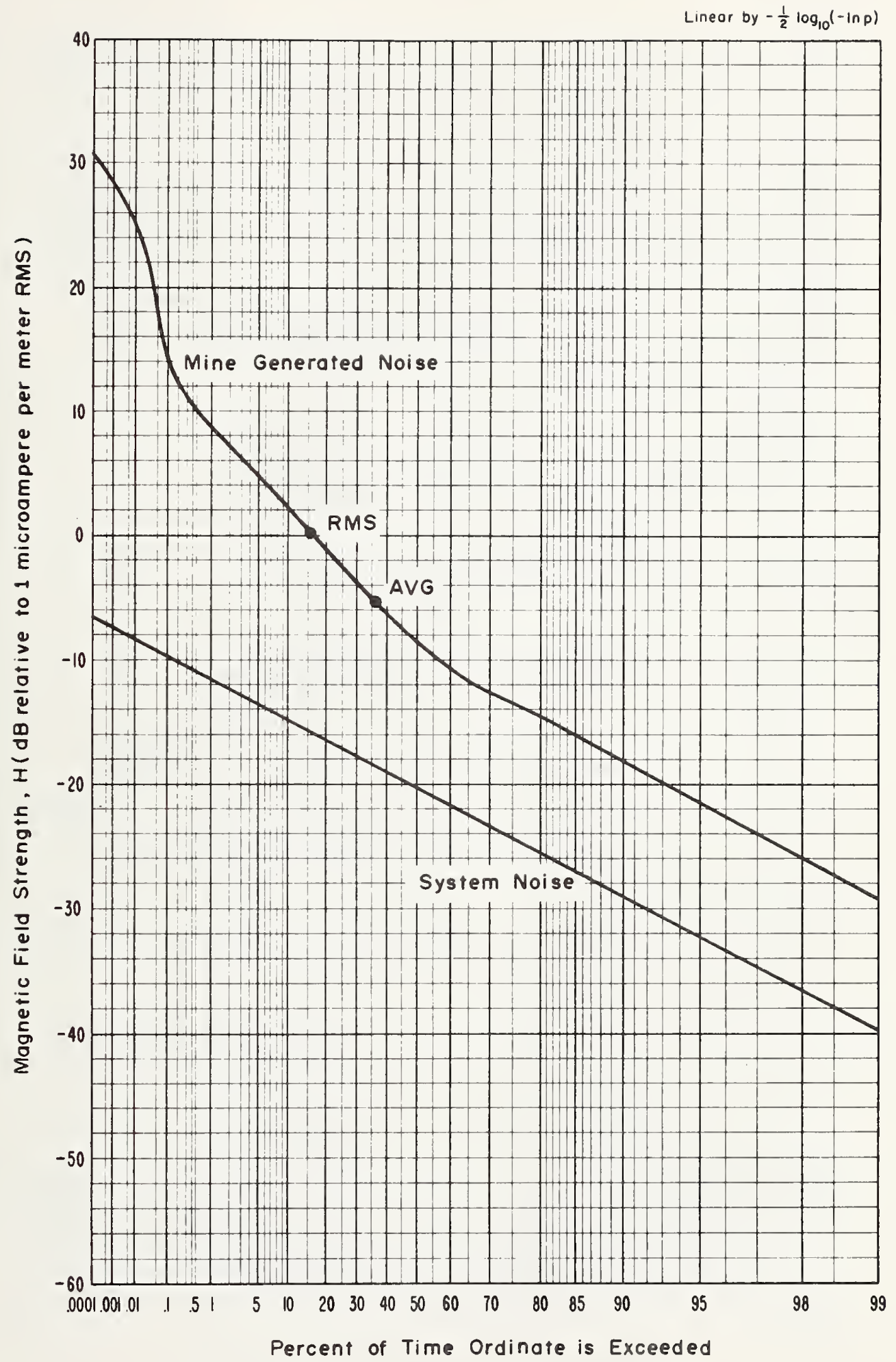

Figure 4-69 APD, $10 \mathrm{kHz}$, roof bolt measurements, $1.0 \mathrm{kHz}$ predetection bandwidth, Apri1 12, 1973, 2:45 p.m., McElroy Mine. 


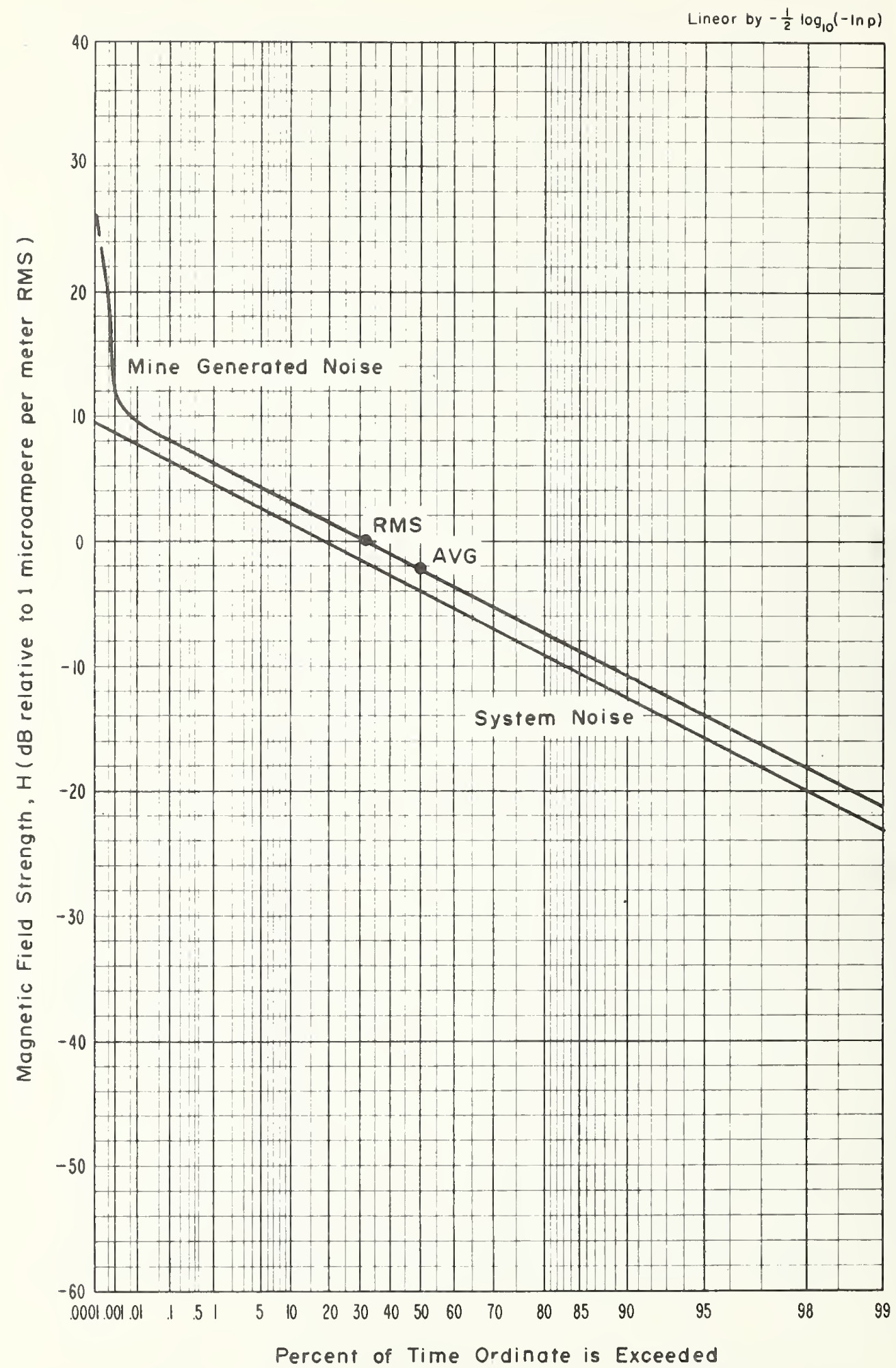

Figure 4-70 APD, $150 \mathrm{kHz}$, roof bolt measurements, $1.2 \mathrm{kHz}$ predetection bandwidth, Apr 11 12, 1973, 2:45 p.m., McE1 roy Mine. 


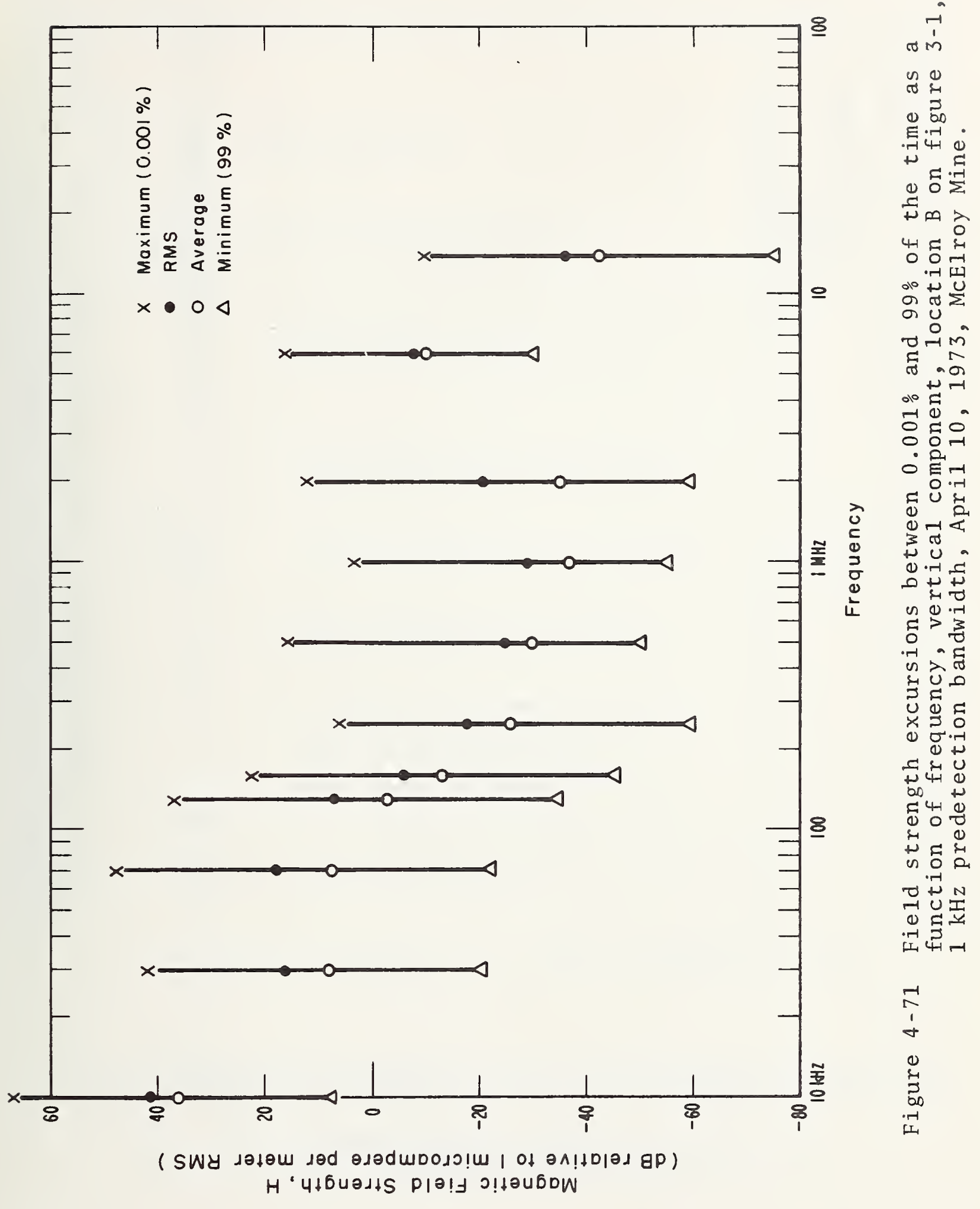




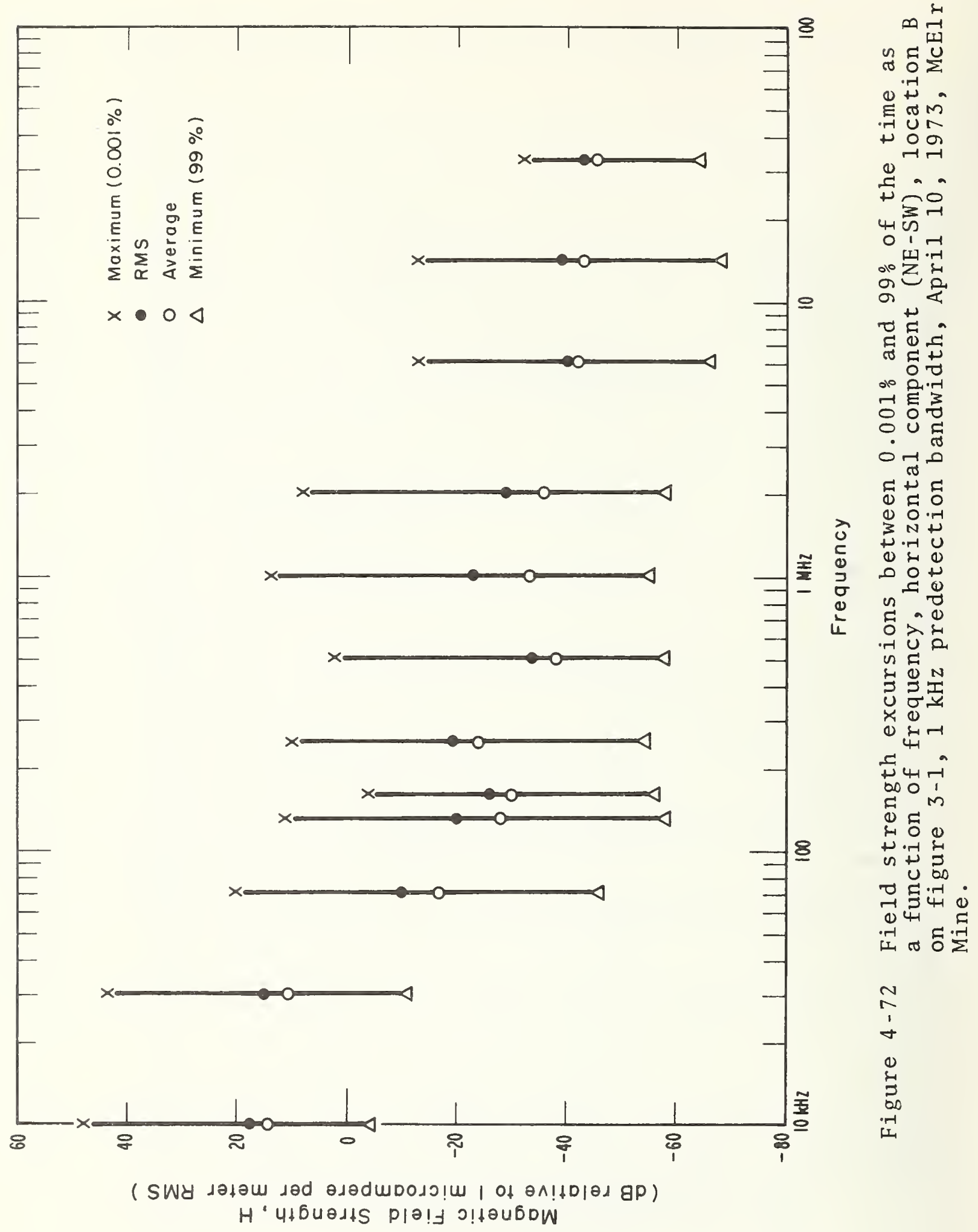




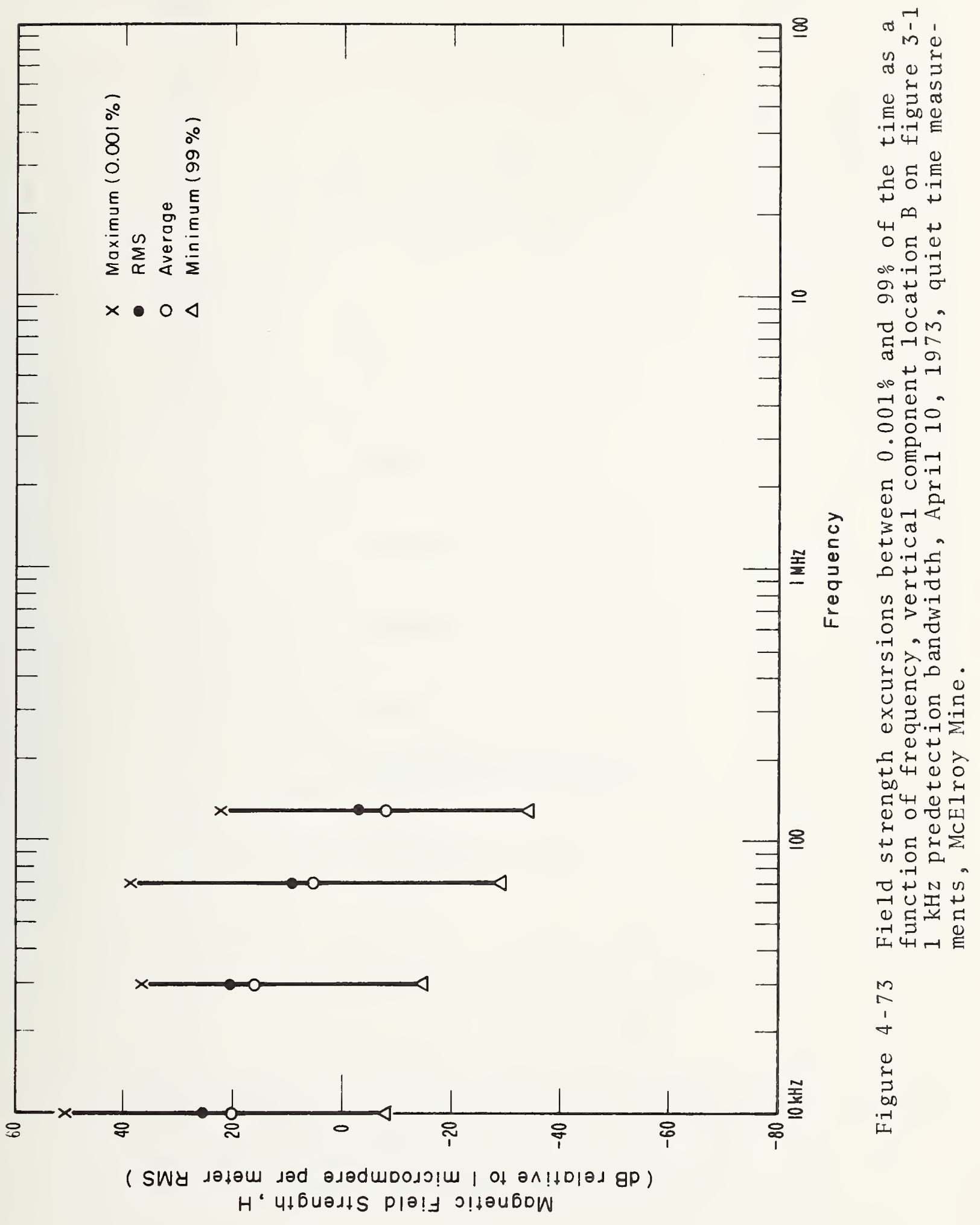




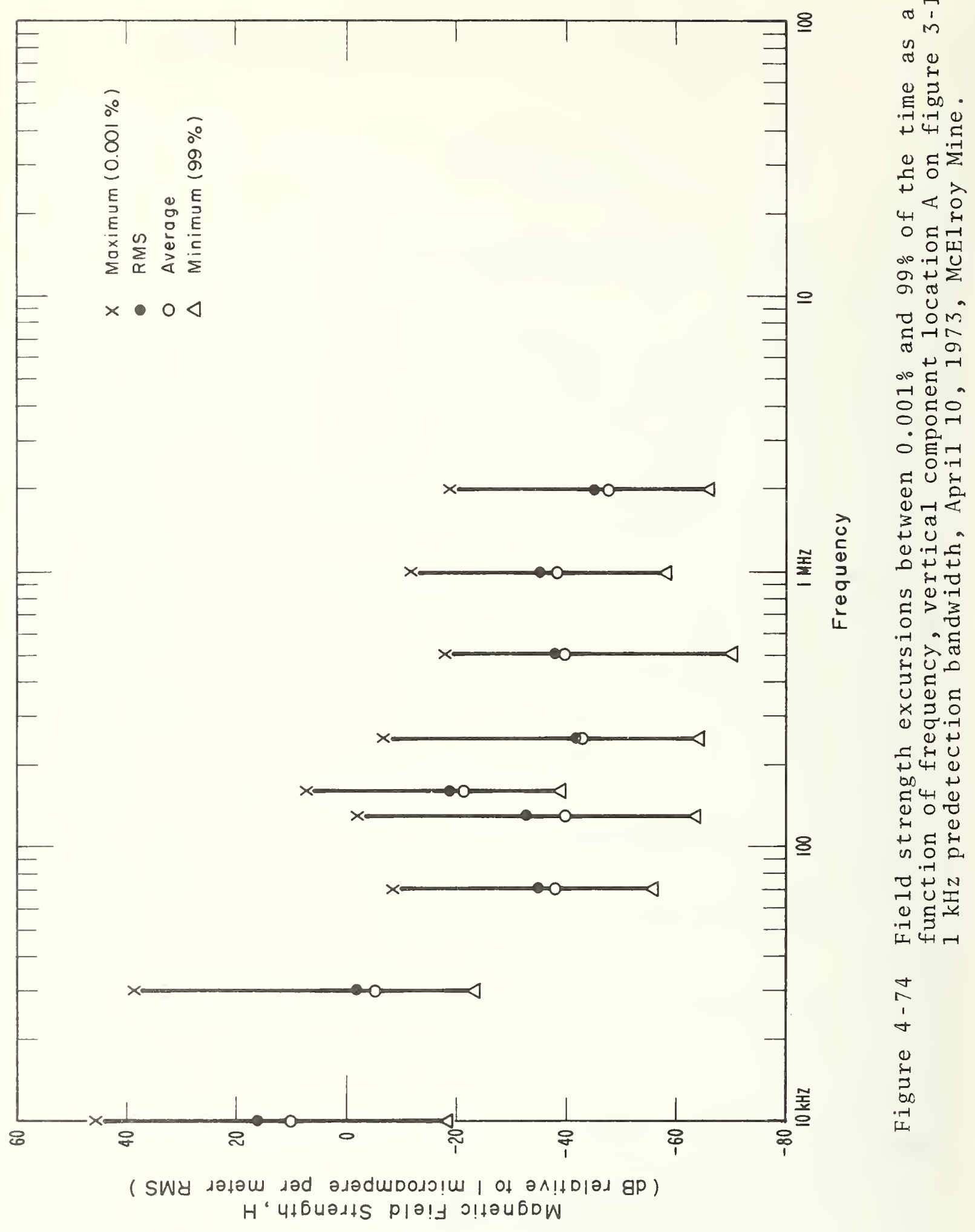




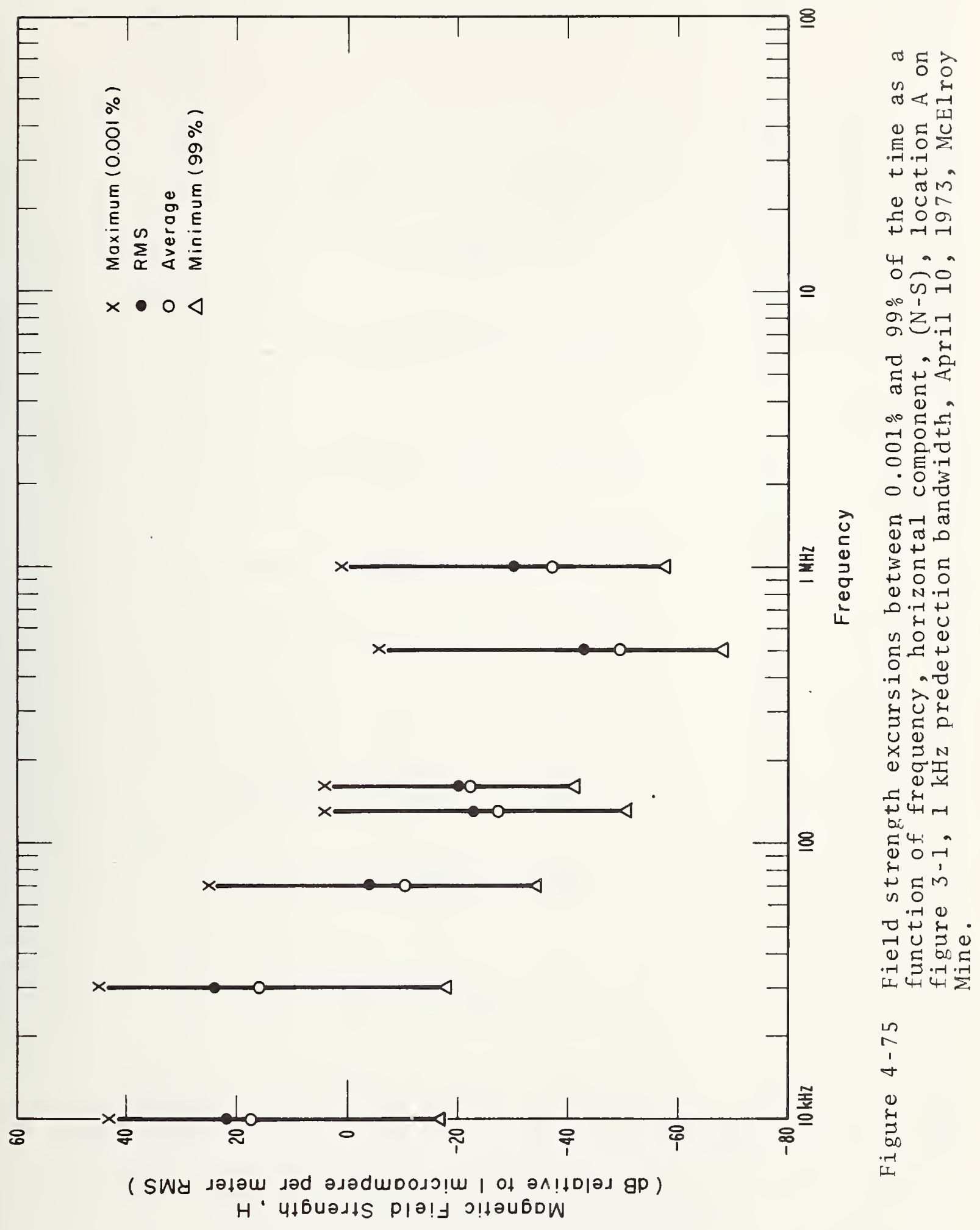




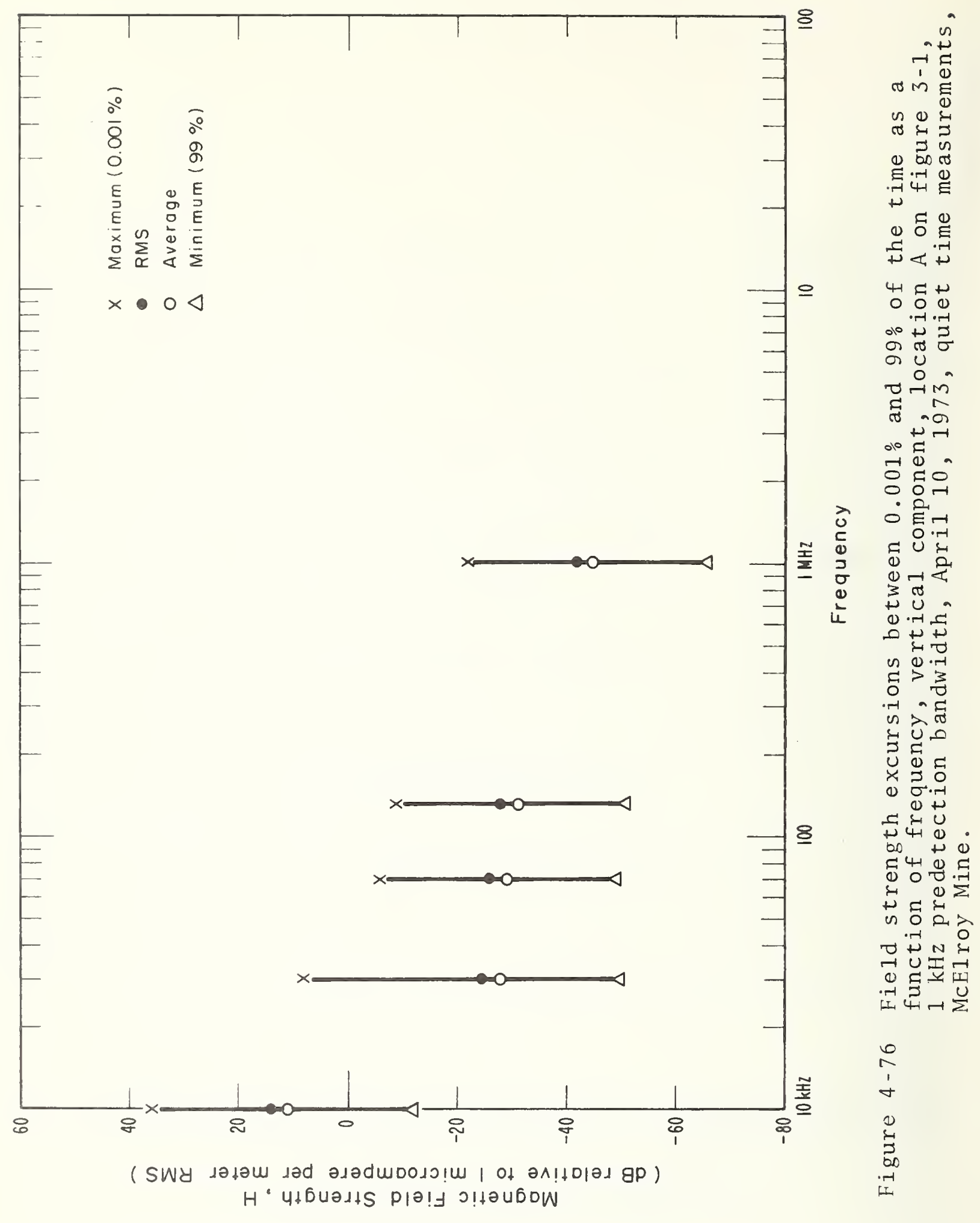




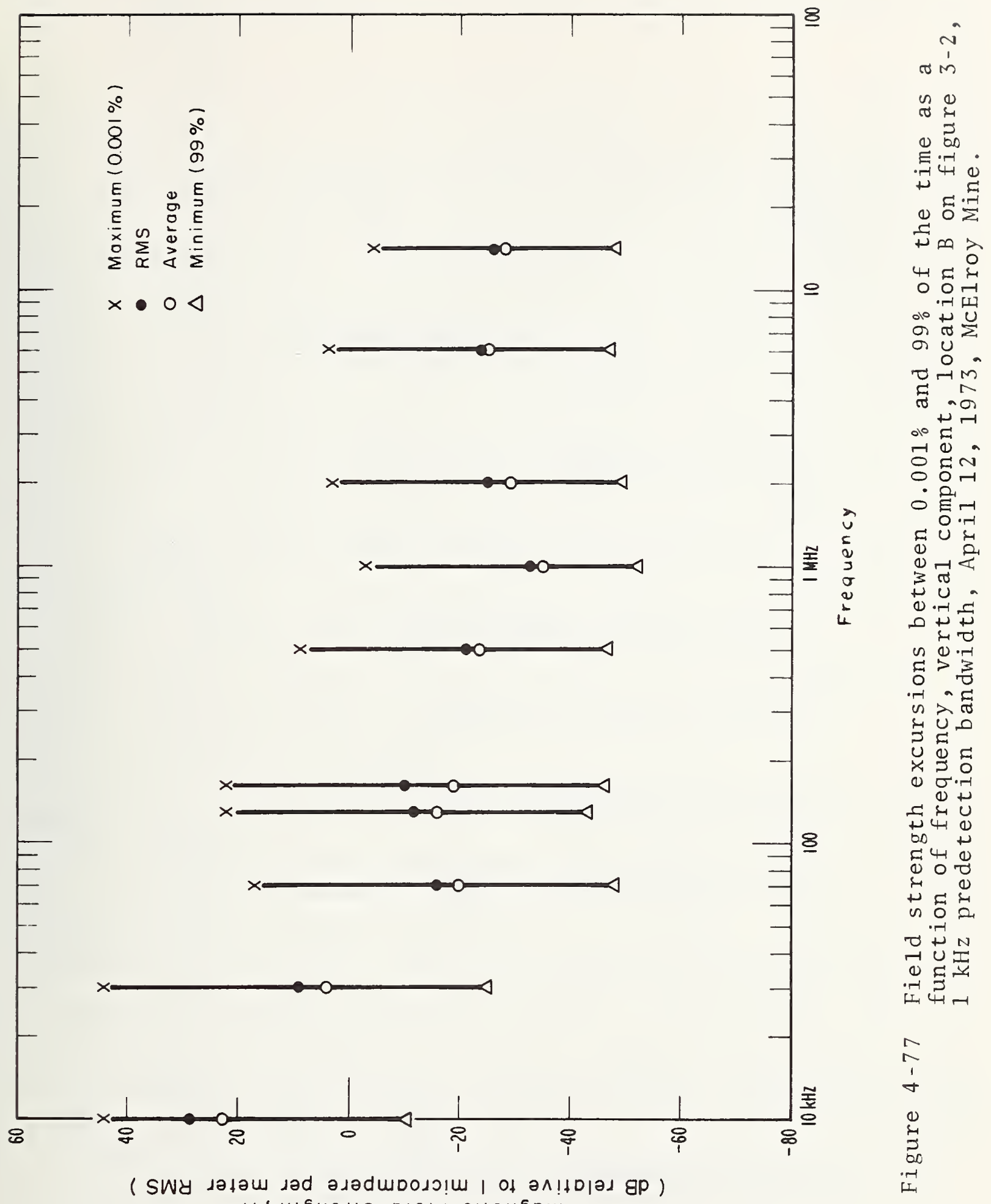




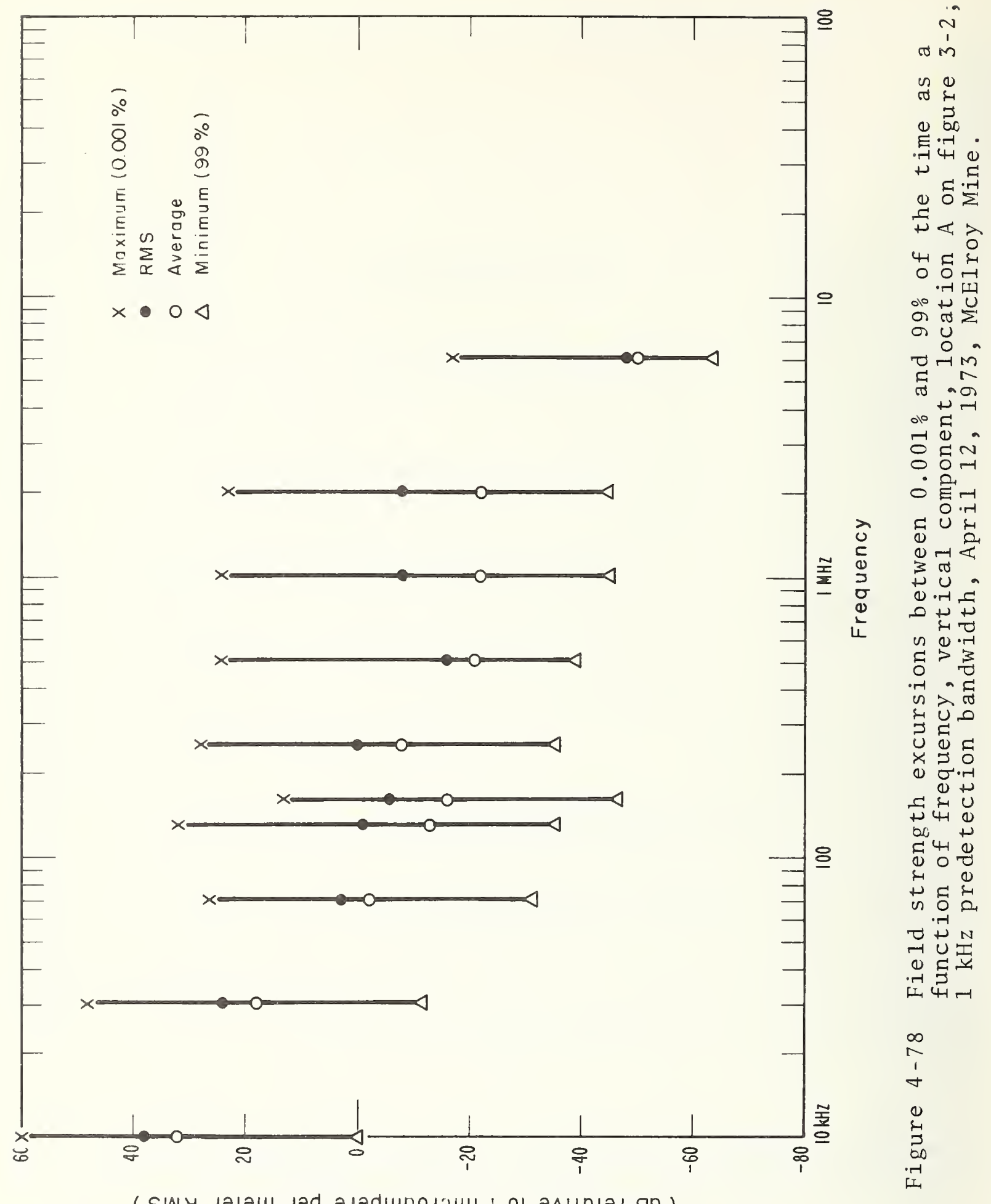

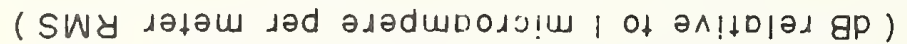

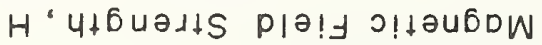




\section{CONCLUS IONS}

The range of magnetic-field noise levels in McElroy is $130 \mathrm{~dB}$, from $90 \mathrm{~dB}$ above $1 \mu \mathrm{V} / \mathrm{m}$ at $60 \mathrm{~Hz}$ to $40 \mathrm{~dB}$ below $1 \mu \mathrm{V} / \mathrm{m}$ at $180 \mathrm{kHz}$. This compares with the $125 \mathrm{~dB}$ range in Robena, except that the Robena levels were higher, from $+105 \mathrm{~dB}$ to $-20 \mathrm{~dB}$ with respect to $1 \mu \mathrm{A} / \mathrm{m}$. Grace Mine had a range of $158 \mathrm{~dB}$, from $+122 \mathrm{~dB}$ to $-36 \mathrm{~dB}$. In the lower por tion of the spectrum, below $3 \mathrm{kHz}$, McElroy was approximately $20 \mathrm{~dB}$ quieter than Robena in most cases. However, from $3 \mathrm{kHz}$ to $100 \mathrm{kHz}$ the magnetic-field noise levels in Robena and McElroy were both relatively high, 10 to $80 \mathrm{~dB}$ above $1 \mu \mathrm{A} / \mathrm{m}$, near operating equipment, compared to levels in Grace and Itmann mines of -10 to $50 \mathrm{~dB}$ above $1 \mu \mathrm{A} / \mathrm{m}$. From $100 \mathrm{kHz}$ to $200 \mathrm{kHz}$, McElroy and Itmann had the highest levels, -20 to $+15 \mathrm{~dB}$ above $1 \mu \mathrm{A} / \mathrm{m}$. Data from Robena is not available in this frequency range, but levels may well be comparable to those in McElroy and Itmann.

Along haulageways, McElroy was the quietest (by a small margin) of the mines visited. From $30 \mathrm{kHz}$ to $180 \mathrm{kHz}$, this level was equal to or less than $-30 \mathrm{~dB}$ above $1 \mathrm{\mu A} / \mathrm{m}$.

Surface measurements over the underground working section show a number of man-made, cw carriers. If these carriers are omitted, the background, broadband noise is -30 to $-40 \mathrm{~dB}$ with respect to $1 \mu \mathrm{A} / \mathrm{m}$. The carriers come up to $0 \mathrm{~dB}$ with respect to $1 \mu \mathrm{A} / \mathrm{m}$. Below $20 \mathrm{kHz}$, powerline harmonics were the dominant source of noise. The range covers -20 to $+60 \mathrm{~dB}$ above $1 \mu \mathrm{A} / \mathrm{m}_{\mathrm{i}}$.

APD measurements were taken during quiet times as well as during normal operation. The measurements show quiettime levels at some frequencies at least $60 \mathrm{~dB}$ below $1 \mu \mathrm{A} / \mathrm{m}$, but at most frequencies below $1 \mathrm{MHz}$, the peak and rms levels did not change significantly from quiet to operating condition. Levels near operating equipment were $30 \mathrm{~dB}$ above $1 \mu \mathrm{A} / \mathrm{m}$ 
at $30 \mathrm{kHz}$, and near haulageways, were $10 \mathrm{~dB}$ above $1 \mu \mathrm{A} / \mathrm{m}$ at $30 \mathrm{kHz}$. The range of these measurements is consistent with the wide range of levels that have been measured in some other mines. 


\section{RECOMMENDAT IONS}

Particularly in mines similar to McElroy, but also in most other coal mines as well, the wide ranges of magneticfield noise levels due to spatial variations should be used to maximum advantage. For example, keep receivers away from noise sources whenever possible. This applies to frequencies below $200 \mathrm{kHz}$, where interference levels near machinery are extremely severe. Shorter-range, higher-frequency systems could be designed for use near machinery.

Surface noise measurements at McElroy show the need for only one design criterion: avoid powerline harmonics. There are other criteria which show up at other mines, but for low-frequency, through-the-earth communication systems, avoiding use of powerline harmonic frequencies is of primary concern.

\section{ACKNOWLEDGMENTS}

Those making significant contributions to this program are as follows: laboratory development and field use of meas urement equipment, Ed Neisen, Doug Schulze, and Tom Bremer; data processing, Anne Rumfelt, Nancy Tomoeda, Winston Scott, Frank Cowley, and David Stearns. Those making valuable but less time-consuming contributions are Gerry Reeve, Bob Matheson, Don Spaulding, John Chukoski, Lorne Matheson, Dave Lewis, and Sharon Foote.

Winston Scott provided much assistance in proofreading, while Sharon Foote and Janet Becker typed tirelessly through many versions. Jocelyn Spencer and Barbara Bolton provided drafting assistance.

Finally, none of this would have been possible without the excellent cooperation of John Burr of Lee Engineering Company and of Dick Rouse, John Stock, Randy Fizer, and others of Consolidation Coal Company. 


\section{REFERENCES}

[1] Bensema, W.D., Kanda, M., Adams, J.W., Electromagnetic Noise in Robena No. 4 Coal Mine, NBS Tech. Note 654, April 1974 .

[2] The Institute of Electrical and Electronic Engineers, Inc., IEEE Dictionary of Electrical and Electronic Terms, Std. 100,1972 .

[3] Taggart, H.E. and Workman, J.L., Calibration Principles and Procedures for Field Strength Meters ( $30 \mathrm{~Hz}$ to $1 \mathrm{GHz}$ ), NBS Tech. Note 370, March 1969.

[4] Adams, J.W., Bensema, W.D., Kanda, M., Electromagnetic Noise in Grace Hardrock Mine, NBSIR 74-388, June 1974.

[5] Crich1ow, W.Q., et a1., Amp1itude-probability distributions for atmospheric radio noise, NBS Monograph 23 (1960b).

[6] Thompson, W.I., III, Bibliography of ground vehicle communications and control. AKWIC index, Report No. DOTTSC-UMTA-71-3, July 1971.

[7] Spaulding, A.D. and Disney R.T., Man-Made Radio Noise: Part 1: Estimates for Business, Residential, and Rural Areas, Office of Telecommunications OT Report 74-38, June 1974 . 


\section{APPENDIX \\ Decoding of Spectrum Captions}

Spectrum captions are generally organized into the following format:

First 1ine: MP NDT NZS NDA NPO RC DF date, time, frame, serial, where

MP = Two's power of length of Fourier transform, example, $2^{\mathrm{MP}}$ where $\mathrm{MP}=12$

NDT = Detrending option, example, 0 (dc removed)

$\mathrm{NZS}=$ Restart spectral average after output, example, 0 (restarted)

$\mathrm{NDA}=$ Data segment advance increment, example, 2048

$\mathrm{NPO}=$ Number of spectra averaged between output calls, example, 20

$\mathrm{RC}=$ Integration time in seconds per spectra, example, 0.168

$\mathrm{DF} \quad=$ Resolution bandwidth, spectral estimate spacing in hertz, example, 62.5

Date $=$ Date of computer processing, examp1e, 03/21/73

Time = Time of computer processing, example, 15:06:34

Frame $=$ Frame set number, example, 10

Serial = Film frame serial number, example, 42 .

Second 1ine: DTA DA(1) DA(2) DA(3) NSA NRP NPP, where

$\mathrm{DTA}=$ Detrending filter parameter $\alpha$, example, 0.00195

$\mathrm{DA}(1)=$ Detrending filter average, $\mathrm{K}=1$, example, 59.4

$\mathrm{DA}(2)=$ Detrending filter average, $\mathrm{K}=2$, example, 0

$\mathrm{DA}(3)=$ Detrending filter average, $\mathrm{K}=3$, example, 0

NSA $=$ Number of periodograms averaged, example, 20

NRP = Number of data points processed since spectrum initialization, example, 43008

NPP = Number of data points processed since data initialization, example, 43008 . 
Third line: RUN, SESSION, DAY, MONTH, YEAR Gain corr., rec. = tot. constr. =, where

Run and Session = the title of the portrayed frame identifying the digitizing session and run number, example, 2183

Month, Day, Year = date data were recorded in the mine, example, 82573

Gain corr. rec. = receiver gain correction, example, -6 tot. const. = constant gain correction of entire system, example, -46.4

Fourth line: $\mathrm{C}=, \mathrm{RG}=, \mathrm{DG}=, \mathrm{FG}=\mathrm{AG}=$, where

$\mathrm{C}=$ correction curve used with data, example, 25

$\mathrm{RG}=$ receiver gain and accompanying correction in $\mathrm{dB}$ added to the data, example, $200(-6 \mathrm{~dB})$

$\mathrm{DG}=$ digitizer gain, example, 0

$F G=$ filter gain in $d B$, often rounded to nearest single digit, example, 0

$\mathrm{AG}=$ absolute gain correction added to data, example, 52

Fifth line: Top of Scale, Standard Error, Spectral Peak, where Top of Scale = largest scale marking for computer drawn graph, example, $1.000+004\left(1.0 \times 10^{4}\right)$

Standard Error = standard error of curve, example, 0.3162 Spectral Peak = largest spectral peak observed, example, $4.108+003 .\left(4.108 \times 10^{3}\right)$ 
NBS-114A (REV. 7-73)

\begin{tabular}{|c|c|c|c|}
\hline $\begin{array}{l}\text { U.S. DEPT. OF COMM. } \\
\text { BIBLIOGRAPHIC DATA } \\
\text { SHEET }\end{array}$ & $\begin{array}{l}\text { 1. PUBLICATION OR REPORT NO. } \\
\text { NBSIR 74-389 }\end{array}$ & $\begin{array}{l}\text { 2. Gov't Accession } \\
\text { No. }\end{array}$ & 3. Recipient's Accession No. \\
\hline \multicolumn{3}{|l|}{ 4. TITLE AND SUBTITLE } & $\begin{array}{r}\text { 5. Publication Date } \\
\text { June } 1974\end{array}$ \\
\hline \multicolumn{3}{|c|}{ Electromagnetic Noise in McElroy Mine } & 6. Performing Organization Code \\
\hline \multicolumn{3}{|c|}{$\begin{array}{l}\text { 7. AUTHOR(S) } \\
\text { Motohisa Kanda, John W. Adams, and William D. Bensema }\end{array}$} & 8. Performing Organ. Report No. \\
\hline \multicolumn{3}{|c|}{$\begin{array}{l}\text { 9. PERFORMING ORGANIZATION NAME AND ADDRESS } \\
\text { NATIONAL BUREAU OF STANDARDS, BOUlder Labs } \\
\text { DEPARTMENT OF COMMERCE } \\
\text { Washington, D.C. } 20234\end{array}$} & $\begin{array}{l}\text { 10. Project/Task/Work Unit No. } \\
2768412 \\
\text { 11. Concract/Grant No. }\end{array}$ \\
\hline \multirow{2}{*}{\multicolumn{3}{|c|}{ 12. Sponsoring Organization Name and Complete Address (Street, City, State, ZIP) }} & $\begin{array}{l}\text { 13. Type of Report \& Period } \\
\text { Covered }\end{array}$ \\
\hline & & & 14. Sponsoring Agency Code \\
\hline
\end{tabular}

15. SUPPLEMENTARY NOTES

16. ABSTRACT (A 200-word or less factual summary of most significant information. If document includes a significant bibliography or literature survey, mention it here.)

Two different techniques were used to make measurements of the absolute value of electromagnetic noise in and above an operating coal mine, McElroy Mine, located near Moundsville, West Virginia. 300-volt-dc and 480-volt-ac machinery was measured to see the electromagnetic environment it created. One technique measures noise over the entire electromagnetic spectrum of interest for brief time periods. It is recorded using broadband analog magnetic tape and the noise data is later transformed to give spectral plots. The other technique records noise amplitudes at several discrete frequencies for a sufficient amount of time to provide amplitude probability distributions.

The specific, measured results are given in a number of spectral plots and amplitude probability distribution plots.

17. KEY WORDS (six to twelve entries; alphabetical order; capitalize only the first letter of the first kev word unless a ornner name; separated by semicolons). Amplitude probability distribution; coal mine noise; digital data; electromagnetic communications; electromagnetic interference; electromagnetic noise; Fast Fourier Transform; Gaussian distribution; impulsive noise; magnetic field strength; measurement instrumentation; spectral density; time-dependent spectral density.

18. AVAILABILITY $\underline{\mathrm{x}}$ Unlimited

For Official Distribution. Do Not Release to NTIS

Order From Sup. of Doc., U.S. Government Printing Office Washington, D.C. 20402 , SD Cat. No. C13

Order From National Technical Information Service (NTIS) Springfield, Virginia 22151
19. SECURITY CLASS (THIS REPURT)

UNCL ASSIFIED

20. SECURITY CLASS (THIS PAGE)

UNCLASSIFIED
21. NO. OF PAGES

22. Price 
